\title{
The microscopic dimension of paleoclimate in the EPICA-DML(Antarctica) deep ice core
}

\author{
Dissertation \\ zur Erlangung des Doktorgrades \\ der Mathematisch-Naturwissenschaftlichen Fakultäten \\ der Georg-August-Universität zu Göttingen \\ vorgelegt von
}

Aneta Florentina Nedelcu

aus Bucureşti, Romania

Göttingen, 2011 
Referent: Prof. Dr. W. F. Kuhs

Koreferent: Prof. Dr. G. Wörner

Koreferent: Dr. S. H. Faria

Tag der mündlichen Prüfung: 


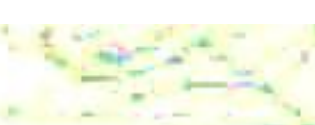

Dedicated to YOU* my dear Reader What would my humble work be without YOU?

* if I am to name a Muse, then the dedication should read: for Barıs "Der Wahre Türke", who takes all the gratitude

"A-nceput de ieri să cadă Câte-un fulg, acum astât, Norii s-au mai răzbunat Spre apus, dar stau grămadă Peste sat."

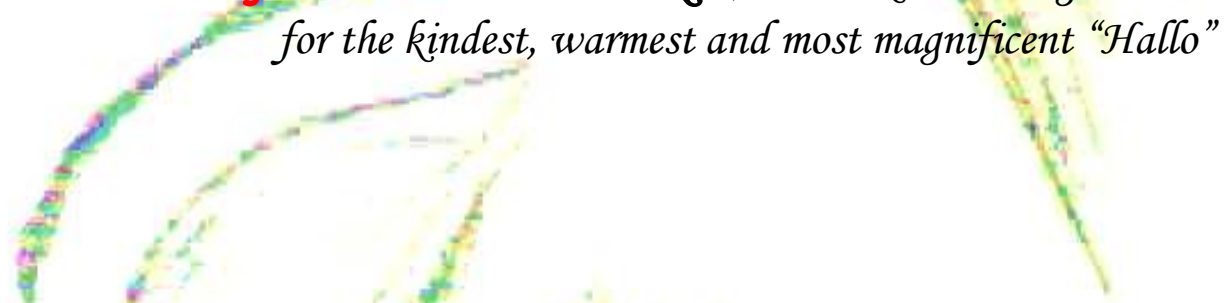

The snowflakes started from yesterday, One by one to fall down way. Now the clouds are a bit lighter On the north side, but still gather' All over the village.

George Coşbuc / Romanian writer "larna pe Uliță" / "Winter on the village's road" $(\sim 1886)$

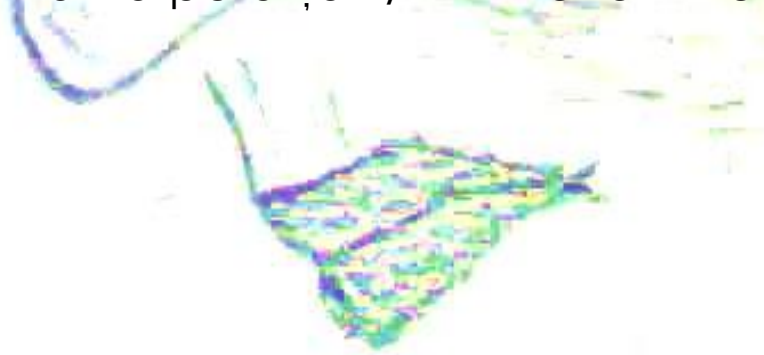

1 nice to know that the English translation of this name is Peace 


\title{
The Romantic Introduction. A Personal Motivation
}

\author{
from some of the 21.November.2007 notes:
}

My dear Reader [...] my personal inner feeling related with all the thousands words You will read in this incomplete and imperfect thesis......

[...] it's really very hard to describe the beauty of the natural phenomenon which generated my interest for the project and even the project itself.

If You didn't guess yet I have in mind the memory of billions and billions of Snowflakes dancing downwards from the Sky to the freshly frozen Earth. As You can see some plain and extremely usual words can not make You feel anything special though nothing compares with (ok if You are an astronaut I agree that the Earth seen from outer space might be as beautiful as the Winter's ballerinas).

Every year I wait eagerly for the first Snow of the Winter, just for that sublime unbelievable feeling one gets when the wonders of the Winter enter on the season's stage. The problem is that from a year to another the Snowflakes choose to come down from the Sky later and later extending my longing for seeing Them and making way for the grief and the fear expressed like: what if They will choose not to come down anymore?

Well, nowadays scientists say They will not choose to disappear so soon. Maybe They will move from one place to another [...] [like those] with billions and billions of Snowflakes transformed into silvery ice under Antarctic weather conditions [...] .........

\section{The Realistic Epilogue. A General Remark}

\author{
"Render unto Caesar the things which are Caesar's, and unto God the \\ things that are God's" (Matthew, 22:21)
}

The mind conquered the world; but the heart remaind unhappy;

They regret what it was.

The eyes saw all the beauty; but the ears heard the hell;

They hope will'e off.

The nostrils perceived the finest fragrance; but the mouth could not speak;

They have no dreams.

The wind so gentle; but the wings were broken;

They rest asleep.

The knowledge so vast; the universe so narrow;

They were foolish.

The wealth incommensurable; but the sorrow deepest;

They were tyrants.

The glory unfair; and the heroes unsung;

They were not acclaimed.

The smile in vain; the soul in pain.

21.February. 2013

\footnotetext{
1"Pay no attention to Caesar. Caesar doesn't have the slightest idea what's really going on." (from Vonnegut K., Cat's Cradle, Dell, N.Y., 1963, pg. 88)
} 


\title{
Summary
}

\author{
"The story is always about searching the truth, no matter what might bring. Even when nothing was what it \\ appeared to be, when everything was hidden, there was a center not even I could run from: who I truly was, what I \\ felt, what I was deep inside." (from The Ice Queen, A. Hoffman, pg. 165)
}

The present work is divided into two main parts: the introductory half and the experimental chapter.

Chapter 1 starts with the brief presentation of the scientific project that facilitated the development of the thesis, then presents a historical survey of the early expeditions towards and in Antarctica, just to reach to the basic geological aspects relevant for the second part of the work, and to end with some glaciological aspects worth of being noticed in the context of the thesis. The third section describes the basic Antarctic meteorology, focus on Dronning Maud Land region, while the forth subchapter tells only a few stories about the EPICA-DML ice core. The last part of Chapter 1 wanted to be a kind of 'encyclopedia' of what can be found as trapped in polar ice; it resulted in some useful but subjective base for the understanding and interpretation of the results presented in the second half of the thesis.

Chapter 2 deals with the presentation of the original results after the employed methods are briefly described. Outcomes from optical microscopy investigations, a few SEM-EDX analyses, and mostly from the first Raman analyses on microinclusions existent in EDML ice, (included as Appendixes), lead to the following conclusions (Chapter 3):

-secondary microinclusions developed in polar ice after its extraction, due to structure relaxation, contain fractionated air enriched in oxygen, $\mathrm{O}_{2}$

-the nitrogen to oxygen $\left(\mathrm{N}_{2} / \mathrm{O}_{2}\right)$ ratio for the investigated relaxation microinclusions took values between 0.3 and 2

-microinclusions containing soluble salts, may exist as solids or as liquid solutions, if their eutectic temperature permits or if they are associated with other substances, like acids

-hardly soluble microinclusions are mainly silicates and/or silica, and to a lesser degree $\mathrm{Ti}$ containing compounds and they are enriched in less clear ice (cloudy ice)

-a number of microinclusions, which could have been formed in the polar atmosphere or in the firn/ice matrix, contain more than one compound (either two different sulfates or a Si compound and sulfate)

-double sulfates of jarosite type composed few of the investigated microinclusions and they can be the result of diagenesis 


\section{CONTENTS}

The Romantic Introduction. A Personal Motivation

The Realistic Epilogue. A General Remark

Summary

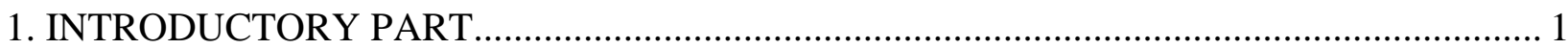

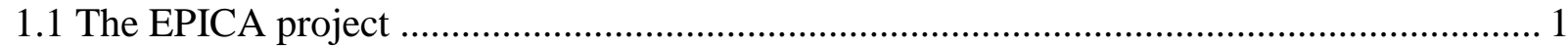

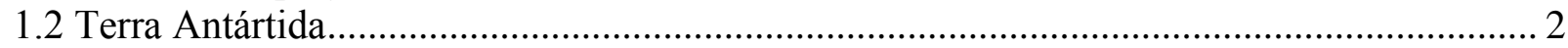

1.2.1 What's in a name? What means Antarctica? ........................................................... 2

1.2.2 What is Antarctica? What is it made of? ................................................................. 2

1.2.3 What about Man becoming aware of Antarctica's existence?...................................... 3

1.2.4 Antarctica' general geology and the Dronning Maud Land region .............................. 5

1.2.5 What more about 'snow-firn-ice from $66^{\circ} \mathrm{S}$ to $90^{\circ} \mathrm{S}$ ' ? ............................................. 6

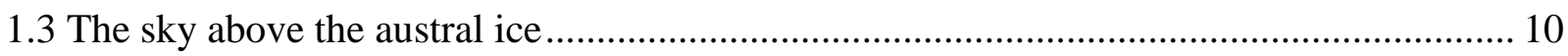

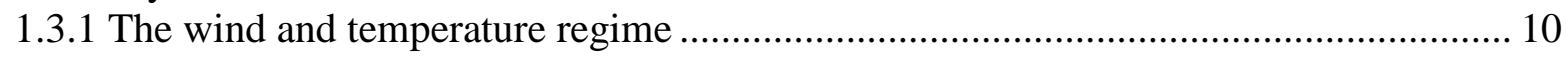

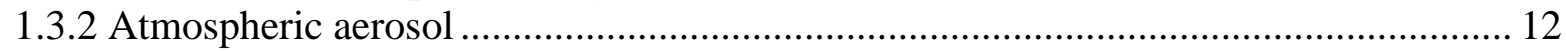

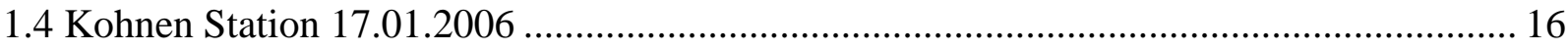

1.5 What is not ice can be trapped in (Antarctic) ice ....................................................... 22

1.5.1 Gaseous microinclusions in polar ice ........................................................... 26

1.5.2 Liquid and solid microinclusions in polar ice ............................................... 28

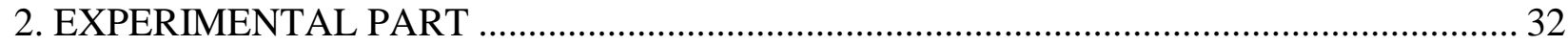

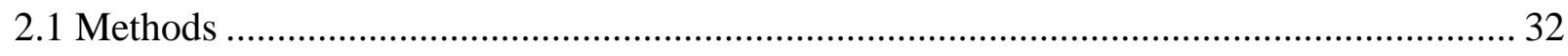

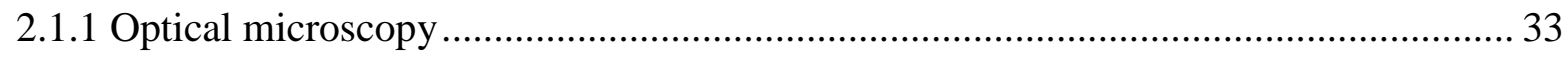

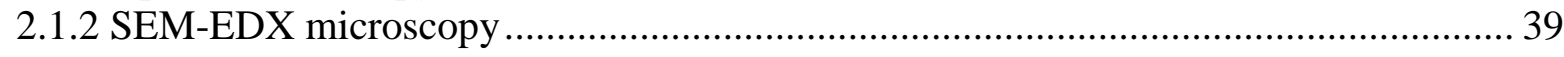

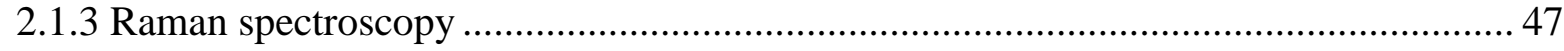

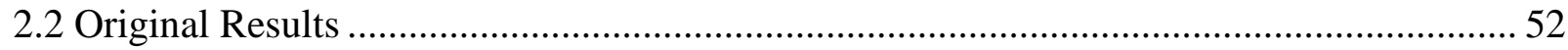

2.2.1 Oxygen enriched relaxation features in EDML ice ............................................ 52

2.2.2 Chemistry of soluble and hardly soluble micro-inclusions in clear and cloudy MIS2

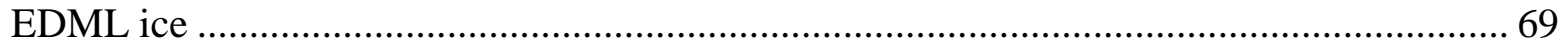

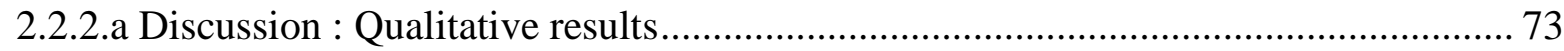

2.2.2.b Discussion : Frequency distribution of the microinclusions................................. 90

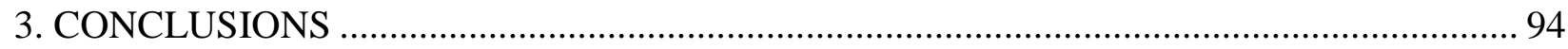

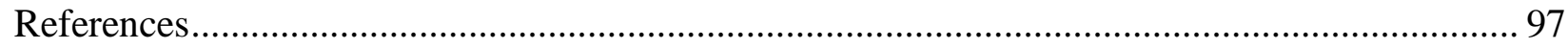

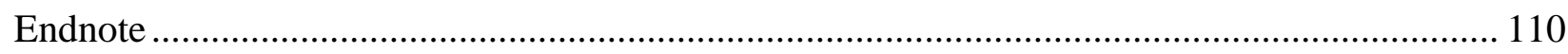

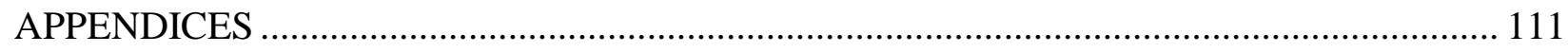




\title{
1. INTRODUCTORY PART
}

\subsection{The EPICA project}

\author{
"All the world's a stage \\ And all the men and women merely players \\ They have their exists and their entrances" \\ Shakespeare "As you like it" 2/7
}

The acronym of the European Project for Ice Coring in Antarctica, EPICA, inevitably makes one think at ample heroic stories with brave characters; and indeed the project has the right mixture of being and producing epic writings.

Starting with the heroes, without who no story could ever exist, apart from their impressive number, most important is their willingness to experience "room temperatures" far below the melting point of water, meaning $-54.5^{\circ} \mathrm{C}$ or $-44.6^{\circ} \mathrm{C}$, the mean annual temperature at the drilling sites, or $-20^{\circ} \mathrm{C}$ the "mean daily" processing temperature in the laboratory.

And continuing with the motivation (the driving force for some or the aims for the most) around which revolves the story: obtaining a full documentation of the atmospheric record archived in Antarctic ice; the stage for another odyssey through the world of science was set.

The background, progress and achievements of the EPICA project is nicely outlined in the Preface of the issues 1-2, volume 29 of Quaternary Science Reviews: "Climate of the Last Million Years: New Insights from EPICA and Other Records" (Barbante et al. 2010).

The project was possible due to the staff and logistics provided by 10 nations: Belgium, Denmark, France, Germany, Italy, Netherlands, Norway, Sweden, Switzerland, and the United Kingdom, and some of the most important specific questions addressed within EPICA are (Barbante et al. 2010):

"- What are the time lags of climatic variations between northern and southern hemispheres and what are the mechanisms responsible for these time lags?

- What are the changes in the pacing and intensity of glacial-interglacial periods?

- What are the processes responsible for the increase of the atmospheric $\mathrm{CO}_{2}$ concentration parallel to the transition from the last glacial epoch to the Holocene?

- What is the role of the Southern Ocean in meridional heat transport and for the variations of atmospheric $\mathrm{CO}_{2}$ concentration?"

The scientific plan was conceived since 1994 and to fulfill its goals two ice cores were drilled. First the EPICA Dome C (EDC) ice core, at $75^{\circ} 06^{\prime} \mathrm{S}, 123^{\circ} 21^{\prime} \mathrm{E}$, next to the FrenchItalian Concordia Station, (south of the Indian Ocean sector of East Antarctica), in a region of low snow accumulation in order to allow changes over several glacial cycles to be recorded, and a second ice core, the EDML core, drilled in Dronning Maud Land (DML), (in the Atlantic Ocean sector of West Antarctica), at $75^{\circ} 00^{\prime} \mathrm{S}, 00^{\circ} 04^{\prime} \mathrm{E}$, now known as Kohnen Station, a site of higher annual snowfall to provide a detailed record of events over the last glacial cycle.

The EDC ice core "was completed at a logged depth of $3259.72 \mathrm{~m}$ in December 2004, yielding a complete stratigraphically ordered sequence going back 800,000 years" while for the EDML ice core "the bed was reached at $2774.15 \mathrm{~m}$, during the 2005 field season" and it "represents the first direct southern hemisphere counterpart of the Greenland records. It is especially suited to study the connection of the southern hemisphere to rapid climate variations in the north" (Barbante et al. 2010). 
EPICA stretched from January 1996 to December 2006 but the official end was celebrated with a symposium held in Venice in November 2008 (resulting in the issues 1-2 of Quaternary Science Reviews, vol.29, 2010).

The specific questions raised by EPICA were given specific answers (EPICA Community Members 2004, 2006) but, as science is, they are still waiting for complete ones. Many new and interesting scientific issues arose while the project was developing or after its end, one of which is the research project "Distribution and chemistry of micro-inclusions in EPICA-DML deep ice core " 2 in the frame of the Priority Program SPP-1158 of the Deutsche Forschungsgemeinschaft (DFG or German Research Foundation). Some of the scientific results obtained (between 03.2008-07.2009) in the frame of the latter DFG funded project (grant number Fa840/1-1), which are presented in the second part of this thesis, try to answer two main questions:

1. What are plate-like inclusions — (typical relaxation features) — filled with?

2. What precisely are the "black dots"-(smallest visible microinclusions)?

\subsection{Terra Antártida}

"Galadriel:) The world is changed: I feel it in the water, I feel it in the earth, I smell it in the air... Much that once was is lost, for none now live who remember it. [...] And some things that should not have been forgotten...were lost. History became legend...legend became myth. [...] (Gollum:) My Precious... [...] My preciousness. [...] (Frodo:) I'm glad you're with me."

from "The Lord of the Rings", the movie

This starting introductory part about Antarctica was to be about Antarctic geology, and to a certain extent it is, but I am not a geologist, so I had to select only the sentences with words expressing a message that was easily understandable and sufficient for me. The compromise was to write this first part as answers taken from basic references to basic questions.

\subsubsection{What's in a name? What means Antarctica?}

It is easier to find someone who does not know what is Antarctica than to learn why Antarctica and not some other word. A linguist would quickly find an explanation: "Ant" can be from anti and "arctica" can be a word in its own, most probably referring to something cold. Now, somebody wrote in Wikipedia, (you know, the nowadays electronic encyclopedia, available via the "holy" internet media, which is offering far more information than the dissertation you read), the meaning of the word Antarctica: "opposite to the arctic" (http://en.wikipedia.org/wiki/Antarctica), (where "arctic" means "near the Bear, north(ern)" (http://en.wikipedia.org/wiki/Arctic)), and that the first formal use of this name, (in 1890s), is attributed to the Scottish cartographer and geographer John George Bartholomew. So, it became easily to foresee the answer for:

\subsubsection{What is Antarctica? What is it made of?}

The first part of the definition for Antarctica, in the Oxford English Dictionary (http://oxforddictionaries.com) says it is "a continent round the South Pole, [...]" and the one for continent: "any of the world's main continuous expanses of land [...]". The definition for

\footnotetext{
2 about which more information can be read at www.dfg.de via the GEPRIS - the DFG's internet database service. Schwerpunktprogramm (SPP) 1158: "Bereich Infrastruktur - Antarktisforschung mit vergleichenden Untersuchungen in arktischen Eisgebieten"
} 
Antarctica follows: "situated mainly within the Antarctic Circle and almost entirely covered by ice sheets". That means, there must be all kind of adventurous, one of the kind stories related with it; in this thesis just a little under the umbrella:

\subsubsection{What about Man becoming aware of Antarctica's existence?}

It seems that ideas of a symmetric world requested for land in the south (http://en.wikipedia.org/wiki/Terra_Austalis) or a continent around the South Pole to exist, the so called Terra Australis Incognita of the theoretical geographers.

A History of Antarctic Science by G.E. Fogg (1992), is the book "first to describe the development of scientific activity in the Antarctic (as distinct from exploration) in all its aspects." (Fogg, 1992), and offers a lot of information about how Man gradually came into discovering the last continental mass, like:

$\rightarrow$ Edmond Halley, Fellow of the Royal Society and Captain in the Royal Navy motivated mainly by his interest in terrestrial magnetism, voyaged southwards and on $1^{\text {st }}$ February 1700 "attained his furthest south, $52^{\circ} 24^{\prime} \mathrm{S}$, and saw his first icebergs, which were of characteristic tabular form. He described them in a letter" as "great Islands of Ice, of soe Incredible a hight and magnitude, that I scarce dare write my thought of it".

$\rightarrow$ James Cook voyaged to the South Seas, and delimited the Antarctic continent, reaching furthest south, $71^{\circ} 10^{\prime} \mathrm{S}$ (at $106^{\circ} 54^{\prime} \mathrm{W}$ ), on $30^{\text {th }}$ January 1774 , when he wrote in his journal " it must be allowed that these prodigious Ice Mountains must add such additional weight to the Ice fields which inclose them as must make a great difference between the Navigating this Icy sea and that of Greenland."

$\rightarrow$ Captain Thaddeus Fabian von Bellingshausen and his fellow Lieutenant Mikhail Lazarev were in charge of an expedition aiming at going as closest possible to the South Pole and they were the first to sight the Antarctic continent in 1820 ( $28^{\text {th }}$ January).

$\rightarrow$ "There seems little doubt, however, that the first landing on the Peninsula was made in February 1821 by Captain John Davies [...] probably at Hughes Bay 6420'S 61 $15^{\prime} \mathrm{W}^{\prime}$.

$\rightarrow$ James Weddell, (between 1822-24) "attained a furthest south of $74^{\circ} 15^{\prime}$ ', which was to remain unsurpassed for nearly 90 years, in the sea which now bears his name." Among others, he measured sea surface temperatures and "he pointed out that a formula produced by Mayer of Göttingen for calculating temperatures at different latitudes took no account of the effects of local features such as rocky or mountainous land [...]". Also he "has achieved a place in the biological literature by having a seal named after him."

$\rightarrow$ James Eights, (in 1846), "discussed the transport of rock and animals by drifting ice, thereby anticipating Darwin by six years", "used the word "tabular" to describe the characteristic shape of Antarctic icebergs, apparently for the first time", "found a fragment of carbonized wood embedded in the conglomerate - the first fossil to be found in the Antarctic" and "was undoubtedly the pioneer in the study of Antarctic invertebrates."

$\rightarrow$ Captain James Clark Ross, who "reached the North Magnetic Pole by sledge" in 1831, lead an expedition that had Antarctica as its main objective. "The first incursion further south was between November 1840 and April 1841 and penetrated through the pack-ice into the open 
waters of what was afterwards called the Ross Sea, discovering the Victoria Land, Ross Island with its active volcano, Mount Erebus and the Barrier (later the Ross Ice Shelf)."

$\rightarrow$ Adrien de Gerlache, a young Belgian naval lieutenant successfully imagined and led the Belgica expedition "the first truly scientific expedition to be specifically directed to the Antarctic since the days of Ross. [...] The science depended on Henryk Arçtowski, a Polish geologist, and Emil Racovitza, a Romanian zoologist. The Belgica entered Antarctic waters at the beginning of 1898 [...] The scientific results were considerable [...]. For the first time a consecutive meteorological record extending over the winter south of the Antarctic Circle was obtained and showed a minimum temperature of $-43^{\circ} \mathrm{C}$. Arçtowski produced the first coherent account of the physical geography and petrology of the Peninsula [...] Racovitza made general studies of flora and fauna, discovering for the first time the smaller terrestrial animals, mites and collembola, which are also abundant among mosses and lichens."

$\rightarrow$ Carsten Borchgrevink, a Norwegian living in Australia, was responsible of the Southern Cross expedition, "to Cape Adare in 1898 to 1900 - the first to overwintering on land within the Antarctic Circle." It produced important meteorological observations, "giving the first detailed picture of the climate of the maritime Antarctic continent [...] [and the] prevailing ESE and SE winds [which] indicated the existence of an anticyclone extending over much of the continent with a corresponding flow of air towards the South Pole at upper levels". Also "landing was made on the Ross Ice Shelf and a furthest south of 78050'S was attained." As a curiosity Brochgrevink disputed his claim to be the first to set foot on the Antarctic continent with other members of the expedition (Bernacchi, 1991).

And continuing to quote from G.E. Fogg (1992) "[w]e have now reached the point where it becomes confusing to deal with separate expeditions" and even if there are still many of "the first" to happen in relation with Antarctica their charm have to be discovered independently by the interested Reader.

It worth mentioning, as a justification for the notes reproduced above, what D.W.H. Walton wrote in the Introduction written for the book To the South Polar Regions by L. Bernacchi: "[i]t is easy to forget that many of the early Antarctic expeditions had scientific objectives every bit as important to the participants as the exploration and sovereignty issues beloved of governments. The well-funded national expeditions of the Heroic Age of Antarctic exploration (1900-1916) have been well, or evenly exhaustively, documented. This period of Scott, Shackleton, Amundsen, Charcot, Nordenskjold, Drygalski and others now dominates Antarctic history and it is their exploits and bravery which colour all our perceptions of this period of human history. Yet there were other earlier or smaller expeditions, much less well known. They were as pioneering in their ambitions, often just as exciting in their exploits, and certainly important in their contributions which, as so often happens, have been largely overlooked."

The "heroic age" of the Antarctic expeditions with their well documented journals, let behind information that is referred to even today, especially when comes about the day to day life on austral ice. The journal of an Antarctic expedition can be found to be repetitive and therefore boring, but sometimes, the climax of the story can be identified if the journal is just leafed through, (as with the case for the one of Scott's last Antarctic expedition, Appendix 1.2A) or can be found already quoted in the subsequent scientific literature, (as is the case with the Mawson's description of katabatic winds at Cape Denison; Appendix 1.2A).

Overall, from this incipient part of Man's relationship with Antarctica it is important to keep in mind the coordinates needed for the "[s]tudents of Antarctic exploration", possible (or prospective) geologists in order to end with a "presentation of a total picture of what nature is 
hiding under millions of square mile of ice" ${ }^{\text {"3 }}$ leadership, strength, character. Coordinates nicely expressed by the words written on the monument erected in memoriam Scott's Polar Party: "to strive, to seek, to find and not to yield" (R.L. Nichols in Craddock, 1982, Appendix 1.2A).

\subsubsection{Antarctica' general geology and the Dronning Maud Land region}

"Praise ye the Lord of earth, / All ye that dwell therein, [...] Ye meteors, fire and hail, / With ev'ry cloud that snows, / As o'er the land they sail, / And various wind that 6lows / The rapid terror of the storm, / At once his mandate to perform. / Ye mountains of the air, / And hill of less degree," PSALM CXLVIII, Smart 1987

In Antarctic geoscience (Craddock, 1982), there are (mainly) two constructive review papers about geological aspects related with Antarctica: Antarctica and Gondwanaland (Craddock, pg. 3), and Structure of Antarctica and outline of its evolution (Grikurov, pg. 791).

In the first review paper, one can read: "early in this century, [...] it was recognized that Antarctica could be divided into two major geologic provinces. The first comprises the larger part of the continent that faces mainly upon the Atlantic and Indian Oceans; since most of this province lies in the area of east longitudes, it is commonly known as East Antarctica. The second province makes up the smaller part of the continent that faces mainly upon the Pacific Ocean; it is commonly known as West Antarctica. East Antarctica is a typical continental shield or stable platform, consisting of a foundation of igneous and metamorphic rocks overlain by a sequence of younger, flat-lying sedimentary and volcanic rocks. By contrast West Antarctica is composed of generally younger rocks that are widely deformed and metamorphosed; the age and nature of the basement rocks are poorly known. Intrusive and extrusive igneous rocks are abundant and some volcanic activity continues there today", as well as other arguments about the relationship between the Gondwana supercontinent and Antarctica.

In the second review paper an extended description of the Antarctica' structure can be found; a structure that is considered to comprise "[t]he following structural units [...] 1) the East Antarctic craton, (2) the Weddell Sea submerged platform, (3) the Ross fold system of the Transantarctic Mountains, (4) the West Antarctic fold system of the circum-Pacific mobile belt, (5) transitional areas and (6) rift zones."

So, as a general line, we learned that East Antarctica is geologically related with the fragmentation of Rodinia supercontinent, and the subsequent consolidation of the Gondwana supercontinent (Kleinefeld, 2003).

Alexander du Toit in Our Wandering Continents (1937, pg.128), pointed out the vital role played by the East Antarctic shield "around which, with wonderful correspondence in outline, the remaining 'puzzle-pieces' of Gondwanaland can with remarkable precision be fitted." (also in Craddock, 1982, pg 4).

On a usual physical map of the Antarctic continent are depicted 17 geographical regions, the so called "Lands", the most extended one being in East Antarctica, namely the Queen Maud Land or Dronning Maud Land, of interest for the data reported further in this thesis. This region, "consist of the stretch of Antarctic mainland between the [...] Falkland Islands Dependencies in the west $\left(20^{\circ}\right.$ west) and the Australian Antarctic Territory in the east ( $45^{\circ}$ east)." The claim for this Antarctic region was made in 1939 by the Norwegian Government (Giaever, 1954). The name comes from the Norwegian Queen Maud (1869-1938) and the territorial claim is since 1959 regulated by the Antarctic Treaty (Näslund, 1998).

\footnotetext{
${ }^{3}$ E.S.W. Simpson (on behalf of G. Söhnge, President of the Geological Society of South Africa) in the opening of the first International Symposium on Antarctic Geology, Cape Town, 16-21 September 1963, (Adie, 1964, pg. vii)
} 
When the Gondwana supercontinent formed, central Dronning Maud Land was located near the eastern margin of southern Africa, therefore it has litho-chronological and tectonic characteristics as those present by the Mozambique Belt exposed in Mozambique, Madagascar, Sri Lanka and southern India (Kleinefeld, 2003).

About the landscape in Dronning Maud Land (Antarctica), and as it interacts with the respective ice sheet and climate, useful information can be found in Näslund (1998). Overall, the mountainous landscape in west and central Dronning Maud Land is formed of typical alpine features, such as cirques, glacial valleys and arêtes. These alpine landforms were formed by wetbased glaciation but the present ice sheet (in Dronning Maud Land region) is cold-based thus it can be considered that the glacial landscape is old, and is not a result of the present glacial and climatological conditions.

The morphological units forming the terrigenous part of Dronning Maud Land are the following: Heimefrontfjella $\left(13^{\circ}\right.$ to $9^{\circ} 15^{\prime} \mathrm{W} ; 7^{\circ} 15^{\prime}$ to $\left.75^{\circ} 15^{\prime} \mathrm{S}\right)$, Kirwanveggen $\left(73^{\circ}\right.$ to $74^{\circ} 15^{\prime} \mathrm{S}$; $06^{\circ} 30^{\prime} \mathrm{W}$ to $1^{\circ} 30^{\prime} \mathrm{W}$ ), Borgmassivet, Mühlighofmannfjella (around $72^{\circ} \mathrm{S}, 5^{\circ} 20^{\prime} \mathrm{W}$ ), Orvinfjella, Wohlthat Massivet (at $71^{\circ} 35^{\prime} \mathrm{S}, 12^{\circ} 20^{\prime} \mathrm{E}$ ), Sør Rondane (around $72^{\circ} \mathrm{S}, 2^{\circ} \mathrm{E}$ ), and Dronning Fabiolafjella (around $71^{\circ} 30^{\prime} \mathrm{S}, 35^{\circ} 40^{\prime} \mathrm{E}$ ). They represent much of the $2.5 \%$ of landscape standing above the ice (Näslund, 1998).

A detailed (petro)chemical description of the geological units of (East) Antarctica is not of interest here, (when needed it can be looked at in the mentioned or other available references). Suffice to note the representative information about the geology in Dronning Maud Land.

For example, the outcrops between $2^{\circ} \mathrm{E}$ to $12^{\circ} \mathrm{W}$ and $17^{\circ} 08^{\prime} \mathrm{S}$ to $73^{\circ} 40^{\prime} \mathrm{S}$ are composed of gneisses, amphibolites, schists and pegmatites, siltstones, greywackes, conglomerates, diorite, gabbro, andesites, basalts. The composition of the gneisses is (entirely) formed of quartz, potash feldspar (mainly microcline), sodic plagioclase (commonly albite-oligoclase) and biotite, and some accessory minerals are apatite, sphene, allanite, zircon magnetite specularite and metallic sulphides (Roots, 1953).

Sør Rondane petrography is based on biotite-hornblende-gneisses, amphibolites, biotiteschists, phlogopite-forsterite-marbles and biotite-granites (van Autenboer and Loy in Adie, 1972).

Information about the chemical composition of individual feldspars, orthopyroxene and garnets, (calculated from Electron Microprobe analyses), collected in the Otto-von-GruberGebirge, central Dronning Maud Land can be found in Kleinefeld (2003). Little variation in the plagioclase and K-feldspar composition is observed; the orthopyroxenes were labeled as ferrosilites; and the majority of the garnets are relatively low in grossular.

\subsubsection{What more about 'snow-firn-ice from $66^{\circ} \mathrm{S}$ to $90^{\circ} \mathrm{S}$ '?}

\footnotetext{
"The palms of our hands are white. / The soles of our feet are white. The whites of our eyes are white. / We are three time white. What is there left? /How much whiter can we get?"

"Three times white" by Ercüment Behzat Lav
}

Antarctica can be defined as the land south of the $66^{\circ}$ parallel of latitude, a continent of which main particularity is the large mass of ice ${ }^{5}$ covering it. This Antarctic ice cap has a thickness of more than $4500 \mathrm{~m}$ (SCAR, www.scar.org) and its oldest ice has (probably)

\footnotetext{
${ }^{4}$ in Fergar, 1992, pg. 60

5 and an artistic definition from Bradfield (2009): Ice sheet. Continuous ice overlying a large land area.

Draw that up to your chin in the night, the music of it breaking, your feet dim hillocks near the horizon of the bed. Lay that sheet, freshly laundered with new snow, over a clothesline, unsnapping in the breeze, pulling the line, the branch it's tied to, pulling it all into contact with the earth.
} 
experienced the cooling-warming events, during the Pleistocene's and (for sure) the ones of Holocene's geological eras. Significant ice sheets developed in Antarctica near the Eocene/Oligocene boundary (aprox $34 \mathrm{Ma}$ ago) (Coxall et al. 2005; Ehrmann and Mackensen, 1992), reaching a stable state around $14 \mathrm{Ma}$ ago (Liu et al. 2010). There has been obtained evidence for a correlation between the evolution of the Antarctic ice sheet and the $\mathrm{CO}_{2}$ concentration in the atmosphere (Pearson et al. 2009; Peters et al. 2010), with one hypothesis considering that higher $\mathrm{CO}_{2}$ concentrations induce ice melting (Ruddiman, 2006; Hogg, 2008).

"We may compare Antarctica to a huge iced cake. The snowfall throughout the year on the surface 'cake' rams down the masses of ice and squeezes them in a downward and outward direction to the edge and the ocean, where massive icebergs break off and drift out to sea" (Giæver, 1954).

Prodi et al. (2008) studied the snow crystals in Antarctica and found "a large variety of ice crystal habits (needles, hexagonal plates, crystals with branches, dendritic crystals, etc.)". Regarding the chemistry of the snow crystals they found that sea-salt has a high contribution, methanesulfonic acid (MSA) has an additional share as some organics like: propionate, acetate, formate and glycolate. Further, in packing of the snow crystals, it can be distinguished between winter and summer snow layers based mainly on the analyses of the constituent grains and density. Fine grains versus coarse ones were attributed to winter and summer snow, respectively; while the winter snow layers have high density and look homogenous when compared with the low hardness summer snow layers containing depth hoar (Endo and Fujiwara, 1973). The surface layers of a snow pack are at the lowest temperature, usually equal with the environmental temperature, and free of significant compressional stresses. Arthern et al. (2010) obtained a good match for Antarctic snow compaction rates measured and modeled. Since the measurements indicate that snow compaction "occurs through slow, viscous deformation of the snowpack, with no significant contribution from sudden collapse of weak layers the modeling was based on rate equations for lattice-diffusion (Nabarro-Herring) creep of material around pores, combined with normal grain growth".

As the snow accumulates at one site transforms into firn, which is more and more compressed until its density equals that of ice (Craven and Allison, 1998; Kipfstuhl et al. 2009) at the ice-firn transition depth, below which only ice can exist, in strata more or less stable depending on a multitude of factors like: the chemical composition of the initial snow, the environmental temperature at which the firn formed, the time allowed for the firn-ice transformation, the stability of below ice layers, the thermodynamic conditions of the comprising ice body, to name a few (Jun and Jacka, 1999; Domine et al. 2007). The average snow accumulation rate, (a vital information for studying the ice sheet dynamics and the global sea level as well as for the climate and ice core dating), is decreasing from the coastal regions of the southern ice cap, where the influence of the oceans is predominant, to the inland ones where there are persistent surface winds (Parish, 1982; Oerter et al. 2000; Parish and Cassano, 2003; Frezzotti et al. 2005; Hou et al. 2007; Banta et al. 2008; Eisen et al. 2008). This can explain why inland basal ice is usually older and the strata of the above standing ice column has a low time resolution stratification (for example the two EPICA ice cores).

Snow and ice metamorphism can be isothermal, non-isothermal, pressure driven or pressureless (Blackford, 2007). Where the weather conditions permit (i.e. in the coastal Dronning Maud Land), the firn layers metamorphosed during (a warm) summer have depth hoar and thin ice layers or ice lenses due to a higher level of solar radiation and temperatures near $0^{\circ} \mathrm{C}$, but the distinction between summer and winter firn disappears with increasing depth (Lunde, 1961; Kärkäs et al. 2005a). Viewed in the light of pressure sintering densification process the density of snow and firn resulted to have three critical densities: $0.55 \mathrm{~g} / \mathrm{cm}^{3}$ until which the compaction of snow takes place; $0.82 \mathrm{~g} / \mathrm{cm}^{3}$ when the pore space closes and air bubbles are formed; and an additional density of $0.73 \mathrm{~g} / \mathrm{cm}^{3}$ when the contact area between the ice particles becomes 
maximum (Freitag et al. 2004 and the references therein, i.e. Maeno and Ebinuma 1983). On the other hand, Fujita et al. (2009) developed a model which explains the relationship between a stronger firn insolation (at Dome Fuji) and smaller gas content (or lower $\mathrm{O}_{2} / \mathrm{N}_{2}$ ratio) in the ice. In general, with respect to gas transport three zones can be distinguished in the firn: a convective zone where air mixing takes place mainly by wind convection, then a zone in which the air can diffuse through the firn pores and the zone below the lock-in depth, the non-diffusive zone, extended until the close-off depth (Landais et al. 2006).

"Biscaye holds the two-foot-long section of Antarctic ice up to a green lamp on a plywood workbench. "See the layers?" he asks. In the bright light the layers are faint stripes, an inch or so thick. To Biscaye they are volumes of information, stacked in an ice library" (Holmes, 2001, pg. 99).

The layers are important for ice dating. In modern times layer counting (or visual stratigraphy, and not only) for ice cores is supported by appropriate technologies enabling a very good documentation. By means of optical scanning ice cores are transformed in photographical images (Takata et al. 2004; Svensson et al. 2005; McGwire et al. 2008a, McGwire et al. 2008b) which can be processed further for extracting the necessary (layering) data. To a certain extent, manual annual layering is useful though subjective; in the case of the Holocene Siple Dome ice, the dating "was more consistent and better quantified" when done via machines (Taylor et al. 2004). Ambiguities in (visual) counting the annual layers in an ice core can be resolved using the results from other measurements, like electrical conductivity, dust concentration (Taylor et al. 1992; Ram and Illing, 1994) detailed glaciochemical analyses (Andersen et al. 2006) or a systematic combination of as many as available parameters (Meese et al. 1997). But, in nature, the mineral ice deforms, in general, by creeping - (it flows in a viscoplastic continuous and slow regime) - on the expense of its macro or micro structural particularities as layers, grains, or lattice perfections and imperfections. "During deformation, the lattice of some crystallites may bend, twist, break, and rotate, changing the original fabric, so they interact continually through exchanges of mass, energy, momenta and entropy", as any other thermodynamic open system (Faria, 2006). "The anisotropy of polycrystals can be induced by strain" and (when the case) by high-temperatures but rather indirectly, since it generates the nucleation of new grains via recristallization, thus affecting in fact the overall heterogeneity (the 'cellular' assemble of crystalline domains) of the polycrystal (Faria et al. 2006b). For example, when the orientational distribution of the grains crystallographic axes (the texture and/or fabric) is analyzed it was observed that polycrystaline ice can be considered to respond anisotropically (frequently the lower depths of an ice core) or isotropically (frequently the shallow depths of an ice core) to the common uniaxial compression acting in the domes of an ice sheet (Alley et al. 1995; Thorsteinsson et al. 1997). Data on fabrics and stereology of the grains in polar ice are important for ice flow modeling (Gagliardini et al. 2009) and (implicit for) ice core dating.

\section{Dronning Maud Land region}

Regarding the physical properties of the surface snow in western Dronning Maud Land, Kärkäs et al. (2005a) found that the •) "density did not have any correlation with elevation, distance from the ice edge or latitude, but was the lowest in the local topographic highs and on the plateau"; •) a mean grain size of $1.5 \mathrm{~mm}$ which "decreased exponentially with the distance from the ice edge"; and •) "4 \% of all measured grains were partly decomposed precipitation crystals in the snow surface, $73 \%$ were rounded grains, $11 \%$ were faceted crystals, $9 \%$ were depth hoar grains and $3 \%$ were surface hoar". It was suggested that five snow zones can be distinguished in western Dronning Maud Land: the saline thin snow cover on sea ice, the hard dense snow on the seaward edge of the ice shelf, the snow in the inner parts of the ice shelf, the snow above the grounding line (and behind the first mountain range), the low density snow on 
the local topographic highs (such as ice domes or ice rises) (Kärkäs et al. 2002). Also, Kärkäs et al. (2005b) investigated the chemistry of snow from the coastal areas of western Dronning Maud Land and found that $\bullet$ ) "the ions of marine origin decreased exponentially with increasing distance from the coast"; $\bullet$ ) "The $\mathrm{NO}_{3}{ }^{-}$concentration showed no significant trend from the coast to the inland regions"; •) non-sea-salt potassium, "nss $K^{+}$and $n s s \mathrm{Ca}^{2+}$ demonstrated higher concentrations near the nunatak areas"; •) " $\mathrm{Mg}^{2+}$ had no significant sources other than sea spray".

Some interesting morphological features observable on the Antarctic plateau were described in the Sør Rondane mountainous area (Dronning Maud Land): major and smaller fields of blue ice, windscoopes (trenches on the wind-exposed side of most nunataks), aeolian glaciers (snow dunes around nunataks that can extend over several kilometers), weathering signatures as: honeycomb erosion, felsenmeere (mountain top detritus), imposing towers with 500-800m sheer vertical, salt encrustations (among others) (van Autenboer 1964). In particular, the peculiar blue ice areas are seen as a prospective source of (paleo)climate information. They are bare ice fields kept with a negative mass balance by high velocity winds, covering $~ 1 \%$ of the Antarctic surface likely to form around rocky obstacles that stop the ice flow. Even if the dating of such ice is challenging the paleoclimatic information stored in it may have a higher resolution and an older age than the traditional ice from deep ice cores (Sinisalo and Moore, 2010).

Birnbaum et al. 2010 describe the snow dunes (barchan-type or transverse dunes) formed by winds with speeds larger than $10 \mathrm{~m} / \mathrm{s}$ were observed to occur with a frequency of three to eight per year at Kohnen station site (Dronning Maud Land). The building of such surface features implies that the snow (and consequently the climate related information trapped in it) is mechanically relocated and remixed (but only on a decameter scale). The material that enables the apparition of barchan dunes are snow particles that are rounded and not too large but robust, meaning that they are altered normal drift snow crystals. "Remixing of weathered, aged snow leads to a pore-space structure in the dunes significantly different in grain size, grain shape and connectivity, density, hardness, permeability and temperature conductivity from normally deposited snow", thus generating distinctive looking layers in the snowpack that can influence the ice age-gas age difference (acting as a lid that seals the air at lower depth than in a non-stratified firn column). Dune horizons (with small and well interconnected pores) have been identified as being preserved in firn cores but their frequency is less than the one of the main meteorological condition (strong winds caused by large scale pressure systems not by enhanced katabatic flow) considered as being their cause. It resulted that another necessary condition is the absence of precipitations (or only of diamond dust type).

\section{'last but not least'}

About other issues like subglacial lakes and volcanoes, ice streams and ice shelves, ice ponds and crevasses, meteorites and biologic life as well as ice melting and flow, ice bedrock interaction or ice humans interaction the Reader is kindly ask to understand that it was not possible to write here. 


\title{
1.3 The sky above the austral ice
}

\begin{abstract}
"Out on the ice shelf the Sun had been shining in the morning. Then, a thick low overcast moved in with warmer and moister air from the north, and the visible world become invisible. [...] There was no horizon, no shadow, no perception of depth or height above surface, or of obstacles like sastrugi ${ }^{6}$ and snow waves. A great white nothing: Whiteout. An explorer's torment, a pilot's curse, a meteorologist weather. "Schwerdtfeger, 1984, pg.1
\end{abstract}

\subsubsection{The wind and temperature regime}

\section{General considerations}

According to a dictionary (Lewis, 1991; Dunlop, 2005) the air is defined as the mixture of gases which form the earth's atmosphere excluding aerosols, dust particles, precipitations and pollutants. Ordinary air may be regarded as a mixture of dry air and water vapor.

The atmospheric science which studies the physics, chemistry and dynamics of the air masses together with their interaction with the environment, (land, ocean, biota), is recognized to be meteorology. "Its goals are the complete understanding, accurate prediction, and artificial control of atmospheric phenomena. It is one of the most complex fields of both natural and applied science." (Stringer, 1972).

The "averaged weather" or the "averaged states of the atmosphere at a given instant" is considered as climate, for whose characterization the daily atmospherical fluctuations are neglected but the variability of the weather elements and the occurrence of extreme events are considered (Peixoto and Oort, 1992). Climate is the research object of climatology. "The aim of climatology is to discover, explain, and exploit for the benefit of man the normal behaviour of atmospheric phenomena, bearing in mind that irregularities in atmospheric behaviour define the norms for smaller-scale phenomena. [...] It's a science - really an applied science - whose methods are strictly meteorological, but whose aims and results are geophysical" (Stringer, 1972).

The roots of meteoro- and implicit climatology are with the ancient Greek philosophers (Aristotle's Meteorologica) but around the time Antarctica was finally indubitably sighted the concepts of "weather brought by the wind" (by von Buch, 1820), "weather explained using polar and equatorial air currents" (by Dove, 1827), "climate appearing as alternating cold and warm masses of air" (by Howard, 1820), "kinetics of a cyclone" (by Dove, 1828) were developed (references in Stringer, 1972).

For Antarctica the main weather features concerns the ubiquitous katabatic winds and the short summer as well as the coreless winter. Due to the specific geography of the southern hemisphere at low latitudes, Antarctica is isolated by a semipermanent baroclinic zone, resulting in the coldest and harshest climate for this continent. The katabatic wind regime is a lower branch of the meridional circulation between Antarctica and northerly latitudes, which in turn is strongly determined by the continent's orography. The slope of the terrain directly determines the intensity of the katabatic winds, therefore the strongest of these winds are (to be) found near the steep coastal regions. "The katabatic wind system is among the most persistent surface flow regimes in the world, rivaling even with the trade-wind regime", but the wind directions are determined by a topographically influenced forcing mechanism, the cold negatively buoyant air

\footnotetext{
${ }^{6}$ plural for sastruga, a Russian name, [meaning 'groove'] for the irregularity or wave formation in the hard snow, caused by persistent wind, perpendicular to the wind direction, slopping gently on the windward side and steeply to leaward. They arise by snow dune coalescence. The term is also used for ridges parallel to the wind direction produced by mechanical abrasion. They may be up to $2 \mathrm{~m}$ high (Lewis, 1991; Dunlop, 2005).
} 
from a broad horizontal area being constrained to concentrate and follow a certain number of pathway channels over the continent. The persistence of the katabatic winds regime can be a consequence of vorticity conservation and additionally supported by the underlying orography. It results that the intense cyclonic disturbances frequent around the Antarctic coastline follow the strong baroclinic zone surrounding the continent and only occasionally penetrating into the continent (Bromwich and Parish, 1998). More about the surface Antarctic wind regime can be found in Schwerdtfeger (1984).

The temperature regime near the surface of the Antarctic plateau, coined by the radiation conditions, (the variations in the global radiation and the albedo), shows the two remarkable features written above: the very short polar "summer", (about 30 days, between mid-December and mid-January) and the "coreless" winter $^{7}$ (during the first part of the winter the temperature inversion in the boundary layer is very strong, meaning that "the energy flux outgoing from the surface, is comparatively small and the atmospheric radiation from the warmer and moister layer large). Everywhere in the interior of the continent the lowest winter temperatures are mainly the result of enduring negative values of the effective longwave radiation combined with low windspeeds" (Schwerdtfeger, 1984). Thus it is possible for very low surface temperatures to be attained, the lowest of which was $-89.2^{\circ} \mathrm{C}$ at Vostok in 1983 (SCAR, www.scar.org).

\section{Dronning Maud Land region}

Schlosser et al. (2010) analyzed the precipitation measured at Kohnen Station, Dronning Maud Land, (during 2001-2006), and found it "to be highly episodic, with, on average, approximately eight high-precipitation events per year that can bring more than half of the total annual accumulation. The duration of the events varies between 1 day and about 1 week. On most days in the remaining time of the year, however, daily precipitation sums are about one order of magnitude smaller than that for the high-precipitation events. Synoptic weather patterns causing these events were directly connected to frontal systems of cyclones in only $20 \%$ of the 51 investigated cases. The majority of the events occurred in connection with (blocking) anticyclones and correspondingly amplified Rossby waves, which lead to advection of warm, moist air from relatively low latitudes".

Birnbaum et al. (2006) emphasize the importance of visual observation of the precipitation at Kohnen Station, Dronning Maud Land which can detect snow falls of $1 \mathrm{~mm}$ to over $5 \mathrm{~mm}$ water equivalent (per event) that contribute considerably to the total annual accumulation. The synoptic processes (during the observation time: summer 2001/02 and 2004/05) responsible for these high rates of snow were grouped into three categories: (I) "occluding fronts of eastward moving low pressure systems [that] reach the plateau"; (II) "Frontal clouds of lows or secondary lows which form east of the Greenwich Meridian and move to the west (retrograde movement) [which] influence the plateau"; (III) "large-scale lifting processes due to an upper air low west of Kohnen Station cause snowfall on the plateau".

The alternative for the visual observations of weather in Antarctica is modeling. Wacker et al. (2009) investigated a weather episode (on 02.1999 "several low-pressure systems moved southwards and eastwards towards and along the coast"), in Dronning Maud Land via a highresolution, non-hydrostatic weather forecast COSMO Model and concluded that the near-surface temperature has a weak daily cycle ("which appears to be caused to some extent by the treatment of processes in snow and soil in the standard model configuration") and that the precipitation is dominated by topographic effects (the plateau has a steep margin). "The simulations show the

\footnotetext{
7 "Coreless winters are winters in which the mean monthly temperatures during a number of months differ little from each other." (Kodama and Wendler, 1984)
} 
general decrease of precipitation toward the interior, as seen in the accumulation climatology, however, the decrease is not monotonous".

The moisture sources for the precipitations falling in DML (Kohnen station being the main arrival point for the air parcels) are located mainly between $40^{\circ}$ and $60^{\circ} \mathrm{S}$ in the Atlantic Ocean (40-80\% of all snow falls) having an initial temperature between $0^{\circ}$ and $20^{\circ} \mathrm{C}$ and reaching the EPICA-DML drilling site within four days. Other sources can be formed in the Southern Ocean or on the continent, less in the Pacific Ocean and none in the Indian Ocean. In general, the annual accumulation is determined by compact events with increased snow fall and in particular the ones studied for 1998 can be put into relation with the presence of a strong El Niño circulation (Reijmer and van den Broeke, 2001).

\subsubsection{Atmospheric aerosol}

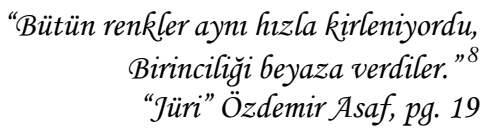

\section{General considerations}

The atmospheric aerosol is defined as "finely divided liquid droplets or solid particles (or nuclei) that are uniformly dispersed and able to remain suspended in the atmosphere rather than settling out" (Lewis, 1991; Dunlop, 2005).

Although the Antarctic atmosphere is considered to be the cleanest part of the Earth's gaseous envelope the impurities it contains, (implicit the aerosol), are very important for the climate study. In Göktas (2002) one can read a very nice introduction on what is relevant to be known about aerosol when it is related with investigations of Antarctic ice. Starting with the classification into the three recognized categories: Aitken particles $\left(10^{-3}\right.$ to $\left.10^{-1} \mu \mathrm{m}\right)$, large particles $\left(10^{-1}\right.$ to $\left.1 \mu \mathrm{m}\right)$ and giant particles (over $\left.1 \mu \mathrm{m}\right)$, Göktas (2002) describes further how the atmospheric aerosol forms: by gas-to-particle or bulk-to-particle conversion, how it is transported, (mainly at the tropospheric level) just to be later on deposited via wet or dry processes (cited in Göktas, 2002 : Jaenicke and Schütz, 1988; Davidson et al. 1996). The principal sources that generate aerosol particles in the Antarctic atmosphere, (but not only), can be the mineral dust, sea-salt, biogenic (including human) activity, volcanoes, and there are two main possibilities to study the nature of the polar aerosol: the direct investigations of the polar air and/or the analyses of the polar snow and ice. A (let's say) comprehensive description of the chemicals that can exist in the polar atmosphere and can be preserved in polar ice is given in the introductory part of the section 1.5 (What is not ice can be trapped in Antarctic ice). In the following paragraphs of this part the emphasis is on the interrelation between the existence and transport in the Antarctic atmosphere of some ionic aerosol species which are main proxies for (polar) climate research.

A snow chemistry survey across Antarctica showed very variable concentrations of the major ions function of the geographical (regional) location and the time of the year (Bertler et al. 2005). On the vertical axis, the sites with an elevation less than 2000m "are predominantly influenced by sea salt, with no significant post-depositional aerosol loss or enrichment taking place" while on the horizontal scale, the Na concentration decreases significantly at sites situated in the Antarctic interior. "The change from very low to very high concentrations seems to occur within a narrow band in the vicinity of the coast. While high Na deposition is readily explained in

\footnotetext{
8 "All colours grew dirty at the same rate: / white was given the winning prize." "Jury" by Özdemir Asaf in Fergar, 1992, pg. 111.
} 
coastal areas due to high sea-salt input, the narrow zone of marine air-mass intrusions (mesoscale cyclonic activity) coincides with the rapid decrease of $\mathrm{Na}$ concentrations in the Antarctic interior". In this zone, "the katabatic wind streams, transporting Na-depleted air masses from the interior towards the coast, compete with the Na-rich coastal air masses". In most (near coast) regions of Antarctica, $\mathrm{Na}$ concentration variation is followed by the $\mathrm{Cl}$ ions variability, except for the Antarctic interior (with low-accumulation zones) where additional $\mathrm{Cl}$ input could be afforded by $\mathrm{HCl}$ precipitation (De Angelis and Legrand, 1995).

$\mathrm{Ca}, \mathrm{Mg}$ and $\mathrm{K}$ can originate from sea-salt, local ice-free regions and global dust. The marine input produces orders-of-magnitude higher concentrations of these ions resulting in an observed overall inverse relationship with elevation. Across Antarctica, $\mathrm{Ca}, \mathrm{Mg}$ and $\mathrm{K}$, "show overall low concentration values and the continent-wide pattern might be used to distinguish between typical 'global' or hemispherical dust content from local Antarctic sources" (Bertler et al. 2005).

The overall $\mathrm{SO}_{4}{ }^{2-}$ and $\mathrm{NO}_{3}{ }^{-}$concentrations seem largely independent of elevation across the Antarctic atmosphere. But the $\mathrm{SO}_{4}{ }^{2-}$ anion has many sources and "while primary aerosol $\mathrm{SO}_{4}$ species (sea spray) and secondary marine-biogenic $\mathrm{SO}_{4}$ should exhibit a rapid decrease with increasing elevation, volcanic $\mathrm{SO}_{4}$ aerosols enters through the upper atmosphere and therefore should have a stronger signal in the Antarctic interior". The " $\mathrm{NO}_{3}{ }^{-}$is predominantly a secondary aerosol, produced in the strato- and ionosphere. Higher $\mathrm{NO}_{3}$ concentrations are therefore expected within the boundary of the polar vortex due to the influence of upper atmospheric air masses". In particular the preservation of $\mathrm{NO}_{3}{ }^{-}$in the polar snow is affected by various postdepositional and photochemical mechanisms that lead to a loss of this anion "especially at low accumulation sites which partially offsets the trend towards higher $\mathrm{NO}_{3}{ }^{-}$in the Antarctic interior" (Bertler et al. 2005).

Apart from the spatial variability the different species acting as aerosol nuclei in the (Antarctic) atmosphere have also a temporal evolution, the so called seasonality. In Legrand and Mayewski (1997) one finds "the fundamentals that have to be known" about the correlations between the chemistry of polar ice cores and the paleo-atmosphere. The seasonal variations of the soluble mineral species related with the Antarctic climate are as follows: •) Na has a well-marked winter maximum; •) $\mathrm{Ca}$ has a little variation probably because "the marine input, which is maximum in winter, tends to overshadow the dust contribution, which peaks in summer"; $\bullet \mathrm{NO}_{3}{ }^{-}$ and $\mathrm{SO}_{4}{ }^{2-}$ have a moderate maxima in spring and summer, while $\bullet$ ) ammonium presents no specific seasonality. Over extended periods of time the $\mathrm{Na}$ concentrations in polar ice has low values during warm stages and higher ones over the last ice age. Also, the Ca profile has peaks during the cold climate stages as well as the mineral dust considered to be correlated with an expansion of arid terrains. On the other hand, the $\mathrm{SO}_{4}{ }^{2-}$ ions have a moderate glacial-interglacial increase indicating a marine and biogenic origin for the excess $\mathrm{SO}_{4}{ }^{2-}$ in Antarctica.

The $\mathrm{Na}$ profile over the last climatic cycle (the last 120,000 years) was not easy to be explained, since it has somehow an unexpected shape, which suggests that the sea salt content of the glacial time atmosphere was enhanced. This was puzzling because the sea salt was linked with the unfrozen (sea ice free) ocean surface, and as it was determined, the sea ice expands over several hundreds of kilometers around the ice caps during the cold climates, increasing the distance between the open waters and continental Antarctic sites. A higher wind speed at the sea surface and/or a more efficient meridional transport between middle and high latitudes during glacial periods were supposed to favour the increased Na concentrations (Legrand and Mayewski, 1997; and the references therein). An alternative explanation has been offered in the recent years after investigations of the composition of frost flowers. These are icy features that "grow on newly-formed sea ice from a saturated water vapour layer" (Kaleschke et al. 2004). The surface area for these frost features was calculated as being $1.4 \mathrm{~m}^{2}$ per $\mathrm{m}^{2}$ of ice surface and their microstructures were observed to be typical of very fast growing crystals (Domine et al. 2005; 
also Obbard et al. 2009). Rankin et al. (2000) measured a depletion in sulfate relative to $\mathrm{Na}$ in frost flowers from (Brunt Ice Shelf) Antarctica, and chemical analyses of coastal ice cores showed that the strong sea salt signals come from a fractionated source and thus may be related with frost flowers (Rankin et al. 2002). "The microstructural chemistry of frost flowers is complex, relying as it does on the conditions when they form, air and substrate temperature, chemical concentrations in the water and surface skim, and relative humidity, and on changes in all of these conditions plus the availability of additional precipitation as they grow". Extended investigations and their interpretation related with the previous quoted phrase as well as comments about the role played by the frost flowers in atmospheric chemistry can be found in the corresponding source: Obbard et al. 2009, and the references therein.

As a concluding paragraph it is nice to remark that lizuka et al. (2008) pinpointed the main chemistry of the austral and boreal atmosphere, by comparing the results from chemical analyses of different polar ice samples. It was observed that the dominant chemical compounds preserved in the ice vary with the climatic period (glacial or interglacial) and the region where the ice was sampled, i.e. Greenland versus Antarctica, probably because of the high concentration of $\mathrm{Na}^{+}$and $\mathrm{SO}_{4}{ }^{2-}$ ions in the marine influenced atmosphere above the Antarctic ice sheet and a more continental influenced atmosphere, enriched in $\mathrm{Ca}^{2+}$ ions, above Greenland, plus a more reductive capacity of Arctic and Antarctic atmospheres during the last glacial maximum, LGM, than during the Holocene (which would explain why nitrate, chloride and $\mathrm{CaCO}_{3}$ are preserved in the LGM ice).

The primary chemical reactions involving $\mathrm{Cl}^{-}, \mathrm{NO}_{3}{ }^{-}, \mathrm{SO}_{4}{ }^{2-}, \mathrm{Na}^{+}, \mathrm{Mg}^{2+}$, and $\mathrm{Ca}^{2+}$ species in polar ice and atmosphere are as follows:

$$
\begin{aligned}
& \text { (I) } \mathrm{CaCO}_{3}+\mathrm{H}_{2} \mathrm{SO}_{4} \Rightarrow \mathrm{CaSO}_{4}+\mathrm{H}_{2} \mathrm{O}+\mathrm{CO}_{2}, \mathrm{MgCO} \mathrm{H}_{2} \mathrm{SO}_{4} \Rightarrow \mathrm{MgSO}_{4}+\mathrm{H}_{2} \mathrm{O}+\mathrm{CO}_{2} \\
& (\mathrm{I}) \mathrm{Ca}\left(\mathrm{NO}_{3}\right)_{2}+\mathrm{H}_{2} \mathrm{SO}_{4} \Leftrightarrow \mathrm{CaSO}_{4}+2 \mathrm{H}_{2} \mathrm{NO}_{3}, \mathrm{Mg}\left(\mathrm{NO}_{3}\right)_{2}+\mathrm{H}_{2} \mathrm{SO}_{4} \Leftrightarrow \mathrm{MgSO}_{4}+2 \mathrm{HNO}_{3} \\
& \text { (II) } 2 \mathrm{NaCl}+\mathrm{H}_{2} \mathrm{SO}_{4} \Leftrightarrow 2 \mathrm{Na}_{2} \mathrm{SO}_{4}+\mathrm{HCl}, \mathrm{MgCl}_{2}+\mathrm{H}_{2} \mathrm{SO}_{4} \Leftrightarrow \mathrm{MgSO}_{4}+2 \mathrm{HCl} \\
& \text { (II) } 2 \mathrm{NaNO}_{3}+\mathrm{H}_{2} \mathrm{SO}_{4} \Leftrightarrow \mathrm{Na}_{2} \mathrm{SO}_{4}+2 \mathrm{HNO}_{3}, \mathrm{Mg}\left(\mathrm{NO}_{3}\right)_{2}+\mathrm{H}_{2} \mathrm{SO}_{4} \Leftrightarrow \mathrm{MgSO}_{4}+2 \mathrm{HNO}_{3} \\
& \text { (III)CaCO} \mathrm{Ca}_{3}+2 \mathrm{HNO}_{3}=>\mathrm{Ca}\left(\mathrm{NO}_{3}\right)_{2}+2 \mathrm{H}_{2} \mathrm{O}+\mathrm{CO}_{2}, \mathrm{MgCO}_{3}+\mathrm{HNO}_{3}=>\mathrm{Mg}\left(\mathrm{NO}_{3}\right)_{2}+2 \mathrm{H}_{2} \mathrm{O}+\mathrm{CO}_{2} \\
& \text { (IV) } \mathrm{NaCl}+\mathrm{HNO}_{3} \Leftrightarrow \mathrm{NaNO}_{3}+\mathrm{HCl}, \mathrm{MgCl}_{2}+2 \mathrm{HNO}_{3} \Leftrightarrow \mathrm{Mg}\left(\mathrm{NO}_{3}\right)_{2}+2 \mathrm{HCl}
\end{aligned}
$$

The dominant chemical compounds depend only on the ions abundance and the priority sequence of chemical reactions: calcium sulfate forms first, (I), then the other sulfates, (II), followed by nitrate, (III), chloride, (IV), and carbonate compounds (Iizuka et al. 2008; and the references therein).

\section{Dronning Maud Land region}

Based on size-segregated aerosol measurements, (at Aboa station, $\left(73^{\circ} 03^{\prime} \mathrm{S}, 13^{\circ} 25^{\prime} \mathrm{W}\right.$ ) in western Queen (Dronning) Maud Land, Antarctica, during summer time), a general understanding of the sea-salt chemistry was gained (Kerminen et al. 2000). It has been found that, the sea-salt mass size distribution was tri-modal with a submicron mode centering between 0.5 and $1 \mu \mathrm{m}$, accompanied by two supermicron modes, (70\% of the sea-salt mass), that peaked slightly below $2 \mu \mathrm{m}$ (the most dominant) and somewhere between 2 and $10 \mu \mathrm{m}$ (Kerminen et al. 2000). On the other hand, Stenberg et al. (1998) grouped the ions existent in snow from western Dronning Maud Land, DML, in two groups: "one with sea-salt elements and methane sulfonate 
and the other with nitrate and sulfate". From the spatial variation pattern of ions concentrations it was concluded that "the sources for sea-salt elements and methane sulfonate are local, whereas the sources for nitrate and sulfate are a mixture of local and long-range transport". It was established that the sulfate deposited in ice from Dronning Maud Land has also other sources than the marine biota, like the degassing volcanoes or terrestrial dust (Jonsell et al. 2005).

According to the experimental results of Kerminen et al. (2000), a large fraction of supermicron nss- $\mathrm{SO}_{4}{ }^{2-}$ (and also the $\mathrm{NO}_{3}{ }^{-}$) was bounded to sea-salt particles, in which they have replaced some of the particulate chloride. "The average chloride loss was more than $90 \%$ for submicron particles and decreased to about 50\% for particles larger than $3 \mu \mathrm{m}$ in diameter". It seems that "by providing a medium for heterogeneous reactions, sea-salt particles have the potential to influence the concentration and gas-particle partitioning of various sulphur, nitrogen, and halogen compounds in the Antarctic atmosphere" and later on in the Antarctic snow and ice.

The first seasonal signals measurements of ammonium, calcium, and sodium species, in ice cores from East Antarctica, DML, revealed no significant concentration change with the accumulation rate. "While the sea-salt-related component sodium peaks simultaneously with calcium, the maximum ammonium concentration occurs in the snow with a time lag of 2 months after the sea-salt peak. More than $60 \%$ of the calcium concentration can be attributed to an ocean source" (Sommer et al. 2000). Low non-sea-salt nss- $\mathrm{SO}_{4}{ }^{2-}$ and $\mathrm{Na}^{+}$and high $\mathrm{Cl}^{-} / \mathrm{Na}^{+}$ concentrations were found for the summer time snow layers at Dome Fuji (east DML, $77^{\circ} 30^{\prime} \mathrm{S}$

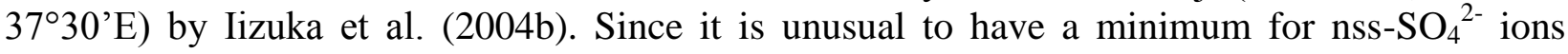
during the austral summer a sublimation-condensation mechanism was considered: "in summer, water vapor sublimates from within the snow in the daytime and condenses on the surface as frost in the nighttime, resulting in a dilution of the nss-SO ${ }_{4}^{2-}$ concentration".

For the EPICA deep drilling site in Dronning Maud Land at Kohnen Station, $\left(75^{\circ} \mathrm{S}, 0^{\circ} \mathrm{E}\right)$, chemical aerosol composition investigations (over bi-weekly intervals during the February 2003 to December 2005 period), revealed distinct late summer maxima for nss- $\mathrm{SO}_{4}{ }^{2-}$ and a broad November maximum ${ }^{9}$ for $\mathrm{NO}_{3}{ }^{-}$. The biogenic sulfur and sea salt concentrations were low, and the arrival of sea ice derived sea salt particles at Kohnen Station could not be clearly detected, "since even during mid-winter the $\mathrm{nss}_{-} \mathrm{SO}_{4}{ }^{2-}$ to $\mathrm{Na}^{+}$ratio was generally too high to unambiguously identify a sulfur depleted sea salt $\mathrm{SO}_{4}{ }^{2-}$ fraction". Nevertheless, this might indicate a relative importance of the sea ice related source for sulfate anion at this location. Moreover, it was concluded that the "ionic signals archived in firn do not straightforwardly depend on the atmospheric loading of the boundary layer" at the Kohnen Station deep drilling site, but are affected by various depositional processes (Weller and Wagenbach, 2007).

Concentrations of (more than) $350 \mathrm{ng} \mathrm{m}^{-3}$ for nss- $\mathrm{SO}_{4}{ }^{2-}$, were measured at Kohnen Station during the summers of 2000 and 2002 (January/February, in daily resolution), while lower values were typical for 2001 (Piel et al. 2006). When compared to other aerosol constituents measured at Kohnen Station, nss- $\mathrm{SO}_{4}{ }^{2-}$ accounted for $70 \%$ of the aerosol mass (while nitrate only for $7.4 \%$ ) and the sea salt contributed barely $8 \%$ to the total aerosol mass. "The high acidity of the aerosol (with $\mathrm{H}^{+}$accounting for about $77 \pm 4 \%$ of the total cation equivalents) was found to be a characteristic feature" for Kohnen Station site. "Between 33\% and $76 \%$ of the total nitrate and between $71 \%$ and $88 \%$ of total chloride were present as free acids ( $\mathrm{HCl}$ and $\left.\mathrm{HNO}_{3}\right)$. The fractions of non-sea-salt $\mathrm{Mg}^{2+},-\mathrm{K}^{+}$and $-\mathrm{Ca}^{2+}$ were roughly about $50 \%$ of their total amounts, indicating a significant terrestrial origin" (Piel et al. 2006).

\footnotetext{
${ }^{9}$ Isaksson et al. (2001) found in firn from Amundsenisen region (DML) a concentration of $\mathrm{NO}_{3}{ }^{-}$higher than at other sites on the plateau, (of $54.5 \mathrm{ng}$ g-1), which persist in the upper $0.6 \mathrm{~m}$ of the firn core.
} 
The deposition of marine aerosol in the Dronning Maud Land area is influenced by "the occurrence of a blocking high pressure ridge over the eastern and enhanced storm activity over the western Atlantic sector of the Southern Ocean (SO)". These characteristic variations of the atmospheric circulation occur with periods of 4-5 and 12-14 yr, the prior being associated with the Antarctic Circumpolar Wave, which is a prevalent feature of SO atmosphere dynamics over the last two millennia, and are responsible for an increased sea salt export into DML (Fischer et al. 2004).

Air mass back trajectory analyses, using nss- $\mathrm{SO}_{4}{ }^{2-}$ and methane sulfonate, MS, data documented an efficient long-range transport to Kohnen Station via the free troposphere (Piel et al. 2006). A vigorous frontal activity preceded records of increased nss-SO ${ }_{4}^{2-}$ and MS concentrations (by more than an order of magnitude within 2 days), which persisted for about 2 days and covered around $27 \%$ of the total atmospheric MS and $17 \%$ of the nss- $\mathrm{SO}_{4}{ }^{2-}$ observed budget. "Trajectory analyses documented an air masses intrusion from the marine boundary layer", but an "efficient removal of aerosols by wet deposition en route and below cloud precipitation scavenging above the measuring site" determined (the) "observed low MS and nss$\mathrm{SO}_{4}{ }^{2-}$ concentrations during this event. After passage of the frontal system, the source region of the air masses changed to the free troposphere above continental Antarctica" that determined (and seems, in general, to be closely related with) an increase of MS and nss- $\mathrm{SO}_{4}{ }^{2-}$ concentrations (Piel et al. 2006).

For other locations, Williamson et al. (2007) investigated the aerosol input in snow and firn from McMurdo Dry Valleys (Antarctica) and found that even if among different valleys the local terrestrial sources contribute to the amount of major ions or trace metals ( $\mathrm{Fe}, \mathrm{Al})$, the results for sodium and methylsulfonate were in line with the documented decreasing trends relative to elevation and to distance from the coast. The same at South Pole where Bergin et al. (1998) found for the first time comparable aerosol and firn chemistry "with winter minima due to coarse mode sea salt and summer maxima due to accumulation mode sulfate aerosol". On the other hand, Delmas et al. (2003) observed that there is a loss of the methylsulfonate acid (MSA) deposited in the Antarctic (Dome F) snow toward the gases in the firn and atmosphere, due to snow metamorphism, solid phase migration and snow or ice $\mathrm{pH}$, while Pasteur and Mulvaney (2000) observed that for some Antarctic firn and ice layers the $\mathrm{MSA}^{-}$anion is no longer encountered in the summer layers when it is deposited but in the winter ones probably due to diffusion and cation trapping processes.

\subsection{Kohnen Station 17.01.2006}

\footnotetext{
"The prediction of complex systems may be best described by the title of the talk, which Edward Lorenz gave ... in 1972: "Predictability: Does the Flap of a Butterfly Wings in Brazil set off a Tornado in Texas?" S. Spassov, Diss.ETH no.14976, Zürich, 2002, pg.18
}

The EPICA deep ice core drilling activities at Kohnen station $\left(75^{\circ} 00^{\prime} 06^{\prime \prime} \mathrm{S}, 00^{\circ} 04^{\prime} 04^{\prime \prime}\right)$ in Dronning Maud Land, started during the 2001/02 field season and were terminated on 17 January 2006 at a logged drilling depth of $2774.15 \mathrm{~m}$ (www.esf.org - EPICA project) and thus a new 'ice archive', the EDML ice core, was recovered.

The drilling site was carefully chosen as being representative for the region (Isaksson 1994; Oerter et al. 1999; Isaksson et al. 2001; Göktas et al. 2002; Göktas, 2002; Richardson- 
Näslund, 2004), because there is no major dome structure in DML ${ }^{10,11}$, after 3 years of investigations, at a location 2892 meters a.s.l. (above sea level) with a mean annual temperature of $-44.6^{\circ} \mathrm{C}$ and a mean accumulation rate of $64 \mathrm{~kg} / \mathrm{m}^{2}$

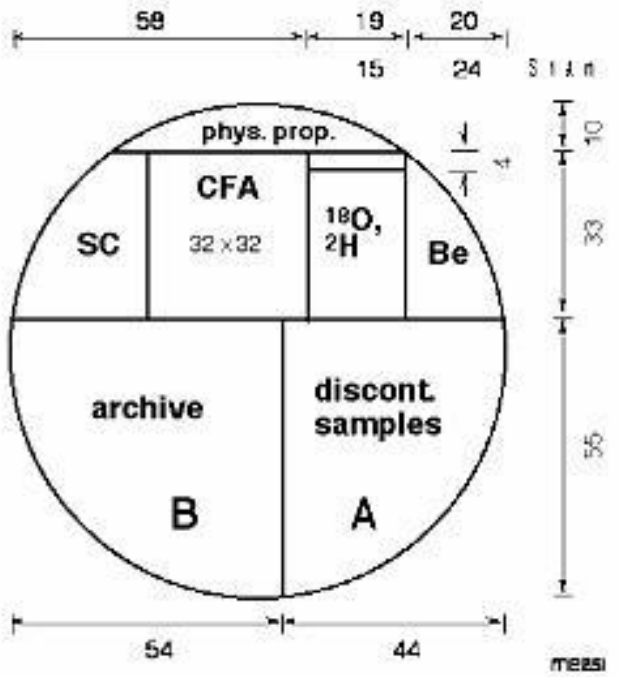
(Stauffer et al. 2004).

The ice core recovered at Kohnen station was processed at the Alfred Wegener Institute, Bremerhaven, Germany according to the scheme depicted in Figure 1.4.1 and sent for different chemical analyses (isotopes measurements - the ${ }^{18} \mathrm{O}-,{ }^{2} \mathrm{H}-$ piece), ion concentrations (CFA-Continuous Flow Analyses-piece), beryllium (Be-piece) or physical investigations (phys.prop.-piece), heavy metals concentration, mechanical properties, dust, organic acids (discont. samples-piece) among others (private communication S. Kipfstuhl, 2008).

$\leftarrow$ Figure 1.4.1 Cutting scheme for the EDML ice core.

The dimensions are in $\mathrm{mm}$. The diameter of the core is

$98 \mathrm{~mm}$. (private communication S. Kipfstuhl, 2008)

For the almost entire length of the EDML ice core (starting at $113 \mathrm{~m}$ depth) the results from visual stratigraphy were documented as images, employing a digital scanner designed to scan ice cores of $10 \mathrm{~cm}$ width and up to $170 \mathrm{~cm}$ length (resolution 115 pixels per $\mathrm{cm}$ ), (Lambrecht et al. 2004), and they are stored at www.pangaea.de (or Faria et al. in preparation). In Svensson et al. (2005) a description of the machine can be found for which the operating principle is similar to that of the dark field microscopy (Faria et al. 2010). Representative linescanner images for the EDML ice core are reproduced in Figure 1.4.2 and in Faria et al. (2010). For the Greenland Ice Sheet Project 2 (GISP2) ice core annual layers are clearly identifiable, at least in the upper part of the core, (it seems this is a feature of the Greenland ice cores but not of all Antarctic ones due to the lower accumulation rate of the latter); and from the visual stratigraphy of this core it was observed that: "changes in bubble and grain structure caused by near-surface, primarily summertime formation of hoar complexes provide the main visible

\footnotetext{
10 "The area surrounding the EDML drilling site is situated between two transient ice divides which fork at approximately $75.1^{\circ} \mathrm{S}, 1^{\circ} \mathrm{E}$. [...] The flow velocity field is, in general, divergent along the course of and in between the two branches of the ice divide. [...] The horizontal strain field, calculated from the velocities, shows lateral extension and smaller longitudinal compression. [...] The annual mean velocity magnitude of 12 survey points amounts to $0.74 \mathrm{ma}^{-1,}$ (Wesche et al. 2007).

11 "Based on its topography, western DML can be subdivided into four regions, three of which are: (1) the major ice shelves Riiser Larsenisen, Ekströmisen and Fimbulisen; (2) the lower inland ice regions Ritscherflya and Hellehallet; and (3) the high-altitude plateau area with an elevation $>2500 m$ a.s.l., i.e. the Wegener Inlandeis made up by Amundsenisen and Wegenerisen. A clear borderline between coastal/lower inland ice regions and the plateau consists of (4) the nunatak areas of the Heimefrontfjella, Kirwanveggen and Mühlig Hofmann Gebirge mountain ranges, which penetrate the ice sheet, reaching heights of about $2700 m$ a.s.l. Acting as a barrier to air masses approaching from the Weddell Sea and the Atlantic Ocean to the north, this chain of mountains has a large impact on the accumulation distribution, separating the area into two distinct accumulation regimes. The surface topography of the plateau is smooth, with wind-shaped features, i.e. small-size sastrugi (10-15 cm high) [...], indicating that the mean wind velocities in this part of Antarctica are moderate. Undulations with amplitudes on the metre scale and wavelengths on the kilometre scale have been linked to bedrock morphology [...]. Large areas of Amundsenisen have been delineated as ice drainage basins feeding the Filchner Ice Shelf with the ice divide as far north as $75^{\circ} \mathrm{S}$ [...]. Major outlets from Amundsenisen are Stancomb-Wills Ice Stream, draining into the Brunt Ice Shelf, and Jutulstraumen, feeding Fimbulisen" (Rotschky et al. 2007).
} 
annual marker in the Holocene, and changes in "cloudiness" of the ice correlated with dustiness mark Wisconsinan annual cycles" (Alley et al. 1997a). This ice core provided a refined record of the layer accumulation allowing the identification of events like "Little Ice Age" but the correlation of the GISP2 record with data from other sites should consider the fact that the ice registered a combination of local Greenland and global climate (Meese et al. 1994; O'Brien et al.

Figure 1.4.2 Line-scanner images of EDML ice core (from www.pangaea.de, courtesy of Dr. S. Kipfstuhl, Alfred Wegener Institute). The EDML depths at the top and at the bottom of the images are (from left to right): 934.5-934.7 and 2405.7-2405.9 $\mathrm{m}$. The width of the ice is ca. $9 \mathrm{~cm}$. The ice is of (marine isotope stage)-MIS2 and MIS6 age (EPICA Community Members 2006), and small parts of it were used for investigations described in ch.2). The whiter parts are cloudy bands, which are stratigraphic features indicating the layering in the ice. They appear due to an enhanced light scattering by the incorporated impurities (the higher the concentration of impurities, the brighter the layer). Dark parts are clear ice with a very low amount of impurities. It is remarkable the change in the horizontality of the cloudy layers starting with tiny undulations at $\sim 1700 \mathrm{~m}$ and evolving towards extended $\mathrm{z}$ shape folds at $\sim 2400 \mathrm{~m}$ caused by the ice flow (Faria et al. 2010). Analogous stratigraphic disturbances were observed for the GRIP (Fuchs and Leuenberger 1996; Landais et al. 2004) and GISP2 (Meese et al. 1997) ice cores and they were explained in terms of significant flow effects the primary causing mechanisms being boudinage (for an embedded less viscous layer) (Gow, 1972; Cunningham and Waddington, 1990) and folding (Alley et al. 1997b; DahlJensen et al. 1997).
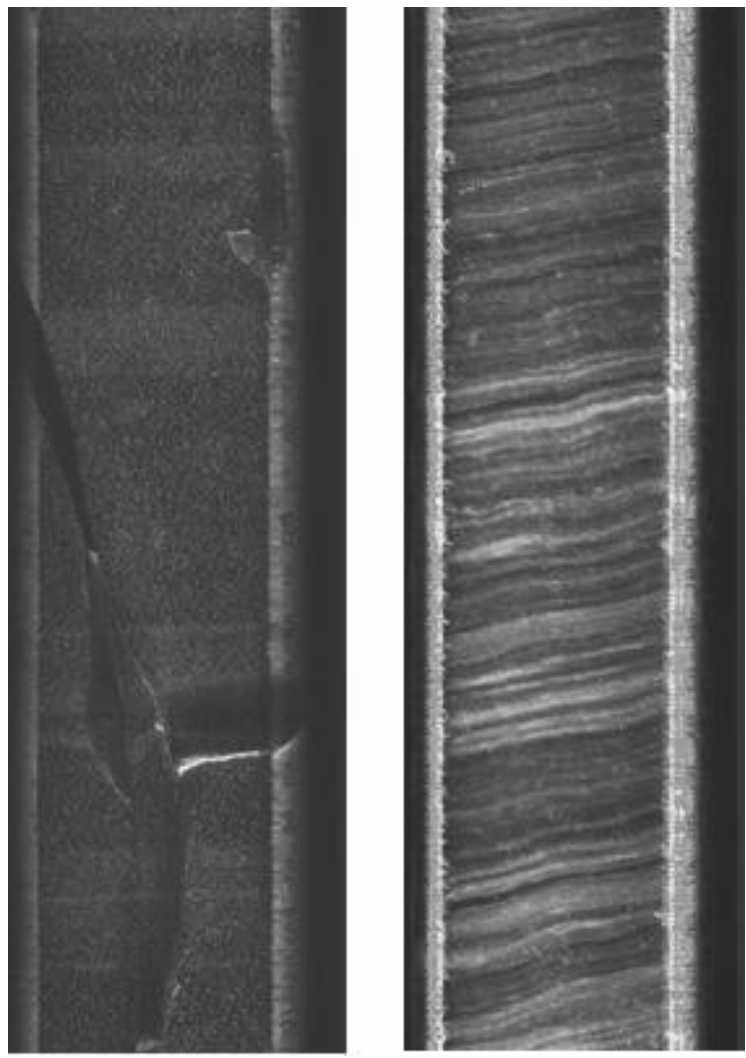

1995). For Greenland Ice core Project (GRIP) and North Greenland Ice core Project (NGRIP) ice cores cloudy band $^{12}$ stratigraphy correlates (overall) with the measured dielectric profile (DEP) (Shimohara et al. 2003). Further, for the NGRIP ice line scanning investigations were used to conclude that the brightest visible layers resulted from the coldest (weather) events because they can be correlated with the peaks in the spectra of chemical impurities, dust and electrolytical conductivity of melt water. Also for the NGRIP ice, "down to a depth of $2600 \mathrm{~m}$ the horizontal layering is very regular; below this depth, small irregularities in the layering start to appear, and below $2800 \mathrm{~m}$ the visual stratigraphy becomes more uncertain, perhaps because of penetration into climatically warmer ice" (Svensson et al. 2005). In the case of Dome Fuji (Antarctica) ice core, the light scattering profile had intensity peaks well correlated with the peaks in the $\mathrm{Ca}^{2+}$ concentration (Takata et al. 2004) but for the Dome C ice core no equivalent investigations were performed. For the recently drilled (North Greenland Eemian Ice Drilling)-NEEM ice core the characteristics of the cloudy band stratigraphy resembles the ones of the EDML ice core: small grain size, millimeter to centimeter large wiggles and folds and larger disturbances in cold ice with a high load of impurities (Kipfstuhl et al. 2010). A more detailed description of the linescanning results for the EDML ice core can be read in Faria et al. (2010).

Also, for the entire length of the EDML ice core, (ice samples from the upper $10 \mathrm{~cm}$ of every $1 \mathrm{~m}$ section of the core), for the first time, a continuous mapping of the microstructure was performed, in the field, shortly after the core extraction (Kipfstuhl, 2007: on www.pangaea.de,

\footnotetext{
${ }^{12}$ Cloudy band: Ice stratum with "cloudy" appearance due to high concentration of micro-inclusions (Faria et al. 2009)
} 
Faria et al. 2010) according to the procedure described in Kipfstuhl et al. (2006). The ice sample is transformed into a mosaic image of 1200 up to 1800 photographs ( $4 \mu \mathrm{m}$ per pixel), which can be further used for various (microstructure) investigations. Figure 1.4.3 presents a typical example with results from ice microstructure mapping procedure.

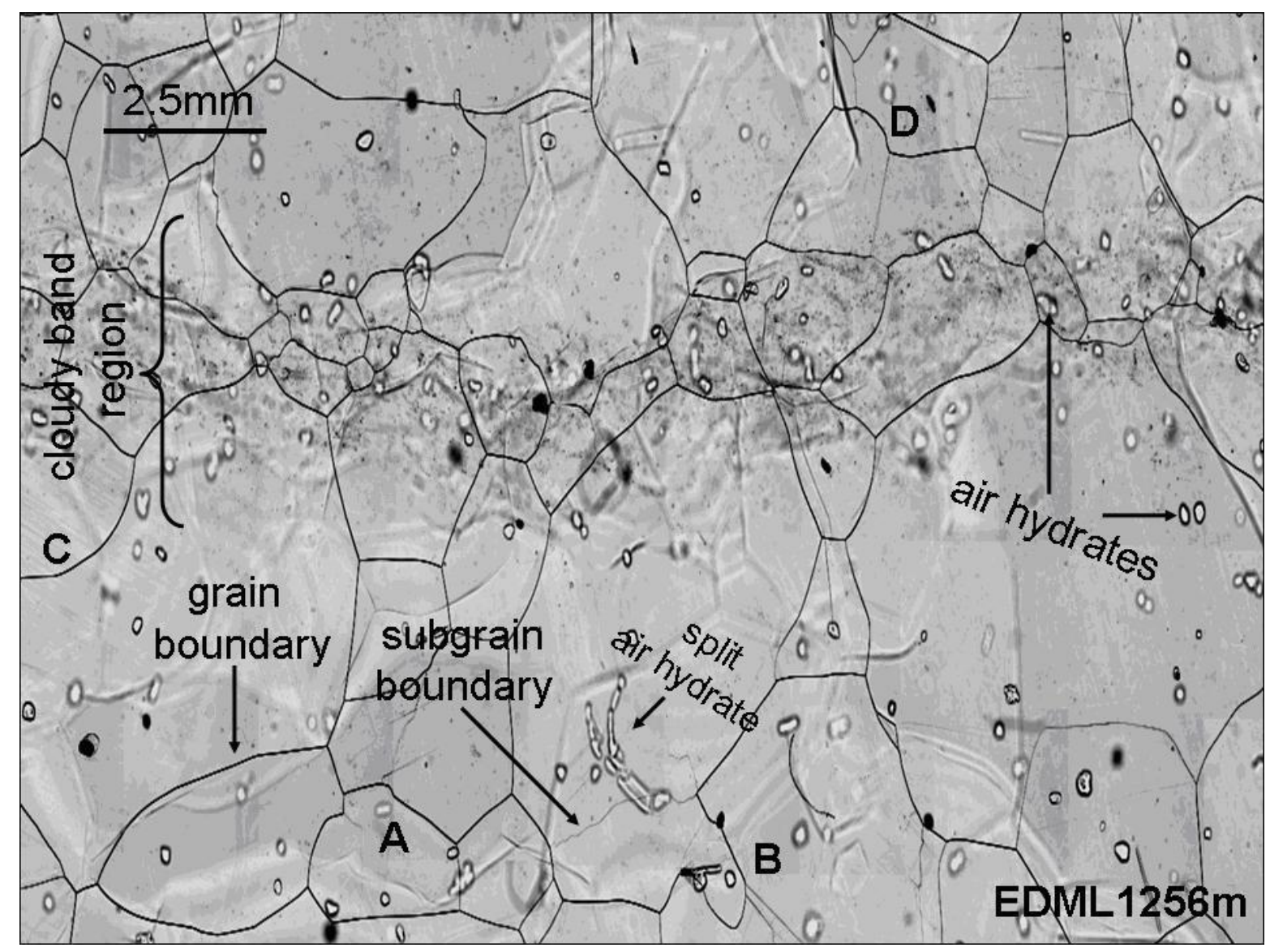

Figure 1.4.3 Microstructure mapping mosaic of about 45 (overlapped) images (2.5 by $1.7 \mathrm{~mm})$ of fresh extracted ice from EDML ice core at $1256 \mathrm{~m}$ depth. The main features that can be observed are depicted in the figure. The majority of the grain boundaries (GB) are high energy ones (Kipfstuhl et al. 2006) while the number of observable subgrain boundaries (sGB) is low. The cloudy band region is distinguishable due to its darker background (produced by a high level of impurities especially as small "black dots") and smaller grains. In the marked regions can be observed: A) GBs pinned by (strong) sGB (Hamann et al. 2007, Weikusat et al. 2009); B) a bulged GB pinned by inclusions (the black circle, as the other ones in the image, is a decomposing air hydrate (AH). Air bubbles which would also appear as black features, coexist with the AHs only between 800-1200 m EDML depths (Faria et al. 2010)). On the convex side of the bulged GB there are sGB different from the ones observable to the left, in the neighboring grain (straight sGB versus zig-zag sGB (Weikusat et al. 2009)) ; C) slip bands - "visible gliding layers of individual crystallites" (Faria and Kipfstuhl, 2004); D) wavy GB pinned by a sGB (Kipfstuhl et al. 2006)

Based on the lattice preferred orientation the EDML ice core could be divided in the following regions: 1) until $\sim 450 \mathrm{~m}$ with random $c$-axis distribution; 2) $~ 450-1700 \mathrm{~m}$ evolution of a girdle fabric; 3) 1700-2020 m slight tendency of concentration of c-axes inside the girdle; 4) below $2020 \mathrm{~m}$ single maximum fabric along the core vertical axis (Hamann et al. 2005; Eisen et al. 2007; Seddik et al. 2008). 
The wealth of information that can be found as the polar ice structure is analyzed at meso- and micro-scale has been and still is exploited such that common beliefs are confirmed or replaced (Faria et al. 2006a; Weikusat et al. 2009; Kipfstuhl et al. 2006, 2009; Faria and Kipfstuhl, 2004). Unexpected orientational distribution of slip bands, different from what is expected for the predicted slip activity induced in natural ice by compression and/or extension could be observed when the structure of ice for the EDC ice core, at the grain scale, was investigated (Faria and Kipfstuhl, 2004). Soft ice strata could be documented in the EDML ice and their provenience was shown to be rather due to dynamic grain boundary structures formed by microshear under conditions of high temperature, moderate stress, small grain size and high impurity content than to preferred orientations of the ice fabric (Faria et al. 2006a). The subgrain boundary density, which can be directly related to the polygonization process, was found to be approximately the same at all depths along the EDML ice core (Weikusat et al. 2009). This observation suggests that the commonly assumed recrystallization regimes for ice, with normal grain growth in the upper regions of the ice sheet, followed by rotation and then migration recrystallization at deeper depths is not realistic. The observations that the subgrain boundaries are heterogeneously distributed within a grain, being less present in the interior of the crystallite, (a "core and mantle" structure), suggests that the stress/strain accumulates within very localized regions of the crystallite. But the interesting result of microstructural studies on EDML ice is the documentation of subgrain boundaries which can not be explained (only) by (re)arrangement of basal dislocations. Their frequent occurrence gives an experimental evidence for the importance of non-basal glide in polar ice (as it is thought that nonbasal slip is activated only when there is the necessity to accommodate strain incompatibilities between neighbouring grains) (Hamann et al. 2007).

In the EDML air-bubble to air clathrate hydrate transition zone $(\sim 800-1200 \mathrm{~m}$, Faria et al. 2010) the mean size of the air bubbles decreases towards the lower depth while the radii of the air hydrates tend to increase and then remain constant, (below $\sim 1200 \mathrm{~m}$ ). Oval clathrates are the most frequent along the EDML core (Hamann et al. 2004); (other shapes are as described in Uchida et al. 1994, Pauer et al. 1996(2000), 1999: irregular, graupel-like, spherical, ellipsoidal, rod-like, faceted, tetrahedral, hexagonal, octahedral, polyfaceted, metamorphosed, splintered or split clathrates). Ueltzhöffer et al. (2010) present data about air bubbles (ABs) in the EDML ice core (and part of the EDC ice core) by means of a specially designed software. For ice thick-sections of $\sim 45 \times 90 \times 5 \mathrm{~mm}$ a number of $\sim 1000$ to 11000 of bubbles was found. "The significantly higher number of bubbles in the Holocene ice of the EDC core compared to the EDML core agrees with [...] the differences in temperature and accumulation between the EDC and EDML sites [...]. The increase in the bubble number of EDML from 360 to $560 \mathrm{~g}^{-1}$ between 10 and $18 \mathrm{ka}$ has a climatic cause: it reflects a change in grain size at the firn/ice transition which is caused by changes in temperature, accumulation and impurity content contemporaneous with the transition from the LGP to the Holocene". For EDML, at shallow depth, the division of bubble size distribution into normal and microbubbles (see section 1.5 or Lipenkov, 2000) is not as obvious as for EDC or Vostok ice but overall a decrease of the ABs size with depth occurs. From the 2D bubble distribution the porosity at the firn/ice transition, for the EDML core, was estimated to be between $10.56 \%$ and $12.61 \%$.

"A density profile of ice cores is one of the fundamental datasets in ice core analyses" (Hori et al. 1999). The snow and firn have high porosity and the atmospheric gases can be transported through this net of pores (Freitag et al. 2002) until they are sealed off in the ice matrix, resulting in an age difference between the air and the ice. For the GRIP and GISP2 the air-ice age difference was found to be around $200 \mathrm{yr}$ and $1400 \mathrm{yr}$ for Holocene and last glaciation respectively (Schwander et al. 1997). For the EPICA ice cores the age difference (with a $\mathrm{CO}_{2}$ lag of $800 \pm 600 \mathrm{yr}$ for EDC) seems to be overestimated and the cause for this dissimilarity could not be properly identified (Loulergue et al. 2007). The accurate age relationship between the ice and 
its (gaseous) impurities is still to be established (Caillon et al. 2003) with recent studies exploiting the isotopic ${ }^{15} \mathrm{~N}$ (of the air's $\mathrm{N}_{2}$ molecules) signature into relation with the dating of the ice (Landais et al. 2006; Dreyfus et al. 2010).

The air preserved in polar ice is an important climate proxy; and climate studies concern time scales of million of years. The age of an object, is often established by radiometric analyses. In the case of polar ice cores due to the small radioactive isotope presence (Wilson, 1995; Legrand and Mayewski, 1997; Petrenko et al. 2009; Sigl et al. 2009) the age is more often calculated by layers counting between reference markers (Hammer and Meese 1993) or using ice flow models (Hondoh et al. 2002; Parrenin et al. 2007), methods which are applicable as long as the initial deposition sequence of the strata is little disturbed. The EDML ice core was the first (extracted from the eastern Antarctic plateau) to offer a higher number of samples for ${ }^{14} \mathrm{C}$ investigations. Van de Wal et al. (2007) quantified the ${ }^{14} \mathrm{C}$ amount in EDML ice core and observed that the production of ${ }^{14} \mathrm{CO}_{2}$ is higher than ${ }^{14} \mathrm{CO}$, (especially at depth in ice from the accumulation zone), indicating that major contamination can be excluded. They propose a model which can be used for dating of the air bubbles in the ice if the error of estimating the ${ }^{14} \mathrm{CO}_{2}$ in situ production is smaller than $25 \%$ (and correcting for diffusion in the firn), but they had no independent data set to validate the model. The model correlates satisfactorily with the ages obtained for EDML ice by volcanic synchronization with the EDC ice, which in turn could be dated using also a mechanical flow model (Parrenin et al. 2007), a method not straightforwardly applicable to the EDML ice core because it was not extracted at a site where the ice has a dome structure (Severi et al. 2007), and a complex ice flow structure requires effort consuming flow models. The EDML-EDC volcanic stratigraphic link was valid until $2366.1 \mathrm{~m}$ (corresponding to $1683.93 \mathrm{~m}$ in EDC) where the age is $128.3 \mathrm{ka}$ (Ruth et al. 2007). The dating was secure only until $2400 \mathrm{~m}$ (Ruth et al. 2007; Severi et al. 2007; Huybrechts et al. 2007), because the deeper meters show significant stratigraphic disturbances (Faria et al. 2010) and the layer synchronization is lost. At depths deeper than $2400 \mathrm{~m}$ the chronology can be established using the measured isotopes and dust concentration patterns.

The particular feature of the EDML ice core is that it affords a high resolution climatic record, in the Atlantic sector of Antarctica, on millennial and sub-millenial resolution. When the isotopic, methane, (and dust) variations along the EDML core are compared with the ones for ice cores extracted in the northern hemisphere (via the GICC05 age scale (Andersen et al. 2006; EPICA Comm. Memb. 2006) or more recent data for NGRIP ice core (Capron et al. 2010a, 2010b)), it can be observed that the cold events in the north can be related with warm episodes in the south. Each Dansgaard-Oeschger (DO) event present in the Greenland ice has an Antarctic Isotope Maximum (AIM) counterpart. The AIMs start significantly before the DO stadials, and have an amplitude linearly dependent on the duration of the DO events (according to the bipolar seesaw model (Stocker and Johnsen 2003) used to explain the millennial climate variability (Blunier and Brook, 2001; EPICA Comm. Memb. 2006)), except for extended cold phases of millennial scale variability in Greenland or for large ice sheets like those formed during the Last Glacial Period (Capron et al. 2010b).

So, as more and diverse glaciological investigations are performed, "we unravel the nature of an ice core, in order to discover how it has treated its records, because a climate proxy that is frozen need not be static" (Faria et al. 2010). 


\subsection{What is not ice can be trapped in (Antarctic) ice ${ }^{13}$}

\section{The ice .....and its 'state of being'}

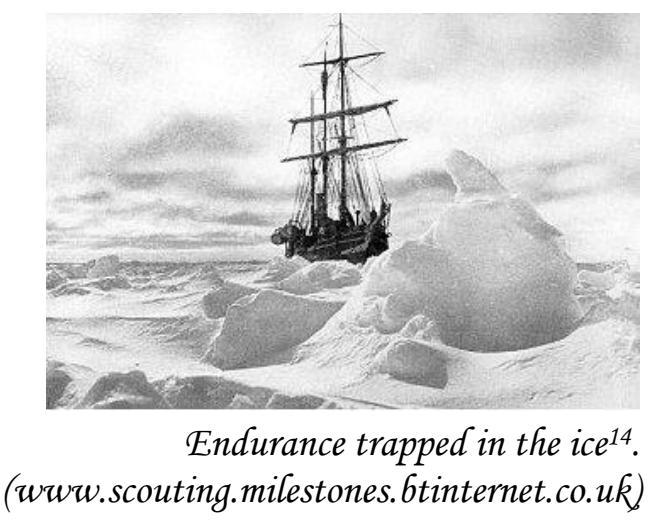

The classical states of matter, solid, liquid, gaseous, are basically distinguished considering the volume occupied, the shape taken, and the strength of the forces between the building units of the substance in a particular state. The usual solid water can be seen as hexagons bonded together in a honeycomb type net, forming infinite sheets, folded sheets, because the hexagons are not planar but twisted, as the cyclohexane in its chair form. In every corner of the hexagons stays the oxygen atom of a water molecule and along the edges are the hydrogen atoms and the two types of chemical bonds: a stronger one responsible for building one water molecule and a weaker one, the so called hydrogen bond, responsible for keeping together more water molecules. The folded layers, known as basal (or glide) planes, are stacked one over another extending the solid water' structure along the space' third dimension (Owston, 1958), generating the most common form of solid water, the ice Ih. The molecular stacking sequence for this ice is such that pairs of molecules are joined in a dumbbell manner (two neighbouring folded hexagons are like the object and its mirror image) (Schulson, 1999).

Natural ice, from the usual snow crystals to the crystallites of the glaciers and the ice caps, is considered to be hexagonal ice, ice $I_{h}$ or ice $I$, in the list with the thirteen (or more (Martin-Conde et al. 2006)) crystalline phases of solid water (Petrenko and Whitworth, 1999). A solid with hexagonal symmetry has four crystallographic axes; the principal one, the $c$ axis, which is perpendicular to the basal plane, and three $a$ axes, in the basal plane, $120^{\circ}$ apart. Parallel or at an angle to the $c$ axes are other two types of crystallographic planes, named prismatic and pyramidal respectively. In hexagonal ice the oxygen atoms from neighbouring basal planes are $2.76 \AA$ apart, giving rise to the so called shuffle planes, (considered as a second type of basal planes, (Petrenko and Whitworth, 1999)), while in a basal plane, due to the folding of the hexagonal rings, the oxygen atoms form sheets which are only $0.923 \AA$ apart (which is the thickness of the basal plane) (Thorsteinsson, 1996). It is obvious that the shuffle planes are less compact and characterized by a smaller number density of chemical bonds when compared with the glide ones. In fact over all ice $\mathrm{I}_{\mathrm{h}}$ has an open structure (Hobbs, 1974). With unit cell dimensions close to $4.5 \AA$ (along $a$ axes, in which the glide planes extend) and $7.35 \AA$ (along $c$ axis, on which the glide planes are stacked) (Röttger et al. 1994) the resulting volume per crystallographic unit cell of approximately $130 \AA^{3}$ (Hobbs, 1974) is occupied only by four water molecules.

\footnotetext{
${ }^{13}$ In the end it was impossible to write about all the items this title might make the Reader to think at; but I took the risk to maintain the title. Anyway, in my eyes the title refers more to the "quotation" that follows.

14 "The picture is by the Shackleton's Last Expedition photographer, F. Hurley. In 1914 Shackleton took the Endurance to the Antarctic where the ship became locked in by pack ice and was crushed".
} 


\section{The 'not ice' staff}

The substances inside a confined amount of matter, which differ from the chemical composition of the material, are defined as impurities (Staveley, 1971); they can be either primary or secondary. Ice as the naturally occurring crystalline solid state of an inorganic substance, water, is a mineral (Nickel, 1995) and from the mineralogical perspective any material that is trapped inside a mineral during its formation becomes an inclusion (Wahler, 1956). According to Hutton's law of inclusions fragments included in a host rock are older than the host rock itself.

\section{From atmosphere's volume 'in the ice body'}

The oxygen, $\mathrm{O}_{2}$, and nitrogen, $\mathrm{N}_{2}$, molecules are generally considered the main chemical components the atmospheric air contains. Also carbon dioxide, $\mathrm{CO}_{2}$, methane, $\mathrm{CH}_{4}$, rare gases (Ar mainly), nitrogen oxides, different isotopes and of course the water that generates the precipitations, can be found in the nowadays Earth's atmosphere.

\section{-the water-}

The most important isotopes investigated in relation with the paleo-atmosphere are the heavy stable isotopes of hydrogen, mainly deuterium, (D), and oxygen, mainly oxygen-18, $\left({ }^{18} \mathrm{O}\right)$, which can be related with the paleo-temperatures. These are in fact the intrinsic isotopes forming some of the water molecules existent in the air that later on are deposited as snow over the ice caps. Especially the ${ }^{18} \mathrm{O}$ is a vital paleo-thermometer for the ice core research (Dansgaard, 1954a; 1954b, Johnsen et al. 1970).

Practically the $\mathrm{D} / \mathrm{H}$ or/and ${ }^{18} \mathrm{O} /{ }^{16} \mathrm{O}$ ratios, (used for calculating the $\delta$ ), in melted ice samples is measured, (via mass-spectroscopy), and the values increase as the temperature, at the time of snow accumulation, increased (Gonfiantini and Picciotto, 1959, Picciotto et al. 1960, Dansgaard et al. 1960). The relative deviation per mille, $\delta$, with respect to a standard (Craig, 1953) (since 1968 the Vienna Standard Mean Ocean Water, VSMOW, (Coplen, 1994)) is calculated and translated in terms of a cold (glacial or stadial) or warm (interglacial or interstadial) climate period (Jouzel et al. 1987). $\delta^{18} \mathrm{O}$ has negative values and, in the scientific literature, when plotted against the age (or the depth) of the ice, the most negative numbers (the highest in absolute value) are a marker for cold stages (low ${ }^{18} \mathrm{O}$ content relative to ${ }^{16} \mathrm{O}$ ) and the opposite for warm climatic periods.

\section{-some gases-}

Reconstructions of ancient atmospheric $\mathrm{CO}_{2}$ variations can help understanding the role of the global carbon cycle in the climate system, whereas age synchronization through the variations in $\mathrm{CH}_{4}$ concentrations reveal that there is a not in phase link in the Antarctic and Greenlandic temperature. On the one hand models of millennial-scale $\mathrm{CO}_{2}$ variations suggest that changes in North Atlantic Deep Water formation can affect atmospheric $\mathrm{CO}_{2}$ concentration through both physical and biological processes in the ocean and terrestrial biosphere; on the other hand changes in meridional overturning circulation, maintains changes in the temperatures at the poles with an onset of the Antarctic warming before warming in Greenland (on a millennial time scale) (Ahn and Brook, 2008). 
$\mathrm{N}_{2} \mathrm{O}$ concentrations in the atmosphere are thought to have as pre-antropogenic sources the terrestrial soils and the nitrification and denitrification processes in the ocean but when measured along an ice core, especially along depth intervals characterized by high dust content, they can be affected by artifacts so correlations with other ice cores are mandatory (Spahi et al. 2005).

\section{-the 'air'-}

Of particular interest for the polar ice research are the so called air inclusions trapped in the ice volume, in the form of air bubbles and air hydrates, which are recognized to offer a unique natural archive of the ancient atmospheric air chemical composition (Delmas, 1994; Stauffer et al. 2004; Langway, 2008). They are filled mainly with oxygen and nitrogen but of course other atmospheric gases are present.

Air bubbles start to transform to air clathrate hydrates at a certain depth in a deep ice core, both coexisting along a (so-called) transition zone (Miller, 1969; Shoji and Langway, 1987; Salamatin et al. 1998). On the other hand, it is also possible that the paleoatmospheric air to be embedded in natural ice as minute inclusions (microbubbles), or even "dissolved" in the ice matrix (Shoji and Langway, 1987) and that it can be prone to diffusion (Ikeda-Fukazawa et al. 2005).

It has been shown that there is a relationship between the number and the size of the clathrate hydrates in deep ice cores and the climatic factors at the time of ice formation. Glacial ice usually has a higher clathrate-number concentration but the clathrate mean volume seems to increase with depth in an ice core. On the other hand the morphology of the clathrates is more dependent on the temperature-pressure conditions inside an ice sheet such that a distinction between primary and secondary clathrates can be made (Uchida et al. 1994; Pauer et al. 1996; Pauer et al. 1999).

In the same way two generations of air bubbles exist in polar ice: the normal bubbles formed in the pore close-off zone where the firn transforms into ice, which have the number and the size controlled by the size of the ice grains during the pore closure (and consequently by the temperature and accumulation rate prevailing over the time of snow-ice transformation) and (secondary) microbubbles the number of which is not easy to be determined (i.e. 20\% fraction in the bubbles populations at shallower depths in the Vostok ice core) and is related with the processes of clathrate nucleation and growth, (usually decreased). In the Vostok ice core, microbbubles "are clearly distinguished from normal bubbles by their smaller size [mean radius of $0.04 \mathrm{~mm}$, smoothed spherical surface, and preferable location in the interior of ice crystals down to at least 350-400 m; they can be easily traced in the deeper ice until the conversion of air bubbles to hydrate becomes visible at 600-700 m" (Lipenkov, 2000).

Moreover, it is worth knowing if the same proportion of chemical substances was present in Earth's atmosphere during the geological time, and this can be achieved studying the impurities embedded in natural ice. For example the first investigations on the molecular $\mathrm{N}_{2} / \mathrm{O}_{2}$ ratio in individual clathrate hydrates crystals from the Dye 3 deep ice core revealed a value less than the present one (1.5 versus 3.7) (Nakahara et al. 1988). Later studies reported ratios closer to the one of the nowadays atmosphere (Pauer et al. 1997) but in fact the $\mathrm{N}_{2} / \mathrm{O}_{2}$ proportion is highly affected by fractionation and can vary from clathrate to clathrate (Ikeda-Fukazawa et al. 2001) and within a single clathrate crystal (Ikeda et al. 1997) as processes like preferred enclathration and diffusion of the air molecules are strongly influencing it (Ikeda et al. 2000). 
-some inorganics-

Apart from the gaseous components the air and/or the atmospheric (solid or liquid) precipitations contain soluble or insoluble particles, usually characteristic for a certain region, marine or continental, the former ones (more predominant around Antarctica) enriching the air masses in sea salts whereas the latter ones (more predominant around the Arctic ice cap) in dust particles. The primary aerosol-(described also in section 1.3.2)-in the form of $\mathrm{Na}^{+}, \mathrm{K}^{+}$and $\mathrm{Cl}^{-}$or $\mathrm{Mg}^{2+}, \mathrm{Ca}^{2+}$ and $\mathrm{SO}_{4}{ }^{2-}$ ions or their compounds is (and was) present in polar air and solid precipitations, then trapped in ice, at different time intervals, according to specific seasonal cycles which can be used for dating of an ice core (Legrand and Mayewski, 1997).

Due to the modern, sensitive and very specialized analyzing techniques many other substances could be identified in natural occurring ice. Starting with beryllium-10, $\left({ }^{10} \mathrm{Be}\right)$, a proxy for sun's activity (Usoskin et al. 2004), continuing with lead, (Pb), and its isotopes, useful as a geographical tracer or as an indicator of industrial pollution (Vallelonga et al. 2010 and the references therein; Jimi et al. 2008; Burn et al. 2009) other heavy metals have been identified in ice cores and have been put into relation with the general pattern of the (paleo)environmental conditions (Marteel et al. 2008). Also rare earth elements have been successfully determined in Antarctic ice (Gabrielli et al. 2006a, 2010; Dick et al. 2008); gold, (Au), silver, (Ag), platinum, $(\mathrm{Pt})$, mercury, $(\mathrm{Hg})$ (unpublished results Kriews, AWI; Matsumoto and Hinkley, 1997; Krachler et al. 2008; Gabrielli et al. 2006b; Vandal et al. 1993) as indicators (mainly) for the anthropogenic, extraterrestrial and (less for) natural-volcanic influences could be measured in snow or ice (Van de Velde et al. 2000).

A recent study describes the results from a successful study of finding diamonds in terrestrial polar ice. The first ever found ice layer, preserved inside the ice sheet, containing nanodiamonds and hexagonal diamonds (lonsdaleite), was identified in Greenland ("at a margin site east of Kangerlussuaq, West Greenland, $\sim 1 \mathrm{~km}$ inland from the ice margin") and has around $12.9 \mathrm{ka}$ (Kurbatov et al. 2010).

\section{-the 'special' inorganics ${ }^{15}$ -}

As noted above, the cryosphere embedded inside its layers tracers, which can tell about the sun's activity and consequently about the Earth's magnetosphere activity. The EPICA Dome $\mathrm{C}, \mathrm{EDC}$, ice core, being retrieved from an inland region of Antarctica, benefits from the low accumulation rate in such a way that it covers the highest time interval, around 800000 years (EPICA Community Members, 2004). The last major event of the Earth's magnetic field, a polarity reversal, is centered around $780 \mathrm{kyr}$ and marks of its existence, increased ${ }^{10} \mathrm{Be}$ flux, were found embedded in EDC ice core (Raisbeck et al. 2006). If in this case the retrieved ${ }^{10} \mathrm{Be}$ signal can be somehow biased ${ }^{16}$, investigations of other imprints of the geomagnetic field on ice ${ }^{17}$ revealed, for the EDC ice core, that episodical eolian deposition from highly magnetic deposits took place in interglacial time (Lanci et al. 2008). Hematite, $\gamma-\mathrm{Fe}_{2} \mathrm{O}_{3}$, magnetite, $\mathrm{Fe}_{3} \mathrm{O}_{4}$, maghemite, $\alpha-\mathrm{Fe}_{2} \mathrm{O}_{3}$, (the most common magnetic minerals), when present in the matrix of another mineral, can be used as environmental proxies. Holocene Greenlandic ice seems to be more magnetic than the one from the dustier Last Glacial Maximum, (Lanci et al. 2001). For ice cores which do not extend to much back in time, short-lived low intensity excursions of the Earth's magnetic field are equivalents for a polarity reversal. The new age of the Laschamp

\footnotetext{
${ }^{15}$ the extent of this part was also a result of my interest in magnetism, not only of the available literature.

${ }^{16}$ but still good enough to be used as (probably a more precise) reference event for building a time scale (Dreyfus et al. 2008)

${ }^{17}$ like the isothermal remanent magnetization aquired by the dust particles trapped within the ice, when they are exposed to strong magnetic fields over a short period of time (and at constant temperature)
} 
geomagnetic excursion was better established, (at $40.4 \mathrm{kyr}$ ), when data from polar ice cores were also used (Guillou et al. 2004).

If the quantity of several iron containing particles, deposited in polar ice, would be higher, one could even read the tales of extraterrestrial bodies. Since the meteoric material (which contains Fe from outer space that is transformed in magnetic oxides in the Earth's atmosphere) is present in ice as superparamagnetic grains (nanometric size) we have to resume at identifying it (Lanci and Kent, 2006) and the accretion rate (Lanci et al. 2007), when the peculiar magnetic property of polar ice is addressed. This unique magnetic ice is still to be harvested. And there are plans for doing so. Antarctica seems to offer the best location since its ice is the oldest, even over 1.000.000 years, as is expected for the new location at Dome A, the coldest and driest place on Earth, where a new polar ice core will be drilled (Xiao et al. 2008b; Ren et al. 2009; Cui et al. 2010).

But it is not mandatory for Antarctic ice to be as old as possible to be somehow related with magnetic minerals. Their simple coexistence determines the appearance of new and interesting transformations via species in the biosphere. Cryptoendolithic communities have survived the Antarctic harsh conditions by transforming the hematite, an effective filter for UV solar radiation, available in the colonized sandstone, into goethite (Edwards et al. 2004). These findings here on Earth could help understand or imagine transformation processes in the lithosphere of nearby planets (i.e. Mars). $\left[{ }^{18}\right]$

\title{
1.5.1 Gaseous microinclusions in polar ice
}

\begin{abstract}
"Diamonds," he began [...] "are to be made by throwing carbon out of combination in a suitable flux under a suitable pressure; [...] Consequently the diamonds made by chemists are small and dark, and worthless as jewels. Now I, you know, have given up my life to this problem - given my life to it. (from "The Diamond Maker" by Herbert George Wells)
\end{abstract}

In their paper Void formation by non-basal glide in ice single crystals (Muguruma et al. 1966), Muguruma, Mae and Higashi reported that when ice single crystals are plastically deformed by tension parallel to the basal plane, hexagonal or circular thin plate-shaped microscopic features (named "voids" in the original paper) develop along this plane. These voids were observed during the deformation process in tensile tests undertaken to produce non-basal glide in ice single crystals. They developed at a strain rate of $3 \times 10^{-6} \mathrm{~s}^{-1}$ and strain of a few per cent when working at $-19^{\circ} \mathrm{C}$. They increased in size and number with continuing deformation and formed bands along the $\langle 11-20\rangle$ directions which are active in non-basal glide. Their shape was elongated in the directions in which the bands extended.

Mae (1968) later on extended the work of Muguruma et al. (1966) and tried also to explain the formation of the voids by a diffusion process of vacancies in the ice crystal and the only mechanism assumed to be capable of producing vacancies was the climb of edge dislocations. "In tensile tests, edge dislocations of any sign subjected to tensile stress normal to the extra-half plane climb to adjacent glide planes leaving vacancies near the dislocation line. If the number of vacancies thus created is large and their diffusion is rapid, the dislocation climb will be a source of vacancies to be aggregated as voids". A quantitative proof for this mechanism was given by "calculating the number of vacancies created under a given tensile stress and

\footnotetext{
${ }^{18}$ it was suggested that this section should have also a part about the organics found as trapped in natural ice. In the end the time was too short for writing also about them. I hope for understanding because after all the (original) results, from microinclusions in EDML ice, presented further, are not related to a great variety of organic compounds. Nevertheless, some useful references would be: Legrand and Mayewski 1997; Jacobi et al. 2002; Sun and Ariya, 2006; Legrand et al. 2007; Grannas et al. 2007; Frey et al. 2006, 2009).
} 
diffused to form voids at a certain temperature, and comparing this with the observed total volume of the voids", estimated either by counting or by density measurements. The fact that voids are not formed in compression tests was considered an additional support for the dislocation climb model.

Mae (1968) pointed out that the main factors which contributed to generation of a large number of vacancies sufficient to form voids even at temperatures near the melting point are the large values of both self-diffusion coefficient in ice and the yield stress in non-basal glide (no void formation is observed in deformed ice crystals with basal glide due to a low yield stress). Finally Mae addresses the problem of nucleation and growth of the observed hexagonal voids and considers that sub-microscopic nuclei in the form of gas bubbles may be the reason why excess vacancies grow to voids in deformed ice crystals at high temperature.

This kind of hexagonal or circular thin plate-shaped microscopic features, currently (re)named plate-like inclusions, PLIs, were reported for the first time in Antarctic deep ice cores by Gow (1971), as a consequence of the ice core relaxation (also Gow et al. 1997).

As, after drilling, a piece of ice changes its place, from its natural location inside the ice sheet, to the storage place or the laboratory, there is also a variation of the temperature and the pressure experienced by the ice core after its extraction, thus to a certain extent, the ice changes some of its initial features. Any piece of an ice core has an extremely complex thermal, mechanical, handling and storage history before it is analyzed. What happens with a piece of ice depends very much upon the depth at which it comes from. In the ice sheet pressure and temperature increase with depth. The opposite happens when an ice core is brought to the surface, so the structure of the drilled ice starts to relax (private communication S. Kipfstuhl, 2007).

There are several stages of relaxation as it is the release of the accumulated stress (Gow, 1971). First the effect of compression from the upper ice layers is released before the ice core reaches the surface. Then the relaxation is a function of the ice composition and the ice crystallite's orientation. For ice with air bubbles the relaxation is caused by the release of their pressure (exercised by the air trapped inside) but for deeper ice without air bubbles and in general characterized by strongly aligned crystal c axis orientation the relaxation is via growth of cavities (Gow, 1971).

During lifting of a piece of ice from inside the ice sheet to the surface $(\sim 1 \mathrm{~m} / \mathrm{s})$ the pressure decreases typically with a rate of $\sim 0.1 \mathrm{MPa} / \mathrm{s}$ (Thorsteinsson, 1996; Wilhelms et al. 2007). The temperature history is more complicated. Ice from near the bedrock with a temperature close to the pressure melting point (about $-2{ }^{\circ} \mathrm{C}$ ) experiences the harshest conditions. Within less than an hour the pressure drops from $25 \mathrm{MPa}$ to ambient atmospheric pressure (private communication S. Kipfstuhl, 2007, Wilhelms et al. 2007).

The most obvious effect of ice structure relaxation is that the ice from below the bubblehydrate transition zone (for EDML core about $1200 \mathrm{~m}$ ) originally transparent becomes milkier with storage time. The main reason is the appearance of relaxation features, most of them in cloudy band ice (usually glacial (or stadial) ice which has an increased impurity content). As Gow (1971) first pointed out, the relaxation of the ice cores can be in general attributed to the development, after the core extraction, of inclusions like: cavities, plate-like inclusions and cleavage cracks. For Byrd ice core the degree of relaxation-measured as a change in the density of the ice in time - is much diminished in the deeper part of the core, probably due to the development of a crystal fabric with $c$ axis almost vertically oriented. Gow (1971) noted that the thermal factor plays a more important role in the deeper part of the ice core and the formed relaxation features are filled most probably with air dissolved under pressure in the ice matrix. The effects of ice relaxation were also presented for the Greenland Ice Sheet Project 2 (GISP2) core (Gow et al. 1997) and the observations paralleled closely those from previous studies. Special procedures were needed for the brittle ice, which fractures very quickly (it can splinter or shatter) and requires extensive time for relaxation prior to any (routine) analysis. For this ice 
apart form the usual relaxation changes in its structure, relaxation allowed some healing of existing microcracks or fractures which together with the decompression of the trapped air bubbles lead to a considerable (observable) reduction of the brittleness of the ice. Also inclusions much less regular in shape than the substantially spherical form of the original bubbles were observed and supposed they are filled with the 'dissolved' gas in the ice matrix (Gow et al. 1997). Gow and Meese (2007) discuss (among other items) the relaxation process of the ice core drilled at Siple Dome Antarctica (Taylor et al. 2004). The ice from the brittle zone has undergone minimal relaxation, being prone to fracturing after more than 5 years after it was drilled. This observation was put into relation with the particular (high) stress conditions at the location of the ice core. On the other hand the Siple Dome ice from 700-800 m has been observed to have retained a minimal degree of stress. The considerable relaxation of this ice was explained by its structural characteristics: finer grains and a very strong vertical c axis fabric. Also a very effective stress release via lattice controlled microcraking (cleavage) was observed in this more relaxed ice.

For the EPICA-DML ice core relaxation features were observed in all the available samples (some of them mentioned further in the text). The filling of the relaxation features was analyzed via micro-Raman spectrometry. In this thesis are presented the results from the first micro-Raman investigations of gaseous inclusions preserved in ice from the EDML deep ice core.

\subsubsection{Liquid and solid microinclusions in polar ice}

"To be or not to 6e, that is the question"

Shakespeare, "Hamlet", 3/1

Up to this point the thesis presented the basic chemistry related with the impurities existent in the atmosphere, snow or ice at the poles. Now, something more can be told about the nature of the inclusions engulfed in polar ice. The general differentiation was their state; and if the solid and the gaseous impurities are quickly accepted as being trapped in polar ice, 'liquid impurities in polar ice' may sound unusual. In the end it depends on the eutectic temperature of a mixture of compounds ${ }^{19}$.

Another general way to distinguish between the inclusions in polar ice is their capacity to interact with the water molecules as a solvent, resulting in soluble and hardly soluble impurities. The nitrates and sulfates identified in polar ice are among the soluble inclusions while the (alumino)silicates are the (so called) insoluble ones.

The detailed presentation of these microinclusions in polar ice can be constructed around their name, as in the following lines. The degree of particularization is subjective but at least it is informative.

\section{-a conclusive start-}

Iizuka et al. (2009) analyzed the chemical composition of the particles preserved in LGM ice from Dome Fuji (Antarctica) ice core. Non-volatile compounds obtained after sublimating an ice sample and insoluble particles left after melting the ice and/or dissolving the soluble components were investigated via scanning electron microscopy coupled with energy-dispersive

\footnotetext{
${ }^{19}-75^{\circ} \mathrm{C}$ for $\mathrm{H}_{2} \mathrm{SO}_{4},-43^{\circ} \mathrm{C}$ for $\mathrm{HNO}_{3},-70^{\circ} \mathrm{C}$ for $\mathrm{CH}_{3} \mathrm{SO}_{3} \mathrm{H}$ (Ohno et al. 2005 ; and the references therein); and more eutectic temperatures of various (aerosol) salts in Sakurai (2010).
} 
X-ray spectroscopy (SEM/EDX), ion chromatography and laser scattering. The aim was to find environmental signals based on dust and calcium-ion concentrations; additionally the sodium containing particles were determined. It resulted that approximately $30 \%$ of the non-volatile particles are gypsum, mirabilite or halite and the silicates having $\mathrm{Na}, \mathrm{Mg}, \mathrm{K}, \mathrm{Ca}$ and $\mathrm{Fe}$ as major metals act as principal constituents of the insoluble particles. Also, around $30 \%$ of the investigated particles proved to contain both silicon and sulfur or chlorine meaning that they were a mixture of silicatic and sulfate or chloride salts. A calculated ratio between the soluble particles containing $\mathrm{Ca}$ and the insoluble particles (for Iizuka et al. (2009) study: 0.06-0.14) may be used for the paleoclimate description.

Laj et al. (1997) using induced X-ray emission and SEM/EDX analysis characterized the proportion of $\mathrm{Fe}, \mathrm{Ca}, \mathrm{K}$, and $\mathrm{S}$ between soluble and insoluble impurities deposited in the Greenland ice (from Greenland Ice Core Project, GRIP). The "dominant fraction (from 25 to $100 \%)$ of $\mathrm{Ca}$ and $\mathrm{S}$ deposited in Greenland is soluble, while the proportion of soluble material is lower for $\mathrm{K}$ and $\mathrm{Fe}$ (between 10 and 80\%)". It seems that the sulfur containing particles are emitted in very soluble forms while some minerals (calcium carbonate or iron oxides) are altered during the atmospheric transport.

\section{-incipient studies of insoluble particles trapped in polar ice-}

Gaudichet et al. (1986) by means of analytical transmission electron microscopy (TEM) identified in ice recovered at Dome C, Antarctica, the following types of insoluble microparticles: clays, silica (crystalline and amorphous), feldspars, pyroxenes-amphiboles, metallic oxides, volcanic glass. "Clay minerals were identified in $40 \%$ of total number of the particles, among this clay $32 \%$ of them may be classed in the illite group". •) "Illite is a world-wide detritic component of sediments. In the fraction smaller than 2 microns, it represents $30 \%$ of the mass of deep sea sediments [...]. It is present in the Sahara dust outbreaks [...] as well as in dust plumes from the Asian continent [...]". Apart from illite other identified clays were: kaolinite, chlorite and smectite. •) "Kaolinite is considered to be a low latitude clay [...] formed by an intense weathering process. On a world-wide scale, a high proportion (up to 90\%) of this clay is found in a belt bounded by the tropics" (as for example the Australian desert). •) "As opposed to kaolinite, chlorite may be characterized as the "high latitude clay mineral found in abundance in polar regions of the world where chemical destruction is low"', so it may originate from the Patagonian area in South America. •) "Crystalline silica (quartz or tridymite) represents $13 \%$ of the identified particles". Quartz is considered an indicator for continental aridity and it is more abundant in LGM, (last glacial maximum), ice. •) "Felspar represented $18 \%$ of all mineral particles" and orthoclase and albite were more frequent than anorthite. •) The composition of the identified volcanic shards could be considered of ryolitic type and some silica had shard morphology indicating a volcanic activity of hypersiliceous magmas. "Volcanic glass shards were looked for at a low magnification [...] due to their potential use as an indicator of their sources". For example, two volcanic glass particles "composed of peralkaline trachyte could be the result of localized Antarctic volcanic activity".

After a first mineralogical characterization of insoluble particles in Vostok ice Gaudichet et al. (1988) concluded that they originate in areas of South America because they were mostly illite, feldspar, quartz and weathered volcanic products a combination not characteristic for local sources or for Australian ones. Analyzing further the dust particles of clay type in Antarctic ice from Vostok ice core and in snow from South Pole with a transmission electron microscope (TEM) fitted with an energy dispersive X-ray spectrometer, Gaudichet et al. (1992) identified: illite, smectite, chlorite, kaolinite and vermiculite. The noticeable result was the kaolinite percent $(\sim 10 \%)$ present in the snow and mid-Holocene ice but scarce in the last glacial period ice. 
(Kaolinite was identified as snow crystal nuclei, at South Pole station, in 7 of the 55 clay particles analysed (cited reference: Kumai, 1976)). If this mineral is considered as an indicator of the dust origin then its source would be the Australian soils, which for the glacial climates is overlapped by another source(s) as for example the erodible soils in South America.

Marino et al. (2004) continuing the preliminary investigations of Ghermandi et al. (2003) were among the first to apply the PIXE (particle-induced X-ray emission) technique to the investigation of insoluble dust trapped in Antarctic ice form the EPICA Dome C, (EDC), ice core with focus on insoluble silicon, iron and titanium. These elements have good correlations among each other and therefore, a similar behaviour in the atmospheric dust with insignificant fractionation. The PIXE concentrations for $\mathrm{Si}, \mathrm{Fe}$ and $\mathrm{Ti}$ agree with the total dust mass record along the EDC ice core in that the cold periods MIS2, 4 and 6 are marked by well defined peaks. Extending the PIXE investigations to more elements, ( $\mathrm{Al}, \mathrm{Ca}, \mathrm{Mg}, \mathrm{Na}$ and $\mathrm{K}$ in addition to $\mathrm{Si}, \mathrm{Fe}$, Ti), present in the insoluble dust fraction of EDC ice core, Marino et al. (2008) obtained: •) a LGM/Holocene ratio of 26 for $\mathrm{SiO}_{2}$ and 16 for $\mathrm{Al}_{2} \mathrm{O}_{3} ; \cdot$ ) a low content of Ca and $\mathrm{Na}$ in LGM dust (because these cations are mainly present as soluble salts and with PIXE was detected only the insoluble fraction included in the crystal structure of silicates) as well as •) an enrichment in Ti and $\mathrm{Fe}$ comparable with the observations for the loess from southern South America; $\bullet$ ) a peculiar Al contribution to the Holocene dust as in the case of Australian sediments and •) a somehow enriched fraction of Ti probably from a mixture of volcanic and detrital material. Further, based on the calculation of the Chemical index of Alteration (CIA) ${ }^{20}$ Marino et al. (2008) suggest a possible higher degree of chemical weathering at the dust source for Holocene period than for LGM.

In GRIP (Greenland Ice Core Project) ice, Maggi (1997) found quartz, illite, chlorite, micas, and feldspars in cold stages ice and kaolinite and iron (hydr)oxides in warm stages ice. "The first dust mineral assemblage is related mainly to the mechanical weathering prevailing in arid and cold mid-high-latitude areas, while the second dust mineral assemblage is related mainly to deep chemical weathering in warm and humid low-latitude areas".

\section{-recent studies of soluble particles in polar ice-}

Ion balances of soluble ions trapped in last glacial period ice from Dome Fuji, DF, ice core suggested that $\mathrm{Cl}^{-}$and $\mathrm{Na}^{+}$coexisted with a correlation coefficient of $0.83 ; \mathrm{NO}_{3}{ }^{-}$seems to be compensated by $\mathrm{Ca}^{2+}$ and $\mathrm{K}^{+}$; while the $\mathrm{SO}_{4}{ }^{2-}$ anions are counterbalanced by $\mathrm{Mg}^{2+}, \mathrm{Ca}^{2+}$ and $\mathrm{H}^{+}$ (lizuka et al. 2004a). On the other hand, the same type of investigations on DF Holocene ice indicated a high correlation between $\mathrm{Na}^{+}$and $\mathrm{Mg}^{2+}$ ions and $\mathrm{SO}_{4}{ }^{2-}$ cations. Since this was not observed for corresponding DF surface snow it was concluded that "almost all $\mathrm{Na}^{+}$and $\mathrm{Mg}^{2+}$ in the Holocene ice exists as $\mathrm{Na}_{2} \mathrm{SO}_{4}$ and $\mathrm{MgSO}_{4}$ salts, and the formation of these salts occurs not only in the atmosphere during transport, but also in the firn layer" (Iizuka et al. 2006 and the references therein). Additionally, if not enough $\mathrm{Na}$ or $\mathrm{Mg}$ ions the $\mathrm{SO}_{4}{ }^{2-}$ will be present in ice as a liquid and it will be prone to diffusion especially within the firn layers (but not only) (Rempel et al. 2001; 2002; Barnes et al. 2003a; Traversi et al. 2009).

The existence of sulfate and nitrate salts as solid inclusions in ice have been investigated by addressing the advantages offered by Raman spectroscopy readily adaptable to in situ analyses. Ohno et al. $(2005 ; 2006)$ identified the main (water-)soluble salts preserved in polar ice,

\footnotetext{
20 " $\mathrm{CIA}$ index calculated as $\left[\mathrm{Al}_{2} \mathrm{O}_{3} /\left(\mathrm{Al}_{2} \mathrm{O}_{3}+\mathrm{CaO} *+\mathrm{Na}_{2} \mathrm{O}+\mathrm{K}_{2} \mathrm{O}\right) \times 100\right]$, where $\mathrm{CaO}$ * is the amount of CaO in silicate minerals only (i.e., excluding carbonates and apatite)", (Marino et al. 2008)
} 
(from DF ice core), when their Raman spectra were compared with proper references. "Sodium sulfate and magnesium sulfate were dominant in the interglacial and early-glacial ice, but were not detected in the glacial maximum ice. Instead, the sulfate in the glacial-maximum ice was mainly in the form of calcium sulfate" (Ohno et al. 2006). It was also observed "that methanesulfonate salts and other complex salts exist only in the glacial-period ice" (Ohno et al. 2005). The complex salts, (or the microinclusions trapped in DF ice characterized by a complex Raman spectrum), in Ohno et al. (2005; 2006) were: •) a sulfate with a main peak at $984 \mathrm{~cm}^{-1}$; •) a sulfate with a split main peak (around 990 and $974 \mathrm{~cm}^{-1}$ ); $\bullet$ ) a double salt containing $\mathrm{SO}_{4}{ }^{2-}$ and $\mathrm{NO}_{3}{ }^{-}$(main peaks around 987 and $1068 \mathrm{~cm}^{-1}$ ); •) probably a nitrate for a main peak at $1048 \mathrm{~cm}^{-1}$.

The nature of the magnesium sulfate microinclusions in ice was clarified by Genceli et al. (2009) who present Raman spectra of the recently characterized meridianiite ${ }^{21}, \mathrm{MgSO}_{4} \cdot 11 \mathrm{H}_{2} \mathrm{O}$, (Genceli et al. 2007) as a mineral and as an inclusion in natural ice (from a lake in Japan and from Antarctica). "In the laboratory, as well as in nature, $\mathrm{MgSO}_{4} \cdot 11 \mathrm{H}_{2} \mathrm{O}$ crystallizes from a suspension around its eutectic point, i.e. concentrations between 17.3 and $21.4 \mathrm{wt} \% \mathrm{MgSO}_{4}$ and temperatures between -3.9 and $1.8^{\circ} \mathrm{C}$. If the temperature of the magnesium sulfate reservoir lies above $1.8^{\circ} \mathrm{C}$, epsomite formation occurs instead of meridianiite". The occurrence of the $\mathrm{Mg}$ sulfate in the analyzed Antarctic ice was of 3\% while for the sea ice about $5 \%$ (of all investigated microinclusions). The majority of the encountered inclusions in ice were mirabilite and the distinction between the two minerals was based on a careful examination of as many as possible features in the recorded Raman spectra, since the wavenumbers of the $\mathrm{SO}_{4}{ }^{2-}$ vibrations in meridianiite and mirabilite are very close, (further in Tables 2.2.2.4, 2.2.2.5).

Magnesium was also the cation responsible for stabilization of the methane-sulfonate, $\left(\mathrm{CH}_{3} \mathrm{SO}_{3}^{-}\right), \mathrm{MS}^{-}$, anion, as was observed for a microinclusion in Dome Fuji ice. Sakurai et al. (2010b) explained the preservation of $\left(\mathrm{CH}_{3} \mathrm{SO}_{3}\right)_{2} \mathrm{Mg} \cdot \mathrm{nH}_{2} \mathrm{O}$ in DF ice from LGM by inspecting the phase diagrams of $\mathrm{MS}^{-}$salts of $\mathrm{Na}, \mathrm{K}, \mathrm{Mg}, \mathrm{Ca}$ and considering the temperature regime in the Antarctic atmosphere and in the ice sheet. The magnesium methanesulfonate salt has the lowest eutectic temperature $\left(-5^{\circ} \mathrm{C}\right)$ thus it could remain as a solid inclusion in the polar atmosphere or it could be formed in the Antarctic firn layers (while the other salts may have melted or decomposed and the resulted MS acid may have sublimated). Moreover, because the Holocene Antarctic atmosphere contains sufficient sulfuric acid to neutralize suitable salts, the $\left(\mathrm{CH}_{3} \mathrm{SO}_{3}\right)_{2} \mathrm{Mg} \cdot \mathrm{nH}_{2} \mathrm{O}$ has the highest probability to form and survive in ice from a glacial period.

A main interest in the paleocliamte reconstruction using (polar) ice cores is to understand the relationship between what kind of the impurities are and how they reached in the ice. For the soluble ones it is desirable to know the initial association of their constitutive ions in order to identify their possible sources. The main ionic Antarctic balance differs from the Greenland's one mainly when the proportion of the $\mathrm{Cl}^{-}, \mathrm{Ca}^{2+}$ and $\mathrm{CO}_{3}{ }^{2-}$ species is considered (Legrand and Mayewski, 1997). That the carbonate anions exist as $\mathrm{CaCO}_{3}$ mainly in the GRIP, (Greenland Ice Core Project), last glacial period (LGP) ice while the sulfate ones as $\mathrm{CaSO}_{4} \cdot 2 \mathrm{H}_{2} \mathrm{O}$ throughout both Holocene and LGP Greenlandic ice was the conclusion of in situ micro-Raman and ex situ energy-dispersive X-ray analyzes of microinclusions in solid and sublimated ice samples respectively (Sakurai et al. 2009). This would be in agreement with the label of a more alkaline

\footnotetext{
21 " $\mathrm{MgSO}_{4} \cdot 11 \mathrm{H}_{2} \mathrm{O}$ was originally described (1837) as $\mathrm{MgSO}_{4} \cdot 12 \mathrm{H}_{2} \mathrm{O}$ and became known as Fritzsche's salt. The name, meridianiite, was chosen to reflect the locality on Mars where the MER rover Opportunity observed crystal molds in sedimentary rock that are thought to be caused by minerals that have since dehydrated or dissolved". (Peterson et al. 2007)
} 
ice in Greenland during the cold climate versus an acidic ice in Antarctica (Legrand and Mayewski, 1997; and the references therein).

Nevertheless, Sala et al. (2008) determined the mineralogy of dust in Antarctic ice from the Talos Dome and Ross Sea areas. Ion chromatography, X-ray powder diffraction, and (in situ) Raman spectroscopy were employed to show the existence of calcite, quartz, K-feldspar, albite, amphibole, talc, illite, kaolinite, smectite in the investigated ice. In particular Raman analyses (performed under controlled temperature conditions) offered a direct evidence for the presence of hydrous calcium carbonates, monohydrocalcite, $\left(\mathrm{CaCO}_{3} \cdot \mathrm{H}_{2} \mathrm{O}\right)$, and ikaite, $\left(\mathrm{CaCO}_{3} \cdot 6 \mathrm{H}_{2} \mathrm{O}\right.$, stable below $+3{ }^{\circ} \mathrm{C}$ ), in Antarctic firn.

\title{
2. EXPERIMENTAL PART
}

\subsection{Methods}

\begin{abstract}
"But great passions for glory, fame, power, and self-assertion proved at the same time to be immensely destructive. [...] The ages of heroes and of grand passions erupted in generations of prolonged political and religious wars. [...] How could such passions be tamed? How could human energy be shifted toward constructive, rather than destructive, aims? ” Novak, 1990, pg. 79
\end{abstract}

In this study, the main experimental technique for investigating the microinclusions trapped in EDML ice was Raman spectroscopy. A complementary analytical technique is the energy dispersive X-ray spectrometry, EDX, which for an accurate focus can be coupled to an electron microscope. Here, SEM-EDX analyses were just sporadically used for characterizing the EDML ice and the inclusions in it. Few $\mathrm{EBSD}^{22}$ patterns could also be registered. The machine employed was a cryo field emission environmental scanning electron microscope (cryo-FE-SEM, FEI Quanta 200 FEG) equipped with a nitrogen cooled cryo-stage (Gatan), an EDX detector (EDAX) and an EBSD system. The operating temperature during the SEM-based measurements was not lower than $-150^{\circ} \mathrm{C}$.

Before being able to apply any of the two methods the EDML ice sample must be cut and prepared as careful as possible, especially the (upper) surface which comes into contact with the analyzing beam. The cutting of an EDML ice piece can be done with a band saw or a thinner hand saw, then the polishing is done with a microtome, and finally a nice smooth surface is obtained by (thermal) etching (or slow sublimation). Also, the inclusions inside the EDML ice body must be visualized before performing the (Raman) investigations. For this type of study optical microscopy can be employed. And of course, since the studied material is (EDML) ice it had to be manipulated at temperatures below $0^{\circ} \mathrm{C}$, which was possible in a suitable cold room laboratory. During the Raman measurements the ice specimen was kept in a Linkam (THMS 600) micro-thermo-chamber.

\footnotetext{
${ }^{22}$ a diffraction technique, in a SEM, involving backscattered electrons
} 


\title{
2.1.1 Optical microscopy
}

\author{
"In many dreams the nuclear center; the Self, also appears as a crystal. \\ The mathematically precise arrangement of a crystal evokes in us the intuitive \\ feeling that even in so called "dead" matter, there is a spiritual ordering principle. \\ Thus the crystal often symbolically starts for the union of extreme opposite - \\ of matter and spirit." (M.L. von Franz "Man and His Symbols")23
}

Because the quality of the results, either from Raman or SEM investigations on EDML ice, depend on the quality of the surface of the ice sample ${ }^{24}$, before any experiment, a stratum of a few micrometers was carefully removed, with a microtome, on both sides of the ice specimens, and then they were allowed to sublimate until the best clearness could be observed under a Leica DMLM optical microscope. Documenting pictures were taken with a CCD video camera, Leica DFC290.

A description of the features that can be observed at microscopic resolution in polar ice, via the microstructure mapping method, is available in Kipfstuhl et al. (2006). The recorded images offer information about: "air inclusions (air bubbles and air clathrate hydrates), texture (grain size, shape and orientation) and deformation-related features (subgrain boundaries, slip bands, subgrain islands and loops, pinned and bulged grain boundaries)". At a proper microscopic resolution the smaller microiclusions (colloquially named 'black dots' because they appear like this in the microscopic images) can be documented. Also, features that develop after a defined time has passed from the ice core extraction, more precisely the relaxation features, can be observed.

Results from optical microscopy on EDML ice, with focus on the embedded microinclusions are presented (when the case) in the following sections. In this part, a somehow extended study is presented as:

\section{Notes on plate-like inclusions morphology}

The morphology is defined as the shape, colour, and spatial distribution (configuration) of plate like inclusions, developed in EDML ice. In general plate like inclusions, PLIs, are tridimensional secondary (relaxation) microinclusions; but because most of them, (especially in the upper 2300 meters of the EDML ice core), have one direction of very small length compared to the other two, (and since they were catalogued as 2D optical microscopy images) an in-plane (2D) shape ${ }^{25}$ will be addressed.

Plate like inclusions in EDML ice can be seen as (sometimes partially) transparent with a black contour or black and therefore opaque (micro-)regions in the ice volume. The relief ${ }^{26}$ of the PLIs is good (or moderate), much better than for the air clathrate hydrates-primary microinclusions commonly found in (deeper) polar ice-but not as good as for primary and even secondary air bubbles existent in ice. The relief of an inclusion in a mineral depends upon the difference between the index of refraction of the two, the guest and the host matrix (Kerr, 1977). The Becke line is qualitatively used to distinguish between media with different refractive indexes. In the form of a small area of concentrated light, which follows the outline of an inclusion edge, the Becke line moves into the higher index material as the distance from the inclusion to the microscope lens is increased (Ehlers, 1987). It is the case with air clathrate

\footnotetext{
23 via Wilson, 2003

${ }^{24}$ practical aspects on ice sample preparation for optical microscopy investigations were presented by Dr. Kipfstuhl or Dr. I. Weikusat upon visits at AWI

25 the arrangement of and the relation between the external boundaries of a secondary microinclusion

${ }^{26}$ the appearance or visibility of the outline and the surface (Kerr, 1977)
} 
hydrates in ice, when the Becke line moves inward from the hydrate edge. If the index of refraction of the inclusion is lower than that of the material in which the inclusion is trapped, the Becke line seems to move away from the inclusion edge into the matrix as the microscope stage is lowered and of course if the inclusion is brought back into focus, the Becke line returns to its edge (Ehlers, 1987). This is the case for plate like inclusions; the areas of light concentration above a PLI move outward from the inclusion edges, as the distance from the inclusion to the microscope lens is increased. This means that the light travels more quickly when passing through secondary microinclusions in ice than through air hydrates. Knowing that both inclusions, PLIs and AHs, are filled with (fractionated) air (Nakahara et al. 1988, Nedelcu et al. 2009), the difference between the refractive indexes is due to the difference in their internal structure, more precisely due to the existence of a stable arrangement of the water molecules around the $\mathrm{O}_{2}$ and $\mathrm{N}_{2}$ molecules of the air in the hydrates, decreasing the speed of light when traveling through. Thus it can be assumed that no special, regular arrangement of the water molecules can be expected in the PLIs volume structure. The assumption is further confirmed if it is taken into consideration how the two types of inclusions have been formed. The air hydrates are the result of long time rearrangement of the ice structure around the air molecules trapped as air bubbles in ice when a suitable (local) pressure is attained (Miller, 1969; Shoji and Langway, 1987; Salamatin et al. 2003); while PLIs result as a structurally allowed release of the accumulated (local) pressure in the ice matrix.

As a rule plate like inclusions are considered to have their volume extended on the ice basal plane (the plane defined by the $a$ axes of symmetry), therefore the nomenclature 'plate like', and as a consequence hexagonal profile. From optical microphotographs inspection it resulted that the most numerous PLIs are like this, six sided polygons (regular or asymmetrical hexagons) extended in the ice basal plane. But in 2D optical microscopy images PLIs appear also as polygons with five or four edges. The four sided polygonal shapes are less common than the five sided ones, which are rather pentagons with a small angle between two edges.

Representative optical microscopy images of plate-like inclusions developed in EDML ice, are presented in Figure 2.1.1.1.

The outline of the stable PLIs is sharp (or equant) while for PLIs that started to decompose (or dissolve) is more rounded. The PLIs disappearance is mainly related with a higher temperature (or thermal gradient) in their surrounding environment, and most PLIs which are close to the ice specimen surface decompose more rapidly than the ones placed deeper inside the ice specimen volume. But when and in which way a PLI dissolves, depends on the (micro) structure of the surrounding ice matrix as well as on the (structure) composition of a certain PLI. For example it could be observed that some PLIs transform in time in small round or elongated features (bubbles), in circular arrangement (Fig. 5 in Faria et al. 2009) or they adopt a (so called) annular shape, thinner towards the center of the PLI and a thicker rim along its margins, which probably later on decomposes to small bubbles, (Figure 2.1.1.2).

Annular PLIs could exist also (deep) inside an EDML ice specimen volume, while PLIs evolving towards circles of small bubbles have been observed, (in this study), only in the upper surface micrometers of an EDML ice specimen. Maybe a small available amount of fractionated air inside a secondary relaxation microinclusion, (a PLI), determines an annular shape as the inclusion starts to decompose. A low quantity of air molecules inside the cavernous PLIs body would not be sufficient to counterbalance the pressure from the confining ice matrix.

Another morphological aspect worth discussing is the colour of the PLIs since some of them are seen in the optical micrographs as being entirely black coloured, while others have only black outer margins with a transparent interior (Figure 2.1.1.1).

It is known that "for most (fluid) inclusion in minerals the combination of inclusion shape and the difference in the refractive index between the mineral and the fluid (substance) that fills the inclusion control how bright or dark the inclusion appears in transmitted light. Inclusions 
with flat upper and lower surface transmit light well and appears bright whereas negative crystals irregular or globular inclusions have a focusing and defocusing effect on the light, which when combined with relief, could lead to irregular illumination of the inclusion interior or even total internal reflection. Refractive indices are such that aqueous and hydrocarbon liquid inclusions typically appear bright and gas filled inclusions typically appear dark" (Samson, 2003).

For relaxation inclusions in EDML ice it seems that their shape does not have a greater influence on their colour than has their refractive index, which is determined by the substances inside their volume. At a first glance, it appears that the transparent PLIs are empty while the black PLIs are filled with fractionated air. But Raman spectra for transparent PLIs show that they contain also oxygen and nitrogen in their interior and not always in very small amounts. Unfortunately, a systematic (semi)quantitative comparison between the $\mathrm{O}_{2} / \mathrm{N}_{2}$ ratios for transparent and black PLIs, (i.e. if the transparency can be related with the amount of one of the two gases) has not been done. A factor which seems to determine a change in the PLIs colour is their orientation with respect to the transmitted light propagation path in the optical microscope.
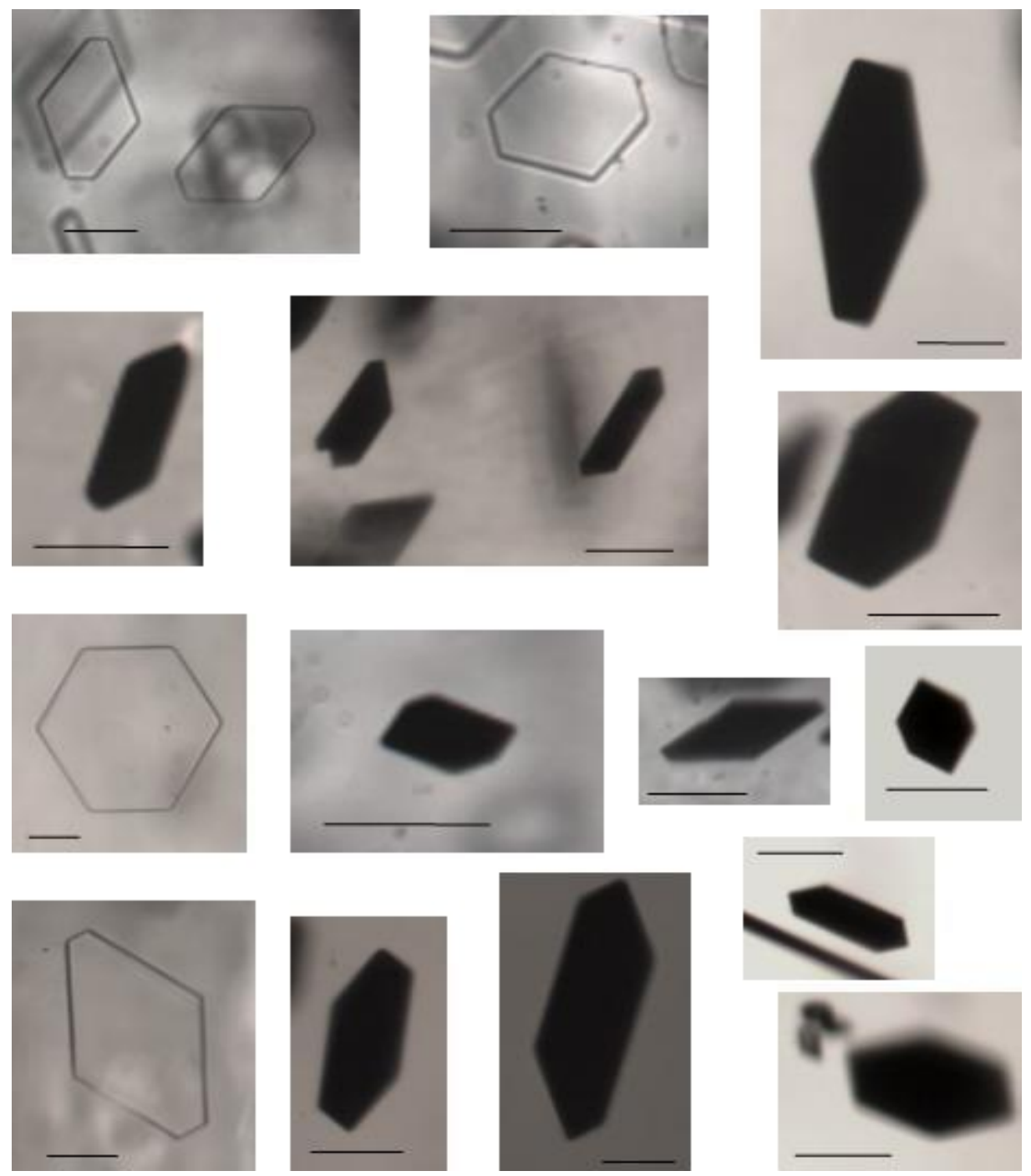

Figure 2.1.1.1 Optical microscopy images of PLIs in EDML ice from 934, 953, 1035, 1184 or $2295 \mathrm{~m}$; (scale bars: $130 \mu \mathrm{m}$ ) 

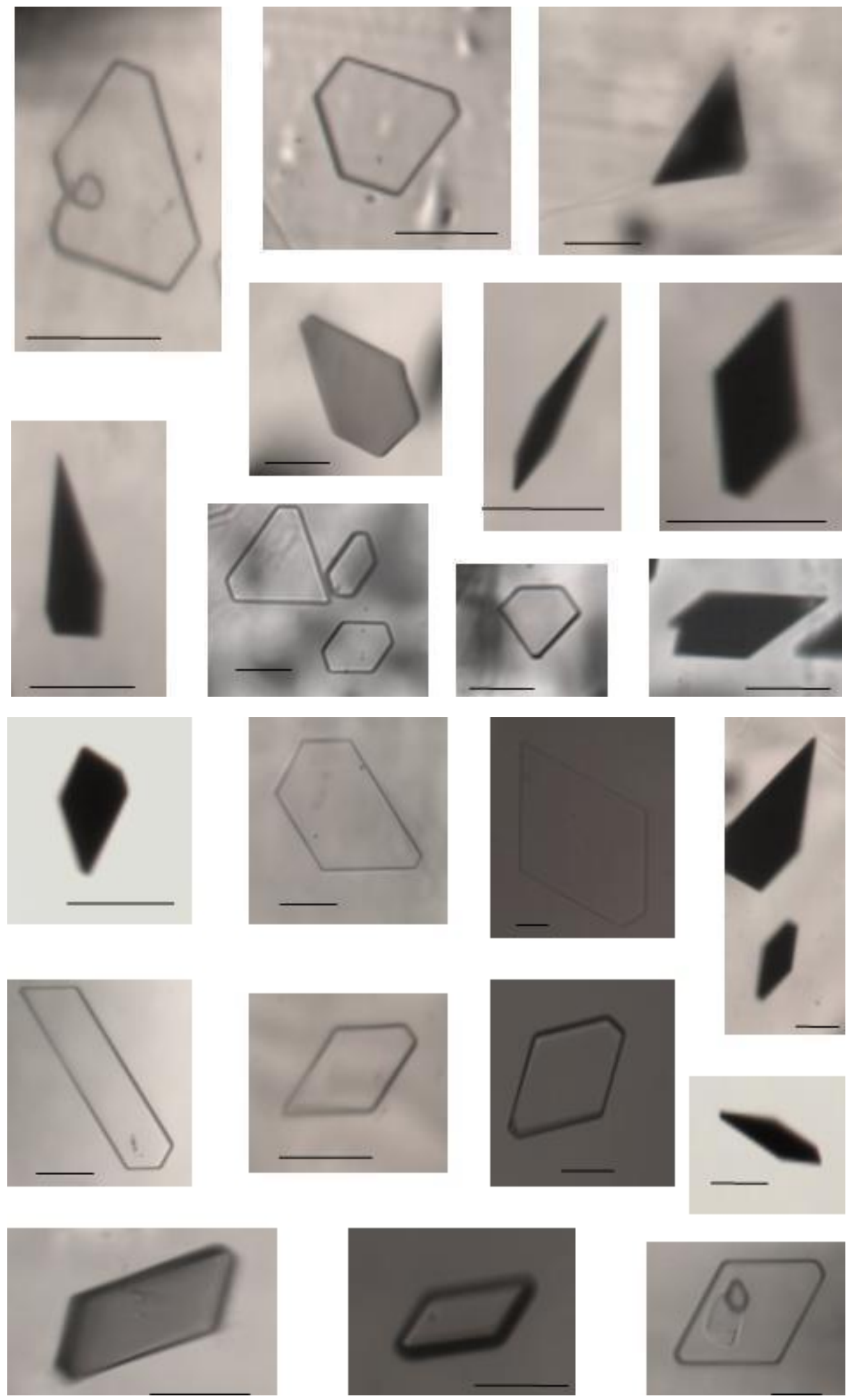

Figure 2.1.1.1 (continuation) Optical microscopy images of PLIs in EDML ice from 934, 953, 1035, 1184 or $2295 \mathrm{~m}$; (scale bars: $130 \mu \mathrm{m}$ ) 


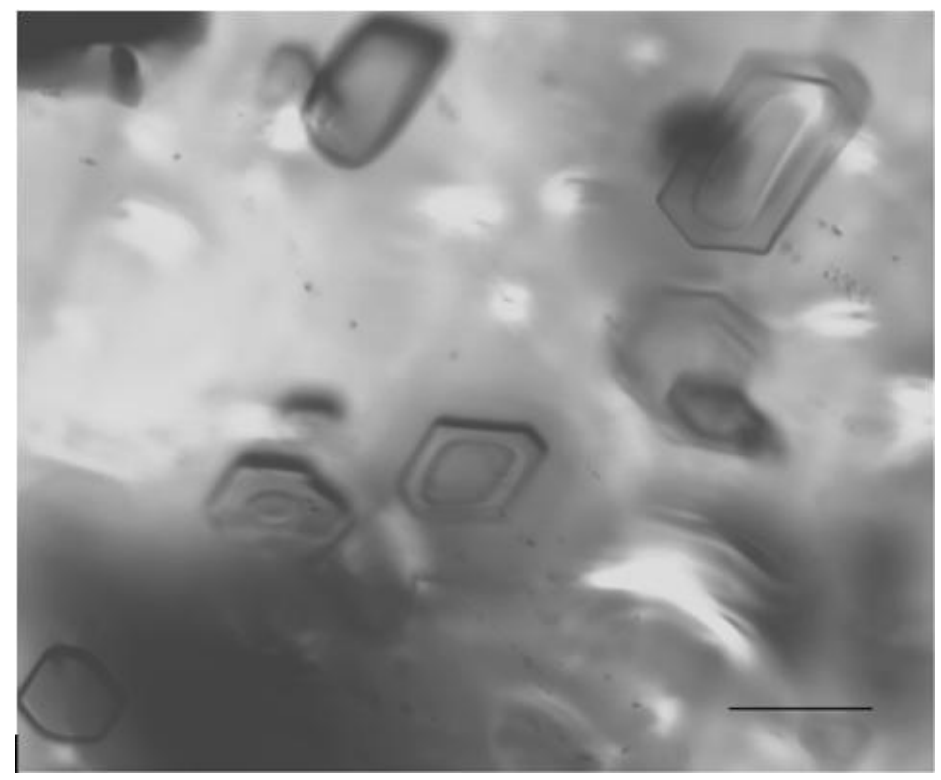

Figure 2.1.1.2 Optical microscopy images of annular (or decomposing) PLIs in EDML ice at $953 \mathrm{~m}$; (scale bars: $120 \mu \mathrm{m}$ )

Those plate like inclusions viewed from aside (perpendicular to their thinnest dimension, which is usually along the ice $c$ axis of symmetry) appear transparent. Also, there can be the situation in which PLIs surfaces (acting as an interface between a denser medium, the ice, to a thinner medium, the air in a PLI) are so oriented that the incident light coming from below the ice specimen is totally reflected when reaching the ice-PLI boundary.

For the investigated EDML ice specimens it could not be identified a special relation between the PLIs distribution and the grain boundaries ${ }^{27}$, GBs. It can be that this is just an incompleteness of this experimental study, since it had been shown that GBs can act as sources and sinks for dislocations (i.e. Hondoh and Higashi, 1983) and a rearrangement of the dislocation lines in the vicinity of grain boundaries in natural ice, as the ice relaxes can provide paths for PLIs development.

In EDML ice relaxation features are observed not only with a relatively thin dimension between slip bands (their body extended along the ice basal plane) but also extending across slip bands, along the ice prismatic planes ${ }^{28}$, and they can be completely black or transparent with a black outline (Figure 2.1.1.3). The overall shape of these relaxation features bears the mark of their particular location, meaning a tendency towards elongation probably due to forces resembling shear stresses or anisotropic diffusion. Relaxed primary bubbles (which can be considered primary due to their size) elongated along the direction of slip bands adopt an elongated hexagonal shape with $90^{\circ}$ sharp corners allowing them to expand their volume towards a lenticular flat form extended in the ice basal plane (Figure 2.1.1.4).

\footnotetext{
${ }^{27}$ nanometer wide regions within polycrystals that separate neibouring grains or crystallites with a misorientation of about $10^{\circ}$, (Schulson and Duval, 2009)

${ }^{28}$ For EDML ice at deeper depths the relaxation features seems to have their longest dimension along the ice prismatic planes but according to Gow (1971) they should be named cavities, (not PLIs).
} 

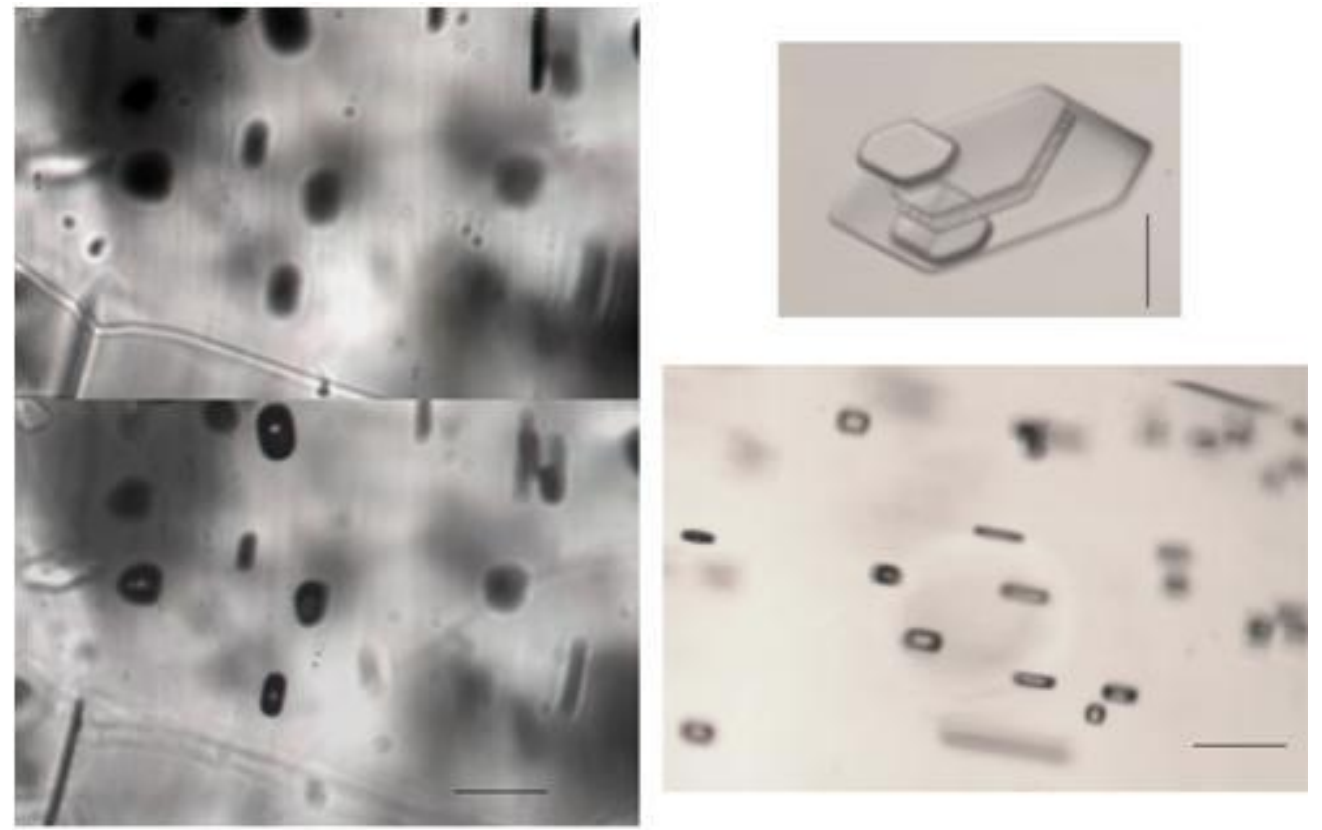

Figure 2.1.1.3 Images showing the characteristic shape of PLIs in EDML ice and their relation with slip bands

(at: left $953 \mathrm{~m}$, right up $2295 \mathrm{~m}$, right down $2345 \mathrm{~m}$; scale bars: $130 \mu \mathrm{m}$ )
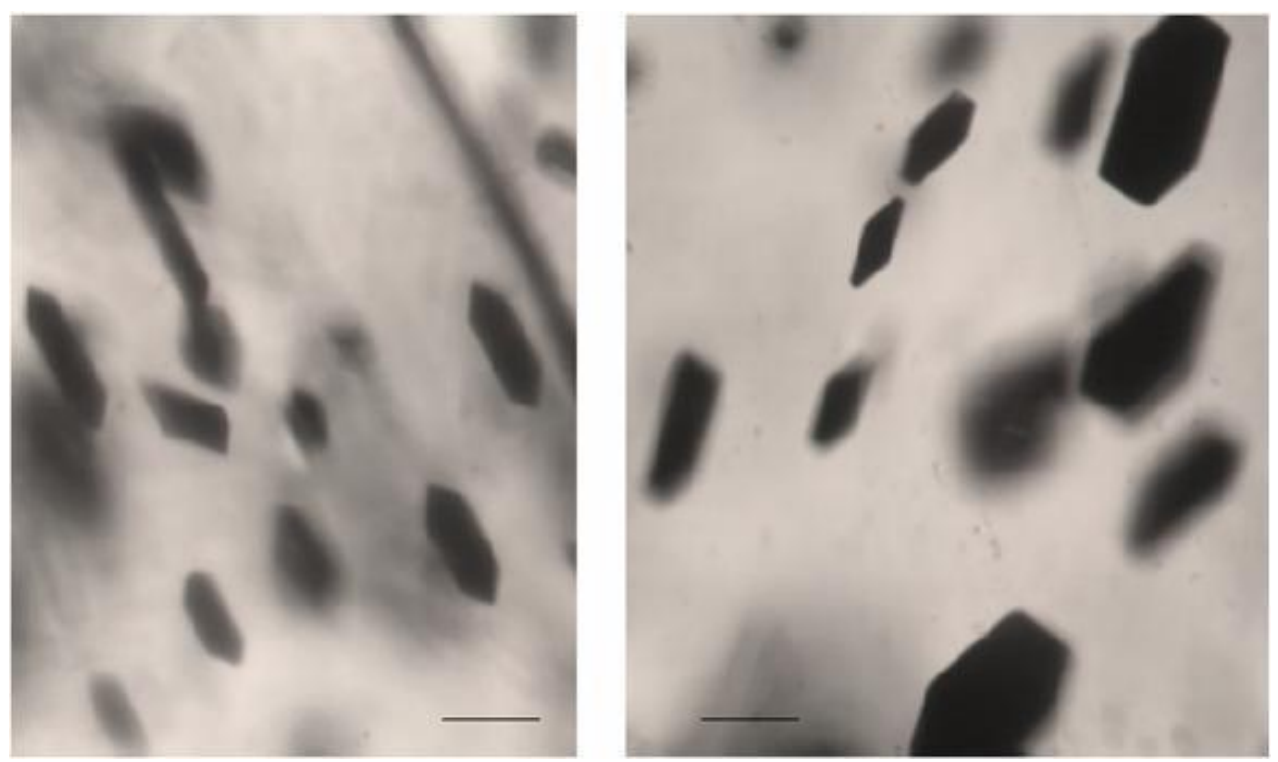

Figure 2.1.1.3 (continuation) Images showing the characteristic shape of PLIs in EDML ice and their relation with slip bands (at: left $934 \mathrm{~m}$, right $1035 \mathrm{~m}$; scale bars: $130 \mu \mathrm{m}$ ) 

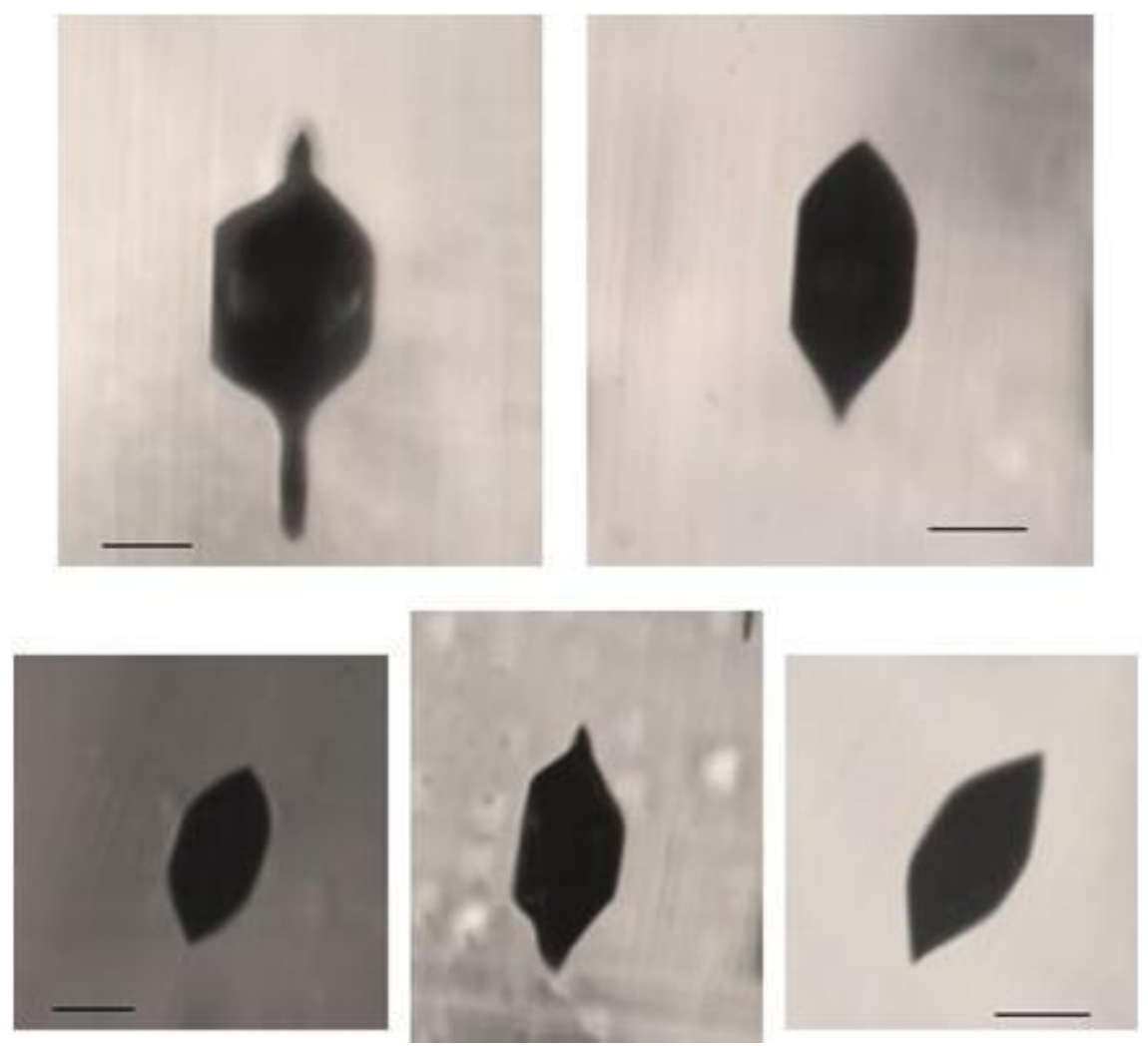

Figure 2.1.1.4 Primary air inclusions in EDML ice (at $934 \mathrm{~m}$ or $1035 \mathrm{~m}$ depth) elongated in the direction of slip bands. The soft lines (visible) around them are slip bands (scale bars: $130 \mu \mathrm{m}$ )

\subsubsection{SEM-EDX microscopy}

"...the role of the instrument in (geologists') thoughts about the earth can be analysed more closely. [...] We observe a thin section of a rock through the microscope. The instrument serves as an extension of the geologist's senses, [...] we can regard the instrument as being 'embodied', or as being in an 'embodiment relationship' to the human observer.

But in other cases it is the instruments themselves that are the direct object of examination, and the readings on their dials, printouts or whatever have to be interpreted. Thus we are engaged in a kind of hermeneutic activity." Oldroyd, 1996, pg. 242-243

Scanning electron microscopy, SEM, investigates a specimen by moving a finely focused electron beam, accelerated by voltages from 200 to 30000 volts, systematically in a raster over the sample's surface (www.fei.com ${ }^{29}$ ). Usually the specimen's surface does not need a complex preparation but it influences the practical resolution, which also depends on the beam intensity, accelerating voltage, scanning speed, working distance and the angle of the specimen surface with respect to the detector. The only constrains imposed for the specimen are due to the vacuum in the specimen chamber and the electron bombardment. If the specimen is non-conducting it will charge up and needs to be coated with a conducting layer.

During the electron bombardment of a sample the following phenomena can occur: the specimen itself emits secondary electrons, X-rays or photons or absorbs electrons or reflects electrons (backscattered electrons) the latter phenomena being used to investigate the crystallographic texture of a material.

\footnotetext{
${ }^{29} \mathrm{http} / / /$ www.fei.com/uploadedfiles/Documents/Content/2006_06_AllYouWanted_pb.pdf
} 
When the analyzed material is ice considerable surface charging occurs when secondary electron imaging ${ }^{30}$ is used. This can be avoided by coating the ice specimen, but more often it is of interest to investigate a naked ice surface and this can be achieved by working with low current and low accelerating voltage or by employing the more tedious technique backscatter electron imaging, EBSD, when reasonably noise-free pictures for fine features of interest can be recovered (Barnes et al. 2002). The results from SEM and SEM-EDX investigations ${ }^{31}$ on EDML ice samples ${ }^{32}$, presented in the following figures (Fig.2.1.2.1 to Fig.2.1.2.9). Their preparation was described in section 2.1 and the scanned area was of $5 \times 5 \mathrm{~mm}$. Before being transferred to the cryo-stage the ice was kept in liquid nitrogen, but some frost formation on the ice surface could not be avoided. The results presented herein were obtained for uncoated EDML ice samples. The image b in Fig. 2.1.2.2 shows an ice surface which is not too far from being "completely roasted" by the high voltage; that is when the marks from the grain boundaries would no longer be observable.

Another important aspect when performing SEM investigations on ice samples is the etching technique used for preparing the ice surface, either prior to analysis outside the SEM chamber by polishing with a microtome and subsequent sublimation at a suitable temperature or in the SEM cryo-chamber by controlling the temperature of the stage and hence the sublimation rate (Barnes et al. 2003b). In Fig. 2.1.2.4 (a, b, c) it is shown the evolution of an EDML ice sample' surface while it is allowed to sublimate and become clear of the frost deposited at the time of sample transfer to the cryo-chamber.

As the ice sublimates in the SEM chamber a dynamic view of the inclusions embedded in its volume can be obtained (figures 2.1.2.1 to 8). The topological distribution of soluble and insoluble impurities has been shown to follow the grain boundary network in the form of thin filaments or the grain interior as single spots; (for example, figures 2.1.2.2 to 5 for the case of EDML ice). Sometimes tridimensional features form due to a local (probably higher) concentration and rearrangement of soluble salts (Obbard et al. 2003). One such example, a "salt flower", is in pictures e and f, Fig.2.1.2.6 proved to contain $\mathrm{C}, \mathrm{Na}, \mathrm{Cl}$ and $\mathrm{K}$ by SEM-EDX analyses (Fig. 2.1.2.7). Its high $\mathrm{K}$ content indicates that this "flower" is an artifact from the measurement procedure, since is not very likely that the EDML ice containes so much $\mathrm{K}$. If the chemical composition of these inclusions is for sure the one detected by EDX (energy dispersive $\mathrm{X}$-ray spectrometry) analyses their location can be questioned since they can drift under the influence of the electron beam (especially the thin threads of frozen hydrated salts) (Baker and Cullen, 2003). "Salty threads" on EDML ice can be seen in Fig.2.1.2.4 image d, Fig.2.1.2.6 images e and f, Fig.2.1.2.7. The voltage used for the EDX results in this study was at least $15 \mathrm{kV}$.

Inclusions appearance can also be monitored using SEM as it changes under the effect of preferred sublimation of ice. Function of the location and the orientation of the inclusion in (or between) the corresponding grain(s), features with hexagonal or spherical symmetry can develop (Obbard et al. 2003), sometimes falsifying their precise location (the same applies to grain boundaries (Barnes et al. 2003b; Barnes et al. 2006)). In Fig.2.1.2.5 image c shows an air bubble between grain boundaries; and in Fig.2.1.2.6 images b and d one can see the evolution of a plate like inclusion formed in a grain volume.

\footnotetext{
${ }^{30}$ if some explanations are necessary, the reference on previous footnote (28) can be useful

${ }^{31}$ the SEM-related investigations were performed with the supervision of Dr K. Techmer

32 the samples were cut at 934, 953, 983, 1294 or $1474 \mathrm{~m}$ depth of the EDML core
} 

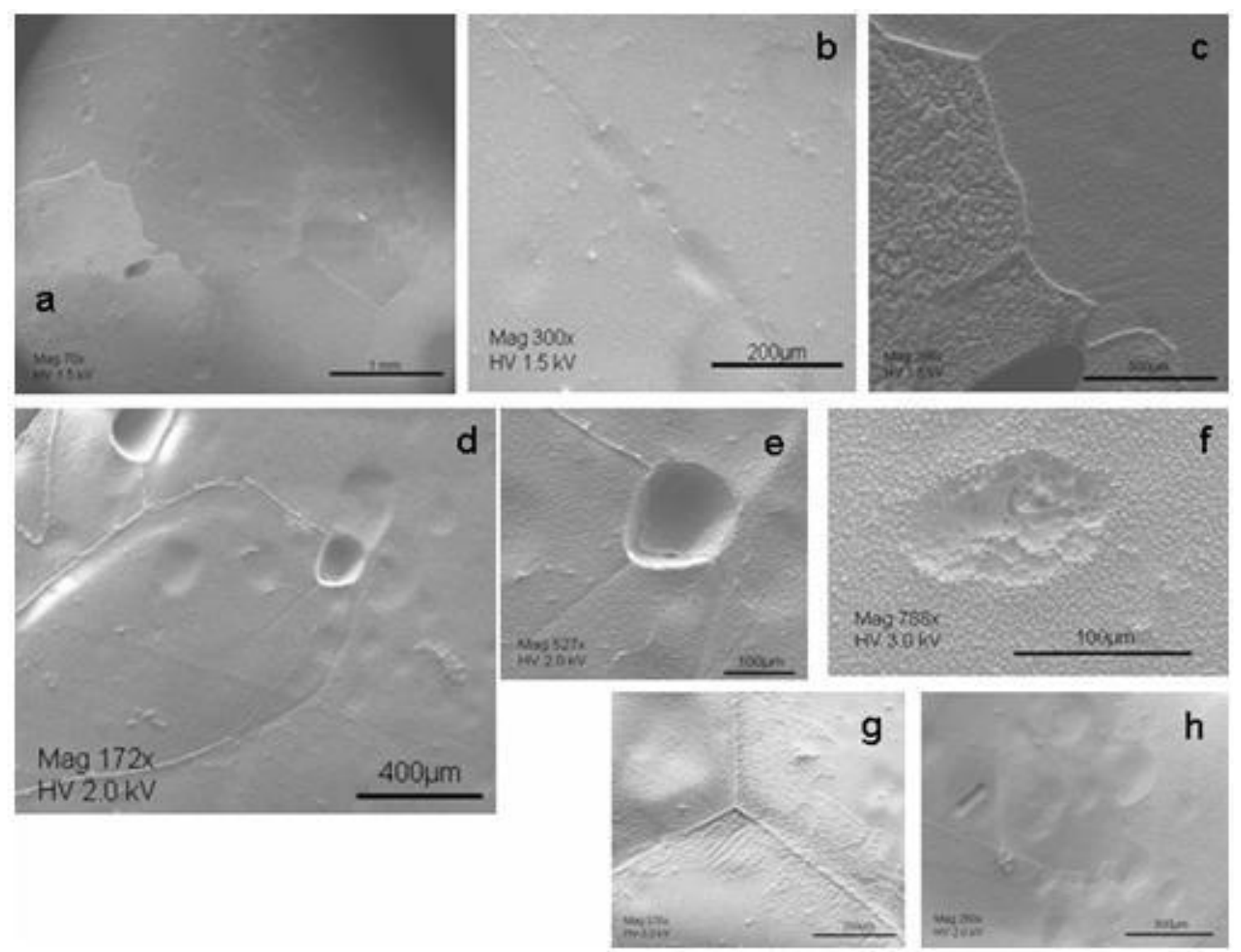

Figure 2.1.2.1 SEM images of EDML ice. a) was taken $30 \mathrm{~min}$. after the start of the experiment. b) and c) show GBs with and without small cavities left by microbbubles. In c) one can observe ice crystallites with different sublimation patterns due to different orientations or different chemical composition. g) and h) show GBs with low and high energy again delineating grains with different sublimation patterns. In g) is a so called triple junction (TJ). e) and f) are enlarged images of surface features in d), produced by an $\mathrm{AB}$ and an $\mathrm{AH}$ respectively. In d) salts are deposited along the upper GB, then they form a thread in the cavity left by the AB, shown in e), and continues on the surface of the ice grain until it reaches and follows the lower GB. The scale in c) and h) is $300 \mu \mathrm{m}$ and in $\mathrm{g}$ ) is $200 \mu \mathrm{m}$. The operating conditions Mag and HV are: a) $70 \mathrm{x}, 1.5 \mathrm{kV}$; c) $286 \mathrm{x}, 1.5 \mathrm{kV}$; e) $527 \mathrm{x}, 2.0 \mathrm{kV}$; g) $376 \mathrm{x}, 3.0 \mathrm{kV}$; h) 260x, 2.0kV. 

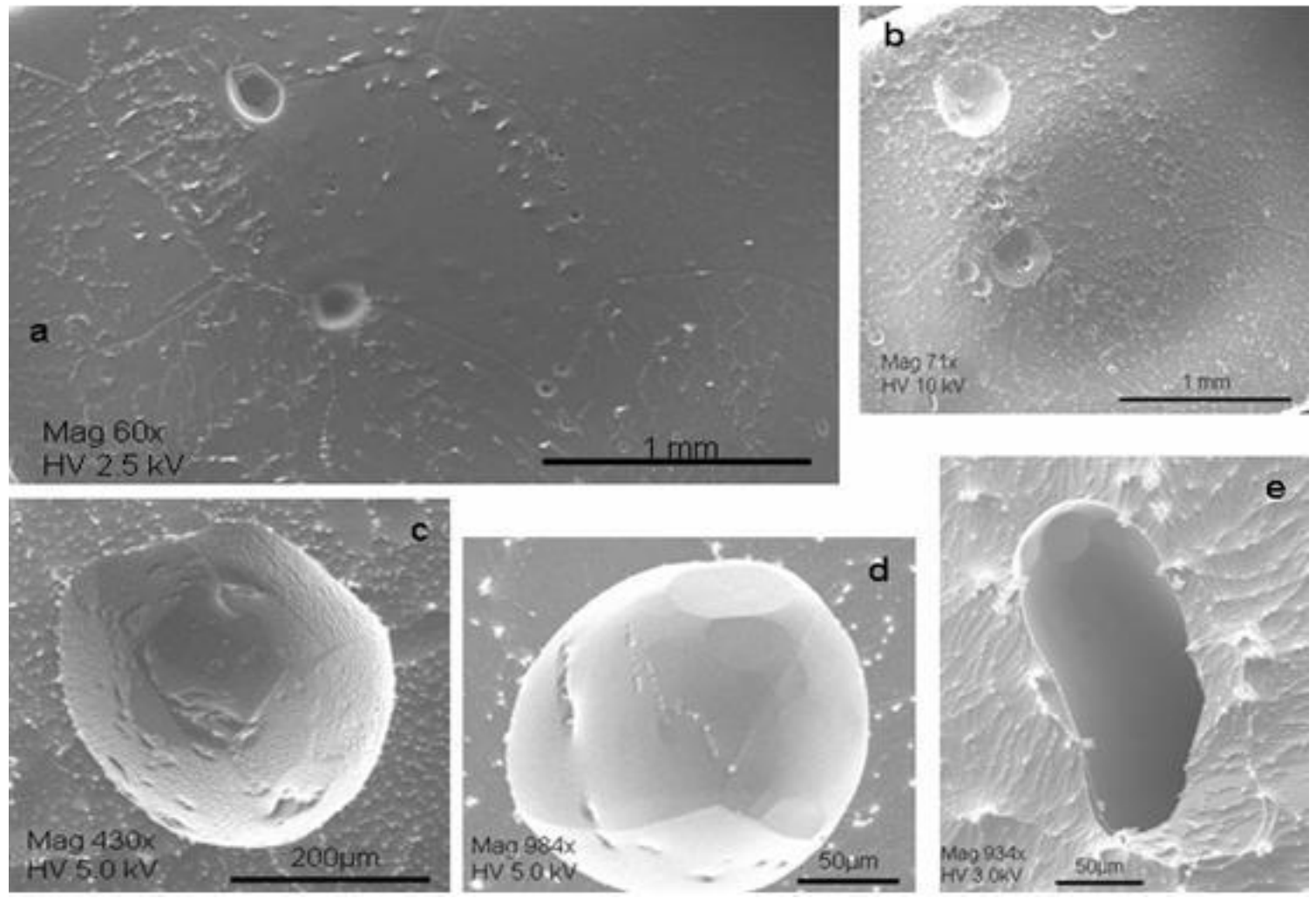

Figure 2.1.2.2 SEM images of EDML ice. In a), marks from microbbubles can be seen along the GBs (i.e. more in the right half of the image). The white spots (in a), i.e. top right) in the vicinity of the GB are microinclusions (microbubbles) below the ice surface. b) was taken $40 \mathrm{~min}$. after a) and the ice surface is no longer smooth (the GBs are not easily distinguished). c) and d) are enlarged images of surface features in b), and are enhanced due to ice sublimation-condensation processes. If d) is a primary $\mathrm{AB}$, then the marks on the surface can be from microimpurities preserved in EDML ice. e) shows an $\mathrm{AH}$.

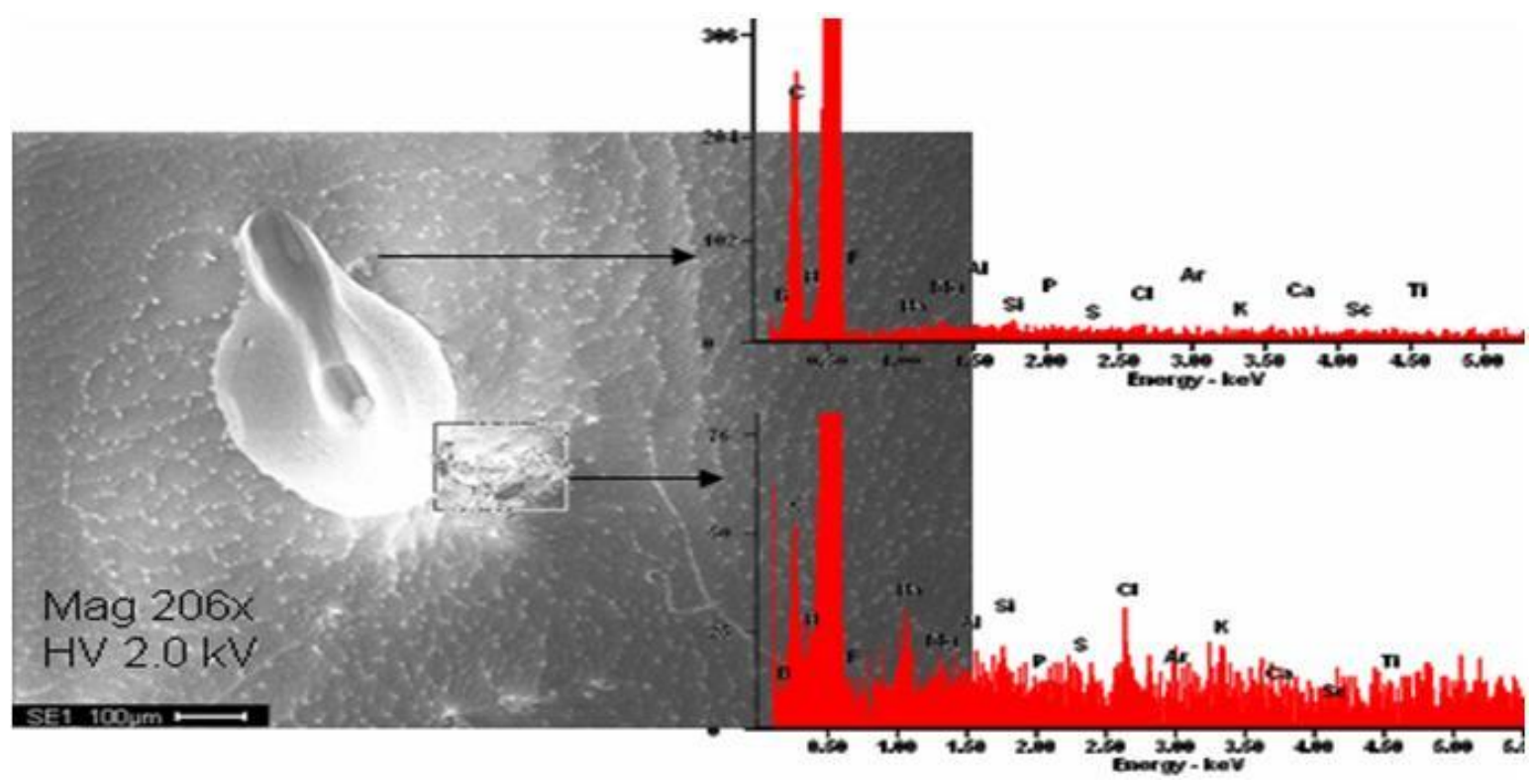

Figure 2.1.2.3 SEM-EDX results of EDML ice. A microinclusion in ice surrounded by microimpurities containing carbon, sodium, chlorine and probably also silicon. 

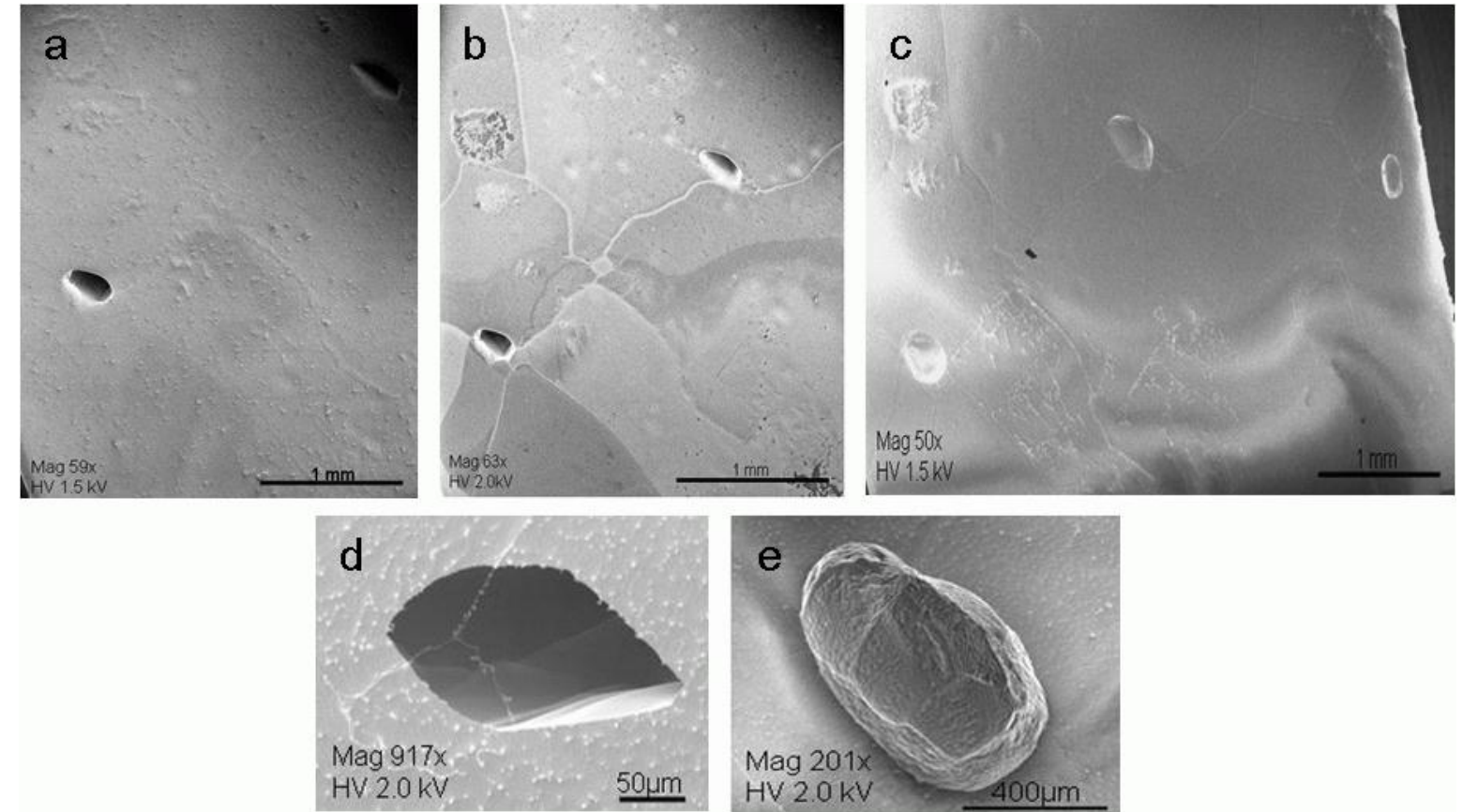

Figure 2.1.2.4 SEM images of EDML ice. b) is taken 10 minutes (min.) later than a) and c) $25 \mathrm{~min}$. later than b). The dark feature in a) is a cavity left by a former microinclusion (i.e. an air bubble, AB). The whiter strong lines in b) are the grain boundaries (GBs) between the ice crystallites, while the fainter lines are sub-GBs which delineate the border between structural regions with a slightly different orientation (thus they appear darkened). The whiter colour of the GBs is also due to salt accumulation along them. d) and e) are enlarged images of surface features in c), and they are considered to be from air inclusions (air hydrates, AHs). Based also on the results described in Baker and Cullen (2003), can be considered that the three white threads in d) are formed by salts. The operating conditions in b) are: Mag 63x, HV 2.0kV
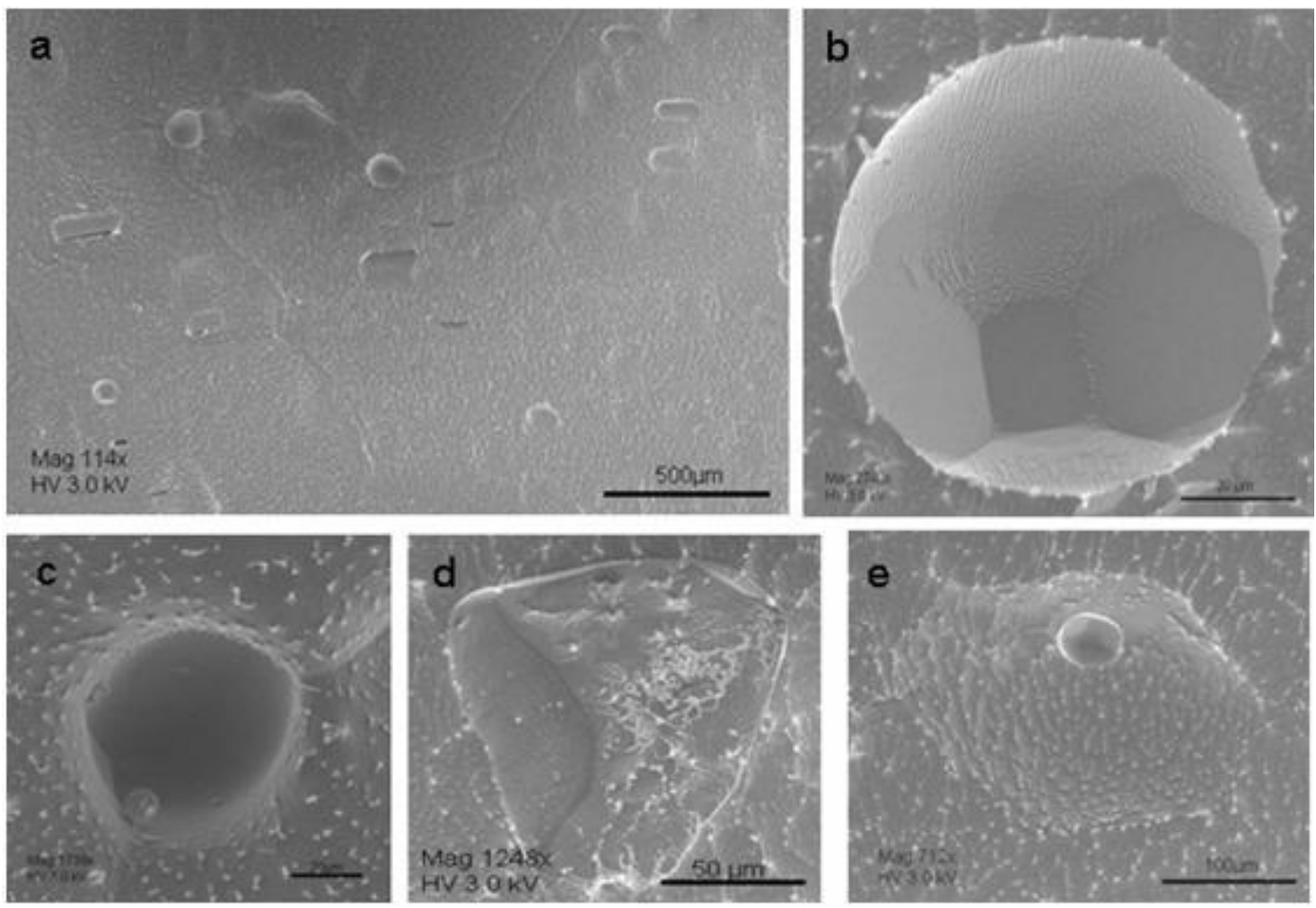
Figure 2.1.2.5 SEM images of EDML ice. c) was taken $60 \mathrm{~min}$. before a), and is an AB at a TJ. The small sphere (bottom left) is a frost feature. b) is a secondary feature (the one in the left down corner of the a) image) resembling cubic ice. The same in e) where it formed on the top of a microinclusion (resembling an $\mathrm{AH}$ ) in ice. The feature in d) resembles an AH. The imperfections on the microinclusion, seen as white spots, can be from microimpurities preserved in EDML ice. d) and e) were taken 90 min. after a). The scale in b) and c) is $20 \mu \mathrm{m}$. The operating conditions Mag and HV are: b) 2740x, 3.0kV; c) 1739x, 3.0kV; e) 712x, 3.0kV
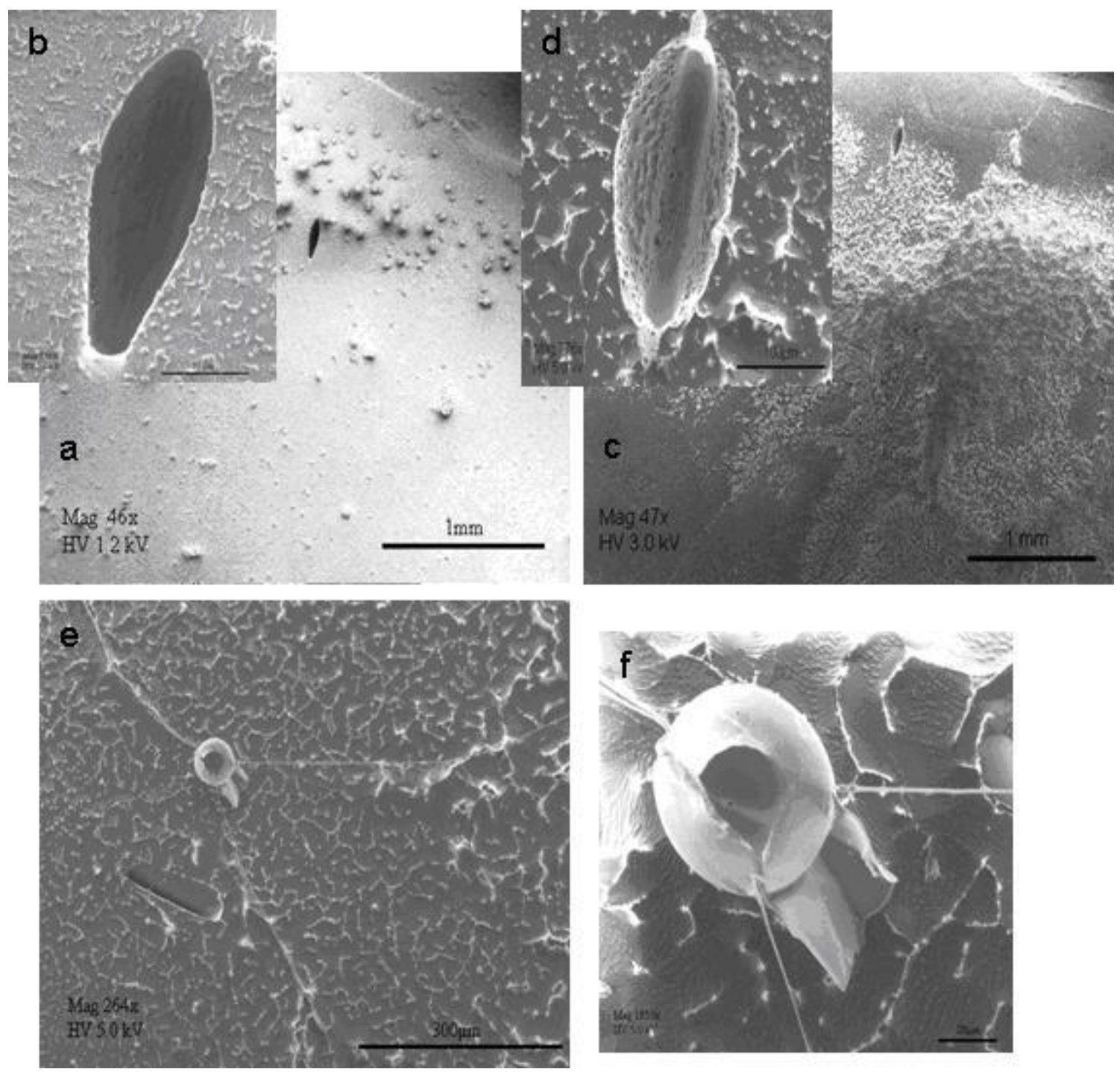

Figure 2.1.2.6 SEM images of EDML ice. The c) image was taken $30 \mathrm{~min}$. after a) and it shows an affected ice surface probably from a high salt content in the ice or an unpredicted salt contamination of the ice surface. b) and d) are surface features (cavities) produced by a relaxation microinclusion, (a plate like-inclusion); d) was taken also $30 \mathrm{~min}$. after b). f) is an enlarged image of the surface feature in e), and it is a "salt flower" (see SEM-EDX results in Fig.2.1.2.7) formed during the SEM investigations. The scale in d), b) and f) is 100,50 and $20 \mu \mathrm{m}$ respectively. The operating conditions Mag and HV are: b) 896x, 2.0kV; d) 776x, 5.0kV; f) 1853x, 5.0kV 


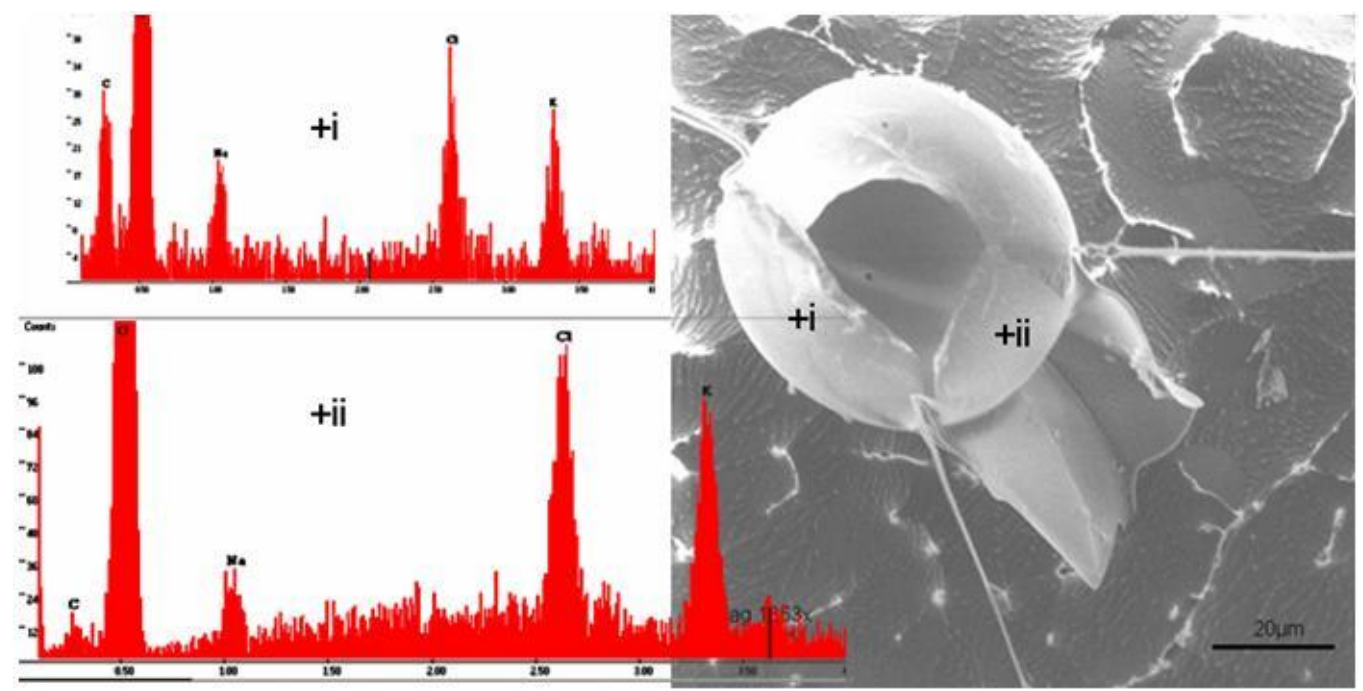

Figure 2.1.2.7 SEM-EDX results of EDML ice. The "salt flower" in Fig.2.1.2.6 f) composed of carbon, sodium, chloride and potassium. The operating conditions are: Mag 1853x and HV 5.0kV

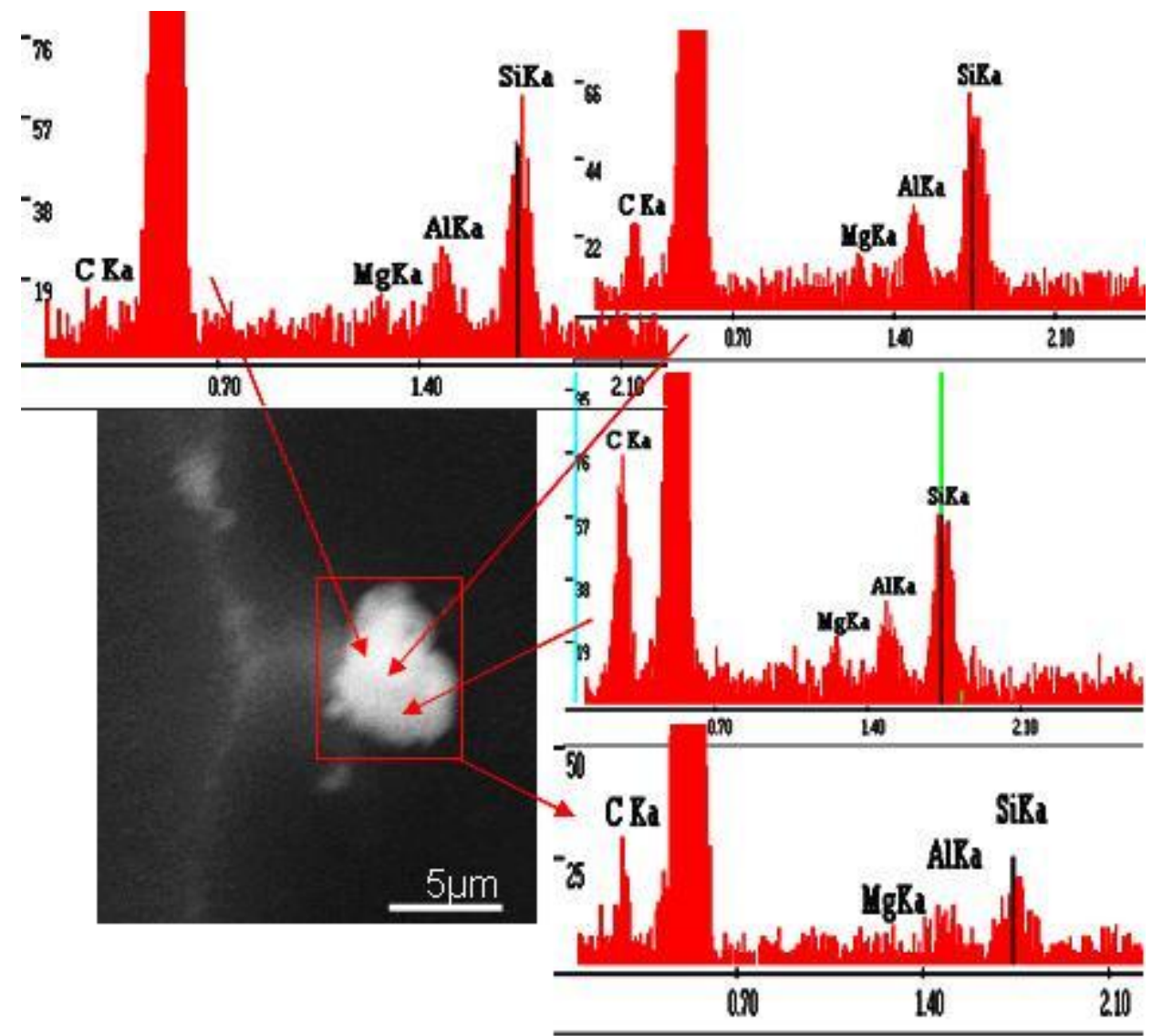

Figure 2.1.2.8 SEM-EDX results of EDML ice. Microimpurities on the ice surface composed of carbon, magnesium, aluminum and silicon. The EDX voltage was of $25 \mathrm{kV}$; the SEM Mag is $17263 \mathrm{x}$. 


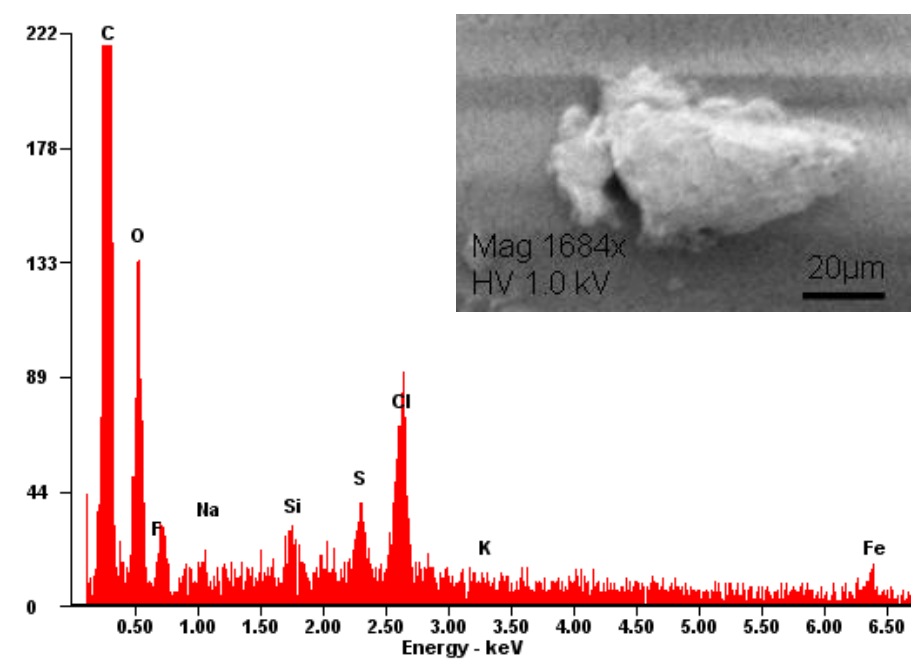

Figure 2.1.2.9 SEM-EDX results of EDML ice. Impurities left from melting an ice sample. The iron presence is to be noticed.

The machine employed, (see section 2.1), for SEM-EDX investigations was equipped also with an EBSD system and a demonstrative EBSD study on EDML ice samples (cut at the $1474 \mathrm{~m}$ depth) could be conducted. The ice samples were prepared as previously described (section 2.1 and above); the voltage was at least $20 \mathrm{kV}$ and the sample was tilted 70 to $75^{\circ}$ from the horizontal. Four of the obtained diffraction patterns are presented in Figure 2.1.2.10. A further basic understanding of the Kikuchi bands indexing was performed but the results could not be included here (e.g. because no extensive calibration of the EBSD system was done).

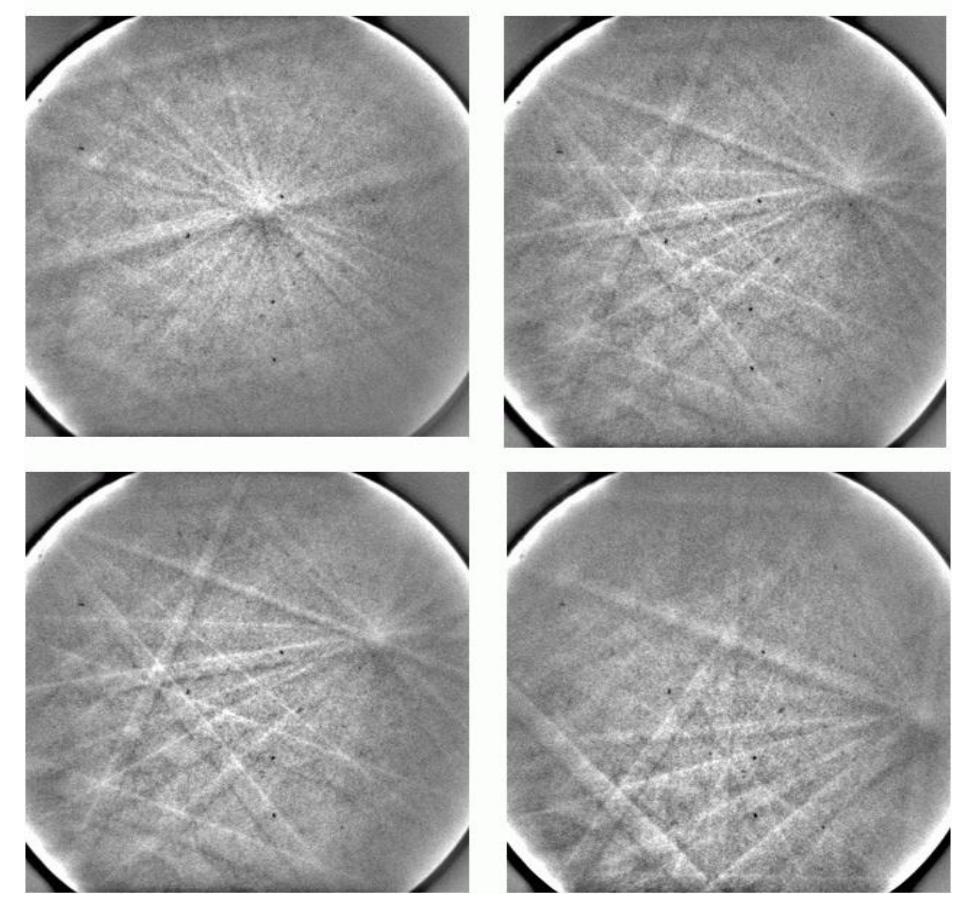

Figure 2.1.2.10 The first EBSD patterns obtained for EDML ice. 


\subsubsection{Raman spectroscopy}

"[...] in 1925, when Raman was attempting to obtain funds to purchase a spectroscope, he told his benefactor: "If I have it, I think I can get a $\mathcal{N}$ obel Prize for India." [...] But the $\mathcal{N}$ obel Committee decided the award should go to Raman alone, and the rest is history." Masters, 2009

\section{General remarks}

All optical spectroscopy techniques are based on the interaction of the electromagnetic radiation with a substance (emission, absorption, scattering). Usually the radiation is characterized by its wavelength, $\lambda$, or wavenumber, $1 / \lambda$, or its energy, $E=(\mathrm{hc} / \lambda)^{33}$, the last being of interest when the atomic structures of a substance are considered, since they can exist only in certain energetic states. For example, the energy of the electromagnetic radiation can take values between $10^{-14}$ and $10^{18} \mathrm{eV}$ (or from radio waves to cosmic radiation), a wide enough spectrum for covering the characteristic energies of the following types of atomic or molecular (energetic) levels: electronic, rotation, vibration, fine structure, hyperfine structure or magnetic structure. In the case of Raman spectroscopy, the vibrational levels of a substance are excited and the energy changes required to cause nuclear motion are detected; and usually only one in every $10^{6}-10^{8}$ photons which scatter can be Raman scattered. The phenomenon of inelastic scattering of light, was first postulated by Smekal in 1923 and first observed in 1928 by Raman and Krishnan, since then referred as Raman spectroscopy (Ewen and Goeffrey, 2005; Masters, 2009).

There are two types of scattering: Stokes and anti-Stokes, the latter one just occasionally preferred involves the transfer of the energy resulted when a molecule is returning to the ground state from an excited state to a scattered photon. Stokes scattering is the most usual type recorded by Raman spectrometers and involves the transfer of the amount of energy necessary for the promotion of a molecule from its ground vibrational state to a higher energy excited vibrational state. The transfer of the energy is intermediated by some virtual states, whose energy is function of the wavelength of the radiation. The difference in energy between the excited and the ground state is measured by subtracting the energy of the scattered photon from that of the incident beam. This is why in general the Raman scattering is given as a shift in energy from the energy of the incident laser beam (Ewen and Goeffrey, 2005).

In practice Raman spectrometry is simple since it requests just a few instrumental parameters for the set up, a minimal spectral manipulation and the data are easy to interpret. It is mainly employed for qualitative studies but also (semi-)quantitative ones can be performed on solid, liquid or gaseous samples almost with no special preparation. The main disadvantages come from sample degradation and fluorescence phenomena.

\section{General experimental settings}

For this work an integrated Horiba Jobin Yvon HR 800 UV Raman system was employed in order to investigate the chemical fingerprint of the substances trapped in the EDML ice. The Micro-Raman $800 \mathrm{~mm}$ focal length spectrograph, equipped with two switchable kinematics gratings, is coupled with an integrated high performance Olympus BX41 microscope with a confocal geometry which allows a high accuracy for laser beam focus. The light wavelength used for sample excitation, $\lambda$, was $488 \mathrm{~nm}$, produced by an air-cooled $\mathrm{Ar}^{+}$external laser. The laser is totally reflected towards the sample under the microscope and the Raman scattering is totally transmitted towards the confocal hole and entrance slit of the spectrograph. The image of the hole, on the entrance slit is adapted by shrinking 5 times. The hole is limiting the area (volume)

\footnotetext{
${ }^{33} \mathrm{~h}=$ Planck constant $\left(=6.626 \times 10^{-34} \mathrm{Js}\right) ; \mathrm{c}=$ speed of light $\left(=3 \times 10^{8} \mathrm{~m} / \mathrm{s}\right)$
} 
of the (transparent) sample from which the Raman signal is collected. The confocal hole is squared and the readout given by the software is the diagonal of the square (in $\mu \mathrm{m}$ ). A small confocal hole means a decrease in the intensity of the Raman signal. The magnification between the sample and the confocal hole depends on the microscope objective magnification, multiplied by a factor of 1.4 (the factor 1.4 arises because the tube length for Olympus objectives is $180 \mathrm{~mm}$ while the lens that form the image has a focal length slightly higher; of $250 \mathrm{~mm}$ ).

For the present Raman investigations satisfying results were obtained using a $\times 50$ long working distance Olympus objective with numerical aperture, $\mathrm{NA}=0.50$. The maximum diameter of the illuminated spot in the investigated sample is limited by diffraction phenomena and can be calculated using the laser light excitation wavelength, $\lambda$, and the numerical aperture, NA, of the microscope objective: $(\lambda / \mathrm{NA}) \times 1.22$. It results that for transparent ice samples the volume from which the Raman signal was collected resembles a (trapezoidal) cone with the basal diameter not larger than $1.19 \mu \mathrm{m}$. So the minimum opening of the confocal hole should be $42 \mu \mathrm{m}$. This study used a confocal hole of 100 or $200 \mu \mathrm{m}$. The spectrograph forms a spectrum on the CCD detector. The HR800 spectrometer has an asymmetric Czerny Turner monochromator. The diverging beam coming from the entrance slit is transformed into a parallel one, and reflected onto the diffracting grating, by a spherical mirror with a focal length of $800 \mathrm{~mm}$. The diffracted first order is collected by another spherical mirror (also $800 \mathrm{~mm}$ focal length) and focused on the CCD detector. For this study a grating of 600 grooves $/ \mathrm{mm}$ and a standard Peltier-cooled CCD detector (Andor, 1024 x 256 pixels) were used. The resulted spectral resolution is approximately $2.2 \mathrm{~cm}^{-1}$. The exposure time was most of the times 30 or $60 \mathrm{~s}$. The laser power was not higher than $25 \mathrm{~mW}$. No significant damage of the ice specimen was observed due to the laser light. The maximum spectral range of the acquired spectra stretched between 200 and $4000 \mathrm{~cm}^{-1}$. Spectral positions were calibrated against the Raman mode of $\mathrm{Si}$ (which has a characteristic peak at $520.4 \mathrm{~cm}^{-1}$ ) at the beginning and at the end of the measurements. Labspec 5 software was used for Raman spectra acquisition, and ORIGIN 6 software for further data analysis.

\section{Calibration measurements}

Because the Raman results were used also for (semi)quantitative analyses a calibration of the Raman machine had to be performed. Raman spectra for the atmospheric air (the air in the Raman laboratory) were measured ${ }^{34}$ for various conditions, (microscope objectives of different magnifications, different exposure times and different confocal hole dimensions), and the results were compared with the standard accepted value for the atmospheric air $\mathrm{N}_{2} / \mathrm{O}_{2}$ (nitrogen to oxygen) ratio of 3.7. The results are gathered in Tables 2.1.3.1 to 3. The corresponding area of the peaks for oxygen and nitrogen in the Raman spectra was obtained by Gaussian fitting. Numerical integration was also addressed, comparatively, but sporadically and the difference between the final values is not more than 0.3 units (results not shown).

The experimental settings used for analyzing the secondary microinclusions in EDML ice used an exposure time not longer than 120 seconds and a 50x objective. The quantitative results obtained from the Raman measurements of atmospheric air with the same settings (Table 2.1.3.2) are less satisfactory than the ones in which a longer exposure time was employed (Table 2.1.3.1 and Bendel 2009). Nevertheless, values over 2 for the $\mathrm{N}_{2} / \mathrm{O}_{2}$ ratio of the atmospheric air have been reported as being used for similar studies (Ohno and Hondoh, 2000).

Here, a value of 3 can be considered as an overall average of the atmospheric air $\mathrm{N}_{2} / \mathrm{O}_{2}$ ratios obtained from the recorded spectra. This would imply that the values for the $\mathrm{N}_{2} / \mathrm{O}_{2}$ ratios calculated for the microinclusions analyzed in this study should be multiplied by $1.23(3.7 / 3)$.

\footnotetext{
${ }^{34}$ some of the measurements were done together with V. Bendel
} 
Table 2.1.3.1 Mean values obtained for the $\mathrm{N}_{2} / \mathrm{O}_{2}$ ratio of the air in the Raman laboratory. Each row of data represents a day of

( 2 to 8 sucesive or not) measurements. (obj.=the microscope objective; $\mathrm{s}=$ seconds; $\mathrm{sd}=$ standard deviation of the mean; max.=maximum)

\begin{tabular}{|l|c|c|c|}
\hline \multicolumn{1}{|c|}{ time-obj. } & mean $\mathrm{N}_{2} / \mathrm{O}_{2}$ & $\mathrm{sd}$ & $\max . \mathrm{N}_{2} / \mathrm{O}_{2}$ \\
\hline $900 \mathrm{~s}-10 \mathrm{x}$ & 3.33 & 0.28 & 3.74 \\
\hline $450 \mathrm{~s}-50 \mathrm{x}$ & 3.32 & 0.25 & 3.75 \\
\hline $800 \mathrm{~s}-100 \mathrm{x}$ & 3.24 & 0.09 & 3.45 \\
\hline $\begin{array}{l}240 \mathrm{~s}- \\
100 \mathrm{x} / 50 \mathrm{x} / 10 \mathrm{x}\end{array}$ & 2.79 & 0.016 & 2.81 \\
\hline $120 \mathrm{~s}-50 \mathrm{x}$ & & & \\
\hline $240 \mathrm{~s} / 120 \mathrm{~s}-50 \mathrm{x}$ & 2.82 & 0.44 & 3.68 \\
\hline overall mean & 3.045 & 0.22 & 2.92 \\
\hline
\end{tabular}

Table 2.1.3.2 Mean values obtained for the $\mathrm{N}_{2} / \mathrm{O}_{2}$ ratio of the air in the Raman laboratory for different conditions

(successive measurements performed in different days). ( $\mathrm{s}=$ seconds)

\begin{tabular}{|l|l|l|l|l|}
\hline \multirow{3}{*}{ time objective } & $100 \mathrm{x}$ & $50 \mathrm{x}$ & $10 \mathrm{x}$ & $5 \mathrm{x}$ \\
\cline { 2 - 5 } & $\mathrm{N}_{2} / \mathrm{O}_{2}$ & $\mathrm{~N}_{2} / \mathrm{O}_{2}$ & $\mathrm{~N}_{2} / \mathrm{O}_{2}$ & $\mathrm{~N}_{2} / \mathrm{O}_{2}$ \\
\hline $5 \mathrm{~s}$ & 1.20 & 2.7 & - & - \\
\hline $10 \mathrm{~s}$ & 2.6 & 2.47 & - & 0.84 \\
\hline $20 \mathrm{~s}$ & 5.4 & 2.2 & - & - \\
\hline $30 \mathrm{~s}$ & 3.10 & 2.87 & 3.35 & 1.03 \\
\hline $60 \mathrm{~s}$ & 2.37 & 2.91 & 2.47 & 2.02 \\
\hline $90 \mathrm{~s}$ & 3.07 & 2.87 & 2.65 & 2.4 \\
\hline $120 \mathrm{~s}$ & 2.5 & 2.65 & - & 2.46 \\
\hline
\end{tabular}

Table 2.1.3.3 Mean values obtained for the $\mathrm{N}_{2} / \mathrm{O}_{2}$ ratio of the air in the Raman laboratory for different conditions (one day of measuring).

(sp.=spectrum; $\mathrm{s}=$ seconds; $\mu \mathrm{m}=$ micrometers - the diemnsion of the confocal hole )

\begin{tabular}{|l|l|l|l|l|l|}
\hline & sp. index & $\mathrm{N}_{2} / \mathrm{O}_{2}$ & & sp. index & $\mathrm{N}_{2} / \mathrm{O}_{2}$ \\
\hline $100 \mu \mathrm{m}$ & & & $100 \mu \mathrm{m}$ & & \\
\hline $100 \mathrm{x}-300 \mathrm{~s}$ & $\mathrm{a} 1$ & 4.15 & $10 \mathrm{x}-120 \mathrm{~s}$ & $\mathrm{a} 16$ & 4.35 \\
\hline & $\mathrm{a} 1$ & 3.54 & & $\mathrm{a} 16$ & 3.84 \\
\hline $10 \mathrm{x}-300 \mathrm{~s}$ & $\mathrm{a} 2$ & 4.24 & $10 \mathrm{x}-90 \mathrm{~s}$ & $\mathrm{a} 17$ & 2.21 \\
\hline $50 \mathrm{x}-300 \mathrm{~s}$ & $\mathrm{a} 3$ & 3.36 & & $\mathrm{a} 17$ & 3.21 \\
\hline $100 \mathrm{x}-120 \mathrm{~s}$ & $\mathrm{a} 4$ & 2.78 & & $\mathrm{a} 17$ & 3.97 \\
\hline & $\mathrm{a} 4$ & 8.98 & $10 \mathrm{x}-60 \mathrm{~s}$ & $\mathrm{a} 18$ & 3.22 \\
\hline $100 \mathrm{x}-90 \mathrm{~s}$ & $\mathrm{a} 5$ & 3.65 & & $\mathrm{a} 18$ & 3.86 \\
\hline $100 \mathrm{x}-60 \mathrm{~s}$ & $\mathrm{a} 6$ & 5.14 & $10 \mathrm{x}-30 \mathrm{~s}$ & $\mathrm{a} 19$ & 4.44 \\
\hline $100 \mathrm{x}-30 \mathrm{~s}$ & $\mathrm{a} 7$ & 3.64 & & $\mathrm{a} 19$ & 3.2 \\
\hline $100 \mathrm{x}-10 \mathrm{~s}$ & $\mathrm{a} 8$ & 4.72 & $10 \mathrm{x}-10 \mathrm{~s}$ & $\mathrm{a} 20$ & 1.36 \\
\hline $50 \mathrm{x}-120 \mathrm{~s}$ & $\mathrm{a} 9$ & 2.95 & $200 \mu \mathrm{m}$ & & \\
\hline $50 \mathrm{x}-90 \mathrm{~s}$ & $\mathrm{a} 10$ & 3.74 & $50 \mathrm{x}-120 \mathrm{~s}$ & $\mathrm{a} 21$ & 2.9 \\
\hline $50 \mathrm{x}-60 \mathrm{~s}$ & $\mathrm{a} 11$ & 3.61 & & a21 & 3.27 \\
\hline $50 \mathrm{x}-30 \mathrm{~s}$ & $\mathrm{a} 12$ & 3.62 & & a21 & 4.53 \\
\hline $50 \mathrm{x}-10 \mathrm{~s}$ & $\mathrm{a} 13$ & 0.17 & & a21 & 3.21 \\
\hline $300 \mu \mathrm{m}$ & & & & a21 & 3.77 \\
\hline $50 \mathrm{x}-120 \mathrm{~s}$ & $\mathrm{a} 15$ & 3.68 & & a21 & 3.29 \\
\hline
\end{tabular}


Though, the numerical values presented in this thesis are not corrected for this difference. The preference for not modifying these final $\mathrm{N}_{2} / \mathrm{O}_{2}$ ratios is (partially) justified by the fact that the experimental settings would not be totally equivalent. On the other hand there is a question about the degree of reliability of the results from the calibration measurements. More explicitly, in Bendel (2009) calibration results are presented (with values over 3 for the $\mathrm{N}_{2} / \mathrm{O}_{2}$ ratio for the atmospheric air with the same Raman machine), and in Table 2.1.3.3 also values closer to the accepted $\mathrm{N}_{2} / \mathrm{O}_{2}$ ratio of the atmospheric air are shown, meaning that the real factor which should be used for correction or which have to be adjusted is to be established. Some of the numbers in Table 2.1.3.3 corresponding to low measurement times are much better (closer to the reference 3.7 value), than the ones in Table 2.1.3.2.

Moreover, if a detailed analysis of the raw Raman data is made, (different number of points which are selected to define a peak, different method for peak area calculation, or even different software employed for calculations), values close to the standard $\mathrm{N}_{2} / \mathrm{O}_{2}$ ratio of 3.7 can be obtained (for example the case of the spectrum 'a21', Table 2.1.3.3, for which after several modifications of the $\mathrm{O}_{2}$ or/and $\mathrm{N}_{2}$ peaks shape a 3.7 ratio was obtained). Due to the time constrains it was impossible to have a more extended calibration analysis than the one described here (or in Bendel 2009 where the $\mathrm{N}_{2} / \mathrm{O}_{2}$ ratios obtained by numerical integration and a Gaussian fit (which agree within their limit of error) have some variability with time but a good reproducibility for the 50x objective and a confocal hole of $200 \mu \mathrm{m}$. A correction factor of 3.73 / 3.24 was proposed to be used for the values obtained by numerical integration.)

\section{The inherent measurement error}

The results for the $\mathrm{N}_{2} / \mathrm{O}_{2}$ ratio of three different air inclusions existent in EDML ice obtained from successive and equivalent Raman measurements are depicted in Table 2.1.3.4. The standard deviation of the mean, (sd), is good for the air hydrate case but resulted to have the lowest value for the plate-like inclusion, (PLI), case. It would be hazardous to consider that for all analyzed PLIs the reproducibility is as good as the example selected here and this is reflected by the data in Appendix 2.2.1.G (detailed results from the $\mathrm{N}_{2} / \mathrm{O}_{2}$ ratio calculation for all PLIs).

Table 2.1.3.4 Values for the $\mathrm{N}_{2} / \mathrm{O}_{2}$ ratio for three different air inclusions in EDML ice. (PLI=plate-like inclusion)

\begin{tabular}{|c|c|c|c|}
\hline No. & Air bubble & Air hydrate & PLI \\
\hline & $\mathrm{N}_{2} / \mathrm{O}_{2}$ & $\mathrm{~N}_{2} / \mathrm{O}_{2}$ & $\mathrm{~N}_{2} / \mathrm{O}_{2}$ \\
\hline 1 & 2.00 & 3.55 & 0.4 \\
\hline 2 & 2.5 & 3.5 & 0.47 \\
\hline 3 & 2.32 & 3.4 & 0.51 \\
\hline 4 & 2.04 & 3.6 & 0.44 \\
\hline 5 & 2.6 & 3.2 & 0.46 \\
\hline 6 & 2.31 & 3.76 & 0.52 \\
\hline 7 & 1.43 & 3.5 & 0.46 \\
\hline 8 & 2.5 & - & 0.4 \\
\hline 9 & 1.87 & - & 0.46 \\
\hline mean & 2.17 & 3.51 & 0.46 \\
\hline sd & 0.37 & 0.17 & 0.04 \\
\hline
\end{tabular}




\section{Other considerations on error causing factors}

Even though the measurement aspects of and the interpretation of the data from (micro)Raman analyses of inclusions trapped in a material or in ice are already presented in the literature (Rosasco and Roeder, 1979; Wopenka and Pasteris, 1986; Pasteris et al. 1988; Sakurai et al. 2010a) each study has its own particularities resulting in a specific degree of confidence.

For investigations related with plate-like inclusions (PLIs), errors may arise from: a bad (not perfectly clear) ice sample surface, a too thick ice matrix above the investigated microinclusion, an improper orientation of the investigated PLI, interferences with the atmospheric air constituents existent around the ice sample, or the sensitivity of the detector. All these disadvantages were tried to be minimized prior and after the registration of a Raman signal from a given relaxation microinclusion, by a careful ice sample preparation and handling, additional repeated recordings of ice Raman signal and atmospheric air Raman spectra. The Raman spectrum for the ice matrix showed that is preferable to work with confocal holes not larger than $200 \mu \mathrm{m}$ and for exposure times not longer than 60s because otherwise interferences with the atmospheric air around the ice sample would become significant and a background correction would have been needed. Since the exact extent of this kind of artifact is not easy to be established (as it is not constant) it was chosen to work in conditions in which it would be minimal. For confocal holes of $100 \mu \mathrm{m}$ or $200 \mu \mathrm{m}$ and irradiation times of $30 \mathrm{~s}$ or $60 \mathrm{~s}$ the signal due to the atmospheric air surrounding the ice sample is manifested (mainly) in the $\mathrm{N}_{2}$ stretching modes region of the Raman spectrum as a small (and broad) peak not higher than 50 counts in intensity. Its presence can broaden the peak due to the $\mathrm{N}_{2}$ existent in a secondary inclusion embedded in ice.

For a good Raman signal the investigated PLI should be as thick as possible and if the case oriented in such a way that its smallest dimension (the height or the dimension along the $\mathrm{c}$ axis of the ice crystallite in which the PLI is embedded) is as close as perpendicularity with the incident light traveling in an optical microscope used for observing the PLI.

For microinclusions that do not contain air, the most important factors which induced measurement errors were caused by the low available resolution for identifying them. A video camera could not be used so the selection of a certain microinclusion was done via the microscope' oculars. It was not hard to distinguish impurities in (EDML) ice as long as they were not transparent (thus not appearing exactly as the ice matrix). For example it would be difficult to locate air hydrates $(\mathrm{AH})$ but even the smallest air bubbles (AB) or plate-like inclusions (PLI) could be differentiated. The smallest particles that could be identified inside the ice matrix were $2 \mu \mathrm{m}$ in diameter, but microinclusions bigger than $10 \mu \mathrm{m}$ were not measured. Usually in the laser focus were placed only not so transparent spots (this can be observed for micro-inclusions of 4,5 or more $\mu \mathrm{m}$ ) or on (truly) black spots (some gray spots are less transparent inclusions smaller than 5 micra). It was interesting to observe that the whitest (/milkiest) micro-inclusion gave a Raman spectrum as for gypsum and the black ones were silicates.

Another two important sources of errors are the misplacement (or instability) of the laser beam focus and the fluorescence phenomena. There were also cases when the microinclusion was (physically) affected by the energy of the laser beam, or they provided no distinctive Raman signal. Values for a measurement yield (the percent of the Raman spectra with other (new) peaks than the ones of the ice matrix from the number of all recorded Raman spectra for microinclusions trapped in the ice matrix) are between $20 \%$ and $70 \%$. 


\title{
2.2 Original Results
}

"There is a Sufi tale of the holy fool Nasruddin, who lost a key in the middle of the street one night and promptly went to look for it under the nearest lamppost, for at least there he could see."

M. Bowen, 'Thin Ice', 2005, pg.304

\subsubsection{Oxygen enriched relaxation features in EDML ice}

\author{
Como vai você? \\ Eu preciso saber da sua vida \\ Peça a alguém pra me contar sobre o seu dia... ${ }^{35}$
}

\section{General information}

As the EDML ice microstructure was (re)inspected several years after the drilling of the core evident changes could be documented, in the form of secondary microinclusions: regular hexagonal microinclusions, considered characteristic relaxation features, currently named platelike inclusions, PLIs, and secondary (micro)bubbles, MBs. Other relaxation features, as described by Gow (1971) were also observed but they were not investigated further.

The selected ice samples were stored at $\mathrm{AWI}^{36}$, Bremerhaven, at $-30^{\circ} \mathrm{C}$ since short after drilling of the ice core and at $\mathrm{GZG}^{37}$, Göttingen, at $-80^{\circ} \mathrm{C}$ since autumn 2008 . Sample preparation and optical microscopy investigations were performed in a cold room laboratory at $-20^{\circ} \mathrm{C}$ for a first group of samples and at $-10^{\circ} \mathrm{C}$ for a second set. The starting investigations were mainly qualitative and the results were published as a short correspondence in Journal of Glaciology (Nedelcu et al. 2009). These results are presented in this thesis but they are considered separately, as resulting from a first set of investigated ice samples. General information about the second set of investigated ice samples are presented in Table 2.2.1.1.

Characteristic pictures for the selected EDML ice samples, taken using optical microscopy, are presented in Figure 2.2.1.1. and Appendix 2.2.1.A. It is obvious that the ice structure is no longer as clear as the one characteristic for fresh-drilled ice (Fig. 2.2.1.1. and Appendix 2.2.1.B or Kipfstuhl, 2007; Kipfstuhl et al. 2006; Faria et al. 2009, 2010).

The information that can be extracted from the type of data presented in Appendix 2.2.1.A, regards the number density of the PLIs, their shape and their location. Also their morphology was described in section 2.1.1.

The PLIs number density was just approximated by comparing the images for the ice samples from different depths and it is higher for dirty ice, (cold period ice), and moderate for clear ice, (warm period ice).

General facts, related with the relaxation after drilling, as the case for other Antarctic and Arctic ice cores (Gow, 1971) were also observed for the EDML ice. In the ice from the upper part of the core (until $\sim 2300 \mathrm{~m}$ ) the relaxation features do not resemble the ones observed in the older ice.

\footnotetext{
${ }^{35}$ From a song usually correlated with Roberto Carlos. In English: How are you? / I need to know about your life / Ask someone to tell me about your day ... (via internet)

${ }^{36}$ Alfred Wegener Institute for Polar and Marine Research

${ }^{37}$ Geowissenschaftliches Zentrum der Universität Göttingen or Geoscience Center of University of Göttingen
} 


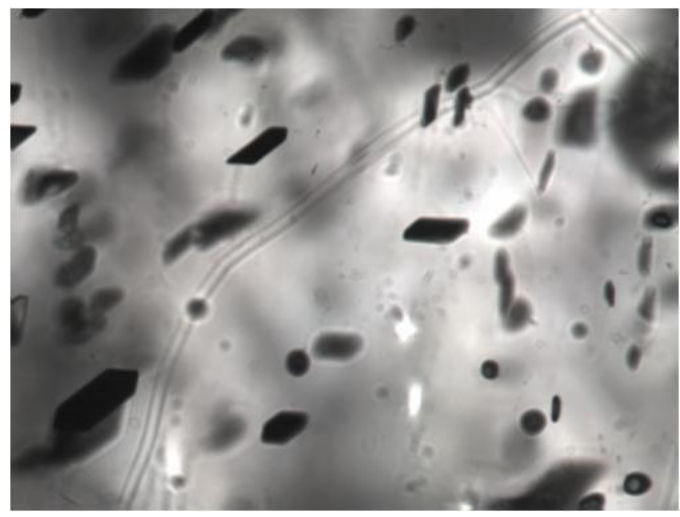

a

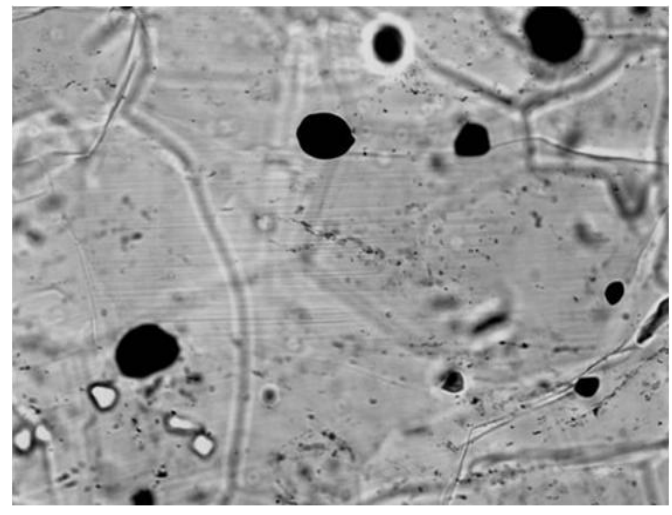

b

Figure 2.2.1.1 Optical microscopy pictures of a) relaxed and b) fresh-drilled ${ }^{38}$ EDML ice from 953.9 $\mathrm{m}$ depth (image width: a) $1.3 \mathrm{~mm}$ b) $2.5 \mathrm{~mm}$ ).

Table 2.2.1.1 General information about the investigated EDML ice samples

\begin{tabular}{|c|c|c|c|c|c|c|}
\hline $\begin{array}{c}\text { EDML } \\
\text { depth }^{1} \\
(\mathrm{~m})\end{array}$ & $\begin{array}{c}\text { EDML } \\
\text { Age }^{2} \\
(\text { yr BP) }\end{array}$ & $\begin{array}{l}\text { Marine } \\
\text { Isotope } \\
\text { Stage }^{2}\end{array}$ & $\begin{array}{c}\text { Ice sheet } \\
\text { temperature }^{3} \\
\left(\mathrm{~K} /{ }^{\circ} \mathrm{C}\right)\end{array}$ & $\begin{array}{c}\text { Ice sheet } \\
\text { pressure }^{3} \\
\text { (MPa) }\end{array}$ & $\begin{array}{c}\text { Fracture } \\
\text { stress }^{3} \\
\text { (MPa) }\end{array}$ & $\begin{array}{c}\delta^{18} \mathrm{O} \\
\text { measured }^{2} \\
{ }_{00}\end{array}$ \\
\hline 953.9 & 19900 & MIS2/LGM & $235 /-38$ & 9 & 0.53 & -50.68 \\
\hline 983.8 & 21400 & LGM & $235 /-38$ & 9 & 0.42 & -51.11 \\
\hline 1105.9 & 26600 & LGM & $236 /-37$ & 10 & 0.54 & -52.84 \\
\hline 1745.2 & 63900 & MIS4 & $246 /-27$ & 15.8 & 0.59 & -49.54 \\
\hline 2295.8 & 117600 & MIS5 & $258 /-15$ & 20.7 & 0.6 & -45.87 \\
\hline 2345.9 & 125000 & MIS5 & $260 /-13$ & 21.3 & 0.7 & -44.13 \\
\hline 2405.8 & 146300 & MIS6 & $261 /-12$ & 21.6 & 0.59 & -51.13 \\
\hline
\end{tabular}

$\mathrm{m}=$ meters; yr BP = years before (present $/$ ) $1950 ; \mathrm{K} /{ }^{\circ} \mathrm{C}=$ Kelvin / degrees Celsius; $\mathrm{MPa}=$ mega Pascal; $\%$ = per mille. ${ }^{1}$ The last number, indicating the $\mathrm{cm}$ level of an $1 \mathrm{~m}$ ice core, is informative. ${ }^{2}$ Data from (EPICA Comm.Memb.2006). ${ }^{3}$ Values from (Wilhelms et al. 2007).

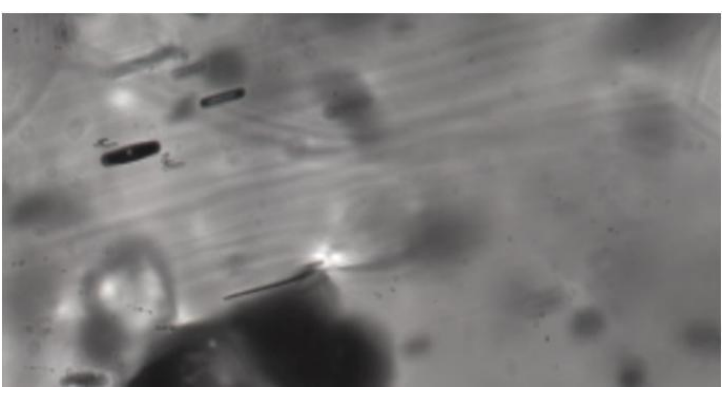

a

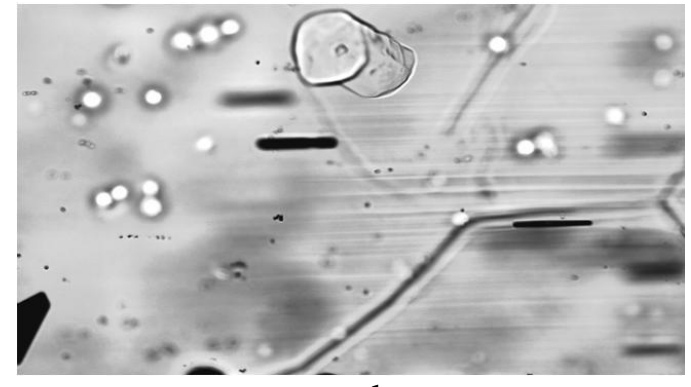

$\mathrm{b}$

Figure 2.2.1.2 Optical microscopy images of plate like inclusions

developed along slip bands; from a) $1105.9 \mathrm{~m} \mathrm{~b}) 1134 \mathrm{~m}$ (image width $1.3 \mathrm{~mm}$ ). Other features observable in b are: air hydrate: top, grain boundaries: bottom right and the white spots which most probably are due to surface imperfections.

\footnotetext{
${ }^{38}$ the image is from www.pangaea.de, CKipfstuhl, (Kipfstuhl, 2007)
} 
It was observed that plate like inclusions are strongly related with parts in the ice crystallites where slip bands exist (Figure 2.2.1.2, Appendixes 2.2.1.A and Fig. 2.1.1.3, Fig. 2.1.1.4). The characteristic foliated outline of the slip bands is easily observable until $2000 \mathrm{~m}$ and a bit indistinguishable until $2400 \mathrm{~m}$ where practically it is hard to be identified. What is indeed remarkable is that they are still preserved, and only a minimal degree of relaxation seems to have affected them, manifested by generally thin long (secondary) inclusions aligned along and between their packed straight layers (Appendix 2.2.1.A: IVa). Thicker and shorter relaxation inclusions are also observable between slip bands (Appendix 2.2.1.A: IVb, VIa, VIc), but probably they can be thought as having been formed by another mechanism than the one generating the thinner ones.

The role of impurities embedded in the ice should be considered and their role as nucleating centers (Mae, 1968; Gold, 1972; 2003a; 2003b) in the formation of secondary features in ice seems to be of prime importance. Moreover processes related with defects of a vacancy type are also related with temperature gradients. Thermal activation is not impossible to be supplied as the ice structure starts to relax. Not only from the external environmental conditions but also locally inside the drilled ice matrix the combination of gradual release of the confining pressure exercised by the ice sheet, the minute microstructure organization and the specific composition of the ice can offer the necessary energy for the formation of secondary microinclusions by vacancy diffusion and their consequent segregation.

Any local microstructural event that involves a rearrangement of the lattice should involve a (micro)change in the local temperature. For example the chemical impurities trapped in ice can act as (pre)melting centers (Wettlaufer, 1999; Rempel et al. 2001); the reorganization of the grain boundaries net prior but also after an ice core recovery, in the form of simple sliding or more complex extension take place on free energy expense which as a rule cannot be lost but is transformed among other forms also the thermal type being involved; for example the continuous motion of dislocations towards their absorption in subgrain boundaries (the consumption of dislocations) or their annihilation corresponds to a loss of entropy of the (micro)system in which they exist and this is inevitably expressed as a release of latent heat (Faria et al. 2006b).

As a very general rule one can observe that PLIs prefer to be more concentrated towards the center of an ice grain, leaving a small but well defined region along the grain boundaries with clear ice (ice with less or no relaxation features).

Usually the investigated microinclusions were taken pictures using the video camera attached to the microscope coupled with the Raman spectrometer and the dimensions of a specific inclusion were more or less approximated from these images. The specific description for the PLIs investigated in this study, (shape, outline, dimensions, colour, orientation), is summarized in Appendix 2.2.1.C. The aspect ratio $(\mathrm{n}=\mathrm{L} / \mathrm{l}$, as the ratio between the largest (L), and the smallest dimension (1), of a PLI) is plotted in Figure 2.2.1.3. In general, the smallest dimension is considered to be along the $c$ crystallographic axis of the ice crystallite and the long direction extends in the basal planes.

Values for the aspect ratio less than 25 are a characteristic of the relaxation microinclusions developed in ice samples from depths until $2300 \mathrm{~m}$. For deeper ice the aspect ratio of the relaxation features is considerable lower (it was difficult to identify and measure accurately a small and a long dimension). Higher values than 25 for the aspect ratio are sporadically present but for EDML ice samples selected from depths above $2300 \mathrm{~m}$. PLIs with an aspect ratio higher than 100 were not so common. 


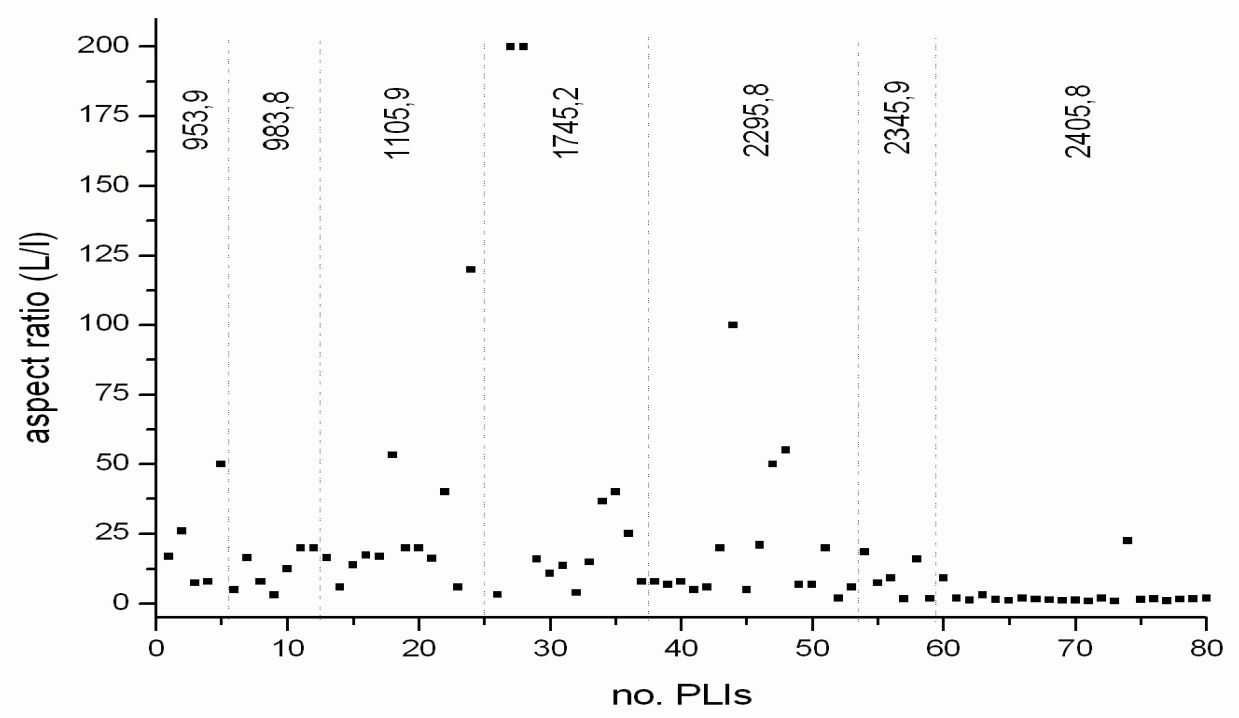

Figure 2.2.1.3 The ratio between the largest (L) and the smallest (1) dimension of an investigated PLI

\section{Qualitative information}

The Raman spectra (as individual graphs of Raman intensity (in counts) function of Raman shift (in $\mathrm{cm}^{-1}$ ) for the relaxation microinclusions discussed in this study are plotted in Appendix 2.2.1.D. An example of such Raman spectra can be seen (also) in Figure 2.2.1.4. For the first set of investigated ice samples the Raman graphs are presented in Appendix 2.2.1.E.

The main Raman signal for air bubbles, ABs, and air clathrate hydrates, AHs, existent in polar ice is due to oxygen, $\mathrm{O}_{2}$, and nitrogen, $\mathrm{N}_{2}$ (Nakahara et al. 1988; Pauer et al. 1997). When it comes to relaxation features in polar ice, plate-like inclusions, PLIs, one expects them to be empty cavities or filled with small amounts of water vapor or with $\mathrm{O}_{2}$ or $\mathrm{N}_{2}$ (Gow 1971), diffused from the ice matrix or from nearby air bubbles or hydrates. The obtained Raman signal for PLIs demonstrates that indeed $\mathrm{O}_{2}$ and $\mathrm{N}_{2}$ can be found inside PLIs volume (Nedelcu et al. 2009). The two new peaks which are present in the PLIs spectra around 1557 and $2331 \mathrm{~cm}^{-1}$ can be assigned to the characteristic stretching modes of oxygen and nitrogen since they are very close to the characteristic wavenumbers of $\mathrm{O}_{2}$ and $\mathrm{N}_{2}$ as free gases (1560 and $2335 \mathrm{~cm}^{-1}$ respectively (Champagnon et al. 1997) or 1556 and $2331 \mathrm{~cm}^{-1}$ respectively cited in Chazallon et al. (1998)).

The appearance of these peaks in the recorded Raman spectra of PLIs can not be a simple artifact, neither due to the existing $\mathrm{O}_{2}$ and $\mathrm{N}_{2}$ in the air of the laboratory (and in the Linkam chamber) nor from any contamination due to the technical equipment. One cannot exclude completely a falsification of the signal in the $\mathrm{O}_{2}$ and especially $\mathrm{N}_{2}$ characteristic vibrations region but this can not bias the resulted peak intensity more than would be considered acceptable for qualitative studies. However, the considerable number of Raman spectra recorded for the ice matrix (where no inclusion was visible) in which no significant peak exists at or around the wavenumbers characteristic for $\mathrm{O}_{2}$ or $\mathrm{N}_{2}$ assures that the Raman spectra obtained for PLIs are reliable and reflect their chemical image, at least from a qualitative point of view. Only if the Raman signal is recorded for larger exposure times (more than 120s) and wider confocal holes (more than $300 \mu \mathrm{m}$ ), in the ice Raman spectrum observable peaks in the $\mathrm{N}_{2}$ and $\mathrm{O}_{2}$ stretching modes region appear (due to the $\mathrm{O}_{2}$ and $\mathrm{N}_{2}$ in the air from the Raman laboratory).

Compared with the Raman wavenumbers for the $\mathrm{O}_{2}$ and $\mathrm{N}_{2}$ molecules trapped in air hydrates, which are considerably red shifted (1547 and $2323 \mathrm{~cm}^{-1}$ for $\mathrm{O}_{2}$ and $\mathrm{N}_{2}$ respectively, 
(Nakahara et al. 1988; Ikeda et al. 1997) due to the enclathration effect, the results for PLIs suggest a considerable amount of vibrational energy for the $\mathrm{O}_{2}$ and $\mathrm{N}_{2}$ molecules, approximately

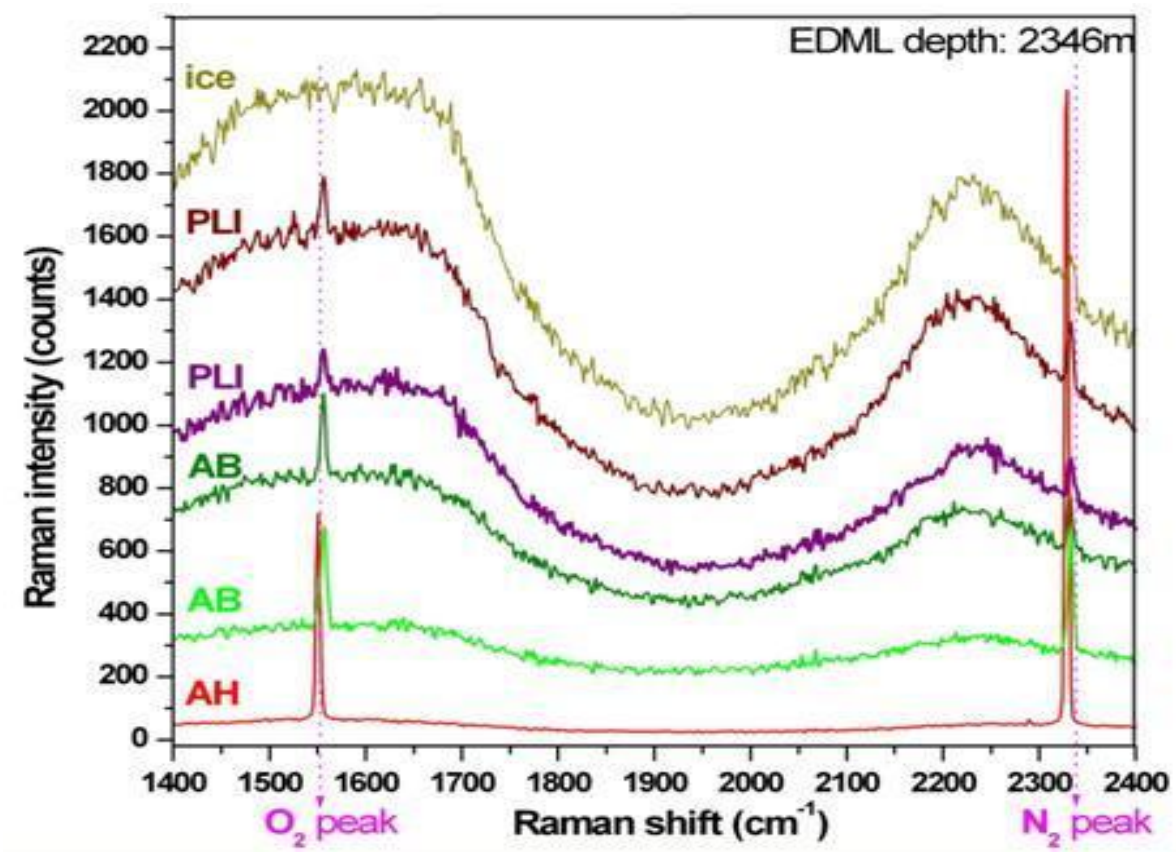

Figure 2.2.1.4 Characteristic Raman spectra for plate-like inclusions, (PLI), (secondary) air bubbles, (AB), and air hydrates, (AH) found in EDML ice from $2345.9 \mathrm{~m}$. The ice Raman spectrum is also plotted for comparison. (The intensity for $\mathrm{AH}$ has been reduced five times)

equal to the energy of the molecules as free gases. These observations are not difficult to accept if it is considered that the body of a PLI is filled after a PLI forms and that the amount of the filler is low compared with the space available to be filled. Moreover the enclathration process develops in time (Shimada and Hondoh, 2004) at suitable (increased) pressure-temperature conditions, and plate-like inclusions are related rather with a release in the internal pressure existent in the polar ice. A preferred arrangement of the $\mathrm{O}_{2}$ and $\mathrm{N}_{2}$ molecules inside the PLIs volume is unlikely to exist as it can be the case with the air hydrates (i.e. an enrichment in oxygen along the outer shell of an air hydrate due to the combination between local (hydrostatic) ice pressure and the formation / dissociation pressure of hydrates (Pauer et al. 1997)). Whatever the location of the gases inside an air bubble, hydrate or PLI, when a Raman spectrum for freshly decomposed air-containing inclusion was recorded, it has been observed that the $\mathrm{O}_{2}$ Raman signal disappears completely (or more rapidly) while the one for $\mathrm{N}_{2}$ can still be recorded (Figure 2.2.1.5). At this stage of data interpretation it cannot be concluded that this behaviour is due to the difference in the amount of the two gases in the air-containing inclusion or because of their ability to escape from the respective inclusion or simply because of instrumental factors. Most probably all of these aspects contribute to the results in Fig. 2.2.1.5.

The peaks for the $\mathrm{O}_{2}$ and $\mathrm{N}_{2}$ in the Raman spectra of PLIs and (secondary) air microbubbles, MBs, (which had their diameter of $\sim 80 \mu \mathrm{m}$ ), are not so well defined as those obtained for primary inclusions like air hydrates, AHs, and air bubbles, ABs, (Raman spectra of which can be seen in Figure 2.2.1.6). The $\mathrm{O}_{2}$ and $\mathrm{N}_{2}$ peaks for secondary microinclusions in (EDML) ice usually are not symmetrical (without a nice bell shape outline) and have low intensity (when compared with the ones for ABs or AHs). Apart form the fact that this is a direct evidence (or consequence) of the low amount of $\mathrm{O}_{2}$ and $\mathrm{N}_{2}$ inside the PLIs and/or MBs volume 
there can be other causes which could have had a negative influence on the Raman peaks morphology.

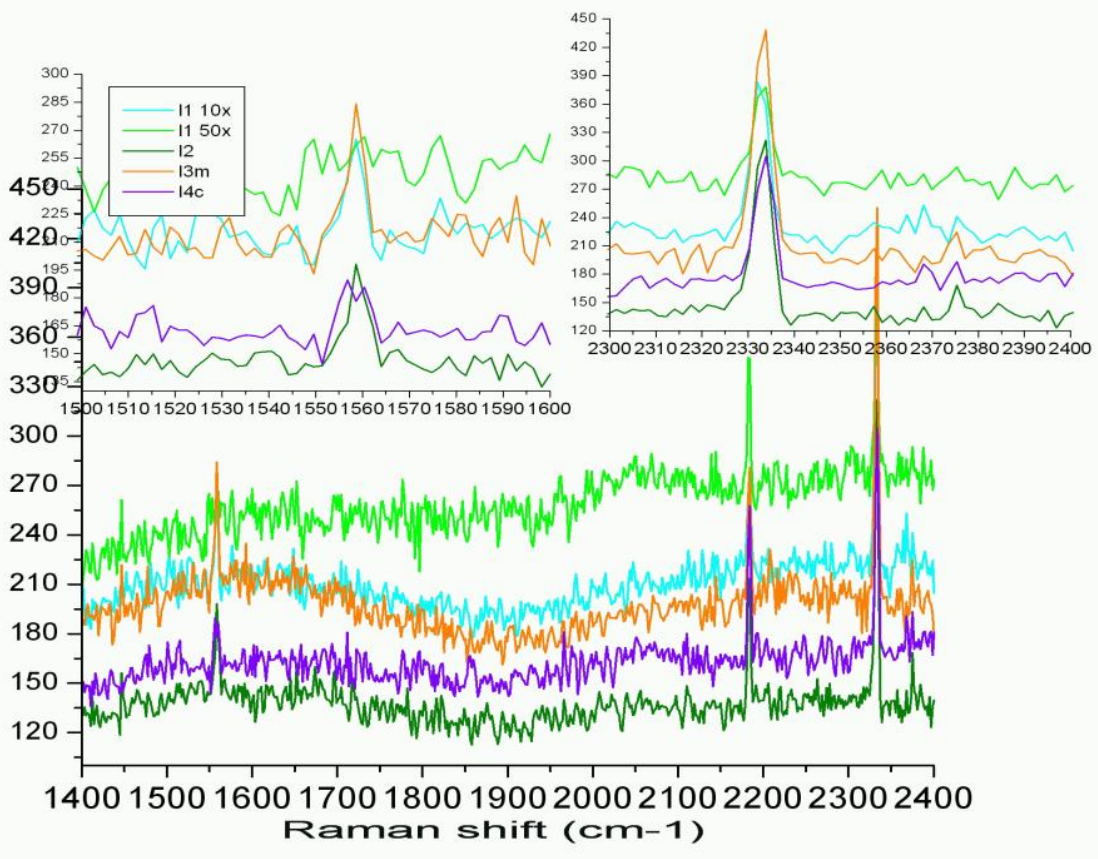

a)
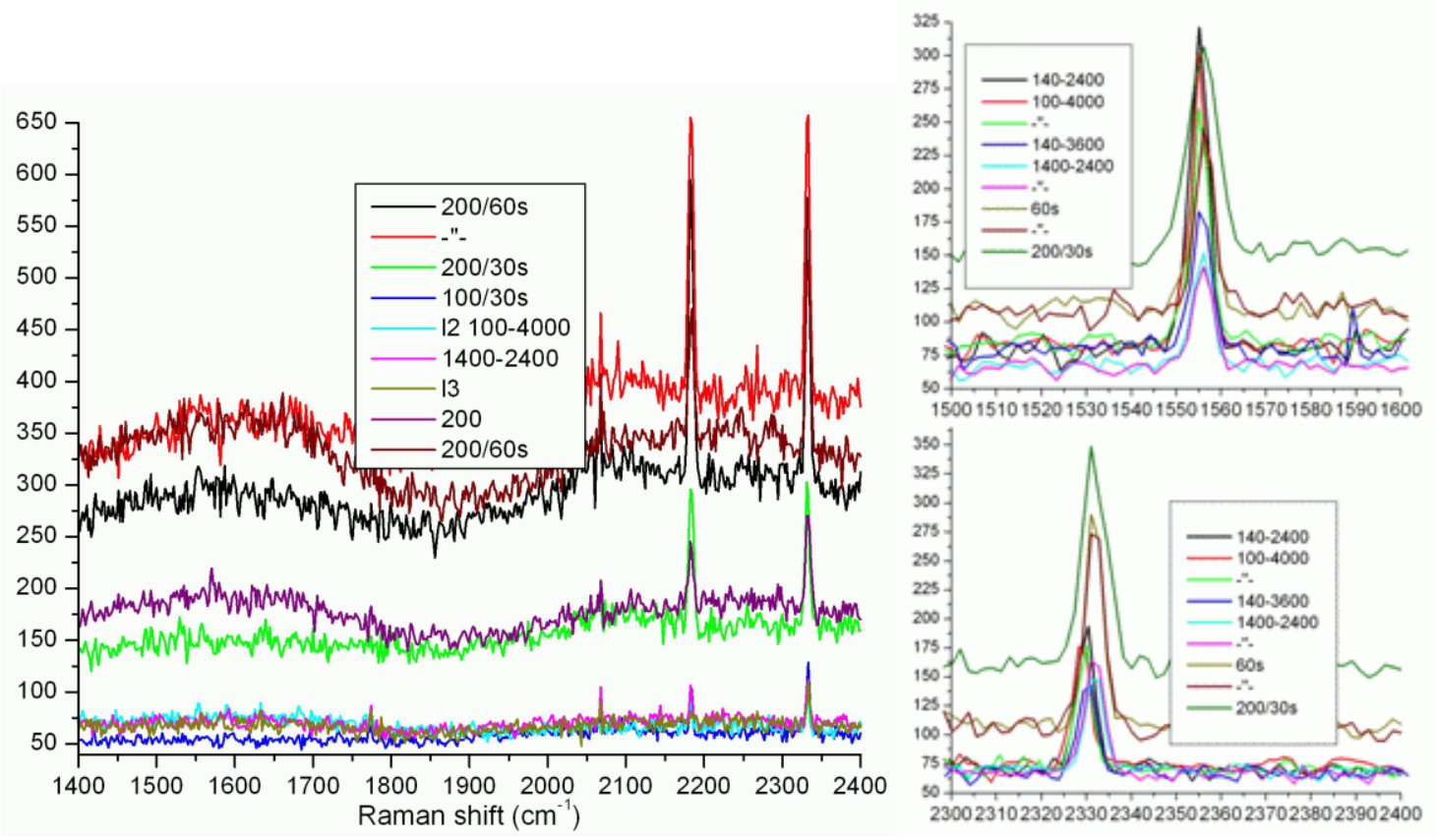

b)

Figure 2.2.1.5 Raman spectra (intensity in counts) for: a) relaxed air hydrate (EDML depth: 983.8 $\mathrm{m})$. The peak due to the oxygen molecules (around $1555 \mathrm{~cm}^{-1}$ ) is very narrow while the one of nitrogen is still good. b) freshly decomposed air bubble (EDML depth: $1745.2 \mathrm{~m}$ ), right: Raman spectra of the air bubble in the region of the $\mathrm{O}_{2}$ and $\mathrm{N}_{2}$ peaks, before decomposition; (l=location, $\mathrm{m}=$ margin, $\mathrm{c}=$ center, $\mathrm{s}=$ seconds, $100 / 200=$ confocal hole dimension) 


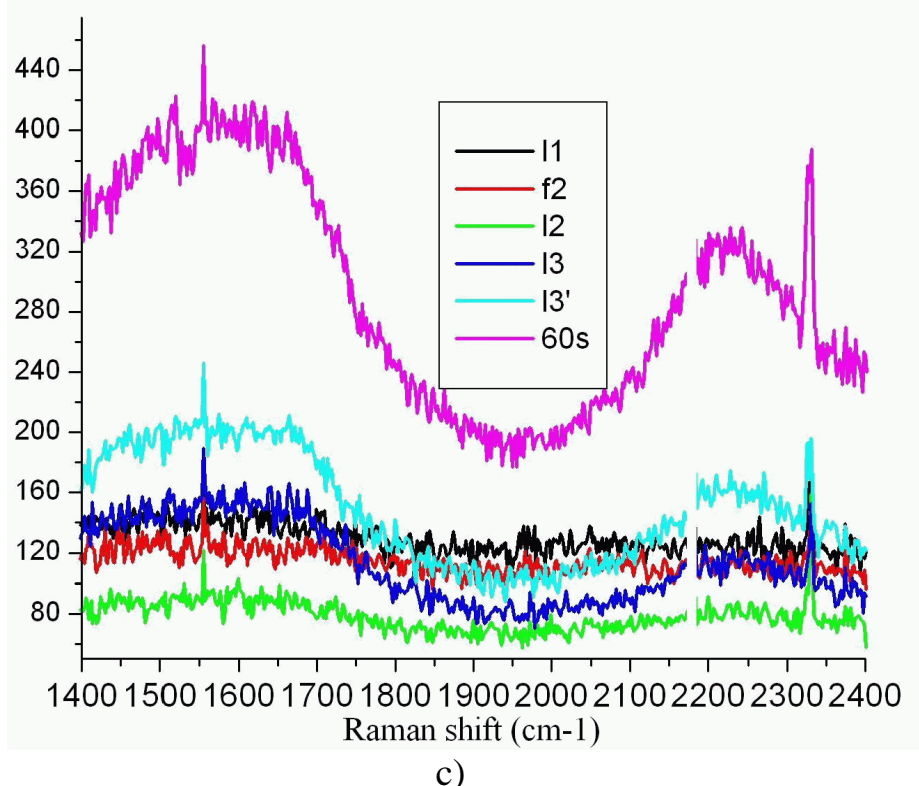

Figure 2.2.1.5 (continuation) Raman spectra (intensity in counts) for: c) decomposed air hydrate (EDML depth: $1745.2 \mathrm{~m}$ ). The peak due to the oxygen molecules (around $1555 \mathrm{~cm}^{-1}$ ) is very narrow while the one of nitrogen is still good. (l=location, $\mathrm{m}=$ margin, $\mathrm{c}=$ center, $\mathrm{s}=$ seconds, $100 / 200=$ confocal hole dimension)
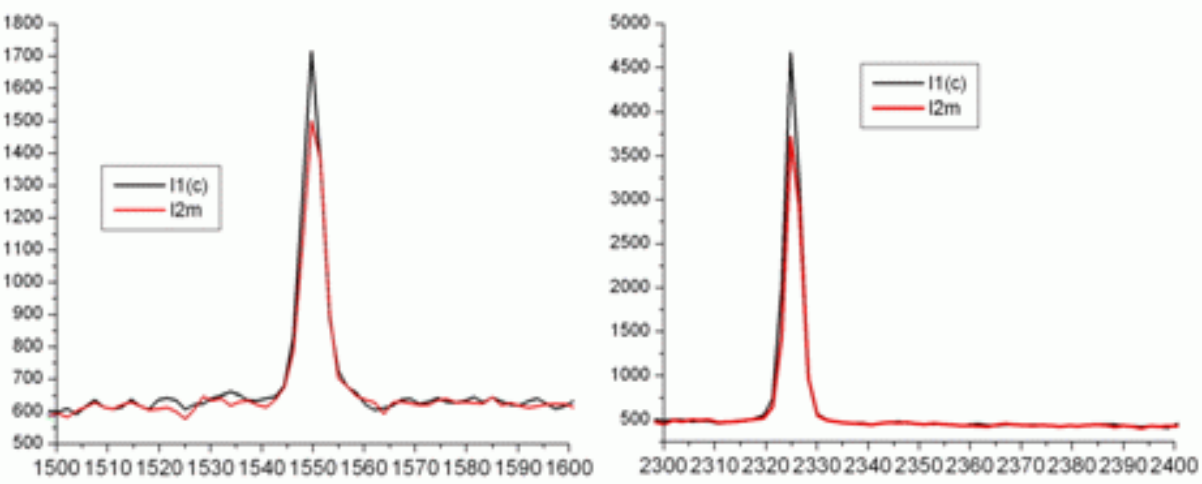

a)
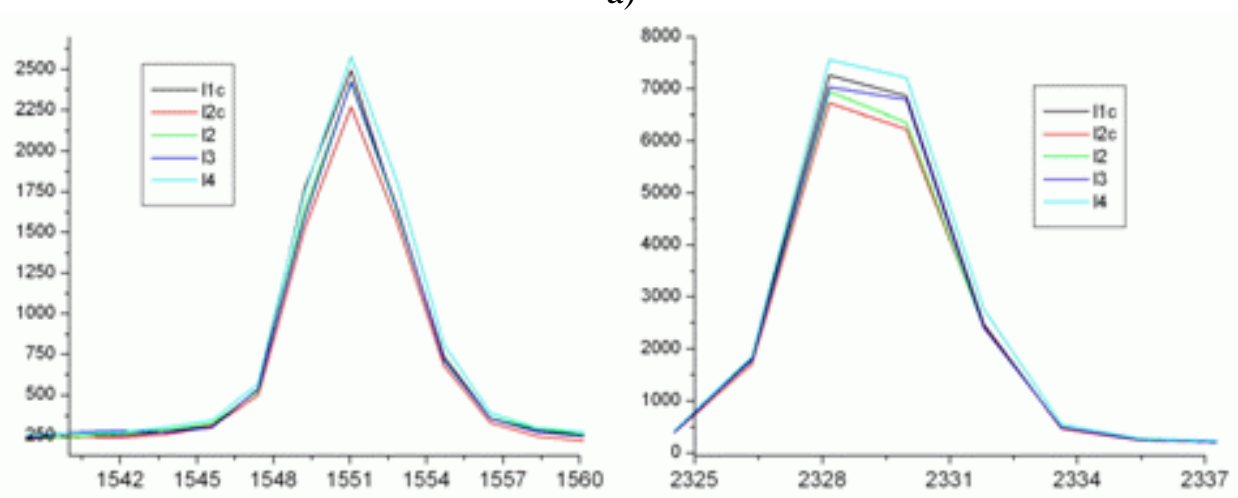

b)

Figure 2.1.1.6 Characteristic Raman spectra in the spectral region were the peaks of $\mathrm{O}_{2}$ and $\mathrm{N}_{2}$ are observed, (intensity in counts function of Raman shift in $\mathrm{cm}^{-1}$ ), of air hydrates ( $\mathrm{a}$ and $\mathrm{b}$ ) 

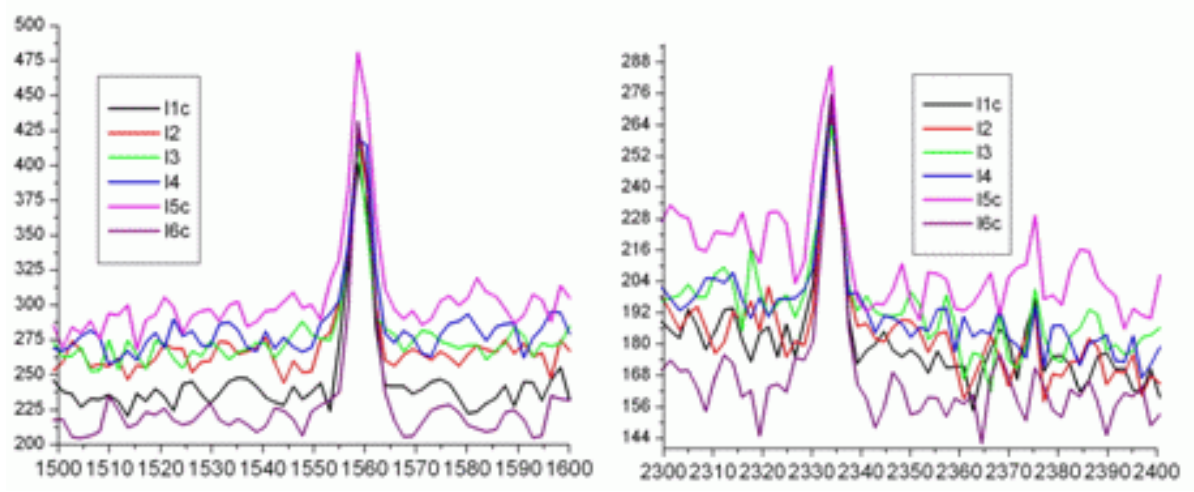

c)

Figure 2.1.1.6 (continuation) Characteristic Raman spectra in the spectral region were the peaks of $\mathrm{O}_{2}$ and $\mathrm{N}_{2}$ are observed, (intensity in counts function of Raman shift in $\mathrm{cm}^{-1}$ ), of air hydrates (a and b) and air bubbles (c) in EDML ice. (l=location, $\mathrm{m}=$ margin, $\mathrm{c}=$ center)
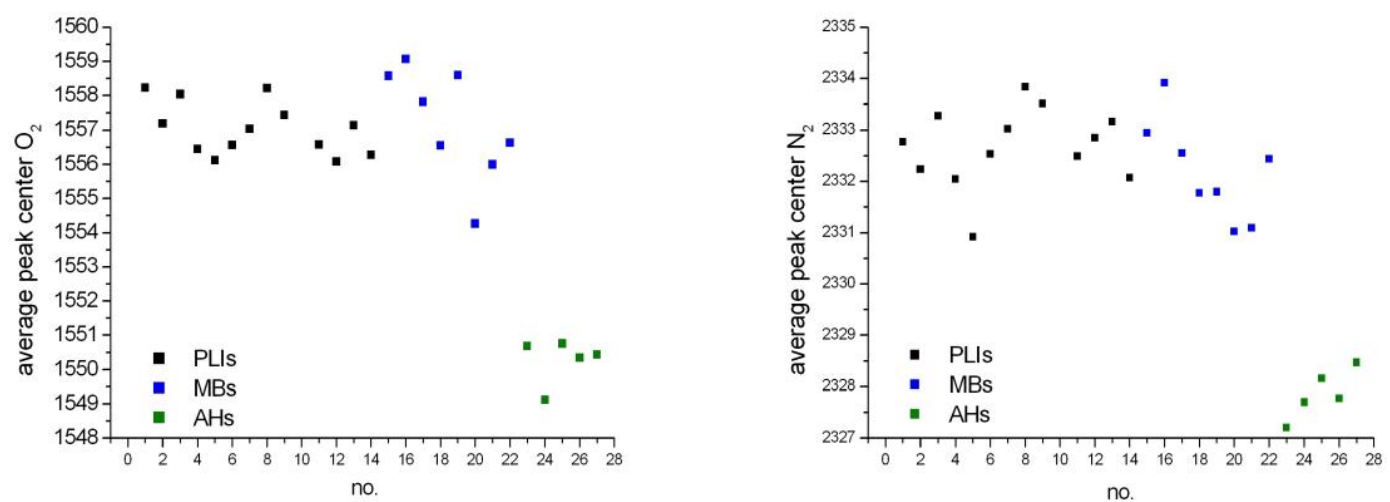

Figure 2.2.1.7 Graphs representing the values for the peak centers of $\mathrm{O}_{2}$ and $\mathrm{N}_{2}$ in the Raman spectra of the investigated microinclusions

The obtained average values for the center of the peaks for $\mathrm{O}_{2}$ and $\mathrm{N}_{2}$ in the Raman spectra of plate-like inclusions, secondary (micro) air bubbles, and air clathrate hydrates are presented in Figure 2.2.1.7. The numerical data are tabulated in Appendix 2.2.1.F, where the specification of the way of determining the peak center was included, meaning by integral calculations or by a Gaussian fitting procedure. It resulted that the final (averaged) values for the $\mathrm{O}_{2}$ and $\mathrm{N}_{2}$ peak centers in the Raman spectra, differ by one unit for the same type of microinclusion trapped in the studied ice. The values are within those for atmospheric air cited in other works (i.e. Champagnon et al. 1997; Chazallon et al. 1998; see above).

As can be seen in Figure 2.2.1.7 (and as expected from the existtance or the lack of a crystalline structure) the center of the $\mathrm{O}_{2}$ and $\mathrm{N}_{2}$ peaks in the Raman spectra of AHs is at lower wavenumbers than the ones for PLIs and MBs. These results are a confirmation that the corresponding obtained (averaged) values for PLIs and MBs, are reliable. For individual investigated relaxation inclusions values which differ by 2 or more units than the average were observed and this could have been due to a more significant influence of the experimental errors.

A quantification of the quality of the $\mathrm{O}_{2}$ and $\mathrm{N}_{2}$ peaks in the Raman spectra (a measure of the symmetry of the peaks) is presented in Figure 2.2.1.8.

The $\mathrm{O}_{2}$ and $\mathrm{N}_{2}$ peaks in the Raman spectra can be characterized using the data of their corresponding $\mathrm{H} / \mathrm{h}) \mathrm{W}$ ratio, where $\mathrm{H}$ is the height of the peak and the $(\mathrm{h}) \mathrm{W}$, meaning $\mathrm{hW}$ or $\mathrm{W}$, is the peak's width at the half of its height. These ratios are depicted in Figure 2.2.1.8A for the 
case when integration calculus was used and Figure 2.2.1.8B for the Gaussian fitting case, for each Raman spectrum used in this study (there can be more than one value for a given microinclusion).

The values for the ratio $\mathrm{H} / \mathrm{hW}$ in Figure 2.2.1.8A for the $\mathrm{N}_{2}$ peaks in the PLIs Raman spectra are less than 12 at any investigated depth whereas for the $\mathrm{O}_{2}$ peaks values seem to increase with depth more than 3 times. This would be an evidence for a better Raman signal produced by the $\mathrm{O}_{2}$ existent in the PLIs volume. Also for the investigated MBs the tendency is the same as for the PLIs. It is obvious that the values for AHs should be much higher compared with the ones for PLIs and MBs and from the data in Figure 2.2.1.8A it is not clear if they follow any trend.
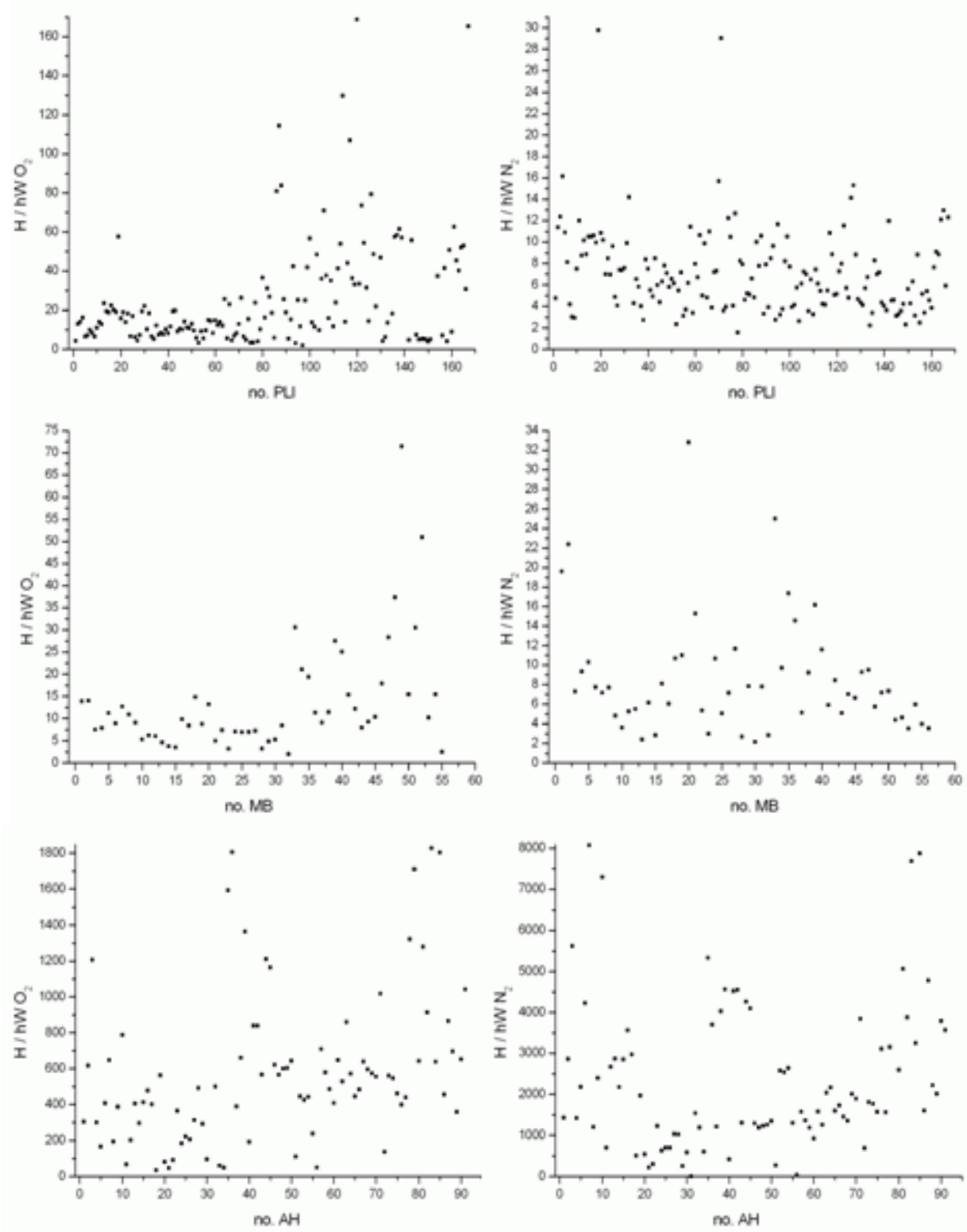

Figure 2.2.1.8A Graphical representation of $\mathrm{H} / \mathrm{hW}$ values, obtained by integration calculus, of the $\mathrm{O}_{2}$ and $\mathrm{N}_{2}$ peaks in the Raman spectra of different investigated microinclusions embedded in EDML ice. 
When the Gaussian fitting was used, Figure 2.2.1.8B, the ratio $\mathrm{H} / \mathrm{W}$ for PLIs seems to have less variability for both $\mathrm{O}_{2}$ and $\mathrm{N}_{2}$ peaks and a slight increasing trend towards the $2405.8 \mathrm{~m}$ depth. For MBs the $\mathrm{H} / \mathrm{W}$ values are more stable and smaller than for the PLIs. In the case of the AHs high and small $\mathrm{H} / \mathrm{W}$ values were obtained but they were calculated only in the 2345.9 ice sample case.
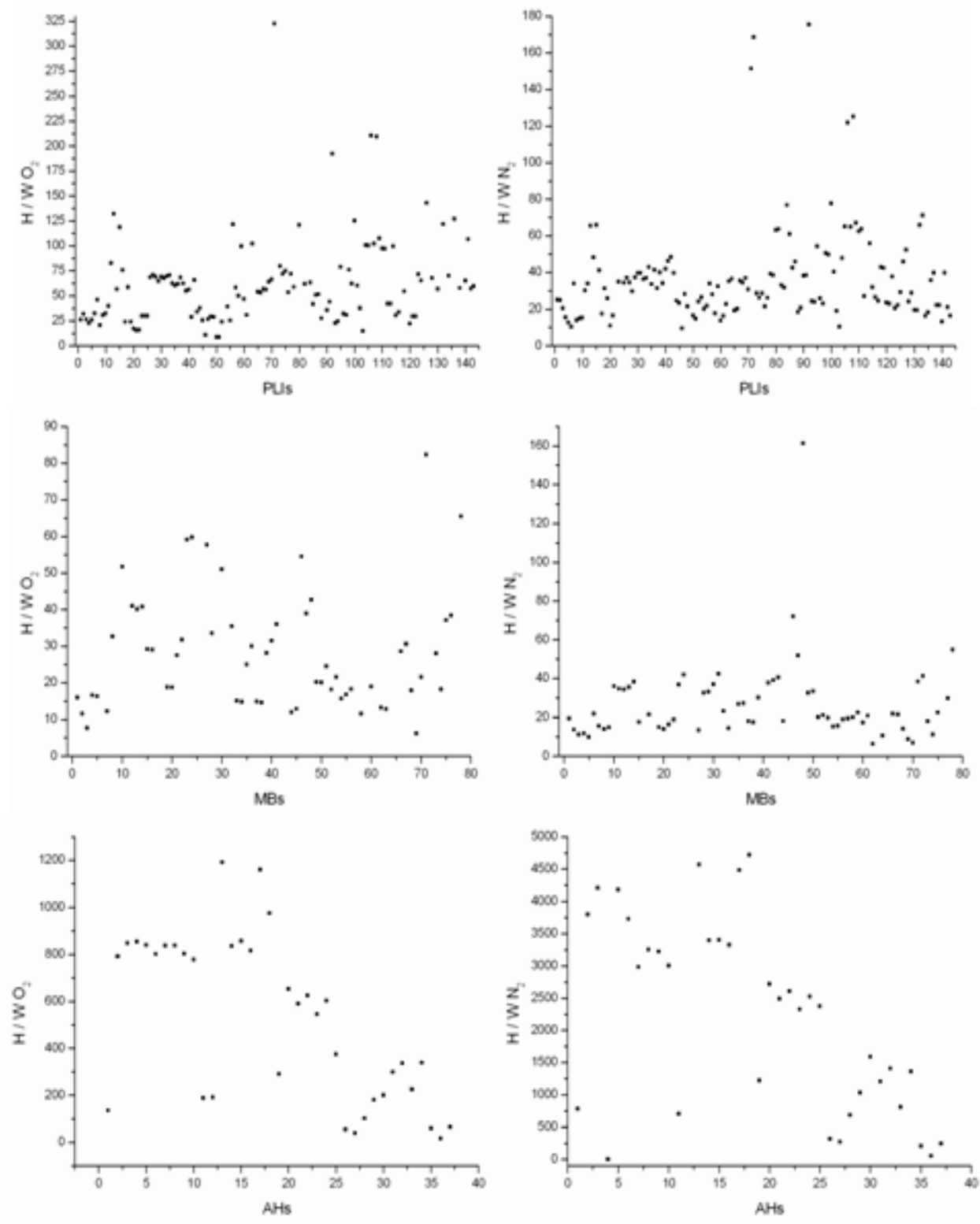

Figure 2.2.1.8B Graphical representation of $\mathrm{H} / \mathrm{W}$ values, obtained by Gausssian fitting, of the $\mathrm{O}_{2}$ and $\mathrm{N}_{2}$ peaks in the Raman spectra of different investigated microinclusions embedded in EDML ice.

\section{Quantitative information}

The amount of a substance existent in a defined volume on which a laser beam is focused is reflected in the intensity of the backscattered light and can be visualized in the registered spectrum. The Raman peaks have a higher intensity and are better defined for PLIs with a bigger volume (i.e. PLI11, 17, 21, 28 Appendix 2.2.1.D). From the available data it cannot be concluded if the bigger volume of the PLI lead to a subsequent enhancement in the amount of $\mathrm{O}_{2}$ or/and $\mathrm{N}_{2}$ via diffusive processes; or a considerable (greater) amount of $\mathrm{O}_{2}$ and $\mathrm{N}_{2}$ existed dissolved in the 
ice matrix and resulted in the formation of a larger PLI. Theoretically speaking a bigger PLI volume might accommodate a greater amount of substances when available in the ice matrix around the PLI or an older PLI may be filled in time with a varying amount of possible fillers (neither of these two possibilities implying a direct low or high value for the corresponding $\mathrm{N}_{2} / \mathrm{O}_{2}$ ratio).

As mentioned before, the numerical values discussed here are not modified by any correction factor, i.e. neither from the calibration of the Raman machine nor from ratio of the cross sections of $\mathrm{N}_{2}$ and $\mathrm{O}_{2}$.

For the first set of investigated EDML ice samples, the obtained values for the $\mathrm{N}_{2} / \mathrm{O}_{2}$ ratios, calculated using the areas, (from Gaussian fitting), of the $\mathrm{N}_{2}$ and $\mathrm{O}_{2}$ peaks in the Raman spectra (Pauer et al. 1997) take values between 0.4 to 3.8 (Nedelcu et al. 2009). The extreme values of the interval could be artifacts from the way they were calculated. The values between 0.7 and 2 can be considered the most characteristic ones for this set of measurements, since for air bubbles or air hydrates in polar ice values around 3, (close to the present atmospheric air $\mathrm{N}_{2} / \mathrm{O}_{2}$ ratio of 3.7), are more representative. Besides even if PLIs are under-investigated so far, the fact that they are secondary inclusions (formed after the ice core extraction) may justify the expectation of lower values for their $\mathrm{N}_{2} / \mathrm{O}_{2}$ ratio as for other primary air inclusions. Values for $\mathrm{N}_{2} / \mathrm{O}_{2}$ ratio lower than 3 have been reported for air hydrates in polar ice (Nakahara et al. 1988; Ikeda et al. 1999; Ikeda et al. 2000), but they are not representative, rather determined by the depth at which the investigated inclusions formed (i.e. within the bubble-clathrate transition zone in Vostok ice core, Ikeda et al. 1999), directly related with the preferential pressure at which $\mathrm{O}_{2}$ or $\mathrm{N}_{2}$ is enclathrated, and also as a consequence of the difference in the $\mathrm{N}_{2}$ and $\mathrm{O}_{2}$ diffusion coefficients in ice.

For the second set of ice samples Figures 2.2.1.9, 2.2.1.10, 2.2.1.11 show the calculated $\mathrm{N}_{2} / \mathrm{O}_{2}$ ratios for PLIs, MBs and AHs. Detailed graphs for the individual PLIs $\mathrm{N}_{2} / \mathrm{O}_{2}$ ratios are shown in Figure 2.2.1.12 and detailed numerical data are reproduced in Appendix 2.2.1.G.

For PLIs the $\mathrm{N}_{2} / \mathrm{O}_{2}$ ratio slightly increases as the depth of the (EDML) ice increases, with a larger variance for the '2000m' ice samples. The ratio's values range between 0.3 and 1.1.

The low and the high values are not rigidly correlated with a certain depth (and this might be caused by the limited number of data presented here). For MBs the range of the $\mathrm{N}_{2} / \mathrm{O}_{2}$ ratio extends until 1.7 with the same slight tendency of increasing with depth. Values over 3 are sporadic.

For AHs the obtained $\mathrm{N}_{2} / \mathrm{O}_{2}$ ratios take values between 2.8 and 3.7 with higher individual standard deviations and higher values characteristic for the 2345.9 ice sample.

In Figure 2.2.1.13 the $\mathrm{N}_{2} / \mathrm{O}_{2}$ ratio for PLIs is plotted function of the aspect ratio of the PLIs. No particular relation between a higher $\mathrm{N}_{2} / \mathrm{O}_{2}$ ratio and a longer PLI can be inferred from this graph; just that the values for $\mathrm{N}_{2} / \mathrm{O}_{2}$ for thinner and long PLIs are above the average (say 0.6 here).

Additional data that can offer extra information about the quality of the $\mathrm{O}_{2}$ and $\mathrm{N}_{2}$ peaks in the Raman spectra of a specific studied microinclusion, available (only) for the cases in which the peaks were fitted with a Gaussian type function, are plotted in Figure 2.2.1.14. Namely, the percent from the area of the standard deviation of this calculated area is around 10 (or 14) for $\mathrm{O}_{2}$ case in PLIs (or MBs) and around 25 (or 20) for $\mathrm{N}_{2}$ peak in PLIs (or MBs). Comparatively for AHs this percent is less than 3 .

$\mathrm{R}^{2}$ (the correlation) and $\chi^{2}$ (the goodness of fit) parameters are depicted in Figure 2.2.1.15 and Figure 2.2.1.16 respectively. The values are higher for $\mathrm{O}_{2}$ than for $\mathrm{N}_{2}$ in the case of PLIs and (a bit) higher than for MBs. Of course for AHs they have (very) high values. 


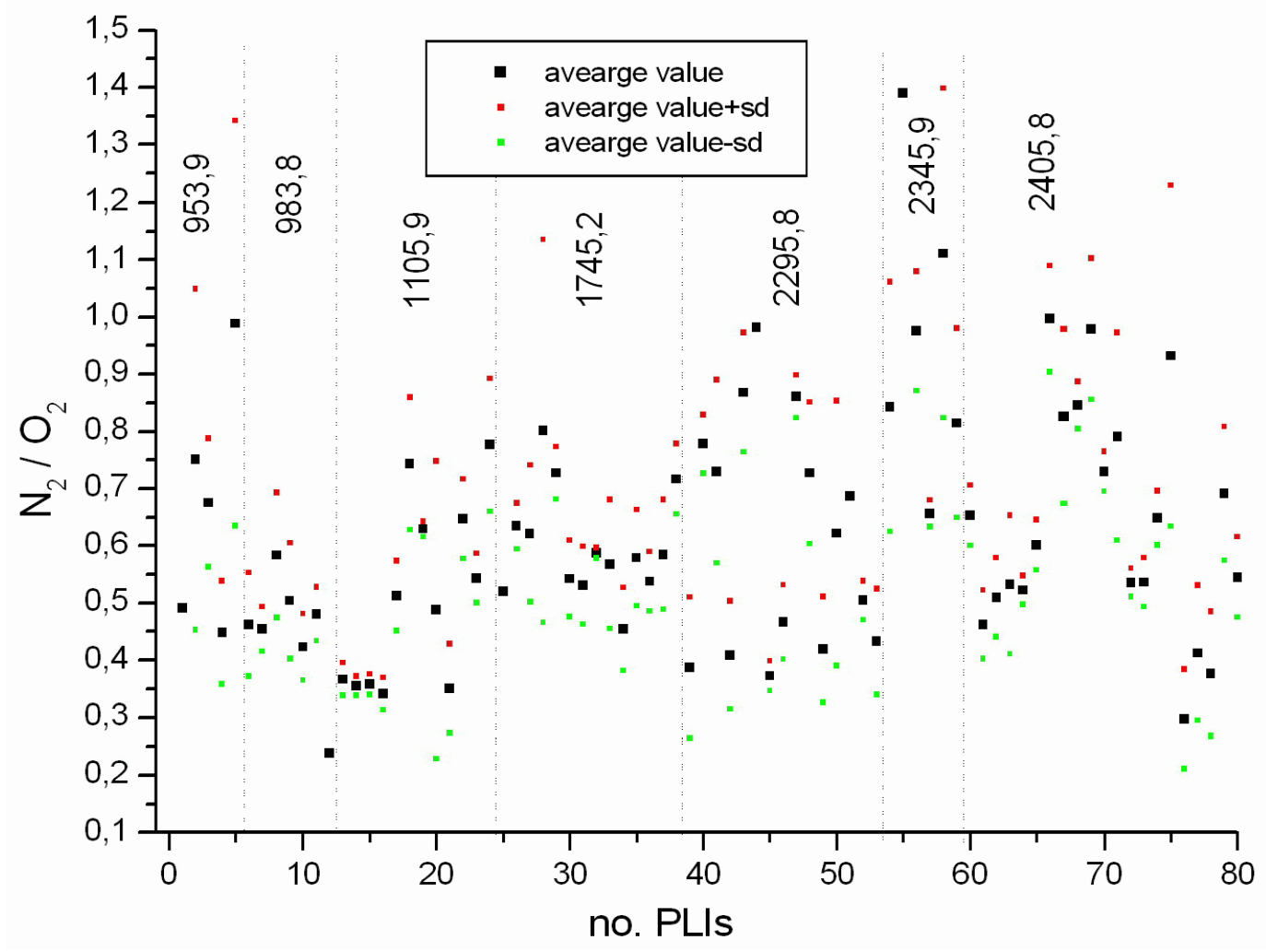

Figure 2.2.1.9 Values for the $\mathrm{N}_{2} / \mathrm{O}_{2}$ ratios of investigated PLIs

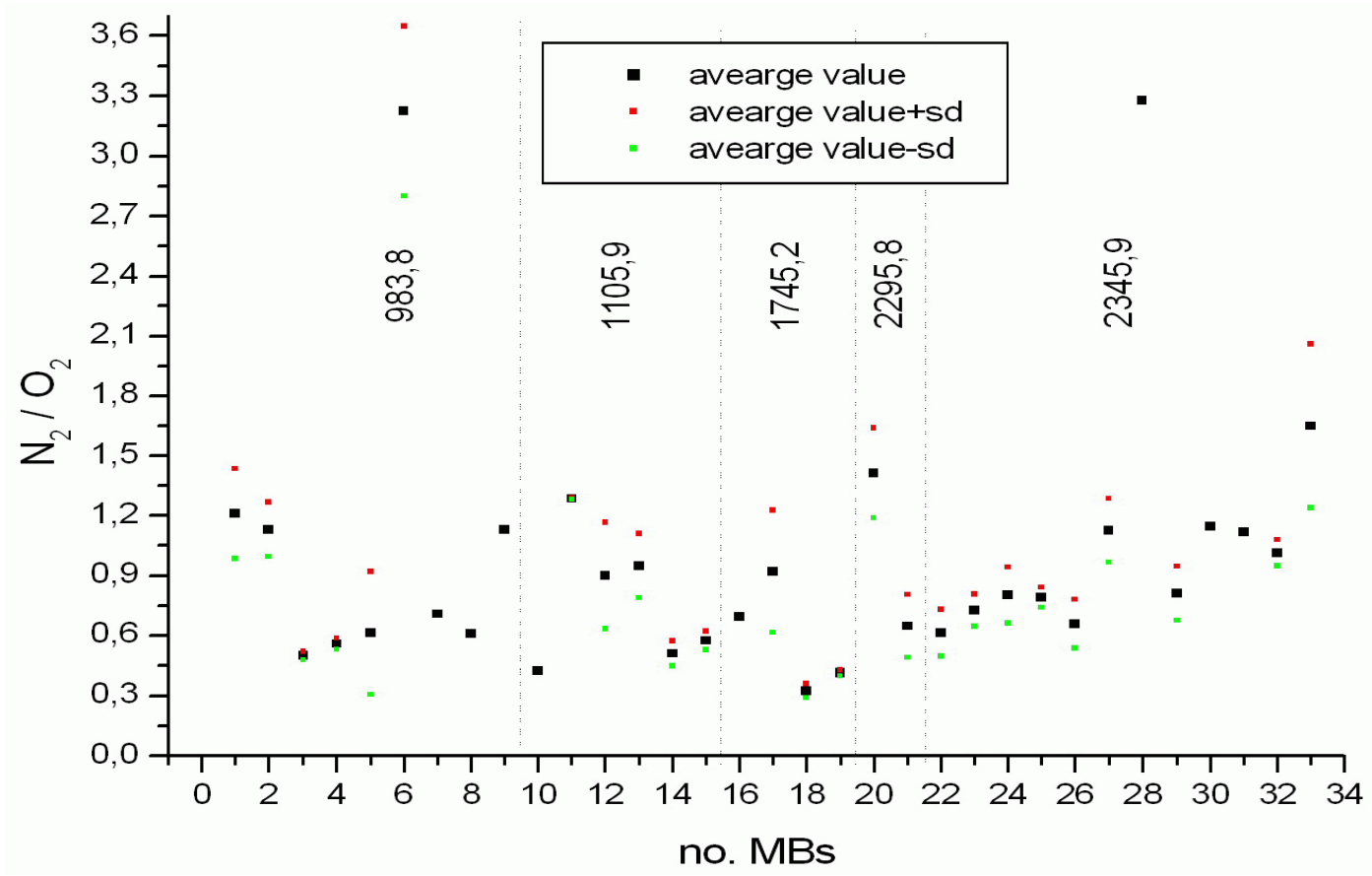

Figure 2.2.1.10 Values for the $\mathrm{N}_{2} / \mathrm{O}_{2}$ ratios of investigated $\mathrm{MBs}$ 


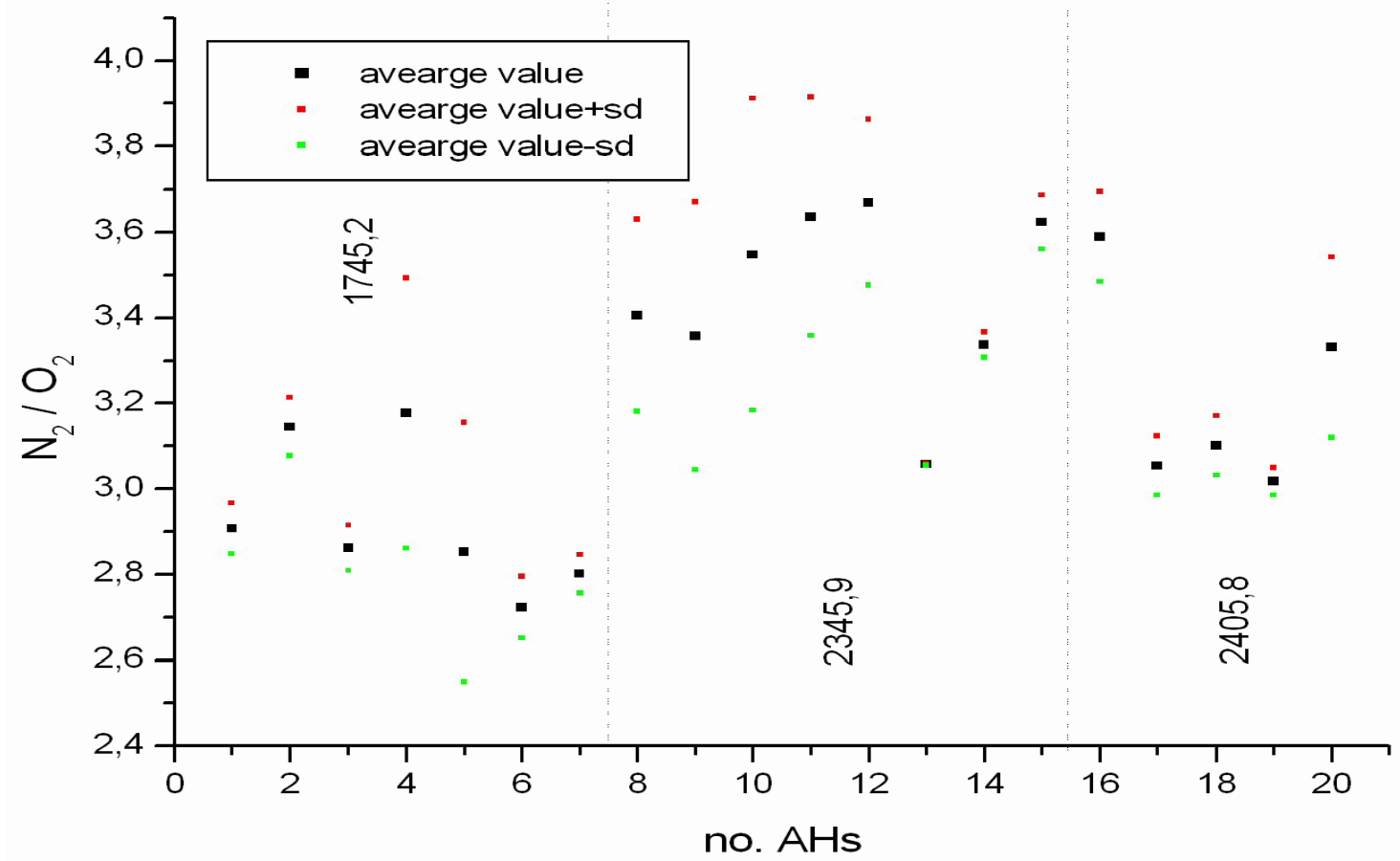

Figure 2.2.1.11 Values for the $\mathrm{N}_{2} / \mathrm{O}_{2}$ ratios of investigated $\mathrm{AHs}$
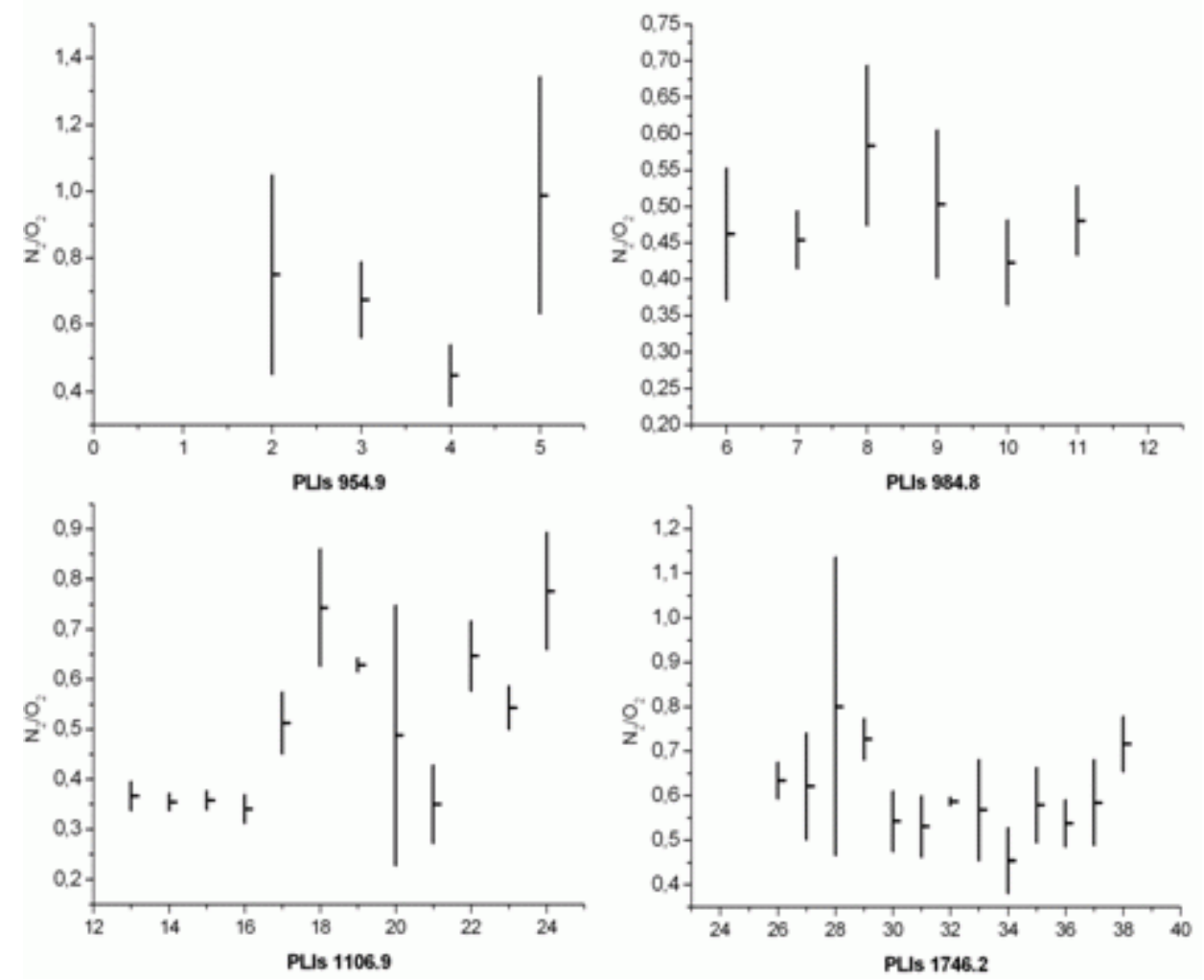

Figure 2.2.1.12 Detailed graphs with the values for the $\mathrm{N}_{2} / \mathrm{O}_{2}$ ratios of investigated PLIs. 

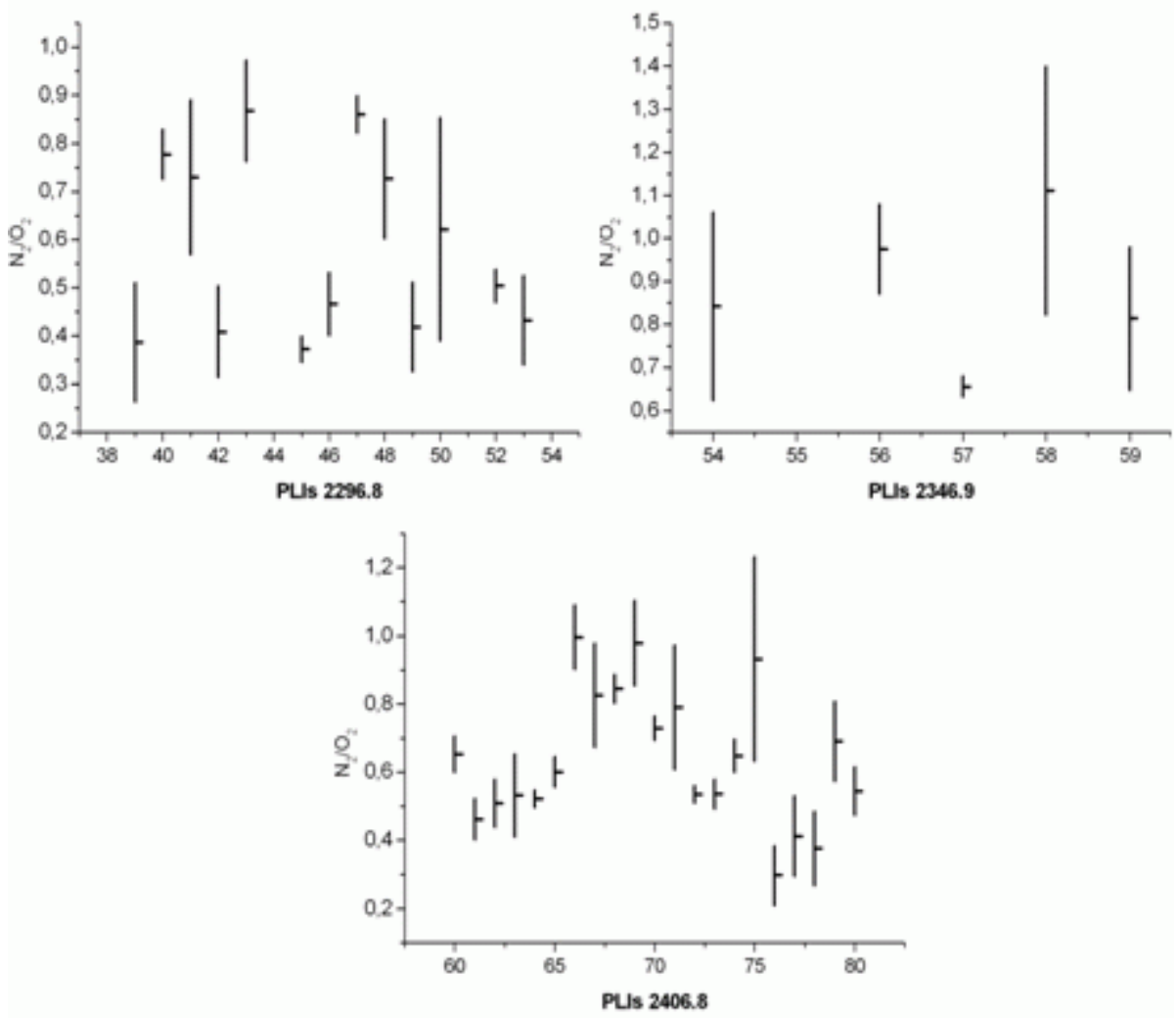

Figure 2.2.1.12 (continuation) Detailed graphs with the values for the $\mathrm{N}_{2} / \mathrm{O}_{2}$ ratios of investigated PLIs.

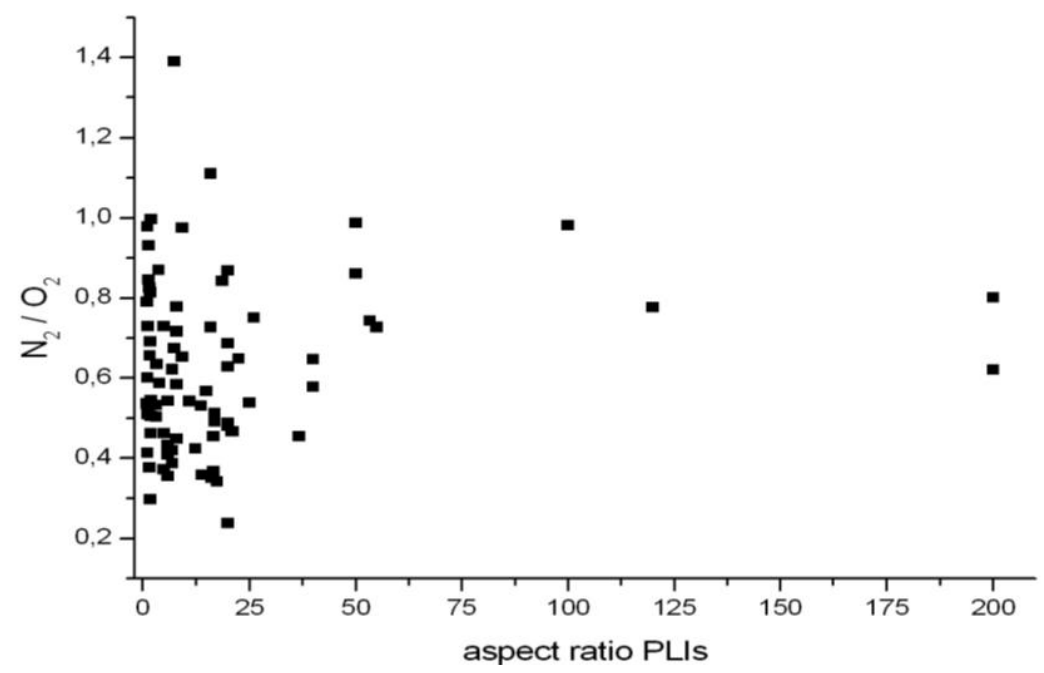

Figure 2.2.1.13 Dependence of the $\mathrm{N}_{2} / \mathrm{O}_{2}$ ratios of investigated PLIs on their aspect ratios (L/l)

\section{Concluding remarks}

The results presented in this chapter show that some rearrangement of the gases trapped in the natural ice matrix is present, prior and after the ice core retrieval. If we admit that PLIs, as relaxation features in ice, are filled with any substance after they form then the identification of $\mathrm{O}_{2}$ and $\mathrm{N}_{2}$ inside PLIs is an evidence for gas diffusion through the natural ice body (IkedaFukazawa et al. 2005). This is a primary process that can influence the accuracy of the 
paleoclimate related signal recovered from natural ice cores, as these are the most important climate archives.

Ohno et al. (2010) after carefully analyzing the spatial distribution of different types of inclusions existent in Dome Fuji ice, explain the observed patterns in terms of the occurrence of heterogeneous nucleation of air hydrates. The solid (soluble) microinclusions embedded in the ice matrix, as well as the defects in the ice matrix (more or less induced by the existing impurities), can act as nucleation centers. Thus, for the upper part of the bubble-to-hydrate transition zone, hydrates can form inside the ice grains (where, usually a high concentration of microinclusions was observed), independently of the existent air bubbles. Or, hydrates can form on the bubbles walls (which are 'large-scale ice defects') especially if any microinclusion is attached to them. Heterogeneous clathrate nucleation, outside the air bubbles, can explain why, at the beginning of the bubble-to-hydrate transition zone, the clathrates can be enriched in $\mathrm{O}_{2}$ molecules (which diffuses more rapidly than $\mathrm{N}_{2}$ ). The same line of thinking is valid for the description of relaxation features in ice.
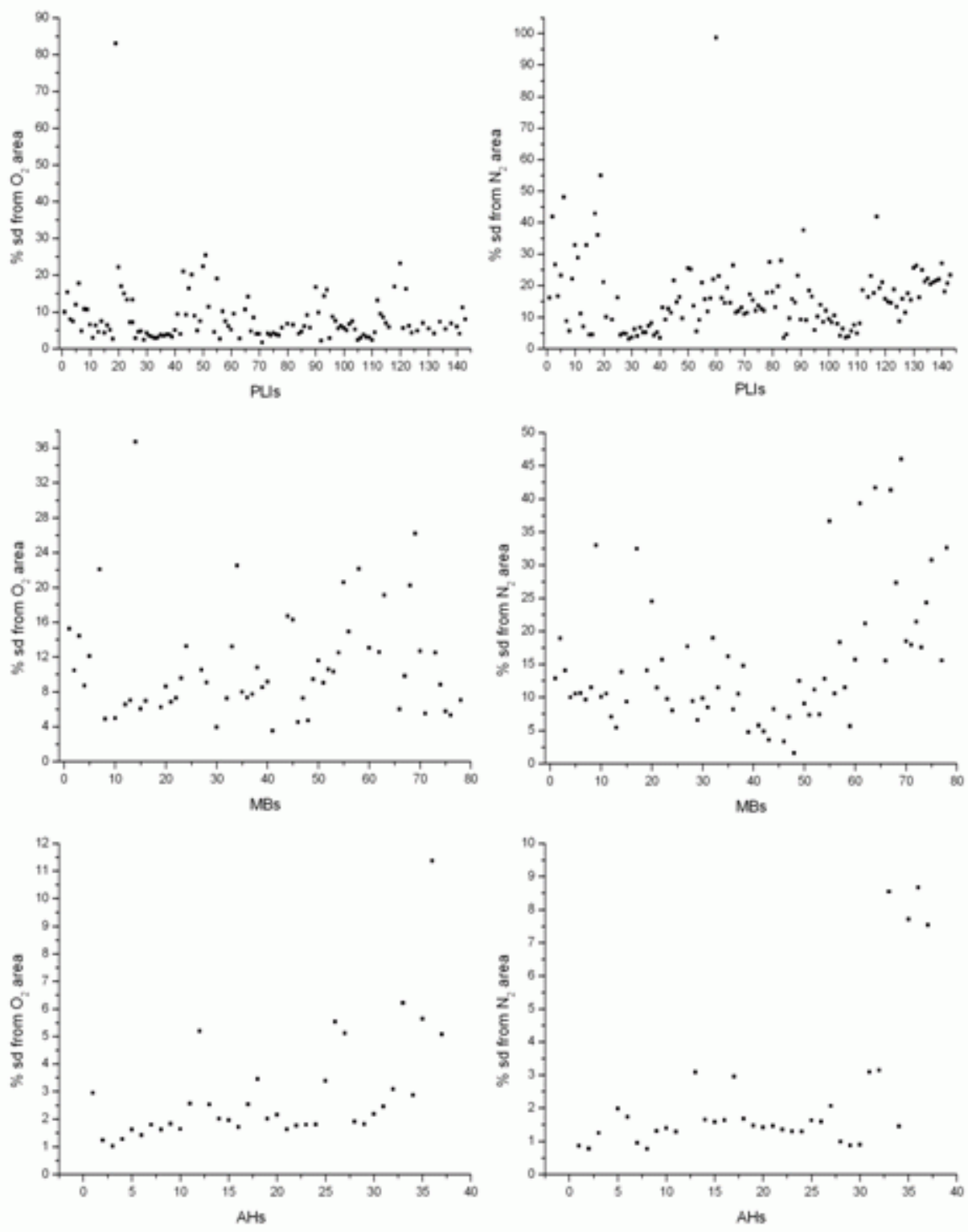

Figure 2.2.1.14 Values for the percent, \%, from the area represented by the standard deviation (sd) of the area for the $\mathrm{O}_{2}$ and $\mathrm{N}_{2}$ peaks in the Raman spectra of different investigated microinclusions embedded in EDML ice. 
Since an important factor leading to the appearance of relaxation features in ice is the temperature experienced by the ice, special care should also be paid to the storage and manipulation conditions when natural ice is processed for further analyses. The $\mathrm{N}_{2} / \mathrm{O}_{2}$ ratios in PLIs lower than 3.7 indicate that $\mathrm{O}_{2}$ can diffuse more rapidly through the ice, maybe accumulating at certain locations, with lattice defects, which later on due to the change in the local pressure-temperature conditions by mechanical relaxation of the ice, segregate and form small planar polygonal cavities with hexagonal symmetry, thin negative crystals lying on the basal plane of a hosting ice crystallite (Nedelcu et al. 2009), meaning plate-like inclusions.
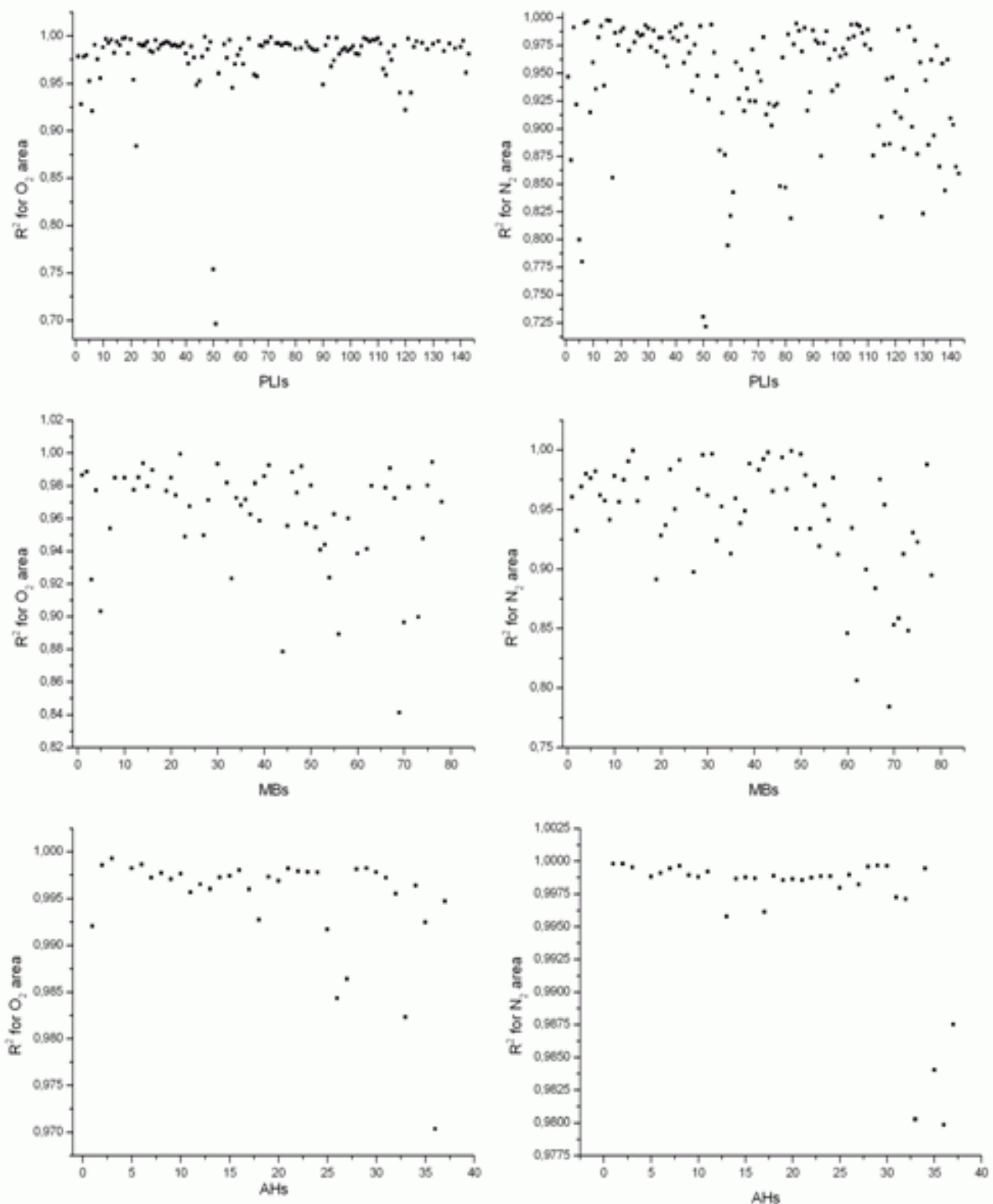

Figure 2.2.1.15 Values for the correlation parameter $\left(R^{2}\right)$ for the $\mathrm{O}_{2}$ and $\mathrm{N}_{2}$ peaks area in the Raman spectra of different investigated microinclusions embedded in EDML ice. 

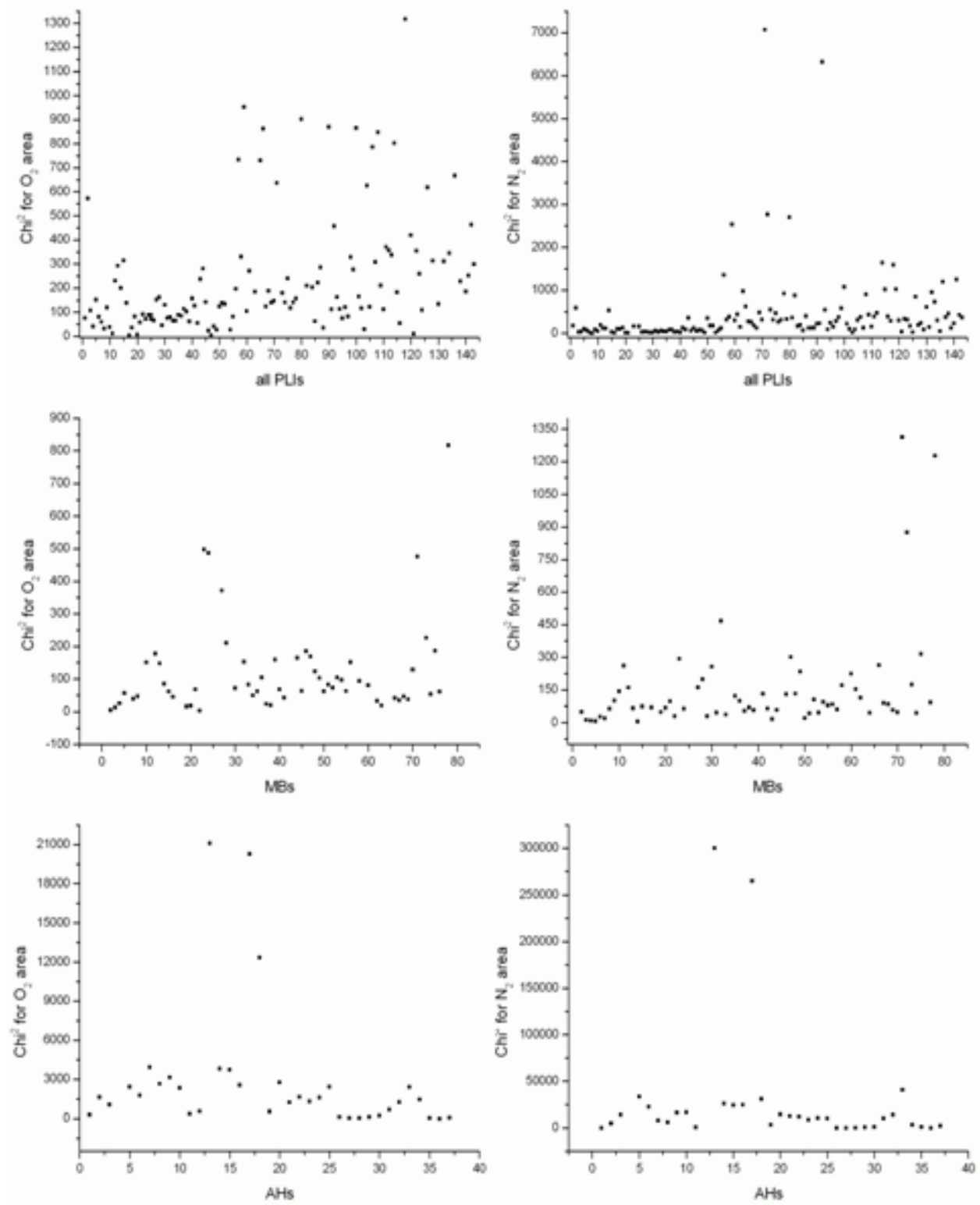

Figure 2.2.1.16 Values for the Chi parameter $\left(\mathrm{Chi}^{2}\right)$ for the $\mathrm{O}_{2}$ and $\mathrm{N}_{2}$ peaks area in the Raman spectra of different investigated microinclusions embedded in EDML ice. 


\title{
2.2.2 Chemistry of soluble and hardly soluble micro- inclusions in clear and cloudy MIS2 EDML ice
}

\author{
"There everything ends / and nothing: / there everything begins: / \\ the rivers say farewell in the ice, / the sky has married the snow, / \\ [...] there / the solitude of the world is lonely, / and for this the stone / \\ become music, it lifted / its delicate towers, it lifted itself / \\ to cry or to sing / yet it was silent." "Antarctic Stones" Pablo Neruda ${ }^{39}$
}

\section{Results}

The EDML ice samples were selected from regions along the EDML ice core where bands of clear following cloudy ice could be observed by visual inspection. It is mainly the case for glacial time (EDML) ice this is why the emphasis was on ice from MIS2 (marine isotope stage 2), or the so called last glacial period, LGP. For comparison ice samples from other geological times (MIS4, MIS5 and MIS6) were also investigated. The cloudy ice was identified by visual inspection, (with the naked eye or the microscope), of the ice against a light source and it was considered to be a whiter (or more opaque) region between transparent ice layers.

The selected ice samples (named with their corresponding depth) and some supplementary data are presented in Table 2.2.2.1.

Table 2.2.2.1 General information about the investigated EDML ice samples

\begin{tabular}{|c|c|c|c|c|c|}
\hline $\begin{array}{c}\text { EDML } \\
\text { depth }^{\mathbf{1}} \\
(\mathbf{m})\end{array}$ & $\begin{array}{c}\text { EDML } \\
\text { age }^{\mathbf{2}} \\
(\mathbf{y r} \text { BP) }\end{array}$ & $\begin{array}{c}\text { Marine } \\
\text { Isotope }_{\text {Stage }^{2}}\end{array}$ & $\begin{array}{c}\text { Ice sheet } \\
\text { temperature }^{3} \\
\left(\mathbf{K} /{ }^{\circ} \mathbf{C}\right)\end{array}$ & $\begin{array}{c}\text { Ice sheet } \\
\text { pressure }^{3} \\
(\mathbf{M P a})\end{array}$ & $\begin{array}{c}\boldsymbol{\delta}^{\mathbf{1 8}} \\
\text { measured }^{\mathbf{2}} \\
\text { \%o }\end{array}$ \\
\hline $\mathbf{9 3 4 . 6}$ & 19000 & MIS2 & $<235 /-38$ & $<9$ & -49.79 \\
\hline $\mathbf{1 0 1 6 . 9}$ & 22900 & MIS2 & $<235 /-38$ & $>9$ & -51.01 \\
\hline $\mathbf{1 0 3 5 . 9}$ & 23700 & MIS2 & $<235 /-38$ & $>9$ & -50.06 \\
\hline $\mathbf{1 1 8 4 . 9}$ & 30700 & MIS2 & $>237 /-36$ & $>10$ & -49.32 \\
\hline $\mathbf{1 8 5 5}$ & 71600 & MIS4 & $>248 /-25$ & $<17$ & -47.32 \\
\hline $\mathbf{2 2 9 5 . 8}$ & 117500 & MIS5 & $<258 /-15$ & $>20.5$ & -45.65 \\
\hline $\mathbf{2 4 0 5 . 8}$ & 145400 & MIS6 & $>261 /-12$ & $>21.5$ & -51.30 \\
\hline
\end{tabular}

$\mathrm{m}=$ meters; yr BP = years before (present $/) 1950 ; \mathrm{K} /{ }^{\circ} \mathrm{C}=\mathrm{Kelvin} /$ degrees Celsius; $\mathrm{MPa}=$ mega Pascal; \%o $=$ per mille. ${ }^{1}$ The last number, indicating the $\mathrm{cm}$ level of an $1 \mathrm{~m}$ ice core, is informative. ${ }^{2}$ Data from (EPICA Comm.Memb.2006). ${ }^{3}$ Values from (Wilhelms et al. 2007).

Appendixes 2.2.2.A to 2.2.2.H show representative graphs with the results obtained from Raman spectrochemical analyses of the investigated solid ${ }^{40}$ microinclusions in EDML ice. The raw numerical data were used (no smoothing or background subtraction was applied) for constructing the graphs; (to a certain extent, the appearance of the Raman signal can be representative for the overall measurement yield).

As a general grouping two main classes of micro-inclusions were identified as existent in EDML ice: sulfates and silicates (including silica). Strong, well defined peaks in the 970-1030

\footnotetext{
39 in Manhire, 2004, pg. 297

${ }^{40}$ By 'solid microinclusion' is understood any observable impurity identified as being trapped in the analyzed EDML ice and does not resemble the gas filled microinclusions. The 'solid micorinclusions' can be liquid solutions since some of the possible substances forming them can be above their eutectic point. Maybe a more realistic denomination is 'easy and hardly soluble microinclusions'.
} 
$\mathrm{cm}^{-1}$ region were attributed to sulfate-containing compounds (Socrates, 2004), while for silicates characteristic peaks were considered the ones obtained between $400-800 \mathrm{~cm}^{-1}$ and 1100 $1400 \mathrm{~cm}^{-1}$ (Socrates, 2004). Additionally, nitrates, hard to identify compounds and some other types of substances (but less frequent) are also present. A detailed classification ${ }^{41}$ of the identified chemicals in the studied EDML ice is as follows; microinclusions formed of:

- sodium or natrium sulfate (mirabilite: $\mathrm{Na}_{2} \mathrm{SO}_{4} \cdot 10 \mathrm{H}_{2} \mathrm{O}$, Appendix 2.2.2.A), or

- (possibly)magnesium sulfate(meridianiite: $\mathrm{MgSO}_{4} \cdot 11 \mathrm{H}_{2} \mathrm{O}$, Appendix 2.2.2.A),

- calcium sulfate (gypsum: $\mathrm{CaSO}_{4} \cdot 2 \mathrm{H}_{2} \mathrm{O}$, Appendix 2.2.2.B),

- (probably) potassium or kalium sulfate (arcanite, $\mathrm{K}_{2} \mathrm{SO}_{4}$ ) or $\mathrm{H}_{2} \mathrm{SO}_{4}$ (Appendix 2.2.2.C),

- a mixture of simple sulfates (Appendix 2.2.2.D),

- double sulfates of jarosite type ( $(\mathrm{Na} / \mathrm{K}) \mathrm{Fe}_{3}\left(\mathrm{SO}_{4}\right)_{2}(\mathrm{OH})_{6}$, Appendix 2.2.2.E),

- silica $\left(\mathrm{SiO}_{2}\right.$ most probably as quartz, Appendix 2.2.2.F),

- silicates and aluminosilicates (Appendix 2.2.2.F),

- a mixture of sulfates and silicates (Appendix 2.2.2.D),

- other identifiable substances like carbonaceous matter or compounds with different anionic groups or counteranions: oxygen $\left(\mathrm{O}^{2-}\right)$, hydroxyl $\left(\mathrm{OH}^{-}\right)$, phosphate $\left(\mathrm{PO}_{4}{ }^{3-}\right)$, nitrate, $\left(\mathrm{NO}_{3}{ }^{-}\right)$ (Appendix 2.2.2.G),

- some other substances including $\mathrm{HNO}_{3}$ (Appendix 2.2.2.H).

A summary with the wavenumbers of the characteristic Raman peaks for the identified minerals follows as Table 2.2.2.2.

Figure 2.2.2.1 presents a relative abundance of the different types of microinclusions found in the analyzed EDML ice samples; and in Table 2.2.2.3 are gathered the numerical data (used in Fig. 2.2.2.1). (In Appendix 2.2.2.I the data in Fig.2.2.2.1 are presented as percent of each class of microinclusion from the total number of assigned microinclusions).

\footnotetext{
${ }^{41}$ The degree of detailing can be enlarged but for a general overview (or simplicity) the most probable mineral name was used in the text (i.e mirabilite for all $\mathrm{Na}^{+}$and $\mathrm{SO}_{4}{ }^{2-}$ containing phases)
} 
Table 2.2.2.2 Summary of the results from micro-Raman analyses of microinclusions in EDML ice, based on data presented in Appendixes 2.2.2.A-H.

\begin{tabular}{|c|c|c|}
\hline $\begin{array}{l}\text { wavenumber(s) } \\
\quad\left(\text { in } \mathrm{cm}^{-1}\right)\end{array}$ & $\begin{array}{l}\text { assigned } \\
\text { to }\end{array}$ & $\begin{array}{l}\text { assigned conform } \\
\text { reference }\end{array}$ \\
\hline $980-986$ & $\begin{array}{c}\mathrm{K}_{2} \mathrm{SO}_{4} \text { arcanite } \\
\text { or } \mathrm{H}_{2} \mathrm{SO}_{4}\end{array}$ & $\begin{array}{c}\text { Ohno et al. } 2005 \\
\text { Sakurai, } 2010 \\
\end{array}$ \\
\hline $988-996$ & $\begin{array}{l}\mathrm{Na}_{2} \mathrm{SO}_{4} \cdot 10 \mathrm{H}_{2} \mathrm{O} \\
\text { mirabilite or } \\
\mathrm{MgSO}_{4} \cdot 11 \mathrm{H}_{2} \mathrm{O} \\
\text { meridianiite }\end{array}$ & Genceli et al. 2009 \\
\hline $1007-1014$ & \multirow{2}{*}{$\begin{array}{c}\mathrm{CaSO}_{4} \cdot 2 \mathrm{H}_{2} \mathrm{O} \\
\text { gypsum }\end{array}$} & \multirow{2}{*}{ Sakurai et al. 2009} \\
\hline $\begin{array}{c}\sim 415, \sim 492 \\
\sim 620, \sim 670, \sim 1138\end{array}$ & & \\
\hline $\begin{array}{c}1013,1110 \\
360,438,458,583 \\
630,1161.5\end{array}$ & $\begin{array}{c}\mathrm{MFe}_{3}\left(\mathrm{SO}_{4}\right)_{2}(\mathrm{OH})_{6} \\
\mathrm{M}=\mathrm{K} \text { or/and } \mathrm{Na} \\
\text { jarosite }\end{array}$ & $\begin{array}{l}\text { Frost et al. } \\
\quad 2006\end{array}$ \\
\hline 1051.6 & $\begin{array}{c}\mathrm{Ca}\left(\mathrm{NO}_{3}\right)_{2} \\
\text { nitrocalcite }\end{array}$ & Ohno et al. 2005 \\
\hline$\sim 465$ & $\begin{array}{c}\mathrm{SiO}_{2} \\
\text { silica, (quartz) }\end{array}$ & Krishnan, 1945 \\
\hline $\begin{array}{l}\sim 480 \\
\sim 508 \\
\end{array}$ & $\begin{array}{l}\mathrm{NaAlSi}_{3} \mathrm{O}_{8} \\
\text { albite }\end{array}$ & $\begin{array}{c}\text { Bendel and Schmidt, } \\
2008\end{array}$ \\
\hline $\begin{array}{l}\sim 477 \\
\sim 515\end{array}$ & $\begin{array}{l}\mathrm{KAlSi}_{3} \mathrm{O}_{8} \\
\text { sanidine }\end{array}$ & $\begin{array}{l}\text { Velde et al. } 1989 \text { in } \\
\text { Frogner et al. } 1998\end{array}$ \\
\hline $\begin{array}{c}\sim 410,480 \\
510,570\end{array}$ & $\begin{array}{c}\mathrm{CaAl}_{2} \mathrm{Si}_{2} \mathrm{O}_{8} \\
\text { anorthite }\end{array}$ & Le Parc et al. 2003 \\
\hline $\begin{array}{c}\sim 428,471,550, \\
\quad 612,876\end{array}$ & $\begin{array}{c}\mathrm{CaTiSiO}_{5} \\
\text { titanite }\end{array}$ & $\begin{array}{l}\text { Łodziński et al. } \\
2005\end{array}$ \\
\hline 963 & $\begin{array}{c}\mathrm{Ca}_{5} \mathrm{OH}\left(\mathrm{PO}_{4}\right)_{3} \\
\text { apatite }\end{array}$ & $\begin{array}{c}\text { McKeegan et al. } \\
2007\end{array}$ \\
\hline$\sim 1370, \sim 1600$ & carbonaceous matter & Jehlička et al. 2009 \\
\hline $\begin{array}{l}\sim 450 \\
\sim 610\end{array}$ & $\begin{array}{l}\mathrm{TiO}_{2} \\
\text { rutile }\end{array}$ & Swamy et al. 2006 \\
\hline $\begin{array}{c}400,520 \\
\sim 640 \\
\end{array}$ & $\begin{array}{c}\mathrm{TiO}_{2} \\
\text { anatase }\end{array}$ & Zhang et al. 2000b \\
\hline $363,444,551$ & $\begin{array}{l}\text { ? silicate } \\
\text { ? sulfate }\end{array}$ & no specific reference \\
\hline $\begin{array}{c}\sim(440,474,564,635,) \\
\sim 677,747,854,1017\end{array}$ & titanite related mineral & no specific reference \\
\hline$\sim 1048$ & $\mathrm{HNO}_{3}$ & Ohno et al. 2005 \\
\hline
\end{tabular}




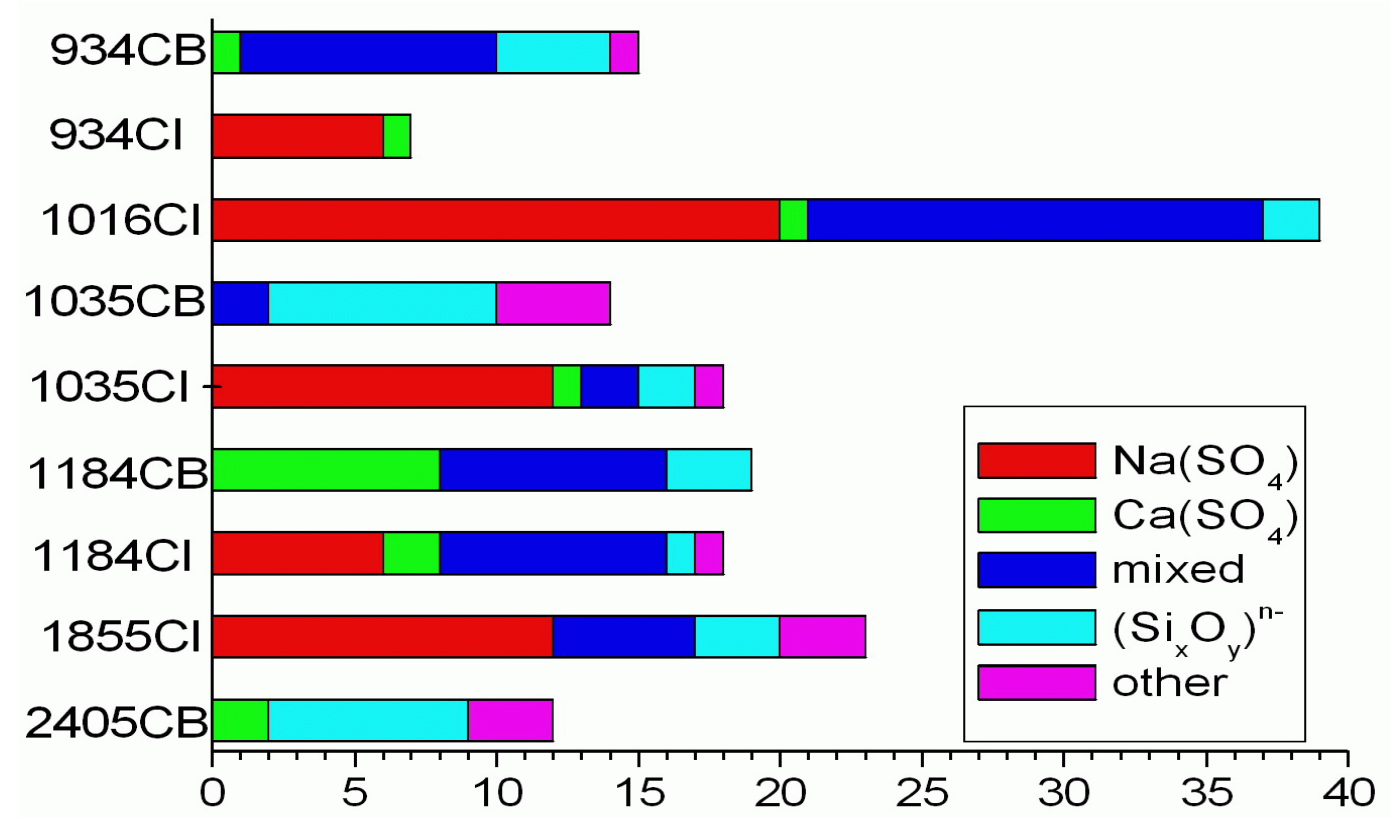

Figure 2.2.2.1 Distribution of the different types of microinclusions identified in the analyzed EDML ice samples, cut from cloudy band (CB) or clear ice (CI) regions. On the horizontal axis is the number of microinclusions. " $\mathrm{Na}\left(\mathrm{SO}_{4}\right)$ " stands for mirabilite (and probably also meridianiite), " $\mathrm{Ca}\left(\mathrm{SO}_{4}\right)$ " for

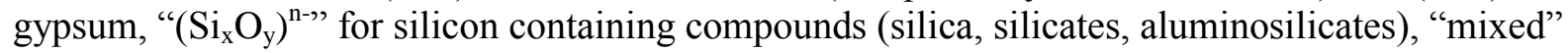
includes microinclusions containing more than one substance, either different sulfates or silicate and sulfate, "other" represents the microinclusions that were assigned but are not included in the other classes, the microparticles that could not be assigned are not depicted.

Table 2.2.2.3. Number distribution of the different types of microinclusions identified in the analyzed EDML ice samples, cut from cloudy band (CB) or clear ice (CI) regions. "(Na)" stands for mirabilite (and if the case also meridianiite), " $\left(\mathrm{SO}_{4}{ }^{2-}\right)$ " for arcanite or $\mathrm{H}_{2} \mathrm{SO}_{4}$, "(Ca)" for gypsum, " $\mathrm{SiO}_{2}$ " for silica, " $\mathrm{Si}_{\mathrm{x}} \mathrm{O}_{\mathrm{y}}$ " for (alumino)silicates, " $\mathrm{mx}$ " includes mixed microinclusions, with either different sulfates or Si containing compounds and sulfate, "oth.id" represents the microinclusions that were assigned but are not included in the other classes, "oth." is for some other microparticles.

\begin{tabular}{|c|c|c|c|c|c|c|c|c|c|}
\hline & $(\mathrm{Na})$ & $\left(\mathrm{SO}_{4}{ }^{2-}\right)$ & $(\mathrm{Ca})$ & $\mathrm{SiO}_{2}$ & $\mathrm{Si}_{\mathrm{x}} \mathrm{O}_{\mathrm{y}}$ & $\mathrm{mx}$ & oth.id & oth. & all \\
\hline $934-\mathrm{CB}$ & - & 5 & 1 & 2 & 2 & 9 & 1 & - & 20 \\
\hline $934-\mathrm{CI}$ & 6 & 1 & 1 & - & - & - & - & - & 8 \\
\hline $1016-\mathrm{CI}$ & 20 & - & 1 & 1 & 1 & 16 & - & - & 39 \\
\hline $1035-\mathrm{CB}$ & - & 3 & - & 6 & 2 & 2 & 4 & 2 & 19 \\
\hline $1035-\mathrm{CI}$ & 12 & 2 & 1 & 2 & - & 2 & 1 & - & 20 \\
\hline $1184-\mathrm{CB}$ & - & - & 8 & 1 & 2 & 8 & - & 2 & 21 \\
\hline $1184-\mathrm{CI}$ & 6 & 1 & 2 & - & 1 & 8 & 1 & - & 19 \\
\hline $1855-\mathrm{CI}$ & 12 & 4 & - & 3 & - & 5 & 3 & - & 27 \\
\hline $2295-\mathrm{CI}$ & 1 & 2 & - & - & - & - & - & - & 3 \\
\hline $2405-\mathrm{CB}$ & - & - & 2 & 1 & 6 & - & 3 & 1 & 13 \\
\hline Sum & 57 & 18 & 16 & 16 & 14 & 50 & 13 & 5 & 189 \\
\hline
\end{tabular}




\title{
2.2.2.a Discussion : Qualitative results
}

\begin{abstract}
"Einmal befragte A66as Arsenios einen alten Ägypter bezüglich seiner eigenen Gedanken (Logimoi). Ein anderer sah das und sprach: Ab6as Arsenios, wie kommt es, daß du, der du eine so große rhomäische und hellenistische Bildung besitzt, diesen einfachen Mann bezüglich deiner Gedanken befragst? Er jedoch antwortete: Die rhomäische und hellenistische Bildung kenne ich zwar, doch das Alphabet dieses Bauern habe ich noch nicht gelernt". ${ }^{42}$
\end{abstract}

\section{Microinclusions with $\mathrm{SO}_{4}{ }^{2-}$}

The sulfate anion $\mathrm{SO}_{4}{ }^{2-}$ has tetrahedric, $\mathrm{T}_{\mathrm{d}}$, symmetry and nine modes of internal vibration $\left(\Gamma_{\text {vibr }}=\mathrm{A}_{1}+\mathrm{E}+2 \mathrm{~F}_{2}\right)$, all Raman active. The symmetric stretching mode, $v_{1}\left(\mathrm{SO}_{4}{ }^{2-}\right)$, is non-degenerate $\left(\mathrm{A}_{1}\right)$, the symmetric bending, $\mathrm{v}_{2}\left(\mathrm{SO}_{4}{ }^{2-}\right)$, is mono-degenerate $(\mathrm{E})$, and the asymmetric stretching, $v_{3}\left(\mathrm{SO}_{4}{ }^{2-}\right)$, and asymmetric bending, $v_{4}\left(\mathrm{SO}_{4}{ }^{2-}\right)$, modes are doublydegenerate $\left(\mathrm{F}_{2}\right)$. In aqueous solutions the wavenumbers for these $\mathrm{SO}_{4}{ }^{2-}$ vibrations are (around): $983,448,1114$ and $607 \mathrm{~cm}^{-1}$ respectively. The $v_{1}\left(\mathrm{SO}_{4}{ }^{2-}\right)$ band, being sensitive to the changes in the $\mathrm{SO}_{4}{ }^{2-}$ surroundings, can be used for gaining information about the interactions between the sulfate anion and the respective countercations (Alpers, 2000; Wang et al. 2005; and the references therein).

For this study the $v_{1}\left(\mathrm{SO}_{4}{ }^{2-}\right)$ vibration was the most evident and was used for distinguishing between different substances forming the investigated microinclusions existent in EDML ice. The other characteristic Raman modes of the sulfate anion did not appear in all the spectra were the $v_{1}$ mode was active. It seems that the peak due to the $v_{2}$ mode of sulfate was the next frequent recorded in the registered Raman spectra, followed by $v_{3}$ and $v_{4}$.

\section{Sodium sulfate—(mirabilite $)-$ microinclusions}

"There is something magical and mysterious about the ice on newly frozen leads. Earlier in the expedition when the temperatures were colder, the ice crystals grew on the new sea ice like chrysanthemum flowers or feathers. $\mathcal{N}$ ow, the new ice on frozen leads is covered with snow crystals, similar to a thick,carpet of fuzz. It reminds me of looking down from a plane onto a forest of deciduous trees. "43

Raman spectra assigned to $\mathrm{Na}_{2} \mathrm{SO}_{4} \cdot 10 \mathrm{H}_{2} \mathrm{O}$ microinclusions in (polar) ice were previously reported (Ohno et al. 2005, 2006; Genceli et al. 2009; Sakurai et al. 2009; Sakurai et al. 2010a; Sakurai, 2010). In Table 2.2.2.4 are gathered characteristic wavenumbers assigned to mirabilite. Figure 2.2.2.2. shows a (representative) Raman spectrum of a microinclusion in EDML ice considered to contain $\mathrm{Na}_{2} \mathrm{SO}_{4} \cdot 10 \mathrm{H}_{2} \mathrm{O}$. Raman spectra for the ice matrix can be seen in Appendix 2.2.2.J.

The main peak, (from $v_{1} \mathrm{SO}_{4}$ ), in the Raman spectra assigned to $\mathrm{Na}_{2} \mathrm{SO}_{4} \cdot 10 \mathrm{H}_{2} \mathrm{O}$ containing microinclusions had (usually) values between 990 and $997 \mathrm{~cm}^{-1}$ (spectra in Appendix 2.2.2.A). The higher values were recorded in the case of the 1035 EDML ice sample and might be caused (also but not only) by the measurement procedure. The other characteristic peaks for mirabilite have, in most of the cases, a low signal to noise ratio. Sometimes, observable peaks that could be from the $v_{2}\left(\right.$ or $\left.v_{4}\right) \mathrm{SO}_{4}$ appear in the Raman spectra assigned to mirabilite, but they can rather be considered characteristic for other compounds (discussed in the following sections).

42 in "Sprüche der Väter", hrsg. u. übers. von Pater Bonifatius. Verl. Styria, 1963, pg. 43

43 in McNair, 1999, pg. 71 
Table 2.2.2.4. Frequency values in the Raman spectra of $\mathrm{Na}_{2} \mathrm{SO}_{4} \cdot 10 \mathrm{H}_{2} \mathrm{O}$, in cm $\mathrm{cm}^{-1}$

\begin{tabular}{|c|c|c|c|c|}
\hline Synthetic $^{\mathrm{a}}$ & Market chemicals $^{\mathrm{b}}$ & $\begin{array}{c}\text { Market available } \\
(\mathrm{RT})^{\mathrm{c}}\end{array}$ & $\begin{array}{c}\text { Market available } \\
\left.80^{\circ} \mathrm{C}\right)\end{array}$ & Assignment \\
\hline $990 \mathrm{vs}$ & 990 & 994 & 997 & $\mathrm{v}_{1} \mathrm{SO}_{4}$ \\
\hline $456 \mathrm{~s}$ & $(\sim 465)$ & 449 & 469 & $\mathrm{v}_{2} \mathrm{SO}_{4}$ \\
\hline $1112 \mathrm{~m}$ & $(\sim 1005)$ & 466 & 1105 & $\mathrm{v}_{3} \mathrm{SO}_{4}$ \\
$1127 \mathrm{sh}$ & & 1102 & 1137 & \\
\hline $613 \mathrm{~m}$ & - & 1132 & 1157 & $\mathrm{v}_{4} \mathrm{SO}_{4}$ \\
\hline
\end{tabular}

${ }^{\mathrm{a}}$ Genceli et al. 2009 (vs=very strong, $\mathrm{m}=$ medium, sh=shoulder); ${ }^{\mathrm{b}}$ Ohno et al. $2005{ }^{\mathrm{c}}{ }^{\mathrm{t}}$ this study (RT=room temperature).

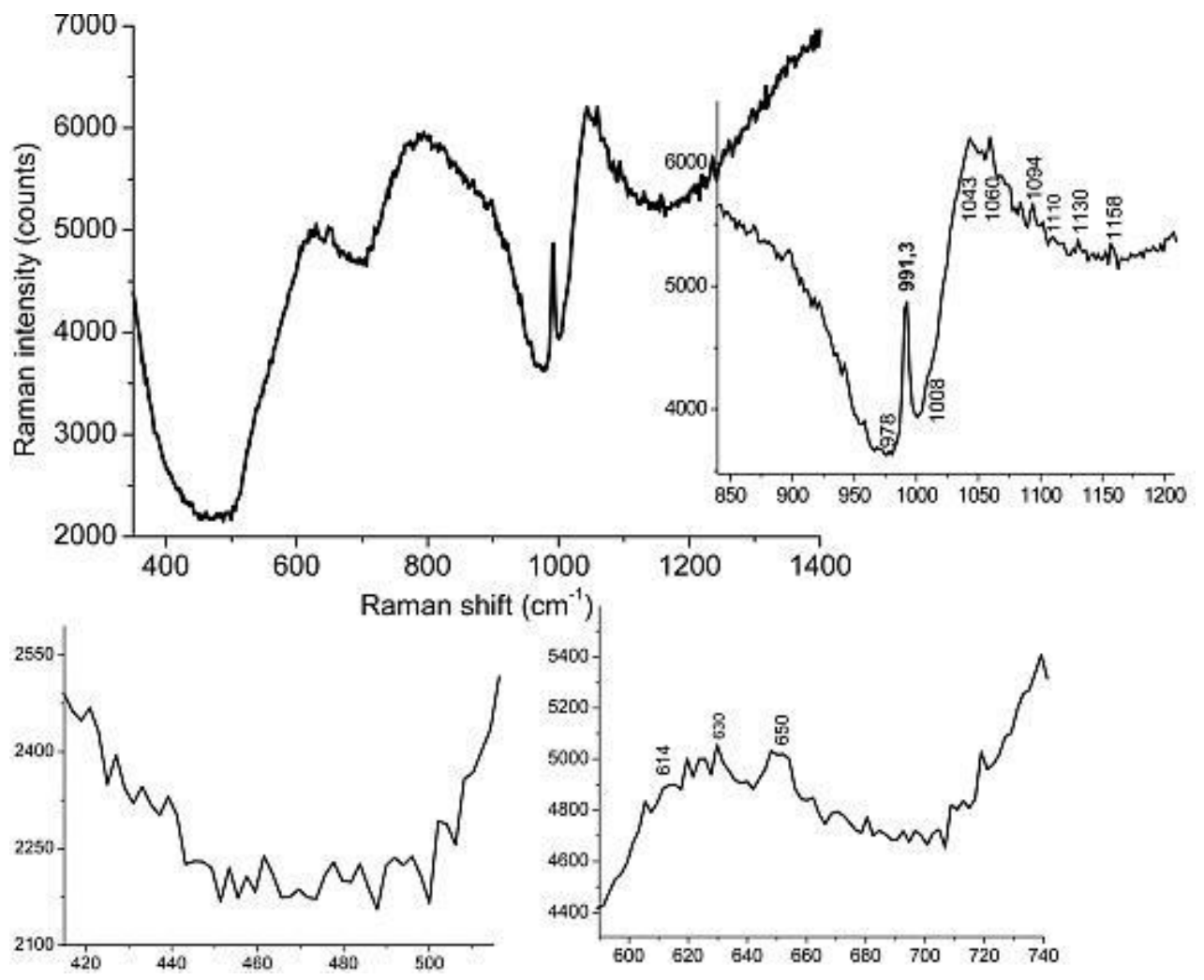

Figure 2.2.2.2. Raman spectrum assigned to a mirabilite containing microinclusion in EDML ice (from Appendix 2.2.2.A: example 3 at 1855 EDML depth, clear ice). The spectral regions of interest have been enhanced and the wavenumbers of some observable peaks have been written. Relevant for mirabilite should be the peaks at: $991,1130,614 \mathrm{~cm}^{-1}$ and probably also the ones at: $1158,650 \mathrm{~cm}^{-1}$.

The shape of the Raman peak of the $\mathrm{SO}_{4}{ }^{2-}$ symmetric stretching in a few spectra assigned to mirabilite is distorted. For example, a shoulder around $986 \mathrm{~cm}^{-1}$ can be identified (Figure 2.2.2.3). (The peak in Fig. 2.2.2.3 can be also seen as two overlapping peaks centered at $986 \mathrm{~cm}^{-1}$ and $\left.990 \mathrm{~cm}^{-1}\right)$. Its most probable source is the existence of some other substance in the investigated microinclusion, most probably a sulfate. A suitable candidate would be the potassium sulfate (arcanite, Table 2.2.2.8). On the other hand, wavenumbers similar with the ones reported for arcanite were reported for $\mathrm{H}_{2} \mathrm{SO}_{4}$ solutions (Wang et al. 2005, Ohno et al. 2005). If the shoulder is from arcanite then it should be in very low amount and well mixed with the mirabilite crystals, but even so it would be expected that some crystalline impurities to 
provide a well defined Raman peak of low intensity (rather the small peak on the high energy side at $1010 \mathrm{~cm}^{-1}$ can be considered as coming from some gypsum impurities, especially that the other characteristic peaks can be identified, Table 2.2.2.6).

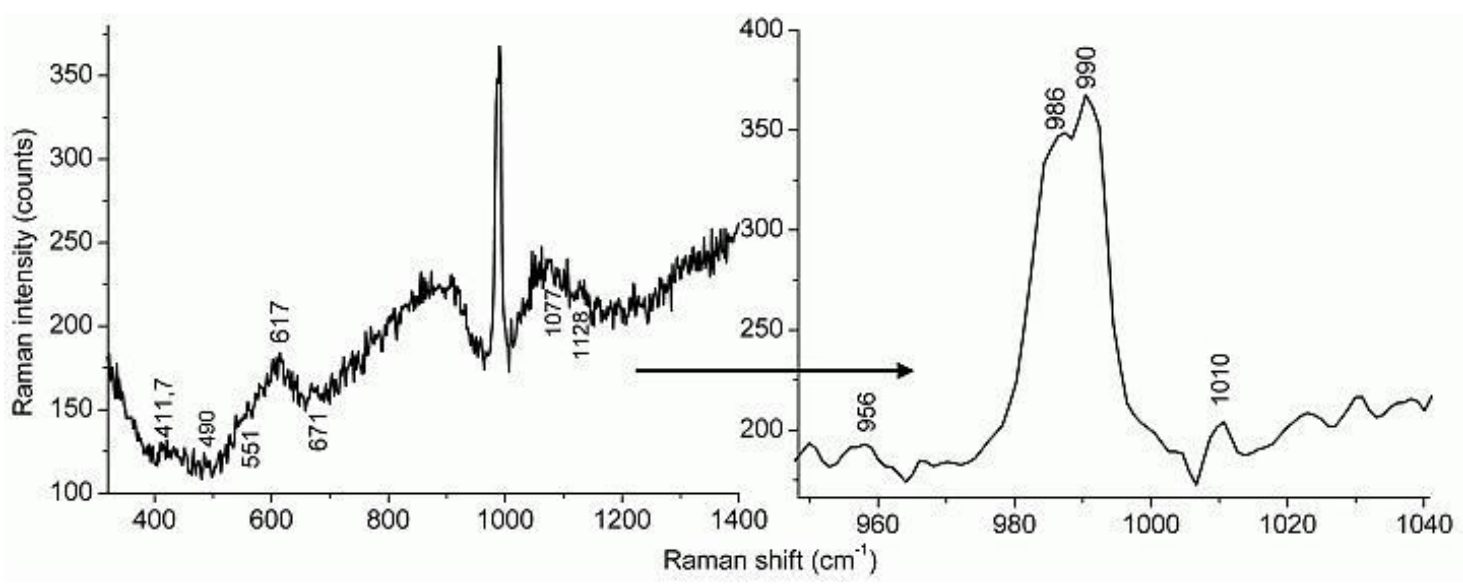

Figure 2.2.2.3. Raman spectrum assigned to a mirabilite containing microinclusion in EDML ice, (Appendix 2.2.2.A: example 6 at 1016 EDML depth).

Therefore, the possibility to have mirabilite and sulfuric acid in the same microiclusion in EDML ice appears more probable. This means that the respective microinclusion (type) is a sodium sulfate solution. The presence of other cations (and/or anions) cannot be excluded. Kanno (1990) considered a sharp peak at $987 \mathrm{~cm}^{-1}$ in Raman spectra of glassy sulfuric acid, as " $a$ strong support for the contention that ionization of concentrated $\mathrm{H}_{2} \mathrm{SO}_{4}$ is almost complete at low temperatures". Tomikawa and Kanno (1998) investigated solutions of sulfuric acid at low temperatures and observed that the $\mathrm{SO}_{4}{ }^{2-}$ anions start to disappear at $\sim 50$ weight $\%$, concentration (at $-40^{\circ} \mathrm{C}$ ). Also, "above $70 \mathrm{wt} \%$, Raman peaks due to $\mathrm{HSO}_{4}^{-}$ions appear and gradually grow to be dominant above $80 \mathrm{wt} \% \mathrm{H}_{2} \mathrm{SO}_{4}$ ". These peaks are at $\sim 890 \mathrm{~cm}^{-1}$ (asymmetric stretching vibration) and $\sim 1040 \mathrm{~cm}^{-1}$ (symmetric stretching). The $700-940 \mathrm{~cm}^{-1}$ spectral region of the Raman spectrum in Figure 2.2.2.3 is not as it would be expected from the ice matrix, (see Figure 2.2.2.2 and Appendix 2.2.2.J). The polarization towards higher wavenumbers of the librational vibrations peak at around $800 \mathrm{~cm}^{-1}$ of (EDML) ice (Fukazawa and Mae, 2000) can be caused by the peak at $\sim 890 \mathrm{~cm}^{-1}$ corresponding to $\mathrm{HSO}_{4}^{-}$anions. If so then the Raman spectrum in Fig. 2.2.2.3 corresponds to a microinclusions in EDML ice containing (concentrated) $\mathrm{H}_{2} \mathrm{SO}_{4}$. Dong et al. (2009) assigned a shoulder at $\sim 986 \mathrm{~cm}^{-1}$ with the formation of $\mathrm{Na}^{+}$and $\mathrm{SO}_{4}{ }^{2-}$ contact ion pairs (see further).

Another example of distorted mirabilite peak is shown in Figure 2.2.2.4. Two shoulders around $980 \mathrm{~cm}^{-1}$ and $987 \mathrm{~cm}^{-1}$ can be identified (also Appendix 2.2.2.A: example 13, 15 at 1016 EDML depth, clear ice). This cannot be an asymmetry caused by the spectrometer. The cause for the shoulder at $980 \mathrm{~cm}^{-1}$ is very likely hydrated $\mathrm{SO}_{4}{ }^{2-}$ anions. Rull and Ohtaki (1997) measured Raman spectra of aqueous alkali sulfate solutions and obtained values of $\sim 980 \mathrm{~cm}^{-1}$ for the $v_{1}$ mode of $\mathrm{SO}_{4}{ }^{2-}$. For $\mathrm{Na}^{+}$cation, which has a positive hydration energy, a positive shift in the band profile and an asymmetry (with increasing concentration of $\mathrm{Na}^{+}$) was identified.

Sakurai (2010) extended the work of Ohno et al. $(2005 ; 2006)$ and investigated the nature of the microinclusions labeled "a sulfate with a main peak at $984 \mathrm{~cm}^{-1}$ " reported in the latter papers as trapped in Dome Fuji ice. He presents evidence for the possibility of having microinclusions in polar ice as liquid solutions with $\mathrm{Na}_{2} \mathrm{SO}_{4}$ and (a high concentration of) $\mathrm{HCl}$. He found this type of impurities also in Holocene EDML ice. This comes to support the abovewritten interpretations. 


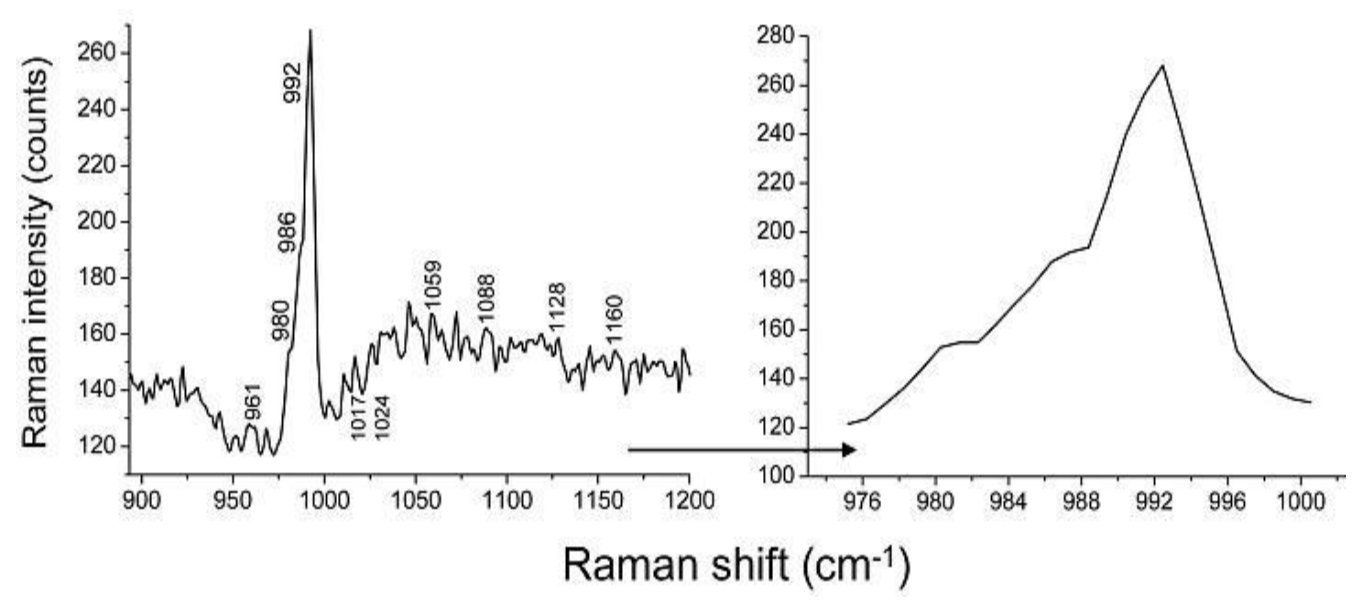

Figure 2.2.2.4. Enhanced part of a Raman spectrum assigned to a mirabilite containing microinclusion in EDML ice, (Appendix 2.2.2.A: example 13 at 1016 EDML depth). The asymmetry of the $v_{1} \mathrm{SO}_{4}{ }^{2-}$ peak at $992 \mathrm{~cm}^{-1}$ is caused by shoulders at circa $980 \mathrm{~cm}^{-1}$ and around $986 \mathrm{~cm}^{-1}$.

If $\mathrm{HCl}$ is the substance inducing asymmetry in the Raman peaks attributable to mirabilite and the mineral is in fact preserved in ice as solution, then Fig. 2.2.2.3 presents a Raman spectrum for a microinclusion in EDML ice that should contain all the $\mathrm{SO}_{4}{ }^{2-}$ anions combined with $\mathrm{Na}^{+}$, while Fig. 2.2.2.4 shows a Raman spectrum of a microinclusion in EDML ice containing some more sulfate anions than $\mathrm{Na}^{+}$(and $\mathrm{Cl}^{-}$) ions. Or in other words, considering also the work of Daly et al. (1972) (presented further in the text), an excess of $\mathrm{HCl}$ and consequently an excess of $\mathrm{H}^{+}$allows the formation of $\mathrm{HSO}_{4}{ }^{-}$from the available $\mathrm{SO}_{4}{ }^{2-}$ ions, either from natrium sulfate or from liquid $\mathrm{H}_{2} \mathrm{SO}_{4}$. Further Sakurai (2010) measured the temperature dependence of some "peak at $984 \mathrm{~cm}^{-1}$ ", type microinclusions in Dome Fuji ice at (and below) $-30^{\circ} \mathrm{C}$ and two shoulders on the high frequency side appeared, (at $\sim 986$ and $\sim 993 \mathrm{~cm}^{-1}$ ), suggesting the occurrence of a phase transition in the system. The microinclusion is supposed to be formed of $\mathrm{H}_{2} \mathrm{SO}_{4}$, mirabilite and thenardite, (anhydrous $\mathrm{Na}_{2} \mathrm{SO}_{4}$ ). It can be also the case for the microinclusion from EDML ice, of which the Raman spectrum is shown in Fig. 2.2.2.4 (but with different proportion between the phases).

The third type of distortion of the $v_{1} \mathrm{SO}_{4}{ }^{2-}$ peak, attributed to mirabilite containing microinlcusions in EDML ice, is (from shoulders) on its high energy side (Figure 2.2.2.5). The center of the distorting feature is around $1000 \mathrm{~cm}^{-1}$ (or/and around $997 \mathrm{~cm}^{-1}$, Figure 2.2.2.6). Again its most probable cause is the existence of another sulfate mineral and of course the presence of sulfuric acid or other free ions cannot be excluded.

Dubessy et al. (1983) used Raman microprobe to determine the sulfate contained in fluid inclusions in halite. They observed that improved spectral resolution revealed the possible existence of a complex sulfate or an association of sulfates. Thus, weak bands (or shoulders) at $\sim 1001$ and $\sim 1009 \mathrm{~cm}^{-1}$ in a Raman spectrum assigned to anhydrite, (which in Dubessy et al. (1983) investigations has the $v_{1} \mathrm{SO}_{4}{ }^{2-}$ around $1019 \mathrm{~cm}^{-1}$ ), can be considered to be from glauberite $\left(\mathrm{Na}_{2} \mathrm{Ca}\left(\mathrm{SO}_{4}\right)_{2}\right)$ and gypsum. The enhanced part of the Raman spectrum in Fig. 2.2.2.5 could reveal the existence of such an association of $\mathrm{Na}$ and $\mathrm{Ca}$ sulfates in EDML ice.

Low intensity peaks around 970, 1010, $1020 \mathrm{~cm}^{-1}$ in the Raman spectra assigned to mirabilite containing microinclusions observed in EDML ice can be identified on a detailed inspection, (Appendix 2.2.2.A: example 6, 7, 8, 14 at 1016 EDML depth, clear ice; example 1, 8, 13,14 at 1855 EDML depth, clear ice), but even if they are produced by a coexisting impurity (and not only from the inherent background), this impurity is in very low amount. A feature at $974 \mathrm{~cm}^{-1}$ is correlated with the ${ }^{18} \mathrm{O}$ fraction of sulfate ions (Rull and Sobrón 1994; Dong et al. 2009). $\left(\mathrm{NH}_{4}\right)_{2} \mathrm{SO}_{4}$ has $v_{1} \mathrm{SO}_{4}$ at $975 \mathrm{~cm}^{-1}$ (Dong et al. 2007; Sakurai et al. 2010a) and also some iron sulfates (Chio et al. 2007). 


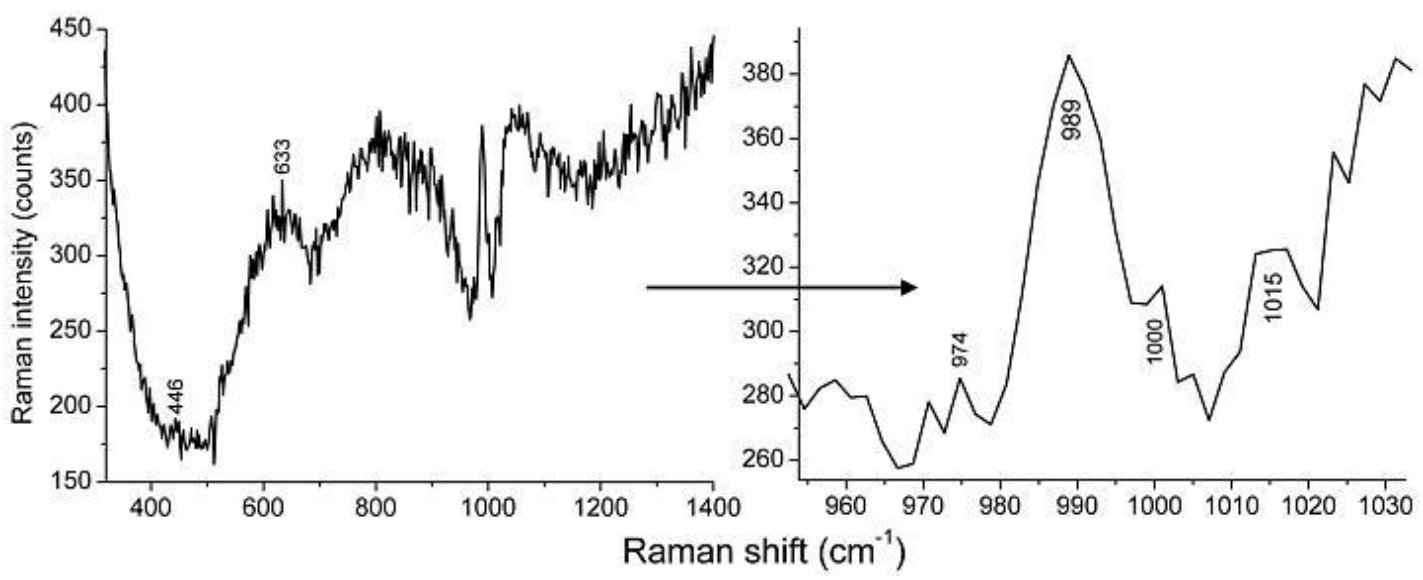

Figure 2.2.2.5. Raman spectrum assigned to a mirabilite containing microinclusion in EDML ice, (Appendix 2.2.2.A: example 6 at 1184 EDML depth). The asymmetry of the $v_{1} \mathrm{SO}_{4}{ }^{2-}$ peak at 989 $\mathrm{cm}^{-1}$ is caused by a pronounced shoulder at circa $1000 \mathrm{~cm}^{-1}$.

\section{Magnesium sulfate—(meridianiite)—microinclusions}

The magnesium sulfate, meridianiite, $\left(\mathrm{MgSO}_{4} \cdot 11 \mathrm{H}_{2} \mathrm{O}\right)$ has a very similar Raman fingerprint with the sodium sulfate $\left(\mathrm{Na}_{2} \mathrm{SO}_{4} \cdot 10 \mathrm{H}_{2} \mathrm{O}\right)$ and they are hard to be distinguished when they are found as microinclusions in (polar) ice (Genceli et al. 2009). In Table 2.2.2.5 reported values for the characteristic Raman peaks' wavenumbers of meridianiite are gathered. With the experimental settings used for this study it was not possible to make a clear distinction between $\mathrm{Na}$ and $\mathrm{Mg}$ sulfates. Nevertheless, a discussion can be constructed for a few Raman spectra attributed to mirabilite containing microinclusions.

A small peak around $440 \mathrm{~cm}^{-1}\left(v_{2} \mathrm{SO}_{4}\right)$ or/and around $620 \mathrm{~cm}^{-1}$ could indicate the presence of meridianiite instead or mixed with mirabilite (Appendix 2.2.2.A: example 11, 18, 23 at 1016 EDML depth; 3, 7 at 1035 EDML depth, clear ice; 4 at 1184 EDML depth, clear ice). Also, in the Raman spectral region 1000 to $1100 \mathrm{~cm}^{-1}$ the ice matrix produces a (usually) sharp peak at $\sim 1047$ $\mathrm{cm}^{-1}$ (Appendix 2.2.2.J). Sometimes this part of the spectrum is rounded and broad maybe due to the $v_{3} \mathrm{SO}_{4}$ at $1070 \mathrm{~cm}^{-1}$ characteristic for meridianiite. It is difficult to clearly say that this is the cause because this peak was not detected for meridianiite microinclusions in Antarctic ice by Genceli et al. (2009). Besides the Raman spectra for the ice matrix (the background also considered) has most of the times a small sharp peak around $1070 \mathrm{~cm}^{-1}$.

Figure 2.2.2.6 shows an enhanced part from a (type of) Raman spectrum that might be assigned to a meridianiite (or $\mathrm{MgSO}_{4}$ ) containing microinclusion instead of mirabilite (in Appendix 2.2.2.A, example: 2 at 934 EDML depth, clear ice; 9 at 1184 EDML depth, clear ice; 1 at 2295 EDML depth, clear ice).

Rull and Sobrón (1994) have studied the $v_{1} \mathrm{SO}_{4}$ band profile for aqueous solutions with mono- and divalent cations. For $\mathrm{Li}^{+}$and $\mathrm{Mg}^{2+}$ an asymmetry on the high wavenumber side was observable and was attributed to different associations of the S-O oscillators or to the perturbation of the water molecules around the $\mathrm{SO}_{4}{ }^{2-}$ anion. Rull et al. (1994) concluded from Raman spectroscopic studies on $\mathrm{MgSO}_{4}$ aqueous solutions that the results obtained in the 200$800 \mathrm{~cm}^{-1}$ spectral range support the conclusion that the $\mathrm{SO}_{4}{ }^{2-}$ symmetry does not change from ion association in the concentration range $0.5-2.8 \mathrm{~m}$ (and for temperatures between 5 to $80^{\circ} \mathrm{C}$ ) and the $\mathrm{Mg}\left(\mathrm{H}_{2} \mathrm{O}\right)$, complex is stable in the same concentration and temperature ranges studied (although the $\mathrm{Mg}-\mathrm{OH}$, bonds become weaker as the temperature increases). Also as the 
concentration of magnesium sulfate increases a shoulder around $995 \mathrm{~cm}^{-1}$ becomes well defined in the Raman spectrum.

Table 2.2.2.5 Frequency values in the Raman spectra of $\mathrm{MgSO}_{4} \cdot 11 \mathrm{H}_{2} \mathrm{O}$, in cm $\mathrm{cm}^{-1}$

\begin{tabular}{|l|l|l|l|c|}
\hline Synthetic & Antarctic ice & Sea ice & Market chemicals & Assignment \\
\hline $990 \mathrm{vs}$ & $990 \mathrm{vs}$ & $990 \mathrm{vs}$ & 989 & $v_{1} \mathrm{SO}_{4}$ \\
\hline $444 \mathrm{~m}$ & $446 \mathrm{~m}$ & $445 \mathrm{~m}$ & $(\sim 435)$ & $v_{2} \mathrm{SO}_{4}$ \\
$457 \mathrm{sh}$ & $454 \mathrm{sh}$ & $458 \mathrm{sh}$ & & \\
\hline $1116 \mathrm{~m}$ & $1117 \mathrm{~m}$ & 1117 & $(\sim 1110)$ & $v_{3} \mathrm{SO}_{4}$ \\
$1070 \mathrm{w}$ & ---- & $1071 \mathrm{w}$ & & \\
\hline $619 \mathrm{~m}$ & $621 \mathrm{~m}$ & $621 \mathrm{~m}$ & $(\sim 607)$ & $v_{4} \mathrm{SO}_{4}$ \\
\hline
\end{tabular}

${ }^{\mathrm{a}}$ Genceli et al. 2009 (vs=very strong, $\mathrm{m}=$ medium, sh=shoulder, $\mathrm{w}=$ wide); ${ }^{\mathrm{b}}$ Ohno et al. 2005

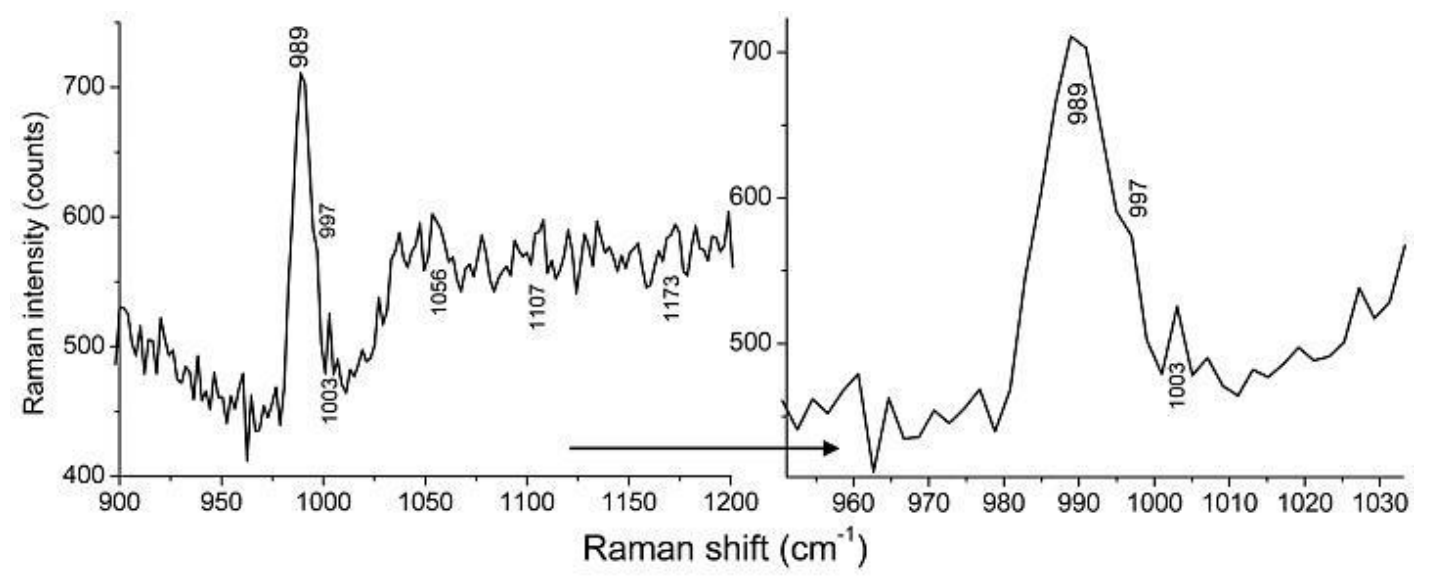

Figure 2.2.2.6 Raman spectrum that can be assigned to a mirabilite containing microinclusion in EDML ice, (Appendix 2.2.2.A: example 11 at 1184 EDML depth, clear ice). The asymmetry of the $v_{1} \mathrm{SO}_{4}{ }^{2-}$ peak at $989 \mathrm{~cm}^{-1}$ is caused by a shoulder at circa $997 \mathrm{~cm}^{-1}$.

On the other hand, Daly et al. (1972) used Raman spectroscopy to determine if any ion pairing occurs in aqueous solutions of sodium and magnesium sulfates. It was observed that when $\mathrm{HCl}$ was added to a solution of $\mathrm{Na}_{2} \mathrm{SO}_{4}$ in the respective Raman spectrum the bands characteristic for $\mathrm{HSO}_{4}{ }^{-}$appeared at approximately $895 \mathrm{~cm}^{-1}$ (S-OH stretching mode) and 1053 $\mathrm{cm}^{-1}\left(\mathrm{SO}_{3}\right.$ symmetric stretching mode), while when $\mathrm{NaCl}$ or $\mathrm{MgCl}_{2} \cdot 6 \mathrm{H}_{2} \mathrm{O}$ solutions were added no change occurred. It seems that both $\mathrm{Na}^{+}$and $\mathrm{Mg}^{2+}$ lowered the intensity of the $\mathrm{vHSO}_{4}{ }^{-}$(at $1053 \mathrm{~cm}^{-1}$ ) and increased the intensity of the $v_{1} \mathrm{SO}_{4}$ peak (at $982 \mathrm{~cm}^{-1}$ ). Thus the existence of $\mathrm{MgSO}_{4}$ ion pairing could be proved. Davis and Oliver (1973) have extended the work of Daly et al. (1972) and measured Raman spectra of more concentrated $\mathrm{MgSO}_{4}$ solutions, using $\mathrm{Na}_{2} \mathrm{SO}_{4}$ solutions as comparison. It resulted that in the Raman spectra of $\mathrm{MgSO}_{4}$ solution exists two peaks at $982 \mathrm{~cm}^{-1}$ and $995 \mathrm{~cm}^{-1}$. The relative intensity of the band at $995 \mathrm{~cm}^{-1}$ increases when $\mathrm{MgCl}_{2}$ is added to the solution. No differences between $\mathrm{Na}_{2} \mathrm{SO}_{4}$ and $\mathrm{MgSO}_{4}$ solutions were observed in the other frequency regions of the Raman spectrum $\left(\mathrm{v}_{2}(\mathrm{E})=450 \mathrm{~cm}^{-1} ; \mathrm{v}_{3}\left(\mathrm{~F}_{2}\right)=1115 \mathrm{~cm}^{-1} ; \mathrm{v}_{4}\left(\mathrm{~F}_{2}\right)=\right.$ $\left.616 \mathrm{~cm}^{-1}\right)$. It was concluded that the band at $995 \mathrm{~cm}^{-1}$ is produced by the sulfate in the contact ion pair $\left[\mathrm{MgSO}_{4}\right]$.

Zhang et al. (2000a) studied the contact ion pairs in magnesium sulfate solutions, (in levitated droplets of $\sim 30 \mu \mathrm{m})$, via Raman spectroscopy and observed that the $v_{1}-\mathrm{SO}_{4}{ }^{2-}$ band has a frequency shift from 982 to $1007 \mathrm{~cm}^{-1}$ as the saturation of the solution increased. Again the shoulder observed at $995 \mathrm{~cm}^{-1}$ was assigned to $\mathrm{MgSO}_{4}$ contact ion pairs. Further, Wang et al. (2005) investigated the hydration-dehydration process of $\mathrm{MgSO}_{4}$ droplets $(\sim 80 \mu \mathrm{m}$ in diameter) by Raman spectroscopy. The $v_{1}-\mathrm{SO}_{4}{ }^{2-}$ band gets weak at $983 \mathrm{~cm}^{-1}$, rises at $995 \mathrm{~cm}^{-1}$, and finally 
becomes a wide peak at $1021 \mathrm{~cm}^{-1}$ in the dehumidifying process. This was explained by formation of contact ion pairs in which the $\mathrm{SO}_{4}{ }^{2-}$ anion is bonded to the $\mathrm{Mg}^{2+}$ cation in a monodentate and then bidentate manner. (The band at $1021 \mathrm{~cm}^{-1}$ was assigned to $\mathrm{MgSO}_{4}$ gels chain structure, (Wang et al. 2008)).

Therefore, the morphology of the peak shown in Fig. 2.2.2.6 can be the consequence of the presence of (liquid) microinclusions in EDML ice containing (solutions or mixtures of/with) magnesium sulfate.

Dong et al. (2009) studied mixed $\mathrm{Na}_{2} \mathrm{SO}_{4} / \mathrm{MgSO}_{4}$ aerosol particles via spatially resolved Raman spectroscopy. For droplets of 1:1 molar ratio as the degree of humidity decreased, the formation of $\mathrm{Na}_{2} \mathrm{SO}_{4}$ phase III (observed Raman peaks at 996, 617, 634 $\mathrm{cm}^{-1}$ ) or blödite $\left(\mathrm{Na}_{2} \mathrm{SO}_{4} \mathrm{MgSO}_{4} \cdot 4 \mathrm{H}_{2} \mathrm{O}\right)$ crystallized (observed Raman peaks at 1071 and $\left.1211 \mathrm{~cm}^{-1}\right)$. On the edges of 2:1 molar ratio $\mathrm{Na}_{2} \mathrm{SO}_{4} / \mathrm{MgSO}_{4}$ aerosol droplets precipitated only anhydrous $\mathrm{Na}_{2} \mathrm{SO}_{4}$ in phase III (at approximately $80 \%$ relative humidity). This can be explained by the existence of more $\mathrm{Na}^{+}$ ions that induce rapid growth of thenardite once the crystallization begins. Also the high concentration of $\mathrm{Na}^{+}$ions permits the formation of contact ion pairs of $\mathrm{Na}^{+}$and $\mathrm{SO}_{4}{ }^{2-}$ as it is proved by the presence of a shoulder at $986 \mathrm{~cm}^{-1}$. "On further decreasing the [relative humidity], another shoulder appears at $1005 \mathrm{~cm}^{-1}$ and evolves finally into the main peak at $62 \%$ [relative humidity], indicating that more and more bidentate [contact ion pairs] of $\mathrm{Mg}^{2+}$ and $\mathrm{SO}_{4}{ }^{2-}$ have formed".

As a general conclusion, an asymmetry on the high energy side of the Raman peak attributable to sodium sulfate, if it is not produced by another of its phases, can have as cause the existence of various quantities of magnesium sulfate but towards the saturation values with respect to this sulfate.

Again it has to be stated that the data presented in this study are insufficient for making a distinction between sodium or magnesium sulfates. But, as long as the peak in the Raman spectra attributed to microinclusions in EDML ice containing mirabilite (or meridianiite) do not have a well defined bell shape it is logical to consider that they are generated by a mixture of related compounds in solid or liquid state.

\section{Calcium sulfate—(gypsum)—microinclusions}

Raman spectra of microinclusions existent in the investigated EDML ice samples considered to contain calcium sulfate are presented in Appendix 2.2.2.B. In Tables 2.2.2.6 and 2.2.2.7 characteristic Raman wavenumbers are shown and a representative example from a gypsum containing microinclusion is shown in Figure 2.2.2.7.

The main peak $\left(v_{1} \mathrm{SO}_{4}\right)$ frequencies in the Raman spectra assigned to calcium sulfate microinclusions are between 1007 and $1014 \mathrm{~cm}^{-1}$. Sometimes a small peak around $1024 \mathrm{~cm}^{-1}$ can be distinguished (Appendix 2.2.2.B example 2 at 1184 EDML depth, clear ice) or a shoulder around $1013 \mathrm{~cm}^{-1}$ (Appendix 2.2.2.B example 13, 7 at 1184 EDML depth, cloudy ice) or a broader peak (Appendix 2.2.2.B example 13' at 1184 EDML depth, cloudy ice).

As for the case of $\mathrm{Na}$ (or $\mathrm{Mg}$ ) sulfate the existence of different forms of Ca sulfate can explain the shape of the $v_{1} \mathrm{SO}_{4}$ recorded for microinclusions in EDML ice. It must be taken into consideration that the shift towards higher frequencies can be due simply to the measurement settings. For example, in Appendix 2.2.2.B the case no. 7 at 1184 EDML depth, cloudy band ice, has all the $\mathrm{SO}_{4}{ }^{2-}$ frequencies shifted by $\sim 5 \mathrm{~cm}^{-1}$, but the $v_{1}, v_{2}, v_{3}$ of sulfate anion can not be observed in all the measured Raman spectra discussed here. Another explanation can be the presence of other sulfates together with gypsum and the most probable is the Na sulfate (example 1 at 1184 EDML depth, clear ice has a small peak at $\sim 990 \mathrm{~cm}^{-1}$ ). 


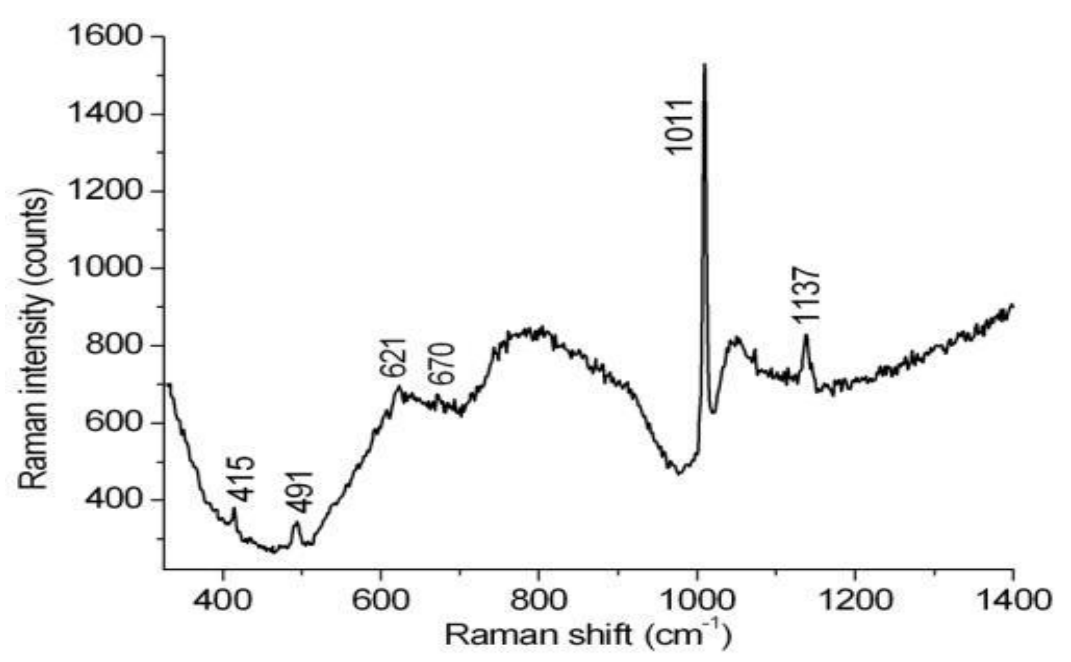

Figure 2.2.2.7 Raman spectrum assigned to a gypsum containing microinclusion in EDML ice (from Appendix 2.2.2.B: example 2 at 2405 EDML depth, cloudy ice).

Table 2.2.2.6 Frequency values in the Raman spectra of $\mathrm{CaSO}_{4} \cdot 2 \mathrm{H}_{2} \mathrm{O}$, in cm $\mathrm{cm}^{-1}$

\begin{tabular}{|l|l|l|c|}
\hline In prepared impure ice & Greenland ice & Market chemicals & Assignment \\
\hline 1007.84 & 1009.05 & 1008 & $v_{1} \mathrm{SO}_{4}$ \\
\hline 413.6 & 414.23 & $(\sim 415)$ & $v_{2} \mathrm{SO}_{4}$ \\
493.07 & 493.04 & $(\sim 495)$ & \\
\hline 1137.33 & 1138.51 & $(\sim 1135)$ & $v_{3} \mathrm{SO}_{4}$ \\
\hline 620.78 & 620.75 & $(\sim 615)$ & $v_{4} \mathrm{SO}_{4}$ \\
670.25 & 670.22 & $(\sim 670)$ & \\
\hline
\end{tabular}

${ }^{\mathrm{a}}$ Sakurai et al. 2009; ${ }^{\mathrm{b}}$ Ohno et al. 2005

Xiao et al. (2008a) performed Raman spectra on individual natural seawater droplets in the efflorescence process and observed that gypsum separates occasionally instead of bassanite, $\mathrm{CaSO}_{4} \cdot 0.5 \mathrm{H}_{2} \mathrm{O}$, (Raman bands at 1012, 431, 490, 1150, 602, 635, $661 \mathrm{~cm}^{-1}$ ), followed by $\mathrm{NaCl}$ and $\mathrm{KMgCl}_{3} \cdot 6 \mathrm{H}_{2} \mathrm{O}$. "However, the presence of $\mathrm{CaSO}_{4} \cdot 0.5 \mathrm{H}_{2} \mathrm{O}$ is astonishing because this phase is always metastable compared to $\mathrm{CaSO}_{4} \cdot 2 \mathrm{H}_{2} \mathrm{O}$ and $\mathrm{CaSO}_{4}$ ". The stability can be caused by the micron-size of the medium.

At this state of data interpretation I consider just that another phase of calcium sulfate can be present in microinclusions trapped in EDML ice. Also the case in which the microinclsions in (EDML/polar) ice contain $\mathrm{CaSO}_{4}$ solutions (it is known that $\mathrm{Ca}$ sulfate can be formed in the atmosphere from calcite, therefore its association with $\mathrm{H}_{2} \mathrm{SO}_{4}$ is not impossible (Zhou and Tazaki, 1996; lizuka et al. 2008)) remains to be further analyzed.

Table 2.2.2.7 Frequency values in the Raman spectra of calcium sulfates, in $\mathrm{cm}^{-1}$

\begin{tabular}{|l|l|l|c|}
\hline Gypsum & Anhydrite & Bassanite $^{\mathrm{a}}$ & Assignment \\
\hline 1008 & 1016 & 1026 & $v_{1} \mathrm{SO}_{4}$ \\
\hline 420 & 490 & --- & $v_{2} \mathrm{SO}_{4}$ \\
494 & & & $v_{3} \mathrm{SO}_{4}$ \\
\hline 1139 & 1163 & --- & $v_{4} \mathrm{SO}_{4}$ \\
\hline 623 & 670 & --- & \\
\hline
\end{tabular}

${ }^{a}$ Sarma et al. 1998; Note: Chio et al. 2004 performed micro-Raman studies of synthetic gypsum powder and during the dehydration process the $v_{1} \mathrm{SO}_{4}$ has shifted from $1007 \mathrm{~cm}^{-1}$ to $1014 \mathrm{~cm}^{-1}$ and lastly to 1026 $\mathrm{cm}^{-1}$ due to the formation of the hemihydrate $\left(\mathrm{CaSO}_{4} \cdot 0.5 \mathrm{H}_{2} \mathrm{O}\right)$ and anhydrous $\left(\gamma-\mathrm{CaSO}_{4}\right)$ forms respectively. 


\title{
Microinclusions with nonequivalent $\mathrm{SO}_{4}{ }^{2-}$ groups. Mixed simple sulfates
}

\begin{abstract}
"Solange es noch sehr jung und dünn ist, nennt man das See-Eis häufig auch, Schwarzeis', weil die dunkle Farbe des darunterliegenden Wassers durch die sehr durchsichtigen Blättchen schimmert. Fällt in diesem Stadium die Lufttemperatur sehr langsam, dann ist das schwarze Eis für kurze Zeit mit weißen Blumen gesprenkelt, die in Gruppen oder in Rosetten aufscheinen. Sie werden bei niedrigen Temperaturen durch Mischung von Salz und Eis gebildet, denn das Meerwasser enhält natürfich Salz." Debenham, 1959, pg 123
\end{abstract}

Some of the Raman spectra presented in Appendix 2.2.2.D show that in the same microinclusion (in EDML ice) different compounds can coexist providing (two Raman) nonequivalent $\mathrm{SO}_{4}{ }^{2-}$ units.

Peaks that can be attributed to mirabilite (at $\sim 990 \mathrm{~cm}^{-1}$ ) and gypsum (at $\sim 1009 \mathrm{~cm}^{-1}$ or $\sim 1013 \mathrm{~cm}^{-1}$ ) appear in the same Raman spectrum, with different intensities (and widths) as if one compound is an impurity for the other. To a certain extent peaks around $990 \mathrm{~cm}^{-1}(986,987$ or $989 \mathrm{~cm}^{-1}$ ) can be from mirabilite or $\mathrm{Na}_{2} \mathrm{SO}_{4}$ solutions (Sakurai, 2010) but the Raman spectrum in Figure 2.2.2.8 may indicate that gypsum coexists with meridianiite. Peaks at $989,1117 \mathrm{~cm}^{-1}$ are characteristic rather for $\mathrm{Mg}$ sulfate than for Na sulfate (Genceli et al. 2009). If the peak at 1076 $\mathrm{cm}^{-1}$ is not an artifact from the fluorescence present in the Raman spectrum then it can be also attributed to meridianiite. The small peak at $975 \mathrm{~cm}^{-1}$ is too well defined to be produced by some kind of isotopic variation (the ${ }^{18} \mathrm{O}$ fraction of sulfate ions (Rull and Sobrón, 1994; Dong et al. 2009)). Ammonium sulfate, $\left(\mathrm{NH}_{4}\right)_{2} \mathrm{SO}_{4}$, can be easily accepted as the source for this peak (Dong et al. 2007; Sakurai et al. 2010a), but also some iron sulfates have $v_{1} \mathrm{SO}_{4}{ }^{2-}$ at $\sim 990$ or $\sim 976 \mathrm{~cm}^{-1}$ (Chio et al. 2007). It should be noticed that Ohno et al. $(2005 ; 2006)$ preferred to label the Raman spectra in which a sharp peak at $\sim 991 \mathrm{~cm}^{-1}$ and a small one at $\sim 974 \mathrm{~cm}^{-1}$ were present as being produced by a 'sulfate with a split main peak'. The true source of this peak in Raman spectra of microinclusions in EDML (/polar) ice remains to be further investigated.

Some of the Raman spectra in Appendix 2.2.2.D have also a peak at $\sim 983 \mathrm{~cm}^{-1}$. As discussed before, it can have as generating compounds either $\mathrm{K}_{2} \mathrm{SO}_{4}$ (Table 2.2.2.8) or $\mathrm{H}_{2} \mathrm{SO}_{4}$ (Wang et al. 2005). Since other characteristic wavenumbers are not distinguishable it is hard to identify the substance.

A tentative discussion results from comparing example 1 at 934 EDML depth cloudy ice, with example 4 at 1016 EDML depth clear ice. In both Raman spectra a peak centered at $983 \mathrm{~cm}^{-1}$ is observable. In the first case the shape of the peak is affected by several shoulders (at 981, $987,990 \mathrm{~cm}^{-1}$ ) while in the second case the peak has just one asymmetry at $\sim 986 \mathrm{~cm}^{-1}$. The further discussion is similar with the one previously written for sodium sulfate containing microinclusions.

In Appendix 2.2.2.C are regrouped the Raman spectra in which a feature (that cannot be only from the background) at $\sim 984 \mathrm{~cm}^{-1}$ is present. Since other vibrational modes of the $\mathrm{SO}_{4}{ }^{2-}$ anion cannot be identified in any of these Raman spectra, I have to be reserved when saying that arcanite was clearly identified in microinclusions investigated in EDML ice. Obviously, this does not mean that kalium sulfate $\left(\mathrm{K}_{2} \mathrm{SO}_{4}\right)$ is not present in EDML ice, because it is hard to accept that all the Raman peaks at $\sim 984 \mathrm{~cm}^{-1}$, (especially in the cloudy type ice), comes from sulfuric acid.

Considering the results and the interpretations presented by Sakurai (2010) it is more prudent to assign any peak at $\sim 984 \mathrm{~cm}^{-1}$ that does not have a sharp bell shape to (liquid) mixtures of (alkaline metals) sulfates and (sulfuric) acid (discussed also above).

Analyzing further the spectra in Appendix 2.2.2.C it can be observed a distortion of the ice matrix Raman fingerprint in the $700-1000 \mathrm{~cm}^{-1}$ spectral region (example: 1' at 934 EDML depth, cloudy ice; 1 at 934 EDML depth, clear ice; 1 at 1184 EDML depth, clear ice; 4 at 1855 EDML depth, clear ice). The broad peak at $\sim 890 \mathrm{~cm}^{-1}$ can be assigned to $\mathrm{HSO}_{4}{ }^{-}$anions (Tomikawa and Kanno, 1998). Figure 2.2.2.9 reproduces a Raman spectrum that can be assigned to microinclusions formed of (liquid solutions of) $\mathrm{H}_{2} \mathrm{SO}_{4}$. 


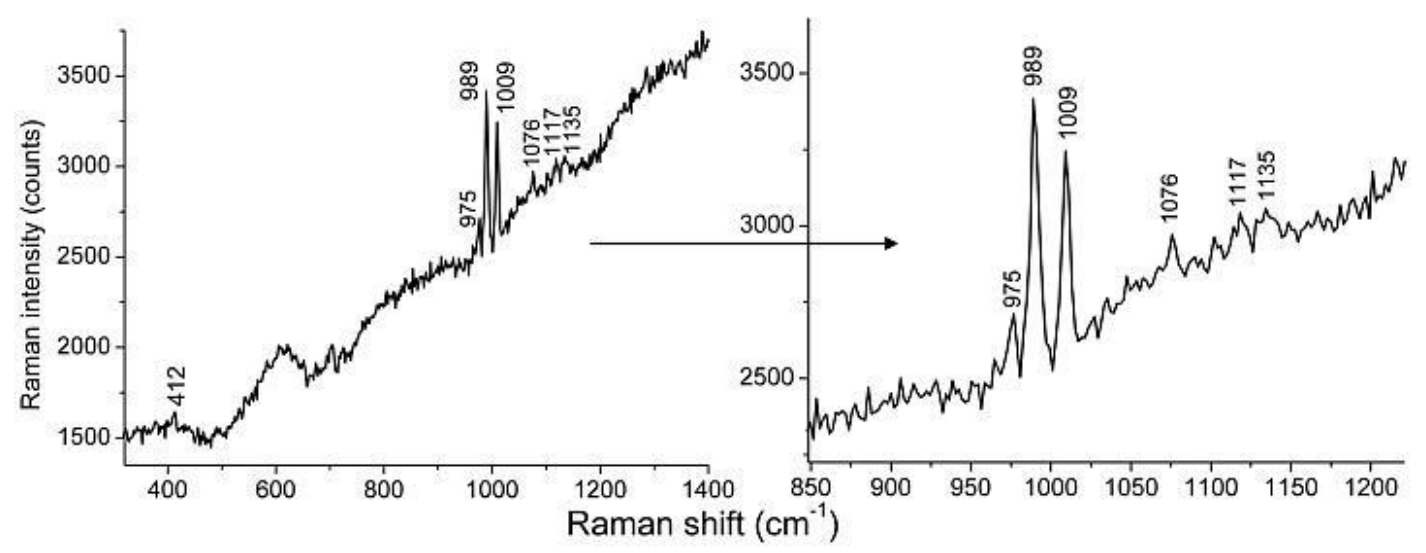

Figure 2.2.2.8 Raman spectrum assigned to a mixed microinclusion in EDML ice containing gypsum, most probably meridianiite and probably $\left(\mathrm{NH}_{4}\right) \mathrm{SO}_{4}$ (from Appendix 2.2.2.D: example 6 at 934 EDML depth, cloudy ice).

Table 2.2.2.8 Frequency values in the Raman spectra of $\mathrm{K}_{2} \mathrm{SO}_{4}$, in $\mathrm{cm}^{-1}$

\begin{tabular}{|c|c|c|c|c|}
\hline Market chemicals & Synthetic $^{b}$ & $\begin{array}{l}\text { Market available } \\
(\mathrm{RT})^{\mathrm{c}}\end{array}$ & $\begin{array}{c}\text { Market available } \\
\left(-80^{\circ} \mathrm{C}\right)\end{array}$ & Assignment \\
\hline 984 & 985 & 984 & 987 & $v_{1} \mathrm{SO}_{4}$ \\
\hline$(\sim 450)$ & 457 & 453 & $\begin{array}{l}458 \\
488\end{array}$ & $v_{2} \mathrm{SO}_{4}$ \\
\hline $\begin{array}{l}(\sim 1005) \\
(\sim 1140)\end{array}$ & $\begin{array}{l}1094 \\
1108 \\
1146\end{array}$ & $\begin{array}{l}1109 \\
1146\end{array}$ & $\begin{array}{l}1097 \\
1111 \\
1150\end{array}$ & $v_{3} \mathrm{SO}_{4}$ \\
\hline $\begin{array}{l}(\sim 620) \\
(\sim 625)\end{array}$ & 622 & $\begin{array}{l}620 \\
627\end{array}$ & 621 & $v_{4} \mathrm{SO}_{4}$ \\
\hline
\end{tabular}

${ }^{\mathrm{a}}$ Ohno et al. 2005; ${ }^{\mathrm{b}}$ Buzgar et al. 2009; ${ }^{\mathrm{c}}$ this study

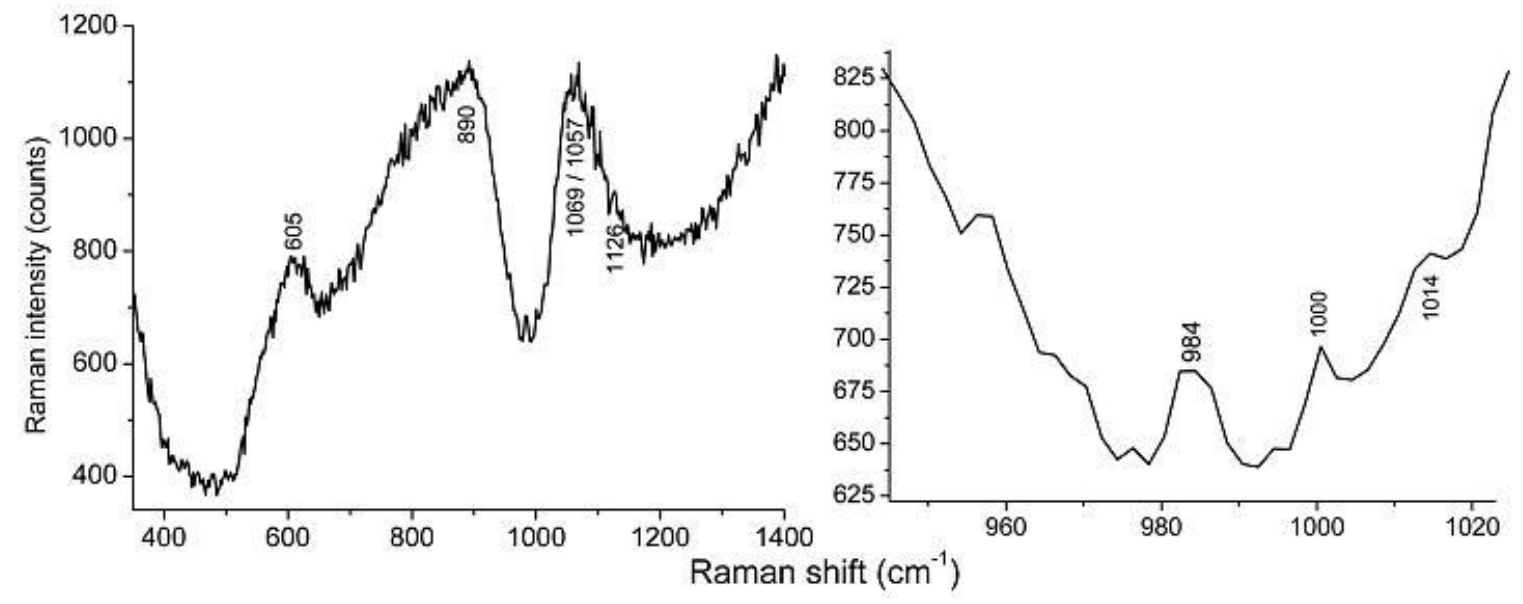

Figure 2.2.2.9 Raman spectrum that can be assigned to a microinclusion in EDML ice containing $\mathrm{H}_{2} \mathrm{SO}_{4}$ (from Appendix 2.2.2.C: example 4 at 1855 EDML depth, clear ice). 


\section{Microinclusions with nonequivalent $\mathrm{SO}_{4}{ }^{2-}$ groups. Double sulfates}

The wavenumbers of the main $v_{1}\left(\mathrm{SO}_{4}\right)$ peaks attributed to $\mathrm{Na}$ or $\mathrm{Ca}$ sulfate salts had a tendency towards a variation over a small interval (i.e. from $989 \mathrm{~cm}^{-1}$ to $996 \mathrm{~cm}^{-1}$ and from 1006 $\mathrm{cm}^{-1}$ to $1013 \mathrm{~cm}^{-1}$ respectively).

This blueshift of the $v_{1}\left(\mathrm{SO}_{4}{ }^{2-}\right)$ mode could indicate that some other simple sulfates, than the ones already reported in similar studies (Ohno et al. 2005; 2006) are trapped in the EDML ice. A successive possibility was to understand if the Raman spectra with two main peaks assignable to the $v_{1}\left(\mathrm{SO}_{4}{ }^{2-}\right)$ might be produced by double sulfate salts (compounds with two different (metallic) cations and two $\mathrm{SO}_{4}{ }^{2-}$ anions) not by a mixture of simple sulfate salts. Anyway, it is not obligatory that a double sulfate salt to show more than one peak in the Raman region characteristic for the $v_{1}\left(\mathrm{SO}_{4}{ }^{2-}\right)$.

On the one hand, it is very difficult to clearly say that double sulfates of the alkaline and earth-alkaline cations $\left(\mathrm{Na}^{+}, \mathrm{K}^{+}, \mathrm{Mg}^{2+}, \mathrm{Ca}^{2+}\right)$ were identified in EDML ice or some other simple sulfate salts than the ones of these metals, because the resolution of the $v_{2}, v_{3}, v_{4}$ vibrational modes of $\mathrm{SO}_{4}{ }^{2-}$ in the recorded Raman spectra is insufficient. Table 2.2.2.9 contains the characteristic Raman frequencies of some double sulfates.

Table 2.2.2.9 Frequency values in the Raman spectra of some double sulfates, in $\mathrm{cm}^{-1}$

\begin{tabular}{|c|c|c|c|c|}
\hline $\begin{array}{l}\mathrm{v}\left(\mathrm{SO}_{4}\right)\left[\mathrm{cm}^{-1}\right] \\
\text { mineral }\end{array}$ & $\begin{array}{l}\mathrm{v}_{1} \\
\text { symmetric } \\
\text { stretching }\end{array}$ & $\begin{array}{l}\mathrm{v}_{2} \\
\text { symmetric } \\
\text { bending }\end{array}$ & $\begin{array}{l}\mathrm{v}_{3} \\
\text { asymmetric } \\
\text { stretching }\end{array}$ & $\begin{array}{l}\mathrm{v}_{4} \\
\text { asymmetric } \\
\text { bending }\end{array}$ \\
\hline $\begin{array}{l}\text { aphthitalite } \\
\mathrm{K}_{3} \mathrm{Na}\left(\mathrm{SO}_{4}\right)_{2}\end{array}$ & 996.23 & 456.25 & 1086.86 & 624.03 \\
\hline $\begin{array}{l}\text { bloedite }^{1} \\
\mathrm{Na}_{2} \mathrm{Mg}\left(\mathrm{SO}_{4}\right)_{2} \cdot 4 \mathrm{H}_{2} \mathrm{O}\end{array}$ & 995.63 & 459.51 & 1190.40 & 621.50 \\
\hline $\begin{array}{l}\text { glauberite } \\
\mathrm{Na}_{2} \mathrm{Ca}\left(\mathrm{SO}_{4}\right)_{2}\end{array}$ & 1003.34 & 473.01 & $\begin{array}{l}1109.41 \\
1144.12\end{array}$ & $\begin{array}{l}623.43 \\
644.64\end{array}$ \\
\hline $\begin{array}{l}\text { syngenite } \\
\mathrm{K}_{2} \mathrm{Ca}\left(\mathrm{SO}_{4}\right)_{2} \cdot \mathrm{H}_{2} \mathrm{O}\end{array}$ & $\begin{array}{l}984.71 \\
1007.86\end{array}$ & $\begin{array}{l}442.81 ; 475.6 \\
494.88\end{array}$ & $\begin{array}{l}1084.99 ; \\
1121.63 \\
1140.92 \\
1167.92\end{array}$ & 643.37 \\
\hline $\begin{array}{l}\text { syngenite }^{2} \\
\text { at } 298 \mathrm{~K}\end{array}$ & $\begin{array}{l}981 \\
1004\end{array}$ & $\begin{array}{l}424 ; 441 ; 471 \\
492\end{array}$ & $\begin{array}{l}\text { 1117; 1138; } \\
1166\end{array}$ & 641 \\
\hline $\begin{array}{l}\text { syngenite }^{2} \\
\text { at } 77 \mathrm{~K}\end{array}$ & $\begin{array}{l}982 \\
1007\end{array}$ & $\begin{array}{l}441 ; 472 ; \\
493\end{array}$ & $\begin{array}{l}1119 ; 1136 \\
1144 ; 1167\end{array}$ & $\begin{array}{l}607 ; 621 \\
634 ; 643\end{array}$ \\
\hline $\begin{array}{l}\text { jarosite }^{1} \\
\mathrm{KFe}_{3}\left(\mathrm{SO}_{4}\right)_{2}(\mathrm{OH})_{6}\end{array}$ & 1004.7 & $\begin{array}{l}352 ; 433 \\
453 ; 571\end{array}$ & $1098 ; 1154.6$ & 624 \\
\hline $\begin{array}{l}\text { natrojarosite }^{1} \\
\mathrm{NaFe}_{3}\left(\mathrm{SO}_{4}\right)_{2}(\mathrm{OH})_{6}\end{array}$ & 1015.2 & $367 ; 447 ; 567$ & $1110 ; 1155$ & 627 \\
\hline jarosite $^{3}$ & $\begin{array}{l}1011.9 \\
1009.8\end{array}$ & $\begin{array}{l}452.8 \\
443.7\end{array}$ & $\begin{array}{l}1153.1 \\
1111.0\end{array}$ & $\begin{array}{l}566.2 \\
623.9\end{array}$ \\
\hline natrojarosite $^{3}$ & $\begin{array}{l}1010.7 \\
1007.0\end{array}$ & $\begin{array}{l}550.2 \\
575.7 ; 624.9\end{array}$ & $\begin{array}{l}1161.8 \\
1153.5 ; 1111.5\end{array}$ & $\begin{array}{l}426.2 ; 434.6 ; \\
443.3 ; 453.9 \\
460.4\end{array}$ \\
\hline $\begin{array}{l}(\mathrm{K}, \mathrm{Na}) \mathrm{Fe}_{3}\left(\mathrm{SO}_{4}\right)_{2}(\mathrm{OH})_{6} \\
\text { EDML ice, this study }\end{array}$ & 1013 & $\begin{array}{l}360 ; 438 \\
458 ; 583\end{array}$ & $1110 ; 1161.5$ & 630 \\
\hline
\end{tabular}

data from RRUFF Raman spectra database (http://rruff.info/);

${ }^{2}$ Kloprogge et al. 2002; ${ }^{3}$ Frost et al. 2006. 
On the other hand, some assumptions can be made. Aphthitalite, $\mathrm{K}_{3} \mathrm{Na}\left(\mathrm{SO}_{4}\right)_{2}$, is a rare mineral thus it would have the lowest probability to be found in microinclusions trapped in Antarctic ice. Blödite, $\mathrm{Na}_{2} \mathrm{Mg}\left(\mathrm{SO}_{4}\right)_{2} \cdot 4 \mathrm{H}_{2} \mathrm{O}$, is unstable below $0^{\circ} \mathrm{C}$ in a pure $\mathrm{Na}_{2} \mathrm{SO}_{4}-\mathrm{MgSO}_{4}-\mathrm{H}_{2} \mathrm{O}$ system, (Marion and Farren, 1999), but the possibility to have blödite microinclusions existent in EDML ice cannot be totally excluded. Glauberite, $\mathrm{Na}_{2} \mathrm{Ca}\left(\mathrm{SO}_{4}\right)_{2}$, decomposes quickly when enough water is present, but here it would be preserved in a 'dry' environment in which the water as liquid or vapor has a very limited probability of existence. Picromerite, $\mathrm{K}_{2} \mathrm{Mg}\left(\mathrm{SO}_{4}\right)_{2} \cdot 6 \mathrm{H}_{2} \mathrm{O}$, appears to have some higher probability of existence in polar ice, since its stability field extends at negative temperatures (Marion and Farren, 1999). Syngenite, $\mathrm{K}_{2} \mathrm{Ca}\left(\mathrm{SO}_{4}\right)_{2} \cdot \mathrm{H}_{2} \mathrm{O}$, formed when is more $\mathrm{K}^{+}$ than $\mathrm{Na}^{+}$, has also a high probability to exist in microinculsions embedded in EDML ice.

Figure 2.2.2.10 shows two Raman spectra of microinclusions existent in EDML ice that could be assigned to double sulfates.
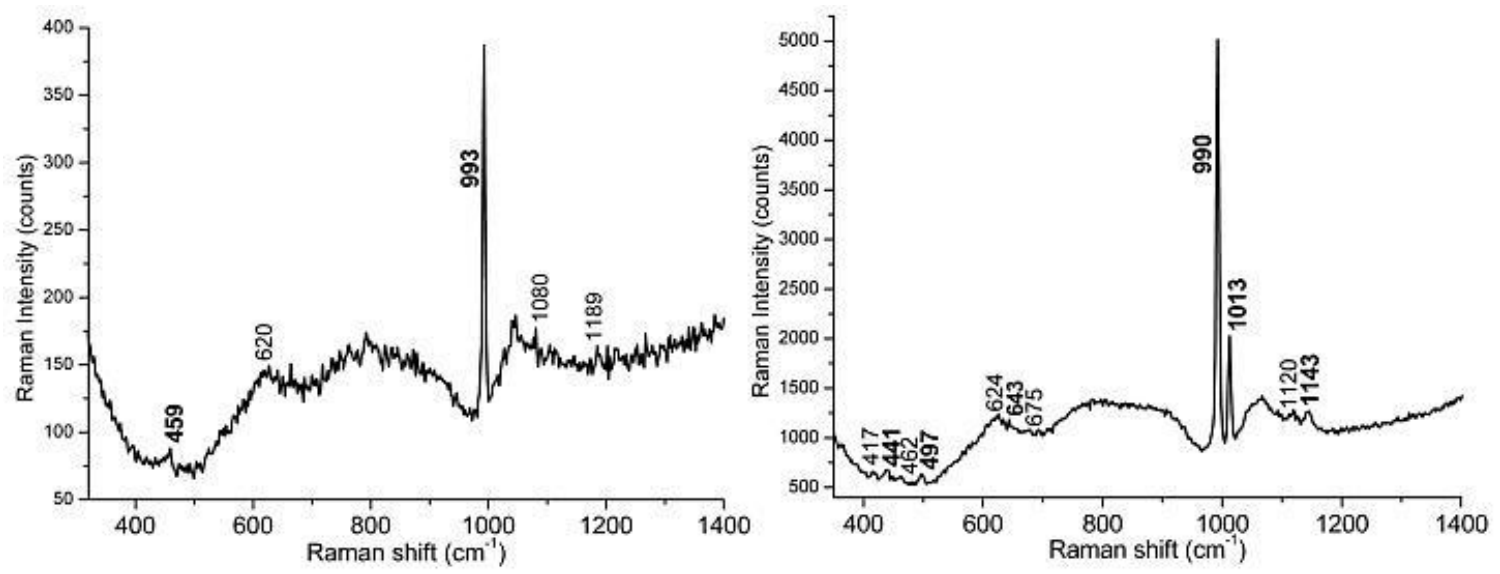

Figure 2.2.2.10 Raman spectra that might be assigned to microinclusions in EDML ice containing double sulfates (left blödite in 1016 sample, right syngenite in 1855 sample).

When credit for the existence of (the above mentioned) double sulfates in EDML ice is given the following scenarios were considered: the compounds were formed before being embedded in the polar snow and (later) ice and they remained unmodified by the evolution of the snow or ice matrix or the salts were formed in situ, in the snow or the ice body. In other words, generally speaking, double sulfates might exist in polar ice via processes like: weathering followed by deposition or via deposition and then diagenesis.

The second scenario implies that the initial impurities engulfed in EDML (/polar) ice attained the specific thermochemical conditions favouring postdepositional transformations of the initial compounds at least at (sub)microscopic scale. An extended discussion about this item has to be the goal of future investigations.

Weathering type phenomena can be accepted as generators of new compounds from a proper substrate. In particular, for Antarctica physical weathering seems to be given more credits than the chemical weathering, which has to be carefully investigated before established as existent (Ugolini and Jackson, 1982). Covered with a thick blanket of snow and ice, Antarctica is a great (cold) desert with a dry and clean air above it, permanently stirred by the prevailing katabatic winds. As a consequence, especially in costal Antarctic regions, the minerals in salt efflorescences encountered on the geological units can be divided into three genetically distinct groups: marine, subglacial and authigenic. Physical weathering is responsible for transportation of sea aerosol and deposition of salts with a maritime origin in the inland regions of Antarctica, while chemical weathering produces authigenic minerals even in remote locations from Transantarctic Mountains (van Autenboer, 1964; Dort and Dort, 1972; Gore et al. 1996; and the 
references therein). Among the identified minerals there are also the simple and double sulfates referred to in this discussion.

In a recent study of rock varnishes, (a dark coating that develops on exposed rock surfaces in all weathering environments), from Victoria Land (Antarctica) Giorgetti and Baroni (2007) identified sulfates of the alunite-jarosite series, (namely jarosite, $\mathrm{KFe}_{3}\left(\mathrm{SO}_{4}\right)_{2}(\mathrm{OH})_{6}$ ), and concluded that they formed in situ after the formation of the varnish itself as an ultra-thin "sedimentary deposit", by accretion onto the external surface of the rock substrate of airborne dust. The minerals in the alunite and jarosite subgroups are hydroxylated (double) sulfates with a monovalent and a trivalent cation, (alunite family $\mathrm{Al}^{3+}>\mathrm{Fe}^{3+}$, jarosite family $\mathrm{Fe}^{3+}>\mathrm{Al}^{3+}$ ). Jarosite, $\mathrm{KFe}_{3}\left(\mathrm{SO}_{4}\right)_{2}(\mathrm{OH})_{6}$, and natrojarosite, $\mathrm{NaFe}_{3}\left(\mathrm{SO}_{4}\right)_{2}(\mathrm{OH})_{6}$, can form under a variety of geological settings, the essential condition being a $\mathrm{pH}<3$ (Alpers, 2000).

Appendix 2.2.2.E shows Raman spectra which have features that resemble more the ones reported for natrojarosite than for jarosite; nevertheless a chemical formula with both sodium and potassium can be used for labeling these microinclusions, $(\mathrm{K}, N a) \mathrm{Fe}_{3}\left(\mathrm{SO}_{4}\right)_{2}(\mathrm{OH})_{6}$. Figure 2.2.2.11 shows comparative Raman spectra of (natro)jarosites in EDML ice and natural sites. The Raman fingerprint of jarosites microinclusions in EDML ice do not clearly match neither with natrojarosite nor with the one of jarosite.

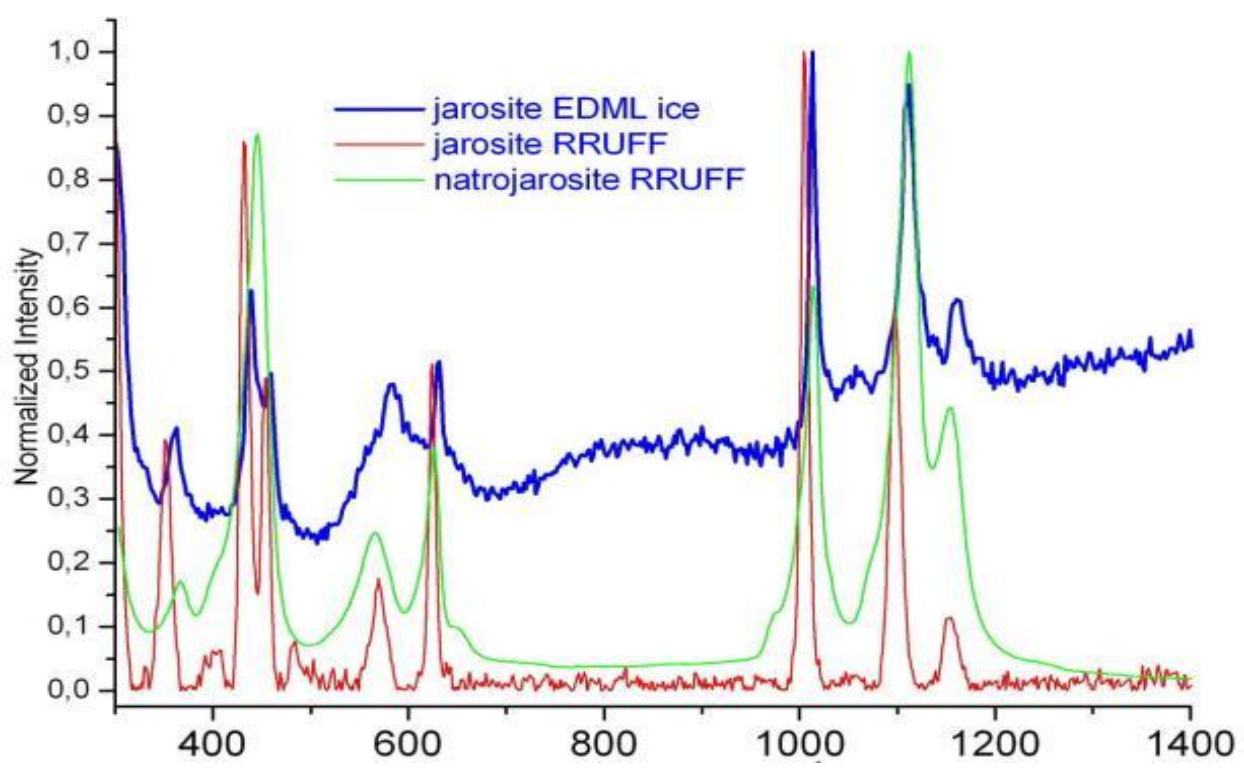

Figure 2.2.2.11 Raman spectrum that can be assigned to a microinclusion in EDML ice containing $(\mathrm{K}, \mathrm{Na}) \mathrm{Fe}_{3}\left(\mathrm{SO}_{4}\right)_{2}(\mathrm{OH})_{6}$ (Appendix 2.2.2.E)

Frost et al. (2006) give a detailed description of the Raman spectra of natural jarosites pointing to their complexity when compared with the synthetic ones (resulting probably from their capacity to act as collector minerals: low concentrations of foreign ions are incorporated in their structure). Misawa et al. (2010) report jarosite in particles of extraterrestrial origin deposited in Antarctic ice 480 ka old from Dome Fuji ice core. They consider it was formed in situ during the long-time storage of these planetary dust particles in Antarctic ice. Also in situ formation of jarosite via weathering was considered by Matsuoka (1995) who studied the rock varnishes in Sør Rondane Mountains, Dronning Maud Land, Antractica.

For the EDML ice case, since the microinclusions with (natro)jarosite contain also mirabilite (Appendix 2.2.2.D, example 2, 3 at 1855 EDML depth, clear ice) or carbonaceous matter, CM, (Appendix 2.2.2.E) another path for their formation has to be taken into account. 
In general, the iron, Fe, measured in Antarctic ice is considered to be entirely derived from continental terrestrial material and although, the iron profile along an ice core, (i.e. the EPICA Dome C), is in good agreement with the one of non sea salt calcium, nssCa, often used to define terrestrial sources, Fe might be preferred in discussions about iron fertilization of the ocean (Wolff et al. 2006). Iron is a key ingredient for the menu of the (Antarctic) marine phytoplankton; insufficient Fe being equal with low carbon production in polar waters. Thus, microinclusions with jarosite and Na sulfate or CM could have formed via biogenic activity prior to their deposition in EDML ice. More thorough analyses may add further light on the jarosite provenience in EDML ice.

\title{
Microinclusions containing silicon (as $\mathrm{SiO}_{2}$, or silicates)
}

\author{
"But when dust falls on a glacier, it is preserved like flowers pressed \\ between pages of a 6ook." Holmes 2001, pg. 99
}

The Raman patterns for aluminosilicates could be assigned to the end members of the plagioclase feldspar series and to a potassium feldspar (Appendix 2.2.2.F). These tectosilicate minerals were to be identified in the 2405CB MIS6 ice sample in a significant amount. Overall, silica and sanidine seems to be the most frequent.

Raman spectra with a (single) main peak at $\sim 465 \mathrm{~cm}^{-1}$ were attributed to quartz, $\mathrm{SiO}_{2}$, (Krishnan, 1945; Gage and Farwell 1981; McKeegan et al. 2007). No other form of $\mathrm{SiO}_{2}(\mathrm{Gage}$ and Farwell, 1981) could be identified.

Spectra with peaks around 480 and $508 \mathrm{~cm}^{-1}$ or 477 and $515 \mathrm{~cm}^{-1}$ can be assigned to aluminosilicates (albite, $\mathrm{NaAlSi}_{3} \mathrm{O}_{8}$ and sanidine, $\mathrm{KAlSi}_{3} \mathrm{O}_{8}$, respectively) (Bendel and Schmidt, 2008). When a shoulder around $455 \mathrm{~cm}^{-1}$ is present together with the peaks attributed to sanidine, (Appendix 2.2.2.F: example 4 at 2405 EDML depth, cloudy ice), it is better to consider that the microinclusion contains microcline, polymorph with sanidine (Frogner et al. 1998).

Peaks at 409, 481, 510 and $565 \mathrm{~cm}^{-1}$ can be attributed to anorthite, $\mathrm{CaAl}_{2} \mathrm{Si}_{2} \mathrm{O}_{8}$ (Le Parc et al. 2003) (Appendix 2.2.2.F: example 2 at 2405 EDML depth, cloudy ice).

More complex Raman spectra were registered, showing peaks around 425, 471, 560, 610, $860 \mathrm{~cm}^{-1}$, (Appendix 2.2.2.F: example 3 at 934 EDML depth, cloudy ice; 1 at 1184 EDML depth, clear ice), one of which was assigned to the calcium titanium neosilicate mineral, titanite, $\mathrm{CaTiSiO}_{5}$ (Lodziński et al. 2005). The other, complex Raman spectra show peaks as for titanite, but red-shifted and additional peaks around 750,800, $850 \mathrm{~cm}^{-1}$ and could not be properly attributed (Appendix 2.2.2.F: example 3 at 2405 EDML depth, cloudy ice; Appendix 2.2.2.D: example 5 at 1184 EDML depth, clear ice). It is very probable that the corresponding microinclusions contain also titanite or (and) another (related) mineral, or titanite containing impurities (Łodziński et al. 2005; and the references therein).

\section{Microinclusions containing silicon and sulfate}

Raman spectra with peaks in the region of the $v_{1}\left(\mathrm{SO}_{4}{ }^{2-}\right)$ mode and additional peaks rather characteristic for compounds with silicon $\left(\mathrm{SiO}_{2}\right.$ or (Al)silicates), (Appendix 2.2.2.D), were recorded from microinclusions existent in the investigated EDML ice samples. Silica is more often associated with ( $\mathrm{Na}$ or/and $\mathrm{Ca}$ ) sulfates than the other silicates.

Figure 2.2.2.12 depicts a Raman spectrum from a type of microinclusion in EDML ice that can contain a mixture of silicate and sulfate.

This type of Raman spectra were recorded only for the case of the 1016 clear ice sample and represent $\sim 50 \%$ of the mixed microinclusions. The peak at $992 \mathrm{~cm}^{-1}$ (or at related wavenumbers) can be considered due to the presence of $\mathrm{Na}$ sulfate but for the peaks in the 300- 
$600 \mathrm{~cm}^{-1}$ spectral region a tentative assignment would plead rather for a silicate than for a(nother) sulfate.

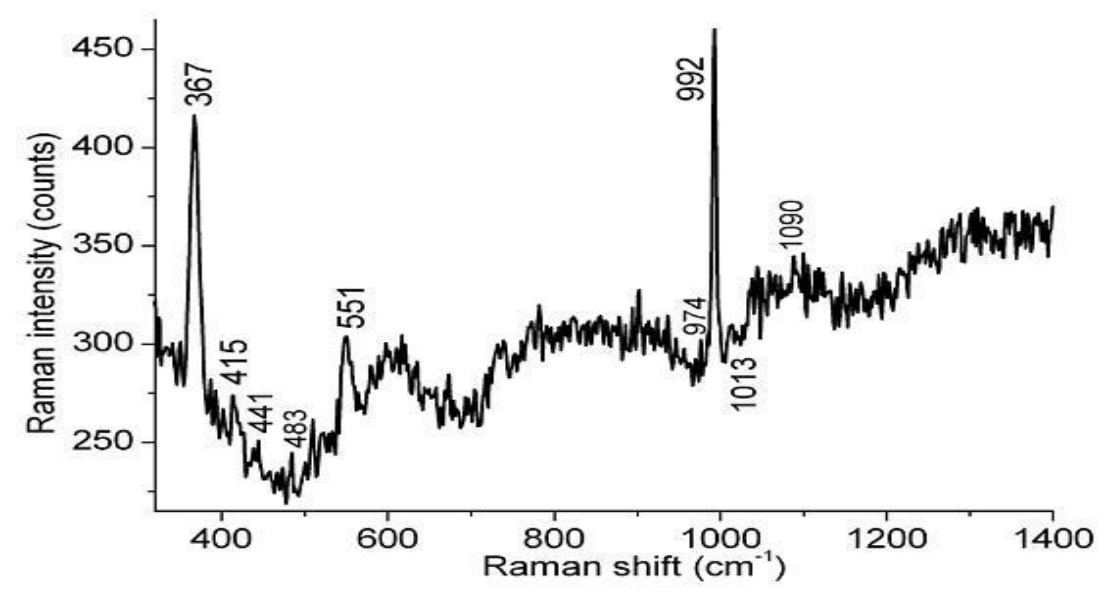

Figure 2.2.2.12 Raman spectrum that can be assigned to a microinclusion in EDML ice containing silicate and sodium sulfate (from Appendix 2.2.2.D: example 16 at 1016 EDML depth, clear ice)

A candidate would be a silicate garnet, andradite $\left(\mathrm{Ca}_{3} \mathrm{Fe}_{2} \mathrm{Si}_{3} \mathrm{O}_{12}\right)$ or one related with it (Bersani et al. 2009; Kolesov and Geiger, 1998). On the other hand, is not easy to explain why the peaks of andradite around 800 or $900 \mathrm{~cm}^{-1}$ are not clearly observable in the Raman spectra of microinclusions in EDML ice. Either they have low intensity and are hidden by the matrix/background Raman signal, or they are simply inexistent.

A particular microinclusion in the 1016CI sample has the Raman spectrum depicted in Figure 2.2.2.13.
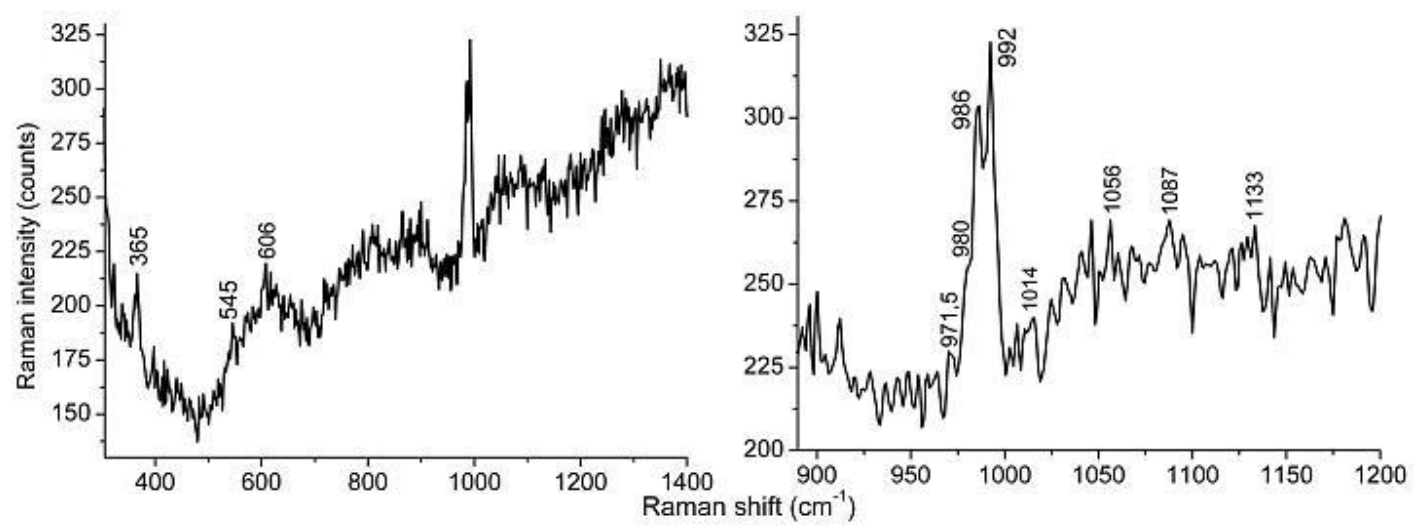

Figure 2.2.2.13 Raman spectrum that can be assigned to a microinclusion in EDML ice containing silicate and sodium sulfate (from Appendix 2.2.2.D: example 8 at 1016 EDML depth, clear ice)

The morphology of the Raman peak(s) in the $900-1000 \mathrm{~cm}^{-1}$ region have been discussed, and can be considered to be from (concentrated) sodium sulfate (or $\mathrm{NaCl}$ ) and (sulfuric) acid solutions (Dong et al. 2009; Sakurai, 2010). The reduction of the peaks in the 300-600 $\mathrm{cm}^{-1}$ spectral region can be caused by a low amount of the producing substance or due to alteration of this compound by for example a to high $\mathrm{pH}$ of this microinclusion. On the other hand, now, it can be speculated that the peaks in the $300-600 \mathrm{~cm}^{-1}$ spectral region are from a sulfate (or a 
compound) related with sodium sulfate (solutions). Future research will clarify the provenience of these Raman peaks.

\section{Other microinclusions identified in EDML ice}

In Appendix 2.2.2.G are presented Raman spectra of microinclusions existent in EDML ice that could be attributed to $\mathrm{TiO}_{2}$ (the mineral forms: rutile (Swamy et al. 2006) and anatase (Zhang et al. 2000b)) apatite, (most probably as hydroxylapatite, $\mathrm{Ca}_{5}\left(\mathrm{PO}_{4}\right)_{3}(\mathrm{OH})$ ), or carbonaceous matter $(\mathrm{CM})$. If the former minerals can have as origin the rocks in the proximity of the EDML ice core drilling site, the CM is more probable to have a marine origin.

One of the spectra (Appendix 2.2.2.G, example 1 at 1855 EDML depth, clear ice), having a peak at $963 \mathrm{~cm}^{-1}$, characteristic for apatite has also a peak at $465 \mathrm{~cm}^{-1}$ from $\mathrm{SiO}_{2}$ and peaks attributable to carbonaceous matter $\left(1371\right.$ and $\left.1606 \mathrm{~cm}^{-1}\right)$. The same type of Raman spectra were reported by McKeegan et al. (2007) for apatite grains in the same quartz-pyroxene-magnetitebearing Akilia metasediments. Because no optical photomicrograph of this microinclusion was taken it cannot be said that the microinclusion in the EDML ice is a quartz-embedded apatite grain which contains graphite as in McKeegan et al. (2007). As a parenthesis, grains defined by a complex chemistry were not especially looked for in EDML ice, and their identification is rather a fortuitousness than a commonality. The probability of a simple association of these compounds in the same microinclusion after their enclosure in the EDML ice matrix seems to be very low. The other Raman spectra show microinclusions containing only apatite or $\mathrm{CM}$ or $\mathrm{SiO}_{2}$. No doubt that if the aggregation of these three compounds was as common as (for example) the association of simple sulfate salts more Raman spectra would have been registered. Moreover, the peaks at 465 and $963 \mathrm{~cm}^{-1}$ (from quartz and apatite respectively) have sharp well defined shape pointing to a very intimate relation between the two minerals. Regarding the peaks due to $\mathrm{CM}$, the spectrum presents a Raman signal from CM affected by a high signal to noise ratio. Nevertheless, because other spectra with a nice shape for the peaks characteristic of CM were registered, it can be considered that $\mathrm{CM}$ exist in the same microinclusion with quartz and apatite.

Jehlička et al. (2009) used micro-Raman microspectrometry to characterize the carbonaceous matter, CM, existent in marbles used for decorative purposes. Based on the ratio between the intensities of the disordered (D-) peak around $1355 \mathrm{~cm}^{-1}$ and the ordered (O-) peak at about $1620 \mathrm{~cm}^{-1}$ it was concluded that three main groups of CM-containing marbles can be distinguished: "(1) Well-ordered CM-graphite of higher grade regional metamorphosed marbles [...] characterized by the low D/O intensity ratio (0.3-0.6) as well as the low O-peak width (18$\left.19 \mathrm{~cm}^{-1}\right)$. (2) Contact metamorphosed [...] and mid-grade regional metamorphosed marbles [...] in which the D/O intensity ratio ranges from 0.6 to 0.9. The O-peak width of $30 \mathrm{~cm}^{-1}$ as the lower limit and $43 \mathrm{~cm}^{-1}$ as the upper limit marks this group. (3) Less graphitized organic matter ("disordered" CM) in low-grade regional metamorphosed rocks [...] exhibits higher values of the D/O intensity ratio (0.9-1.4). The O-peak width is observed to be above $50 \mathrm{~cm}^{-1}$ in this case".

It results that the type of the CM from the analyzed microinclusions in EDML ice is less graphitized organic matter.

\section{Nitrate containing microinclusions}

Microinclusions with $\mathrm{NO}_{3}{ }^{-}$anion were reported as being preserved in polar ice (Ohno et al. 2005; 2006), and they are expected to exist also trapped in the EDML ice. Also, Fukazawa et al. (1998) presented evidence, from Raman investigations, of $\mathrm{SO}_{4}{ }^{2-}$ and $\mathrm{NO}_{3}{ }^{-}$existing at triple junctions in Antarctic ice samples. The preliminary data obtained in this study offered just one good Raman spectra of a nitrate salt containing microinclusion (Appendix 2.2.2. G example 1 at 934 EDML depth cloudy ice). This Raman spectrum has a sharp peak around $1050 \mathrm{~cm}^{-1}$. Because 
for $\mathrm{KNO}_{3}$, (nitre), at least a very small peak around $710 \mathrm{~cm}^{-1}$ would be expected this spectrum was assigned to $\mathrm{Ca}\left(\mathrm{NO}_{3}\right)_{2} \cdot 4 \mathrm{H}_{2} \mathrm{O}$, (nitrocalcite), (Ohno et al. 2005; Sakurai et al. 2010a).

The fact that just one microinclusion in analyzed EDML ice could clearly be considered to contain a nitrate salt does not mean that the nitrate salts are absent but rather that the $\mathrm{NO}_{3}{ }^{-}$ Raman signal is significantly affected by the measurement errors or by Raman peaks overlapping. For example around $1047 \mathrm{~cm}^{-1}$ the (ice) matrix has a peak, which sometimes is enhanced or shifted towards the wavenumbers characteristic for nitrate salts: $1050 \mathrm{~cm}^{-1}$ or 1060 $\mathrm{cm}^{-1}$, (Ohno et al. 2005; Sakurai et al. 2010a) (Figure 2.2.2.14) with a higher frequency for the cloudy type EDML ice (as inferred by lizuka et al. 2008 for LGM ice). It is (also) very probable that the $\mathrm{NO}_{3}{ }^{-}$salts in EDML ice are not as frequent as the other types presented here but this remains to be studied.

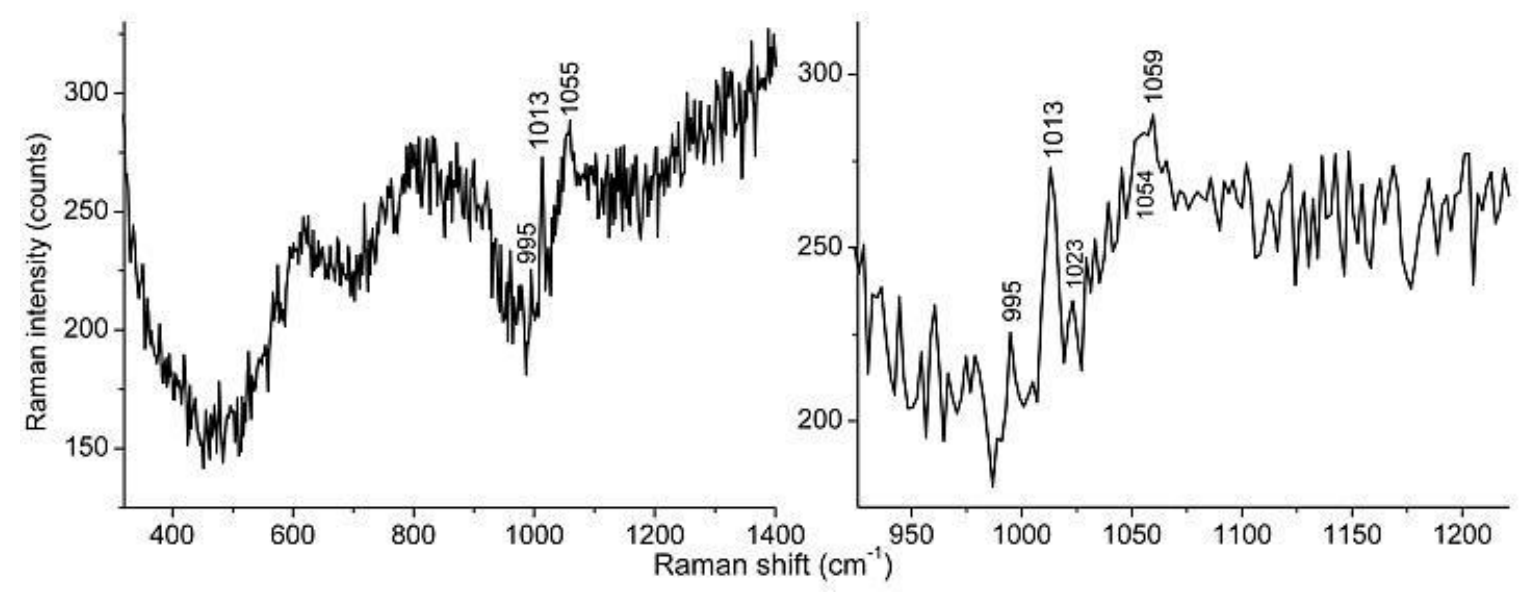

Figure 2.2.2.14 Raman spectrum of a microinclusion in EDML ice that might also contain a nitrate salt (from Appendix 2.2.2.D: example 8 at 1184 EDML depth, cloudy ice)

\section{Other microinclusions in EDML ice}

Appendix 2.2.2.H shows a few Raman spectra for which the assignment is (to a certain extent) questionable.

The Raman peaks at 1046 or $1048 \mathrm{~cm}^{-1}$ (example 1 at 1035 EDML depth, cloudy ice and example 2 at 1184 EDML depth, cloudy ice) can be considered to have been produced by the $\mathrm{NO}_{3}{ }^{-}$anion. Since the expected nitrate salts (of the alkaline and earth-alkaline cations) have Raman peaks at higher wavenumbers it must be concluded that the two examples mentioned above are from microinclusions containing $\mathrm{HNO}_{3}$ (Ohno et al. 2005; Sakurai et al. 2010a). At this stage of data interpretation it should be stated that I have not taken into consideration a sum of other substances that can give a Raman peak around $1048 \mathrm{~cm}^{-1}$ (one example would be nacholite). The simple logical way is to assign the peak to $\mathrm{HNO}_{3}$ containing microinclusions even if Ohno et al. $(2005 ; 2006)$ preferred to name this type of microinclusions "peak at $1048 \mathrm{~cm}^{-}$ ${ }^{1}$ (nitrate?)". This peak is not easy to be identified (i.e. in the 934 EDML ice sample or even in the cloudy ice samples) if the overall Raman intensity of the spectra is low, because in these cases the peak at $\sim 1048 \mathrm{~cm}^{-1}$ can result from the low signal to noise ratio of such measurements.

Insisting on the Raman spectrum of example 2 at 1184 EDML depth cloudy ice, a few other peaks, than the $1048 \mathrm{~cm}^{-1}$ one attributable to $\mathrm{NO}_{3}^{-}$, can be identified. The peaks in the 300$700 \mathrm{~cm}^{-1}$ are from $\mathrm{TiO}_{2}$ in its anatase form. A survey of the literature related with the atmospheric aerosol lets one know that $\mathrm{TiO}_{2}$ is a photocatalyst used for the elimination of $\mathrm{NO}_{\mathrm{x}}$ from the air, also converting $\mathrm{NO}$ to $\mathrm{HNO}_{3}$ (Negishi et al. 1998). It was observed that in its anatase form has a higher photocatalytic activity and better gas-sensing properties (György et al. 2006). Although 
$\mathrm{TiO}_{2}$ is scarce among the aerosol particles it is important in the reduction of $\mathrm{NO}_{2}$ to nitrous acid, (HONO). It has uptake coefficients for $\mathrm{NO}_{2}$ fifty times higher than the humic acids (Beaumont et al. 2009 and the references therein). These findings offer support for assigning the peak at $1048 \mathrm{~cm}^{-1}$ to nitric acid. In the same Raman spectrum there are also peaks at 1012 and $1018 \mathrm{~cm}^{-1}$ that can be assigned to calcium sulfates (gypsum and probably anhydrite). It was observed that $\mathrm{Ca}^{2+}$ or sulfates are related with the preferential nucleation and growth of $\mathrm{HNO}_{3}$ in the atmosphere and polar stratospheric clouds, PSC (Dye et al. 1992), and a recognized source of nitrate in polar ice cores is the stratosphere (Röthlisberger et al. 2002).

On the other hand, it is known that the $\mathrm{HNO}_{3}$ signal in polar ice is affected by various depositional and post-depositional processes (Wolff et al. 2008) mainly due to its higher volatility (as compared with the one of $\mathrm{H}_{2} \mathrm{SO}_{4}$ ). Sakurai (2010) considered the possibility of having stable microparticles of $\mathrm{H}_{2} \mathrm{SO}_{4}$ preserved in polar ice, by estimating the value of its spreading coefficient (on ice). He concludes that when $\mathrm{SO}_{4}{ }^{2-}$ is associated with other anions it is rather to be stable as a particle than as a thin film diffusing within the ice body. In the $\mathrm{HNO}_{3}$ case, since it has a low nucleophilicity and is volatile, it would be expected to be more stable as a thin film (and it was observed that it is like this for the polar stratosphere) but as for $\mathrm{SO}_{4}{ }^{2-}$ the association with other compounds may favour its existence as microparticles in polar ice. Nevertheless, the frequency of this type of microparticles in (EDML) polar ice remains to be investigated in future studies.

Example 1 at 1184 EDML depth, cloudy ice has a peak at $1020 \mathrm{~cm}^{-1}$ that can be from anhydrous calcium sulfate (a small peak at $\sim 1011 \mathrm{~cm}^{-1}$ is also present which is close to the Raman peak of gypsum).

The peak at $1036 \mathrm{~cm}^{-1}$ (example 2 at 1035 EDML depth, cloudy ice) might be from $\mathrm{NaHSO}_{4} \cdot \mathrm{H}_{2} \mathrm{O}$ (Sakurai et al. 2010a), while the one at $608 \mathrm{~cm}^{-1}$ can be from an oxide, for example $\mathrm{TiO}_{2}$ as rutile in a certain orientation that would make the $\mathrm{E}_{\mathrm{g}}$ band at $\sim 450 \mathrm{~cm}^{-1}$ inactive, or $\mathrm{TiO}_{2}$ in its brookite form (Tompsett et al. 1995).

\subsection{2.b Discussion : Frequency distribution of the microinclusions}

Figure 2.2.2.1 and Appendix 2.2.2.I offer a description of the amount of different types ${ }^{44}$ of microinclusions identified in EDML ice.

It resulted that for the MIS2 EDML ice samples mirabilite is well represented in ice formed under mild climatic conditions: interstadial ice, which is usually clear ice. Since the highest amount of Na sulfate is a characteristic of Holocene ice (Ohno et al. 2005; Iizuka et al. 2006; Sakurai et al. 2009), for similar (mild climate) ice more of these sulfates are expected to exist. For the cloudy band MIS2 ice Na sulfate (mirabilite) had no clear Raman signal, but this does not necessarily imply their total absence.

As a relative reference, the results for the 1035CI sample can be considered characteristic for clear MIS2 EDML ice. At the other extreme the 1184CI seems to be the particularity for the clear MIS2 EDML ice, since more Ca sulfate and Si containing compounds are present, suggesting a resemblance with the cloudy band ice type.

Calcium sulfate, $\mathrm{CaSO}_{4} \cdot 2 \mathrm{H}_{2} \mathrm{O}$-gypsum, was identified in almost all the analyzed ice samples, irrespective of their age or cloudiness. $\mathrm{Ca}^{2+}$ is a proxy for glacial or stadial intervals, and it is correlated with the degree of aridity in the source region (Wolff et al. 2006). High frequency of gypsum was previously reported for cold climate ice (Ohno et al. 2005; Sakurai et al. 2009).

\footnotetext{
${ }^{44}$ The most probable mineral name is used (i.e. mirabilite for all $\mathrm{Na}^{+}$and $\mathrm{SO}_{4}{ }^{2-}$ containing phases)
} 
The 1184CB EDML ice sample resulted to have the highest amount of identified gypsum, while the other MIS2 CB ice samples have values for $\mathrm{Ca}\left(\mathrm{SO}_{4}\right)$ microinclusions close to the ones found in MIS4 and MIS6 ice. The MIS2 clear ice has only slightly less amounts of $\mathrm{Ca}\left(\mathrm{SO}_{4}\right)$ particles and this can be easily explained since after all, this ice, is from a glacial period. The particle distribution pattern found in the 1184CB ice is indicative of an intense cloudy band ice. High amounts of calcium sulfate and silicon bearing compounds are expected to exist in such ice (Takata et al. 2004, Svensson et al. 2005). The sample from the clear ice close to the 1184CB has features as the other CBs (more gypsum and silicates). It can be said that this clear ice is just a 'more transparent cloudy ice'. Since this clear EDML ice closely followed the cloudy one, it was produced by the weather patterns bordering the meteorological events that generated the $1184 \mathrm{CB}$ ice. Like this a natural dilution of the amount of soluble impurities, (Ca sulfate), can result.

The microinclusions that can be considered to contain potassium sulfate $\left(\mathrm{K}_{2} \mathrm{SO}_{4}\right.$ : arcanite) or which are (liquid) solutions of $\mathrm{Na}$ sulfate or $\mathrm{H}_{2} \mathrm{SO}_{4}$ are not very frequent and most of the times this peak accompanies other $v_{1}\left(\mathrm{SO}_{4}{ }^{2-}\right)$ peaks suggesting that the compound which produces it, is rather to be found associated with other sulfates. Figure 2.2.2.15 shows the repartition of microinclusions with a Raman peak $\sim 984 \mathrm{~cm}^{-1}$ and Appendix 2.2.2.C shows their Raman spectra. Potassium is in general considered to have terrestrial sources and for the analyzed EDML ice samples it should be more frequent in the cloudy ice considered to be formed at times when enhanced wind activity favoured the deposition of (more) mineral dust. Only two of the (four) CB ice samples would contain arcanite while five of the six CI samples would have at least one microinclusion containing arcanite. This means that $\mathrm{K}$ sulfate is more frequent in the warm climate ice, a conclusion not in line with what was previously observed about the $\mathrm{K}^{+}$anion.

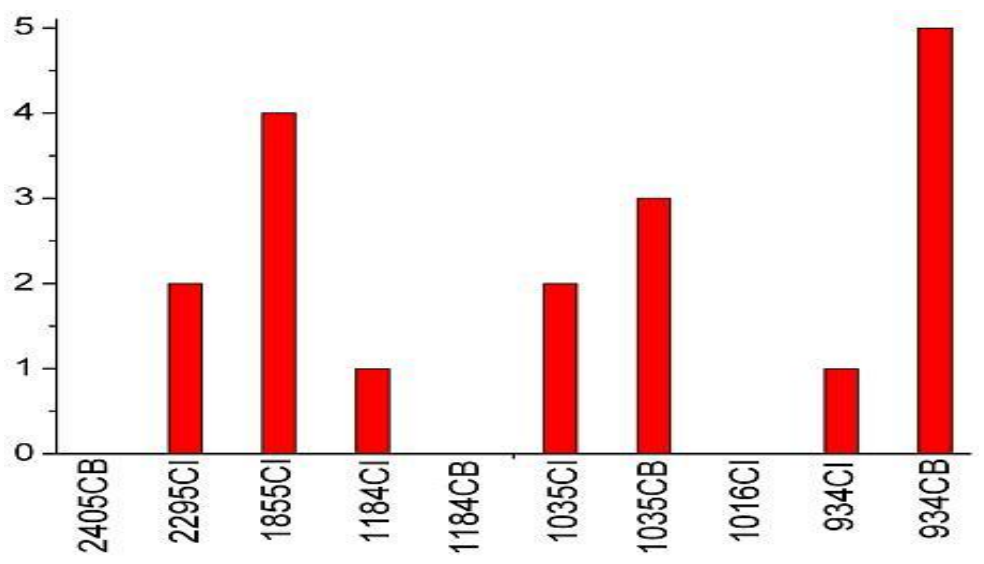

Figure 2.2.2.15 Distribution of microinclusions in EDML ice samples, from cloudy band (CB) or clear ice (CI) regions, that can be considered to contain either $\mathrm{K}_{2} \mathrm{SO}_{4}$ or $_{2} \mathrm{SO}_{4}$ (or a sulfate and sulfuric acid). On the vertical axis is the number of microinclusions.

From Fig. 2.2.2.15 results that (in total) in clear ice there are $25 \%$ more "peak at $\sim 984 \mathrm{~cm}^{-}$ ${ }^{1}$ microinclusions" than in the CB ice; which in fact is not a considerable difference if the related compound is $\mathrm{H}_{2} \mathrm{SO}_{4}$ (alone or associated with other sulfates). A high amount of $\mathrm{SO}_{4}{ }^{2-}$ anions at the DML was found (Weller and Wagenbach, 2007) but for LGM a reductive capacity of the Antarctic atmosphere was supposed (Iizuka et al. 2008). 


\section{Microinclusions with nonequivalent $\mathrm{SO}_{4}{ }^{2-}$ groups. Mixed simple sulfates}

Microinclusions containing two different sulfates were present in almost all the analyzed EDML ice samples, with a somehow enhanced amount in the clear ice. The corresponding countercations in the $\mathrm{SO}_{4}{ }^{2-}$ contained compounds forming these microinclusions were considered to be: $\mathrm{Na}^{+}$(or $\mathrm{Mg}^{2+}$ ), $\mathrm{Ca}^{2+}, \mathrm{H}^{+}$, and possible also $\mathrm{K}^{+}$. The association of different sulfates could have taken place before or after their embedment in EDML ice.

If the formation of such inclusions is facilitated by a higher temperature in a micro- or macroscale environment, then their preference for the clear ice would be explained easily. Because mixed sulfates microparticles are also present in $\mathrm{CB}$ ice their occurrence can be explained taking into account the influence from the ice matrix. Processes related with the evolution of the polar ice microstructure (recristallization, polygonization, grain rotation, localized microshear or microfractures) can induce and favour the aggregation of the impurities embedded in the polar ice structure (Faria et al. 2010). An important aspect for these mixed microinclusions to exist at a measurable size (as for any impurity), is the available quantity of the forming simple compounds. When less microinclusions containing only Ca sulfate are detected, it seems that another variable amount of gypsum exists in mixed microinclusions. Also the degree of crystallinity of such microinclusions comes into question. Amorphous (or nano-crystalline) impurities are more prone to aggregation than single crystals. The morphology of the two independent $v_{1}\left(\mathrm{SO}_{4}\right)$ peaks, present in the Raman spectra of mixed sulfate microinclusions resemble sometimes, the patterns obtained from a main compound with some impurities in it.

If these mixed sulfates containing microinclusions were already formed at the time of their deposition in EDML ice then they must have formed once the seawater froze. Marion et al. (1999) discusses the possibility to have alternative seawater freezing pathways. "The "RingerNelson-Thompson pathway" is the current paradigm for seawater freezing; along this pathway, calcium precipitates as antarcticite $\mathrm{CaCl}_{2} \cdot 6 \mathrm{H}_{2} \mathrm{O}$, and the eutectic temperature is $-54^{\circ} \mathrm{C}$. Along the 'Gitterman pathway' for seawater freezing, calcium precipitates as gypsum $\mathrm{CaSO}_{4} \cdot 2 \mathrm{H}_{2} \mathrm{O}$, and the eutectic temperature is $-36^{\circ} \mathrm{C}$. The theoretical and experimental evidence argue in support of the Gitterman pathway as the thermodynamically stable pathway for seawater freezing. The metastable Ringer-Nelson-Thompson pathway is attributable to slow kinetics and fractional crystallization during the freezing process".

In the analyzed EDML ice the $\mathrm{Na}^{+}$and $\mathrm{Ca}^{2+}$ sulfates are more frequently associated and this can be the result of seawater freezing along the Gitterman pathway.

Another possibility is to have them formed during the residence time (of the simple compounds) in the atmosphere or in the clouds. Like this is more probable to create aerosol particles that are generally enriched in $\mathrm{SO}_{4}{ }^{2-}$. Even if, for example, the initial marine aerosol was created along a Ringer-Nelson-Thompson pathway, it could have been changed when interacting with the available $\mathrm{SO}_{3}$ or $\mathrm{SO}_{4}{ }^{2-}$ existent in the atmosphere. The case in which the enrichment in $\mathrm{SO}_{4}{ }^{2-}$ of microinclusions existent in EDML ice is a result of diagenesis is also possible because it is known that $\mathrm{SO}_{4}{ }^{2-}$ anions are prone to diffusion in ice (Rempel, 2001; Barnes et al. 2003a; Traversi et al. 2009). Obviously, more detailed studies are needed to understand the origin and formation of mixed microinclusions in EDML (/polar) ice.

\section{Microinclusions containing silicon (as $\mathrm{SiO}_{2}$, or silicates)}

The number of microinclusions with Si has low values for the clear MIS2 ice in contrast with the higher ones obtained for the cloudy band MIS2 ice. It is noticeable the high value of Si containing microparticles in the $1035 \mathrm{CB}$ ice sample, mostly as $\mathrm{SiO}_{2}$ and in the $2405 \mathrm{CB}$ ice sample, mainly as silicates. 
Silica, $\mathrm{SiO}_{2}$, can be related with proximal sources (granitic rocks, till deposits) but also with an Aeolian transport from remote paleosoils (Hall et al. 2008, Damiani et al. 2006). Low humidity, high winds and temperature gradients could have persisted during the deposition of snow that formed the investigated EDML ice at $1035 \mathrm{~m}$ depth.

When the ice from $1035 \mathrm{~m}$ is compared with the one from $1184 \mathrm{~m}$ one can observe that it is dominated by $\mathrm{Si}$ and $\mathrm{Ca}$ containing microinclusions, respectively. On the one hand, for the 1035 ice the amount of microinclusions with $\mathrm{Si}$ is sharply depleted in the clear ice following the $\mathrm{CB}$ one, and on the other hand for the 1184 ice the Ca containing microinclusions are decreasing more smoothly towards the clear ice near the CB. This observation pleads for a remote source of the air masses enriched in $\mathrm{Si}$, depositing their precipitations in compact time intervals while more gypsum suggests a somehow localized air masses dynamics smoothly changing in time. Moreover, the analyzed EDML ice at $1035 \mathrm{~m}$ depth has more $\mathrm{SiO}_{2}$ while the one at $1184 \mathrm{~m}$ more silicates. Silica is considered to originate from desert sand and can have a longer residence time in the atmosphere thus being transported over longer distances. Silicates should be available from local sources because they are too heavy for long-range relocation via atmospheric air movements.

On the other hand, there are no Na containing microinclusions in the MIS6 ice sample (2405CB) but this sample has the disadvantage that only a few microinclusions could be properly identified and this can lead to unreliable final results (though, the $1035 \mathrm{CB}$ has $\mathrm{Na}$ ). As at $2400 \mathrm{~m}$ depth the temperature of the EDML ice inside the ice sheet is (about) $-12^{\circ} \mathrm{C}$, and it is commonly assumed that at temperatures above $-15^{\circ} \mathrm{C}$ several properties of (polar) ice start to change (Faria et al. 2010), there is the possibility that the initial chemical composition of the ice at this depth to be perturbed by some essentially physical processes (division, dissolution, diffusion). High resolution micro-structure mapping investigations on samples from the EDML ice core, performed shortly after the ice was drilled reveal that some redistribution of the impurities existent inside the ice matrix occurred, phenomenon more obvious below $2300 \mathrm{~m}$ depth (Faria et al. 2010). Moreover, if we consider that the analyzed sample at $2405 \mathrm{~m}$ depth should have kept in its volume (of $\sim 320 \mathrm{~mm}^{3}$ ), the impurities deposited during 60 months, (EPICA Comm. Memb. 2006; supplem. material), then a diminution of the initial amounts of (easy) soluble inclusions appears very likely.

\section{Microinclusions containing silicon and sulfate}

As discussed for the case of mixed sulfates microinclusions, the mixed silicate and sulfate ones could have been formed by ex situ or in situ aggregation of the available impurities. Reorganization of the (snow, firn and) ice (micro)structure could provide accessible diffusional pathways for chemicals so that sulfate salts to come into contact with silicate (micro)particles. Also it is not excluded that $\mathrm{SO}_{4}{ }^{2-}$ anions deposited on silicate minerals before being trapped in the EDML snow or ice, as they were still a component of the atmospheric aerosol above the Antarctic snow (Kerminen et al. 2000), or still incorporated in the parental rock source as salt efflorescences.

Andreae et al. (1986) investigated individual marine aerosol particles via scanning electron microscopy and electron microprobe analyses. It was observed that a large fraction of the silicate minerals were internally mixed with sulfates most probably due to processes taking place in the clouds. "The reaction between acids sulfates and silicate minerals brought together by incloud processes can also account for the presence of $\mathrm{CaSO}_{4}$ particles on silicate aerosol particles and the low calcium concentration in the silicate component of these particles, since the $\mathrm{Ca}$ extracted from the minerals by $\mathrm{H}_{2} \mathrm{SO}_{4}$ would crystallize as $\mathrm{CaSO}_{4}$ upon evaporation of the cloud droplet". 


\section{CONCLUSIONS}

"I had always liked January. I liked ice. It was beautiful, like diamonds, the brightest thing in the world. I

liked to write my name in the cold, foggy window of my bedroom with my fingertip. I liked how black the sky was, how the stars seemed to hang down lower in the sky. ... I was thinking about the future back, then. I was looking forward." A. Hoffman. The Ice Queen, 2005, pg.209

The polar ice cores are usually labeled "ancient air inside" (under pressure, of course). And this "aether" is not only as bubbles, clathrates, or plate-like inclusions filled with $\mathrm{O}_{2}$ and $\mathrm{N}_{2}$ molecules, but also as cations, anions of many chemical elements or their compounds; and after all even the ice itself is the frozen state of the water that for a while was a part embedded in the "ancient air".

The chemistry of the polar ice, the glaciochemistry, can be seen as a mixture of atmospheric (aerosol) chemistry and a chemistry at temperatures below $0^{\circ} \mathrm{C}$, the first developed ex situ but preserved in situ in polar ice, the second developed or developing in situ in polar ice. The air from up in the sky is trapped down in the polar ice body and than the mixture is reorganized to reach the suitable equilibrium state at a certain location.

Raman spectrochemical analyses performed on micro-inclusions identified in polar ice from the EDML ice core was a sensitive enough method to reveal an unexpected chemical complexity. From the simple Raman fingerprints of the mirabilite or other salts preserved in EDML ice as individual (clusters of nano)crystals towards Raman spectra showing that the salts are no longer "pure crystals" but associated with different compounds and then to Raman patterns attributable to acids or jarosites, the chemistry of the EDML ice (core) is at the same time particular and in line with the one of the other ice cores (i.e. the Dome Fuji ice core).

The similarities, based on the general physical characteristics and chemical beahviour of the impurities trapped in the EDML ice, are as follows:

- the secondary gaseous microinclusions formed as a result of ice structure relaxation (mainly the plate-like inclusions) contain more oxygen than nitrogen (fractionated air due to the higher diffusion coefficient of $\mathrm{O}_{2}$ ) and their shape depends on the degree of stress retained by the ice (i.e. it changes function of the depth of the ice in the ice sheet) or on the temperature of the ice (i.e. they can partially or totally dissolve).

- the amount of different solid salts embedded in the EDML ice volume depends on the amount of the forming cations and their affinity for available anions as well as on the stability of the final salts in (the) specific thermochemical conditions. Macroscopically, the atmosphere above the ice is enriched for example in $\mathrm{Na}^{+}$mainly as $\mathrm{NaCl}$ but contains a small amount of "free" $\mathrm{SO}_{4}{ }^{2-}$ from ( $\mathrm{SO}_{2}$ or) $\mathrm{H}_{2} \mathrm{SO}_{4}$ when compared with anions from other acids. The final chemistry of this system will be characterized by a salt content which will not be clearly dominated by sodium sulfate, (as would be the case for an atmosphere with the acidity mainly from $\mathrm{SO}_{4}{ }^{2-}$ ), but will have also appreciable contributions from other sodium salts, i.e. sodium nitrate (lizuka et al. 2008). It is the case for the so called seasonality of the different species preserved in ice. Microscopically atmospheric particles of different salts can collide and form mixed clusters somehow independent of the overall amount of the respective cations and anions that formed the salts; or the acids can be fixed on the surface of the salt particles. It can be the case for Raman spectra which suggest that the investigated microinclusions preserved in (EDML) ice are a mixture of different compounds. On the other hand, when a micro-particle partially changes its chemistry (i.e. only) with respect to the anions it contains, the process is more dependent then independent of the 
overall amount of ions. It can be the case for Raman spectra which have an acceptable signal from a sulfate salt and a (poor) signal from the corresponding nitrate (Fig. 2.2.2.14).

- the occurrence of liquid microinclusions in EDML ice is in principle related with the existence of acids, $\left(\mathrm{H}_{2} \mathrm{SO}_{4}, \mathrm{HNO}_{3}, \mathrm{HCl}\right.$ being more frequent), as well as their association with (easy soluble) salts (i.e. sodium sulfate would be preferred against calcium sulfate).

Microinclusions for which the Raman spectra have features that can be attributed to sulfuric acid alone ("pure" or unassociated) (Fig. 2.2.2.9) seem to be more frequent than the ones with Raman spectra with peaks from ("pure") nitric acid (Appendix 2.2.2.H example 2 at 1184 EDML depth). The latter seems to be stabilized by other suitable (but insoluble) chemicals (i.e $\mathrm{TiO}_{2}$ ). Both types of inclusions could have been formed ex situ or in situ with $\mathrm{H}_{2} \mathrm{SO}_{4}$ having a higher probability for post-depositional (physical) relocation (via diffusion) especially in ice from deeper regions of the ice sheet where the temperature is usually higher and $\mathrm{HNO}_{3}$ having a higher probability for post-depositional (chemical trans)formation especially at favourable energetically and chemically (catalytic) sites.

It is also the case of the microinclusions that can be considered to contain sodium sulfate but its Raman peak is distorted by different amounts of $\mathrm{SO}_{4}{ }^{2-}$ anions present (Fig. 2.2.2.3 and Fig. 2.2.2.4). Trying to further explain these observations, it can be imagined that a micro-inclusion considered to be formed of $\mathrm{Na}_{2} \mathrm{SO}_{4} \cdot 10 \mathrm{H}_{2} \mathrm{O}$ and concentrated $\mathrm{H}_{2} \mathrm{SO}_{4}\left(\right.$ as $\left.\mathrm{HSO}_{4}{ }^{-}\right)$formed ex situ in the atmosphere above the polar ice, and was preserved unchanged:

$$
\begin{aligned}
2 \mathrm{NaCl}+\mathrm{H}_{2} \mathrm{SO}_{4} \rightarrow \underset{\mathrm{Na}_{2} \mathrm{SO}_{4}+2 \mathrm{HCl}(\uparrow)}{ } & \downarrow+\mathrm{H}_{2} \mathrm{SO}_{4}\left(+\mathrm{H}_{2} \mathrm{O}\right) \\
& \mathrm{Na}_{2} \mathrm{SO}_{4}+\mathrm{HSO}_{4}^{-}+\mathrm{NaSO}_{4}^{-}\left(+\mathrm{H}_{3} \mathrm{O}^{+}\right)
\end{aligned}
$$

On the other hand, a microinclusion that can be considered to contain $\mathrm{Na}_{2} \mathrm{SO}_{4} \cdot 10 \mathrm{H}_{2} \mathrm{O}$ and diluted $\mathrm{H}_{2} \mathrm{SO}_{4}$ (as $\mathrm{SO}_{4}{ }^{2-}$ and probably also as $\mathrm{HSO}_{4}{ }^{-}$) has a higher probability to have been formed (also) in situ in the polar ice:

$$
\begin{gathered}
\mathrm{nNaCl}+\mathrm{pSO}_{4}{ }^{2-}+\mathrm{H}_{2} \mathrm{O} \rightarrow \mathrm{Na}_{2} \mathrm{SO}_{4}+\left[\mathrm{SO}_{4}{ }^{2-}\left(\mathrm{H}_{2} \mathrm{O}\right)_{\mathrm{m}}\right]+\underset{(\uparrow)}{2 \mathrm{HCl}}+(\mathrm{n}-2) \mathrm{NaCl}+? \mathrm{HSO}_{4}{ }^{-} / \mathrm{NaSO}_{4}{ }^{-} \\
\left(\mathrm{H}_{3} \mathrm{O}^{+}+\mathrm{Cl}^{-}\right)
\end{gathered}
$$

The difference would come from the quantity and the form of the $\mathrm{H}_{2} \mathrm{O}$ molecules that are available or exist in the system as well as on the "openness" of the system, i.e. the possibility to remove resulting (volatile or dissociated) products.

The particular chemistry of the EDML ice core resides first of all on the composition of the aerosol that reached the drilling site, the meteorological conditions experienced by the impurities deposited on the EDML snow/ice, as well as on the structural characteristics of the ice sheet at this site (or the way in which the snow/ice kept the inclusions unaltered).

At the EDML site can arrive air masses formed over the Atlantic Ocean at temperatures above $0^{\circ} \mathrm{C}$ (Reijmer and van den Broeke 2001) and the mean temperature at the site is $-44.6^{\circ} \mathrm{C}$. This causes a prime feature of the impurities trapped in the ice: a chemical composition predominantly with maritime influences.

It is an explanation for the case of Raman spectra with peaks from both $\mathrm{Na}$ and $\mathrm{Ca}$ salts (especially) as simple (solid) sulfate salts. (The similar Raman spectra in which there are peaks that can be attributed to $\mathrm{K}$ and $\mathrm{Ca}$ sulfates can be in fact microinclusions containing liquid solutions of $\mathrm{Na}$ sulfate, $\mathrm{H}_{2} \mathrm{SO}_{4}$ (plus probably also $\mathrm{Cl}^{-}$) and (unaltered) Ca sulfate.) It can also be an explanation for the existence of double sulfate salts in EDML ice. 
Even if the jarosites identified in the EDML ice are not formed ex situ but in situ in the polar ice (Misawa et al. 2010) the association of $\mathrm{Na}$ sulfate with $\mathrm{Fe}$ (sulfate) and carbonaceous matter indicates a particularity due to the marine influences at this site.

The possibility to identify the chemical nature of the microinclusions preserved in EDML ice offers the occasion to trace back the origin of the air parcels or their trajectory. For example the type of microinclusions existent in the EDML ice at $1016 \mathrm{~m}$ depth, that have Raman peaks attributable to a silicate (or sulfate) which is not present in the other investigated ice samples (Figure 2.2.2.12) can offer information about the history of the related precipitations (the dynamics of the air masses) or about the weather regime at the time of their transport towards the site of deposition.

Last but not least the ice structure is influenced by and also influences the impurities. The aerosol composition that reaches the EDML site has a particular high concentration of sulfate (Bertler et al. 2005; Piel et al. 2006) thus the ice should also contain a high amount of $\mathrm{SO}_{4}{ }^{2-}$ bounded as salts or "free" as (liquid) solution. The ice (layers) enriched in labile $\mathrm{SO}_{4}{ }^{2-}$ anions (from microinclusions containing sulfuric acid or highly soluble salts) should be more prone to change their structure. It can be the case for the soft ice strata with a "slanted brick wall pattern" microstructure, identified in the EDML ice around 2385m depth (Faria et al. 2006a). On the other hand, the impurities can be relocated by the changes in the ice (micro)structure (Faria et al. 2010; Ohno et al. 2010) a process that can favour changes of their chemistry.

The chemistry of microinclusions existent in polar ice still promises interesting subjects, like trying to decipher if they are primary or secondary or if they are endemic or not. Also the relationship between the different types of inclusions or between impurities and the (structure of the) ice matrix is to be established. Physical processes (i.e. diffusion) that can influence the (climatic) information stored in ice are still not well understood. 


\title{
References
}

\author{
Sadoveanu 45 M., "Venea o moara pe Siret", Ed.Pen.Lit., 1969, [...pg.21] “Eu am \\ venit cu moara pe Siret [...pg.22] - Cum te chiamă? - Anița, cuconaşule...şopti ea. \\ [...pg.237] - Stai bine? SNu ți-i frig? - Mă simt foarte bine. . raspunse mademoiselle \\ Annette".
}

Adie R.J. Antarctic geology: proceedings of the First International Symposium on Antarctic Geology, Cape Town, 16-21 September 1963. North-Holland Publishing Co., Amsterdam, 1964

Adie R.J. Antarctic geology and geophysics / Symposium on Antarctic geology and solid earth geophysics, Oslo, 6-15 Aug. 1970. Universitetsforlaget, Oslo, 1972

Ahn J. and Brook E.J. Atmospheric $\mathrm{CO}_{2}$ and climate on millennial time scales during the last glacial period. Science 322(5898), 83-85, 2008.

Alley R.B., Gow A.J., Meese D.A. Mapping c-axis fabrics to study physical processes in ice. Journal of Glaciology, 41(137), 197-203, 1995

Alley R.B. and 11 others. Visual-stratigraphic dating of the GISP2 ice core: Basis, reproducibility, and application. Journal of Geophysical Research-Oceans, 102(C12), 26367-26381, 1997a

Alley R.B., Gow A.J., Meese D.A., Fitzpatrick J.J., Waddington E.D., Bolzan J.F. Grain-scale processes, folding, and stratigraphic disturbance in the GISP2 ice core. Journal of Geophysical Research-Oceans, 102(C12), 26819-26830, 1997b

Alpers C.N. Sulfate minerals: crystallography, geochemistry, and environmental significance. Mineralogical Society of America, Washington DC, 2000

Andersen K.K. and 11 others. The Greenland ice core chronology 2005, 15-42 kyr. Part 1: Constructing the time scale. Quaternary Science Reviews, 25(23-24), 3246-3257, 2006

Andreae M.O., Charlson R.J., Bruynseels F., Storms H., Vangrieken R., Maenhaut W. Internal mixture of sea salt, silicates and excess sulfate in marine aerosols. Science, 232(4758), 1620-1623, 1986

Arthern R.J., Vaughan D.G., Rankin A.M., Mulvaney R., Thomas E.R. In situ measurements of Antarctic snow compaction compared with predictions of models. Journal of Geophysical Research-Earth, 115, F03011, 2010

Asaf Ö. Dokuza kadar on, Yapı Kredi Yayınları, Istanbul, 2010

van Autenboer T. The geomorphology and glacial geology of the Sør-Rondane, Dronning Maud Land. in Adie 1964, op.cit., pg. 81-103

van Autenboer T. and Loy W. Recent geological investigations in the Sør-Rondane Mountains, Belgicafjella and Sverdrupfjella, Dronning Maud Land. in Adie 1972, op.cit., pg. 563-571

Banta J.R., McConnell J.R., Frey M.M., Bales R.C., Taylor K. Spatial and temporal variability in snow accumulation at the West Antarctic Ice Sheet Divide over recent centuries. Journal of Geophysical ResearchAtmospheres, 113(D23), D23102, 2008

Baker I. and Cullen D. SEM/EDS observations of impurities in polar ice: artifacts or not? Journal of Glaciology, 49(165), 184-190, 2003

Barbante C., Fischer H., Masson-Delmotte V., Waelbroeck C., Wolff E.W. Climate of the Last Million Years: New Insights from EPICA and Other Records. Quaternary Science Reviews, 29(1-2), 1-7, 2010

Barnes P.R.F., Mulvaney R., Wolff E.W., Robinson K. A technique for the examination of polar ice using the scanning microscope. Journal of Microscopy-Oxford, 205, Part 2, 118-124, 2002

Barnes P.R.F., Wolff E.W., Mader H.M., Udisti R., Castellano E., Rothlisberger R. Evolution of chemical peak shapes in the Dome C, Antarctica, ice core. Journal of Geophysical Research-Atmospheres, 108 (D3), 4126, $2003 \mathrm{a}$

Barnes P.R.F., Wolff E.W., Mallard D.C., Mader H.M. SEM studies of the morphology and chemistry of polar ice. Microscopy Research and Technique, 62(1), 62-69, 2003b

Barnes P.R.F., Wolff E., Mallard D.C. Etching channels and grain-boundary grooves on ice surfaces in scanning electron microscope. Journal of Glaciology, 52(179), 645-648, 2006

Beaumont S.K., Gustafsson R.J., Lambert R.M. Heterogeneous Photochemistry Relevant to the Troposphere: $\mathrm{H}_{2} \mathrm{O}_{2}$ Production during the Photochemical Reduction of $\mathrm{NO}_{2}$ to $\mathrm{HONO}$ on UV-illuminated $\mathrm{TiO}_{2}$ Surfaces. ChemPhysChem, 10, 331-333, 2009

Bendel V. and Schmidt B.C. Raman spectroscopic characterisation of disordered alkali feldspars along the join $\mathrm{KAlSi}_{3} \mathrm{O}_{8}-\mathrm{NaAlSi}_{3} \mathrm{O}_{8}$ : application to natural sanidine and anorthoclase. European Journal of Mineralogy, 20(6), $1055-1065,2008$

${ }^{45}$ or in Sadoveanu M. "Le Moulin à la derive”, Bucarest, 1962 
Bendel V. Untersuchungen an Luftblasen im EDML-Eisbohrkern mit Bildanalyse und Ramanspektroskopie. Master Thesis, Ubiversity of Göttingen, 2009

Bergin M.H., Meyerson E.A., Dibb J.E., Mayewski P.A. Relationship between continuous aerosol measurements and firn core chemistry over a 10-year period at the South Pole. Geophysical Research Letters, 25(8), 1189-1192, 1998

Bernacchi L. To the South Polar Regions. Expedition of 1898-1900. Bluntisham Books, Denton, 1991

Bersani D., Andò S., Vignola P., Marino I.-G., Lottici P.P. Micro-Raman determination of the composition of ugrandite garnets. Micro-Raman Spectroscopy and Luminescence Studies, 3037, 2009

Bertler N. and 54 others. Snow chemistry across Antarctica. Annals of Glaciology, 41, 167-179, 2005

Birnbaum G., Brauner R., Ries H. Synoptic situations causing high precipitation rates on the Antarctic plateau: observations from Kohnen Station, Dronning Maud Land. Antarctic Science, 18 (2), 279-288, 2006

Birnbaum G. and 16 others. Strong-wind events and their influence on the formation of snow dunes: observations from Kohnen Station, Dronning Maud Land. Journal of Glaciology, 5(199), 891-902, 2010

Blackford J.R. Sintering and microstructure of ice: a review. Journal of Physics D, 40 (21), R355-R385,

2007

Blunier T. and Brook E.J. Timing of millennial-scale climate change in Antarctica and Greenland during the last glacial period. Science, 291(5501), 109-112, 2001

Bowen M. Thin ice. Henry Holt \& Co., New York, 2005

Bradfield E. Approaching ice : poems, Persea Books, New York, 2010. $175-200$

Bromwich D.H. and Parish T.R. Meteorology of the Antarctic. In Karoly and Vincent, 1998, op.cit., pg.

Burn L.J. and 9 others. An ultra-clean technique for accurately analyzing $\mathrm{Pb}$ isotopes and heavy metals at high spatial resolution in ice cores with sub-pg g(-1) Pb concentrations. Analytica Chimica Acta, 643(2), 228-236, 2009

Buzgar N., Buzatu A., Sanislav I.V. The Raman study of some sulfates. Analele Ştiintifice ale Univ. Al.I.Cuza Iaşi, Geologie. LV,1, 5-23, 2009

Caillon N., Severinghaus J.P., Jouzel J., Barnola J.M., Kang J., Lipenkov V.Y. Timing of Atmospheric CO2 and Antarctic Temperature Changes Across Termination III. Science, 299, 1728-1731, 2003

Capron E. and 11 others. Synchronising EDML and NorthGRIP ice cores using delta O-18 of atmospheric oxygen (delta O-18(atm)) and CH4 measurements over MIS5 (80-123 kyr). Quaternary Science Reviews, 29(12), 222-234, 2010a

Capron E. and 14 others. Millennial and sub-millennial scale climatic variations recorded in polar ice cores over the last glacial period. Climate of the Past, 6(3), 345-365, 2010b

Champagnon B., Panczer G., Chazallon B., Arnaud L., Duval P., Lipenkov V. Nitrogen and oxygen guest molecules in clathrate hydrates: Different sites revealed by Raman spectroscopy. Journal of Raman Spectroscopy, 28, 711-715, 1997

Chazallon B., Champagnon B., Panczer G., Pauer F., Klapproth A., Kuhs W. Micro-Raman Analysis of Synthetic Air-Clathrates. European Journal of Mineralogy 10, 1125-1134, 1998

Chio C.H., Sharma S.K., Muenow D.W. Micro-Raman studies of gypsum in the temperature range between 9 K and 373 K. American Mineralogist, 89, 390-395, 2004

Chio C.H., Sharma S.K., Muenow D.W. The hydrates and deuterates of ferrous sulfate $\left(\mathrm{FeSO}_{4}\right)$ : a Raman spectroscopic study. Journal of Raman Spectroscopy, 38, 87-99, 2007

Coplen T.B. Reporting of stable hydrogen, carbon, and oxygen isotopic abundances. Pure and Applied Chemistry, 66(2), 273-276, 1994

Coxall H.K., Wilson P.A., Palike H., Lear C.H., Backman J. Rapid stepwise onset of Antarctic glaciation and deeper calcite compensation in the Pacific Ocean. Nature, 433(7021), 53-57, 2005

Craddock C. Antarctic geoscience / Symposium on Antarctic Geology and Geophysics, Madison, Wisconsin, U.S.A., August 22-27, 1977. Univ. of Wisconsin Press., Madison, Wisc, 1982

Craddock C. Antarctica and Gondwanaland. in Craddock 1982, op.cit, pg. 3

Craig H. The geochemistry of the stable carbon isotopes. Geochimica et Cosmochimica Acta, 3(2-3), 53-92,

1953

Craven M. and Allison I. Firnification and the effects of wind-packing on Antarctic snow. Annals of Glaciology, 27, 239-245, 1998

Cui X.B. and 7 others. Ice radar investigations at Dome A, East Antarctica: Ice thickness and subglacial topography. Chinese Science Bulletin, 55(4-5), 425-431, 2010

Cunningham J. and Waddington E.D. Boudinage: A source of stratigraphic disturbance in glacial ice in Central Greenland. Journal of Glaciology, 36(124), 269-272, 1990

Dahl-Jensen D., Thorsteinsson T., Alley R., Shoji H. Flow properties of the ice from the Greenland Ice Core Project ice core: The reason for folds? Journal of Geophysical Research-Oceans, 102(C12), 26831-26840, 1997 
Daly F.P., Brown C.W., Kester D.R. Sodium and Magnesium sulfate ion pairing - evidence from Raman spectroscopy. Journal of Physical Chemistry, 76(24), 3664-3668, 1972

Damiani D., Giorgetti G., Turbanti I.M. Clay mineral fluctuations and surface textural analysis of quartz grains in Pliocene-Quaternary marine sediments from Wilkes Land continental rise (East-Antarctica): Paleoenvironmental significance. Marine Geology, 226, 281-295, 2006

Dansgaard W. Oxygen-18 abundance in fresh water. Nature, 174, 234-235, 1954a

Dansgaard W. The O-18-abundance in fresh water. Geochimica et Cosmochimica Acta, 6(5-6), 241-260,

$1954 b$

Dansgaard W., Nief G., Roth E. Isotopic distribution in a Greenland iceberg. Nature 185(4708), 232-232,

1960

Davidson C.I., Bergin M.H., Kuhns H.D. The deposition of particles and gases to ice sheets, in Wolff, E.W. and R.C. Bales (ed.), Chemical Exchange Between the atmosphere and Polar Snow, vol. I 43 of NATO ASI Series, Springer-Verlag, Berlin, Heidelberg, pp. 275-306, 1996

Davis A.R. and Oliver B.G. Raman spectroscopic evidence for contact ion pairing in aqueous magnesium sulfate solutions. Journal of Physical Chemistry, 77(10), 1315-1316, 1973

Debenham F. Antarktis: Geschichte eines Kontinents. 1959, Bertelsmann Lesering, 1959

De Angelis M. and Legrand M. Preliminary investigations of post depositional effects on $\mathrm{HCl}, \mathrm{HNO}_{3}$ and organic acids in polar firn layers, in Ice Core Studies of Global Biogeochemical Cycles, NATO ASI Ser., Ser. I, vol. 30, edited by R. Delmas, pg. 361-381, Springer-Verlag, New York, 1995

Delmas R. J. Ice records of the past environment, The Science Total Environment, 143, 17-30, 1994

Delmas R.J., Wagnon P., Goto-Azuma K., Kamiyama K., Watanabe O. Evidence for the loss of snowdeposited MSA to the interstitial gaseous phase in central Antarctic firn. Tellus series B-Chemical and physical meteorology, 55(1), 71-79, 2003

Dick D., Wegner A., Gabrielli P., Ruth U., Barbante C., Kiews M. Rare earth elements determined in Antarctic ice by inductively coupled plasma-Time of flight, quadrupole and sector field-mass spectrometry: An intercomparison study. Analytica Chimica Acta, 621(2), 140-147, 2008

Domine F., Taillandier A.S., Simpson W.R., Severin K. Specific surface area, density and microstructure of frost flowers, Geophysical Research Letters, 32(13), L13502, 2005

Domine F., Taillandier A.-S., Houdier S., Parrenin F., Simpson W.R.. Douglas T.A. Interactions between snow metamorphism and climate: physical and chemical aspects. In Physics and Chemistry of Ice, Cambridge, UK, 27-46, 2007

Dong J.-L. and 6 others. Raman observation of the interactions between $\mathrm{NH}_{4}{ }^{+}, \mathrm{SO}_{4}{ }^{2-}$, and $\mathrm{H}_{2} \mathrm{O}$ in supersaturated $\left(\mathrm{NH}_{4}\right)_{2} \mathrm{SO}_{4}$ droplets. Journal of Physical Chemistry B, 111(42), 12170-12176, 2007

Dong J.-L., Xiao H.-S., Zhao L.-J., Zhang Y.-H. Spatially resolved Raman investigation on phase separations of mixed Na2SO4/MgSO4 droplets. Journal of Raman Spectroscopy, 40(3), 338-343, 2009

Dort W. Jr. and D. Stage Dort. Marine origin of sodium sulphate deposits in Antarctica. in Adie 1972, op.cit., pg. 659-667

Dreyfus G.B. and 6 others. An ice core perspective on the age of the Matuyama-Brunhes boundary. Earth and Planetary Science Letters, 274 (1-2), 151-156, 2008

Dreyfus G.B., Jouzel J., Bender M.L., Landais A., Masson-Delmotte V., Leuenberger M. Firn processes and delta N-15: potential for a gas-phase climate proxy. Quaternary Science Reviews, 29(1-2), 28-42, 2010

Dubessy J., Geisler D., Kosztolanyi C., Vernet M. The determination of sulfate in fluid inclusions using the mole Raman microprobe - Application to a Keuper halite and geochemical consequences. Geochimica et Cosmochimica Acta, 47(1), 1-10, 1983

Dunlop S. A dictionary of weather, Oxford Univ. Press, Oxford, 2005.

Dye J.E. and 8 others. Particle size distributions in Arctic polar stratospheric clouds, growth and freezing of sulfuric acid droplets, and implications for cloud formation. Journal of Geophysical Research-Atmospheres, 97(D8), 8015-8034, 1992

Edwards H.G.M., Wynn-Williams D.D., Jorge Villar S.E. Biological modification of hematite in Antarctic cryptoendolithic communities. Journal of Raman Spectroscopy, 35(6), 470-474, 2004

Ehlers E.G. Optical mineralogy. Vol.1: Theory and technique. Blackwell Scientific Publ. Palo Alto, 1987

Ehrmann W.U. and Mackensen A. Sedimentological evidence for the formation of East Antarctic ice-sheet in Eocene Oligocene time. Paleogeography Paleoclimatolgy Paleoecology, 93(1-2), 85-112, 1992

Eisen O., I. Hamann, S. Kipfstuhl, D. Steinhage and F. Wilhelms. Direct evidence for radar reflector originating from changes in crystal-orientation fabric, The Cryosphere Discussions, 1, 1-16, 2007

Eisen O. and 15 others. Ground-based measurements of spatial and temporal variability of snow accumulation in east Antarctica. Reviews of Geophysics, 46(1), RG2001, 2008

Endo Y. and Fujiwara K. Characteristics of the snow cover in East Antarctica along the route of the JARE South Pole Traverse and factors controlling such characteristics. Polar Section, National Science Museum, Tokyo, 1973 
628,2004

EPICA Community Members. Eight glacial cycles from an Antarctic ice core. Nature, 429(6992), 623-

EPICA Community Members. One-to-one coupling of glacial climate variability in Greenland and Antarctica, Nature, 444(7116), 195-198, 2006

Ewen S. and Goeffrey D. Modern Raman Spectroscopy: a practical approach, Wiley, Chichester, 2005

Faria S.H. and Kipfstuhl S. Preferred slip band orientations and bending observed in the Dome Concordia (East Antarctica) ice core. Annals of Glaciology, 39, 386-390, 2004

Faria S., Hamann I., Kipfstuhl S., Miller H. Is Antarctica like a birthday cake?, Preprint no. 33/2006 of the Max Planck Institute for Mathematics in the Sciences, Leipzig, 2006a

Faria S.H. Creep and recrystallization of large polycrystalline masses. I. General continuum theory. Proceedings of the Royal Society of London A, 462, 1493-1514, 2006

Faria S.H., Kremer G.M., Hutter K. Creep and recrystallization of large polycrystalline masses. II. Constitutive theory for crystalline media with transversely isotropic grains. Proceedings of the Royal Society of London A, 462, 1699-1720, 2006b

Faria S.H. and 6 others. The multiscale structure of the Antarctic ice sheet. Part I: inland ice, Low Temperature Science, 68, 39-59, 2009

Faria S.H., Freitag J., Kipfsuhl S. Polar ice and the integrity of ice-core paleoclimate records. Quaternary Science Reviews, 29(1-2), 338-351, 2010 preparation

Faria S.H., Kipfstuhl S., Lambrecht A. The EPICA-DML Deep Ice Core. Springer, Heidelberg, in

Fergar F. Modern Turkish Poetry, The Rockingham Press, Ware, 1992

Fischer H., Traufetter F., Oerter H., Weller R., Miller H. Prevalence of the Antarctic Circumpolar Wave over the last two millenia recorded in Dronning Maud Land ice. Geophysical Research Letters, 31(8), L08202, 2004

Fogg G.E. A history of Antarctic science, Cambridge University Press, Cambridge, 1992

Freitag J., Dobrindt U., Kipfstuhl J. A new method for predicting transport properties of polar firn with respect to gases on the pore-space scale, Annals of Glaciology 35, 538-544, 2002

Freitag J., Wilhelms F., Kipfstuhl S. Microstructure-dependent densification of polar firn derived from Xray microtomography. Journal of Glaciology, 50(169), 243-250, 2004

Frezzotti M. and 13 others. Spatial and temporal variability of snow accumulation in East Antarctica from traverse data. Journal of Glaciology, 51(172), 113-124, 2005

Frey M.M., Bales R.C., McConnell J.R. Climate sensitivity of the century-scale hydrogen peroxide $\left(\mathrm{H}_{2} \mathrm{O}_{2}\right)$ record preserved in 23 ice cores from West Antarctica. Journal of Geophysical Research-Atmosphere, 111(D21), D21301, 2006

Frey M.M. and 6 others. Contrasting atmospheric boundary layer chemistry of methylhydroperoxide $\left(\mathrm{CH}_{3} \mathrm{OOH}\right)$ and hydrogen peroxide $(\mathrm{H} 2 \mathrm{O} 2)$ above polar snow. Atmospheric Chemistry and Physics, 9(10), 3261 3276, 2009

Frogner P., Broman C., Lindblom S. Weathering detected by Raman spectroscopy using Al-ordering in albite. Chemical Geology, 151, 161-168, 1998

Frost R.L., Wills R.A, Weier M.L., Martens W., Mills S. A Raman spectroscopic study of selected natural jarosites. Spectrochimica Acta A, 63, 1-8, 2006

Fuchs A. and Leuenberger M.C. delta O-18 of atmospheric oxygen measured on the GRIP Ice Core document stratigraphic disturbances in the lowest 10\% of the core. Geophysical Research Letters, 23(9), 1049-1052, 1996

Fujita S., Okuyama J., Hori A., Hondoh T. Metamorphism of stratified firn at Dome Fuji, Antarctica: A mechanism for local insolation modulation of gas transport conditions during bubble close off. Journal of Geophysical Research-Earth, 114, F03023, 2009

Fukazawa H., Sugiyama K., Mae S., Narita H., Hondoh T. Acid ions at triple junction of Antarctic ice observed by Raman scattering, Geophysical Research Letters, 25(15), 2845-2848, 1998

Fukazawa H. and Mae S. The vibrational spectra of ice Ih and polar ice. Physics of Ice Core Records, Sapporo, Hokkaido Univ. Press, pg 3-24, 2000

Gabrielli P. and 8 others. Direct determination of Rare Earth Elements at the subpicogram per gram level in Antarctic ice by ICP-SFMS using a desolvation system, Analytical Chemistry, 78(6), 1883-1889, 2006a

Gabrielli P. and 10 others. A climatic control on the accretion of meteoric and super-chondritic iridiumplatinum to the Antarctic ice cap. Earth and Planetary Science Letters, 250(3-4), 459-469, 2006b

Gabrielli P. and 11 others. A major glacial-interglacial change in aeolian dust composition inferred from Rare Earth Elements in Antarctic ice. Quaternary Science Reviews, 29(1-2), 265-273, 2010

Gage D.R. and Farwell S.O. Laser Raman spectrometry for the determination of crystalline silica polymorphs in volcanic ash. Analytical chemistry, 53(13), 2123-2127, 1981

Gagliardini O., Gillet-Chaulet F., Montagnat M. A Review of Anisotropic Polar Ice Models: from Crystal to Ice-Sheet Flow Models. Low Temperature Science, Vol. 68, 2009 
Gaudichet A., Petit J.R., Lefevre R., Lorius C. An investigation by analytical transmission electron microscopy of individual insoluble microparticles from Antarctic (Dome C) ice core samples. Tellus, 38B(3-4), 250261,1986

Gaudichet A., De Angelis M., Lefevre R., Petit J.R., Korotkevitch Y.S., Petrov V.N. Mineralogy of insoluble particles in the Vostok Antarctic ice core over the last climatic cycle (150 kyr). Geophysical Research Letters, 15(13), 1471-1474, 1988

Gaudichet A., De Angelis M., Joussaume S., Petit J.R., Korotkevitch Y.S., Petrov V.N. Comments on the origin of dust in East Antarctica for present and ice-age conditions. Journal of Atmospheric Chemistry, 14(1-4), 129142,1992

Genceli F.E., Lutz M., Spek A., Witkamp G.-J. Crystallization and characterization of a new magnesium sulfate hydrate $\mathrm{MgSO}_{4} \cdot 11 \mathrm{H}_{2} \mathrm{O}$. Crystal Growth \& design, 7(12), 2460-2466, 2007

Genceli F.E. and 6 others. Meridianiite detected in ice. Journal of Glaciology, 55(189), 117-122, 2009

Ghermandi G., Cecchi R., Capotosto M., Marino F. Elemental composition determined by PIXE analysis of the insoluble aerosol particles in EPICA-Dome C ice core samples representing the last 27,000 years. Geophysical Research Letters, 30(22), 2176, 2003

Giæver J. The white desert: the official account of the Norwegian-British-Swedish Antarctic Expedition, Chatto \& Windus, London, 1954

Giorgetti G. and Baroni C. High-resolution analysis of silica and sulphate-rich rock varnishes from Victoria Land (Antarctica). European Journal of Mineralogy, 19, 381-389, 2007

Göktas F. Characterisation of glacio-chemical and glacio-meteorological parameters of Amundsenisen, Dronning Maud Land, Antarctica. PhD Thesis, Alfred-Wegener-Inst. für Polar und Meeresforschung, Bremerhaven, 2002

Göktas F., Fischer H., Oerter H., Weller R., Sommer S., Miller H. A glacio-chemicalcharacterization of the new EPICA deep-drilling site on Amundsenisen, Dronning Maud Land, Antarctica. Annals of Glaciology, 35, 347 354,2002

Gold L.W. Process of failure of colunar-grained ice. Philosophical Magazine, 26(2), 311-\& , 1972

Gold L.W. Statistical behaviour of the deformation for first loading of polycrystalline ice. Journal of Glaciology, 49(164), 37-49, 2003a

Gold L.W. Strain and temperature dependence of crack populations in columnar-grain ice. Canadian Journal of Physics, 81(1-2), 311-318, 2003b

Gonfiantini R. and Picciotto E. Oxygen isotope variations in Antarctic snow samples. Nature 184(4698), $1557-1558,1959$

Gore D.B., Creagh D.C., Burgess J.S., Colhoun E.A., Spate A.P., Baird A.S. Composition, distribution and origin of surficial salts in the Vestffold Hills, East Antarctica. Ant. Sci., 8(1), 73-84, 1996

Gow A.J. Relaxation of ice in deep drill cores from Antarctica. Journal of Geophysical Research, 76(11), 2533-2541, 1971

Gow A.J. Glaciological investigations in Antarctica. Antarctic J. U.S., 7(4), 100-101, 1972

Gow A.J. and 6 others. Physical and structural properties of the Greenland Ice Sheet Project 2 ice core: a review, Journal Geophysical Research, 102(C12), 26559-26575, 1997

Gow A.J. and Meese D. Physical properties, crystalline textures and c-axis fabrics of the Siple Dome (Antarctica) ice core, Journal of Glaciology, 53(183), 573-584, 2007

Grannas and 34 others. An overview of snow photochemistry: evidence, mechanisms and impacts. Atmospheric Chemistry and Physics, 7(16), 4329-4373, 2007

Grikurov. Structure of Antarctica and outline of its evolution. in Craddock 1982, op.cit., pg. 791

Guillou H., Singer B.S., Laj C., Kissel C., Scaillet S., Jicha B.R. On the age of the Laschamp geomagnetic excursion. Earth and Planetary Science Letters, 227(3-4), 331-343, 2004

György E., Axente E., Mihailescu I.N., Ducu C., Du H. Doped thin metal oxide films for catalytic gas sensors. Applied Surface Science 252, 4578-4581, 2006

Hall K., Guglielmin M., Strini A. Weathering of granite in Antarctica: II. Thermal stress at the grain scale. Earth Surface Processes and Landforms, 33, 475-493, 2008

Hamann I. and 6 others. Evolution of air bubble and air hydrate ensembles: statistical analysis of the EPICA-DML ice core. poster, EGU 1st general assembly, Nice, 2004

Hamann I., Kipfstuhl S., Lambrecht A. Fabrics and grain-shape orientations in EDML ice core, Antarctica. poster, The 28th NIPR Symposium on Polar Meteorology and Glaciology, National Institute of Polar Research, Tokyo, 2005

Hamann I., Weikusat C., Azuma N., Kipfstuhl S. Evolution of ice crystal microstructure during creep experiments. Journal of Glaciology, 53(182), 479-489, 2007

Hammer C.U. and Meese D.A. Dating ice cores. Nature, 363, 666, 1993

Hobbs P.V. Ice Physics. Clarendon Press, Oxford, 1974

Hoffman A. The Ice Queen. Little Brown, New York, 2005 
35, L01701, 2008

Hogg A.McC. Glacial cycles and carbon dioxide: A conceptual model. Geophysical Research Letters,

Holmes H. The secret life of dust: from the cosmos to the kitchen counter, the big consequences of little things, Wiley, New York, 2001

Hondoh T. and Higashi A. Generation and absorbtion of dislocations at large-angle grain-boundaries in deformed ice crystals. Journal of Physical Chemistry, 87(21), 4044-4050, 1983

Hondoh T., Shoji H., Watanabe O., Salamatin A.N., Lipenkov V.Y. Depth-age and temperature prediction at Dome Fuji station East Antarctica. Annals of Glaciology, 35, 384-390, 2002

Hori A. and 11 others. A detailed density profile of the Dome Fuji (Antarctica) shallow ice core by X-ray transmission method. Annals of Glaciology, 29, 211-214, 1999

Hou S.G., Li Y.S., Xiao C.D., Ren J.W. Recent accumulation rate at Dome A, Antarctica. Chinese Science Bulletin, 52(3), 428-431, 2007

Huybrechts, P., Rybak O., Pattyn F., Ruth U., Steinhage D. Ice thinning, upstream advection, and nonclimatic biases for the upper $89 \%$ of the EDML ice core from a nested model of the Antarctic ice sheet. Climate of the past, 3(4), 577-589, 2007

Iizuka Y., Takata M., Hondoh T., Fujii Y. High-time-resolution profiles of soluble ions in the last glacial period od a Dome Fuji (Antarctica) deep ice core. Annals of Glaciology, 39, 452-456, 2004a

Iizuka Y. and 6 others. $\mathrm{SO}_{4}{ }^{2-}$ minimum in summer snow layer at Dome Fuji, Antarctica, and the probable mechanism. Journal of Geophysical Research-Atmospheres, 109(D4), D04307, 2004b

lizuka Y., Hondoh T., Fujii Y. $\mathrm{Na}_{2} \mathrm{SO}_{4}$ and $\mathrm{MgSO}_{4}$ salts during the Holocene period derived by highresolution depth analysis of a Dome Fuji ice core. Journal of Glaciology, 52, 176, 58-64, 2006

Iizuka Y. and 6 others. A relationship between ion balance and the chemical compounds of salt inclusions found in the Greenland Ice Core Project and Dome Fuji ice cores. Journal of Geophysical Research-Atmospheres, 113(D7), D07303, 2008

lizuka Y. and 6 others. Constituent elements of insoluble and non-volatile particles during the Last Glacial Maximum exhibited in the Dome Fuji (Antarctica) ice core. Journal of Glaciology, 55(191), 552-562, 2009

Ikeda T., Fukazawa H., Mae S., Hondoh T., Langway C.C.Jr. Crystal-orientation dependence of Raman spectra of natural air hydrate single crystal. Journal of Physical Chemistry B, 101(32), 6180-6183, 1997

Ikeda T. and 7 others. Extreme fractionation of gases caused by formation of clathrate hydrates in Vostok Antarctic ice. Geophysical Research Letters, 26(1), 91-94, 1999

Ikeda T., Salamatin A.N., Lipenkov V.Ya., Mae S., Hondoh T. Spatial distribution of air molecules within individual clathrate hydrates in polar ice sheets. Annals of Glaciology, 31, 252-256, 2000

Ikeda-Fukazawa T., Hondoh T., Fukumura T., Fukazawa H., Mae S. Variation in $\mathrm{N}_{2} / \mathrm{O} 2$ ratio of occluded air in Dome Fuji antarctic ice. Journal of Geophysical Research-Atmospheres, 106, D16, 17799-17810, 2001

Ikeda-Fukazawa T., Fukumizu K., Kawamura K., Aoki S., Nakazawa T., Hondoh T. Effects of molecular diffusion on trapped gas composition in polar ice cores. Earth and Planetary Science Letters, 229 (3-4), 183-192, 2005

Isaksson E. Climate records from Shallow Firn Cores, Dronning Maud Land. PhD thesis. Stockholm Univ., 1994

Isaksson E., Karlen W., Mayewski P., Twickler M., Whitlow S. A high-altitude snow chemistry record from Amundsenisen, Dronning Maud Land, Antarctica. Journal of Glaciology, 47(158), 2001

Jaenicke R. and Schütz L. Aerosol Physics and Chemistry, in Fisher, G. (ed.), Landolt-Börrnstein: Numerical Data and Functional Relationship in Science and Technology, Vol.4: Meteorology, Subvol. b: Physical and Chemical Properties of the Air of new Series, Group V: Geophysics and Space Research, Springer, New York, pp. 391-457, 1988

Jacobi H.W. and 7 others. Measurements of hydrogen peroxide and formaldehyde exchange between the atmosphere and surface snow at Summit, Greenland. Atmospheric Environment, 36(15-16), 2619-2628, 2002

Jehlička J., Št'astná A., Přikryl R. Raman spectral characterization of dispersed carbonaceous matter in decorative crystalline limestones. Spectrochimica Acta Part A 73, 404-409, 2009

Jimi S.I., Rosman K.J.R., Hong S., Candelone J.P., Burn L.J., Boutron C.F. Simultaneous determination of pictogram per gram concentrations of $\mathrm{Ba}, \mathrm{Pb}$ and $\mathrm{Pb}$ isotopes in Greenland ice by thermal ionistion mass spectrometry. Analytical and Bioanalytical Chemistry, 390, 2, 495-501, 2008

Jonsell U., Hansson M.E., Morth C.M., Torssander P. Sulfur isotopic signals in two shallow ice cores from

Dronning Maud Land, Antarctica. Tellus series B-Chemical and Physical Meteorology, 57(4), 341-350, 2005

Johnsen S.J., Dansgaard W., Clausen H.B., Langway C.C. Climatic oscillations 1200-2000 AD. Nature 227(5257), 482-\&, 1970

Jouzel J. and 6 others. Vostok ice core-A continuous isotope temperature record over the last climatic cycle (160,000 years). Nature 329(6138), 403-408, 1987

Jun L. and Jacka T.H. Crystal-growth rates in firn and shallow ice at high-accumulation sites. Annals of Glaciology, 29, 169-175, 1999 
Kaleschke L., and 10 others. Frost flowers on sea ice as a source of sea salt and their influence on tropospheric halogen chemistry. Geophysical Research Letters, 31(16), L16114, 2004

Kanno H. Complete ionization of concentrated sulfuric-acid at low temperatures. Chemical Physics Letters, 170(4), 382-384, 1990

Kärkäs E., Granberg H.B., Kanto K., Rasmus K., Lavoie C., Lepparanta M. Physical properties of the seasonal snow cover in Dronning Maud Land, East Antarctica. Annals of Galciology, 34, 89-94, 2002

Kärkäs E., Martma T., Sonninen E. Physical properties and stratigraphy of surface snow in western Dronning Maud Land, Antarctica Polar Research 24(1-2), 55-67, 2005a

Kärkäs E., Teinila K., Virkkula A., Aurela M. Spatial variations of surface snow chemistry during two austral summers in western Dronning Maud Land, Antarctica. Atmospheric Environment 39, 1405-1416, 2005b Boston, 1998

Karoly D.J. and Vincent D.G. Meteorology of the Southern Hemisphere. American Meteorological Society,

Kerminen V.M., Teinila K., Hillamo R. Chemistry of sea-salt particles in the summer Antarctic atmosphere. Atmospheric Environment, 34(17), 2817-2825, 2000

Kerr P.F. Optical mineralogy. McGraw-Hill, New York, 1977

King P. Scott's last journey. Duckworth, London, 1999

Kipfstuhl S., Hamann I., Lambrecht A., Freitag J., Faria S.H., Grigoriev D., Azuma N. Microstructure mapping: a new method for imaging deformation-induced microstructural features of ice on the grain scale. Journal of Glaciology, 52(178), 398-406, 2006

Kipfstuhl J. Thick-section images of the EDML ice core, Alfred Wegener Institute for Polar and Marine Research, Bremerhaven, 2007, http://doi.pangaea.de/10.1594/PANGAEA.663141

Kipfstuhl S. and 8 others. Evidence of dynamic recrystallization in polar firn. Journal of Geophysical Research-Solid Earth, 114, B05204, 2009

Kipfstuhl S., Weikusat I., Faria S.H., Svensson A. Micro-inclusions and micro-structure: their effect on the climate record and on ice rheology. AGU, Fall Meeting, abstract C13B-0559, 2010

Kleinefeld B. The charnockite-anorthosite suite of rocks exposed in central Dronning Maud Land, East Antarctica: a study on fluid-rock interactions, and post-entrapment change of metamorphic fluid inclusions. PhD Thesis, Alfred-Wegener-Inst. für Polar- und Meeresforschung. Bremerhaven, 2003

Kloprogge J.T., Schuiling R.D., Ding Z., Hickey L., Wharton D., Frost R.L. Vibrational spectroscopic study of syngenite formed during the treatment of liquid manure with sulphuric acid. Vibrational Spectroscopy, 28(2), 209221,2002 201, 1984

Kodama Y. and Wendler G. Coreless winter in Adélie Land, Antractica, in 1983. Antarctic Journal, 199-

Kolesov B.A., Geiger C.A. Raman spectra of silicate garnets. Physics and Chemistry of Minerals, 25, 142 151,1998

Krachler M., Zheng J.C., Fisher D., Shotyk W. Atmospheric imputs of Ag and Tl to the Arctic: Comparison of a high resolution snow pit (AD 1994-2004) with a firn (AD 1860-1996) and an ice core (previous 16,000 yr). Science of the Total Environment, 399(1-3), 78-89, 2008

Krishnan R.S. Raman spectrum of quartz. Nature, 155(3937), 452 -452, 1945

Kumai M. Identification of nuclei and considerations of chemical species in snow crystals sampled at South Pole. J. Am. Sc. 33, 833-841, 1976

Kurbatov A.V. and 22 others. Discovery of a nanodiamond-rich layer in the Greenland ice sheet. Journal of Glaciology, 56(199), 2010

Laj P. and 7 others. Distribution of $\mathrm{Ca}, \mathrm{Fe}, \mathrm{K}$, and $\mathrm{S}$ between soluble and insoluble material in the Greenland Ice Core Project ice core. Journal of Geophysical Research-Oceans, 102(C12), 26615-26623, 1997

Lambrecht A., Kipfstuhl J., Wilhelms F., Miller H. Visual stratigraphy of the EDML ice core with a linescanner. http://doi.pangaea.de/10.1594/PANGAEA.208005, 2004

Lanci L., Kent D.V., Biscaye P.E., Bory A. Isothermal remanent magnetization of Greenland ice: Preliminary results. Geophysical Research Letters, 28(8), 1639-1642, 2001

Lanci L., Kent D.V. Meteoric smoke fallout revealed by superparamagnetism in Greenland ice. Geophysical Research Letters, 33 (13), L13308, 2006

Lanci L., Kent D.V., Biscaye P.E. Meteoric smoke concentration in the Vostok ice core estimated from superparamagnetic relaxation and some consequences for estimates of the Earth's accretion rate. Geophysical Research Letters, 34(10), L10803, 2007

Lanci L., Delmonte B., Maggi V., Petit J.R., Kent D.V. Ice magnetization in the EPICA-Dome C ice core: Implications for dust sources during glacial and interglacial periods. Journal of Geophysical Research, 113(D14), D14207, 2008

Landais A., Steffensen J.P., Caillon N., Jouzel J., Masson-Delmotte V., Schwander J. Evidence for stratigraphic distortion in the Greenland Ice Core Project (GRIP) ice core during Event 5e1 (120 kyr BP) from gas isotopes. Journal of Geophysical Research-Atmospheres, 109(D6), D06103, 2004 
Landais A. and 15 others. Firn-air d15N in modern polar sites and glacial-interglacial ice: a model-data mismatch during glacial periods in Antarctica? Quaternary Science Reviews 25, 49-62, 2006

Langway C.C.Jr. The history of early polar ice cores. Cold Regions Science and Technology, 52, 101-117,

2008

Legrand M. and Mayewski P. Glaciochemistry of polar ice cores; a review. Reviews in Geophysics, 35(3), 219-243, 1997

Legrand M. and 15 others. Major 20th century changes of carbonaceous aerosol components (EC, WinOC, DOC, HULIS, carboxylic acids, and cellulose) derived from Alpine ice cores. Journal of Geophysical ResearchAtmospheres, 112(D23), D23S11, 2007

Le Parc R., Champagnon B., Dianoux J., Jarry P., Martinez V. Anorthite and $\mathrm{CaAl}_{2} \mathrm{Si}_{2} \mathrm{O}_{8}$ glass: low frequency Raman spectroscopy and neutron scattering. J. Non-Cryst. Solids, 323, 155-161, 2003

Lewis R.P.W. Meteorological glossary, HMSO, London, 1991.

Lipenkov V.Ya. Air bubbles and air-hydrate crystals in the Vostok ice core. In: "Physics of Ice Core Records", ed. Hondoh T., Hokkaido Univ. Press, Sapporo, 327-358, 2000

Liu X., Huang F., Kong P., Fang A., Li X., Ju Y., History of ice sheet elevation in east Antarctica: Paleoclimatic implications. Earth and Planetry Science Letters, 290(3-4), 281-288, 2010

Łodziński M., Wrzalik R., Sitarz M. Micro-Raman spectroscopy studies of some accessory minerals from pegmatites of the Sowie Mts and Strzegom-Sobótka massif, Lower Silesia, Poland. Journal of Molecular Structure. 744, 1017-1026, 2005

Loulergue L. and 7 others. New constraints on the gas age-ice age difference along the EPICA ice cores, 050 kyr. Climate of the Past, 3(3), 527-540, 2007

Lunde T. On the snow accumulation in Dronning Maud Land. Norsk Polarinst., Oslo, 1961

Mae S. Void formation during non-basal glide in ice single crystals under tension, Philosophical Magazine, 18(151), 101-114, 1968

Maeno N. and Ebinuma T. Pressure sintering of ice and its implication to the densification of snow at polar glaciers and ice sheets. Journal of Physical Chemistry, 87(21), 4103-4110, 1983

Maggi V. Mineralogy of atmospheric microparticles deposited along the Greenland Ice Core Project ice core. Journal of Geophysical Research-Oceans, 102(C12), 26725-26734, 1997

Manhire B. The wide white page: writers imagine Antarctica. Victoria University Press, Wellington, 2004

Marino F., Maggi V., Delmonte B., Ghermandi G., Petit J.R. Elemental composition ( $\mathrm{Si}, \mathrm{Fe}, \mathrm{Ti}$ ) of atmospheric dust over the last $220 \mathrm{kyr}$ from the EPICA ice core (Dome C, Antarctica). Annals of Glaciology, 39, 110-118, 2004

Marino F. and 9 others. Defining the geochemical composition of the EPICA Dome C ice core dust during the last glacial-interglacial cycle. Geochemistry Geophysics Geosystems, 9, Q10018, 2008

Marion G.M., Farren R.E., Komrowski A.J. Alternative pathways for seawater freezing. Cold Regions Science and Technology, 29(3), 259-266, 1999

Marion G.M. and Farren R.E. Mineral solubilities in the Na-K-Mg-Ca-Cl-SO4-H2O system: A reevaluation of the sulfate chemistry in the Spencer-Moller-Weare model. Geochimica Cosmochimica Acta, 63, 9, 1305-1318, 1999

Martin-Conde M., MacDowell L.G., Vega C. Computer simulation of two new solid phases of water: Ice XIII and ice XIV. Journal of Chemical Physics, 125(11), 116101, 2006

Marteel A. and 11 others. Changes in atmospheric heavy metals and metalloids in Dome C (East Antarctica) ice back to $672.0 \mathrm{kyr}$ BP (Marine Isotopic Stages 16.2). Earth and Planetary Science Letters, 272(3-4), 579-590, 2008

Masters B.R. C.V. Raman and the Raman effect. Optics and Photonics News, 20(3), 40-45, 2009

Matsumoto A. and Hinkley T.K. Determination of lead, cadmium, indium, thallium and silver in ancient ices from Antarctica by isotope dilution thermal ionization mass spectrometry. Geochemical Journal, 31(3), 175-181, 1997

Matsuoka N. Rock weathering processes and landform development in the Sør Rondane Mountains, Antarctica. Geomorphology 12, 323-339, 1995

Mawson D. The home of the blizzard: being the story of the Australasian Antarctic Expedition, 1911-1914, Heinemann, London, 1915

McGwire K.C., Hargreaves G.M., Alley R.B., Popp T.J., Reusch D.B., Spencer M.K., Taylor K.C. An integrated system for optical imaging of ice cores. Cold Regions Science and Technology, 53(2), 216-228, 2008a

McGwire K.C., McConnell J.R., Alley R.B., Banta J.R., Hargreaves G.M., Taylor K.C. Dating annual layers of a shallow Antarctic ice core with an optical scanner. Journal of Glaciology, 54(188), 831-838, 2008b

McKeegan K.D., Kudryavtsev A.B., Schopf J.W. Raman and ion microscopic imagery of graphitic inclusions in apatite from older than 3830 Ma Akilia supracrustal rocks, west Greenland. Geology, 35, 591-594, 2007

McNair M.L. On thin ice: a woman’s journey to the North Pole, NorthWinds, Iqaluit, 1999 
Meese D.A. and 8 others. The Accumulation Record from the GISP2 Core as an Indicator of Climate Change Throughout the Holocene. Science, 266, 1680-1682, 1994

Meese D.A. and 8 others. The Greenland Ice Sheet Project 2 depth-age scale: Methods and results. Journal of Geophysical Research-Oceans, 102(C12), 26411-26423, 1997

Miller S.L. Clathrate hydrates of air in Antarctic ice. Science, 165 (3892), 489-490, 1969

Misawa K. and 7 others. Two extraterrestrial dust horizons found in the Dome Fuji ice core, East Antarctica. Earth and Planetary Science Letters , 289, 1-2, 287-297, 2010

Muguruma J., Mae S., Higashi A. Void formation by non-basal glide in ice single crystals, Philosophical Magazine, 13(123), 625-629, 1966

Nakahara J., Shigesato Y., Higashi A., Hondoh T., Langway C.C.Jr. Raman spectra of natural clathrates in deep ice cores. Philosophical Magazine B, 57(3), 421-430, 1988

Näslund J.-O. Ice sheet, climate, and landscape interactions in Dronning Maud Land, Antarctica. PhD Thesis, Department of Physical Geography, Stockholm Univ., 1998

Negishi N., Takeuchi K., Ibusuki T. Surface structure of the $\mathrm{TiO}_{2}$ thin film photocatalyst. Journal of Material Science, 33, 5789 - 5794, 1998

Nedelcu A.F., Faria S.H., Kuhs W.F. Raman spectra of plate-like inclusions in the EPICA-DML ice core. Journal of Glaciology, 55(189), 183-184, 2009

Nickel E.H. The definition of a mineral, The Canadian Mineralogist, 33(3), 689 - 690, 1995

Novak M. This Hemisphere of Liberty, A Philosophy of the Americans. The AEI Press, Washington D.C.,

1990

Obbard R., Iliescu D., Cullen D., Chang J., Baker I. SEM/EDS comparison of polar and seasonal temperate ice. Microscopy Research and Technique 62(1), 49-61, 2003

Obbard R.W., Roscoe H.K., Wolff E.W., Atkinson H.M. Frost flower surface area and chemistry as a function of salinity and temperature. Journal of Geophysical Research-Atmospheres, 114, D20305, 2009

O'Brien S.R., Mayewski P.A., Meeker L.D., Meese D.A., Twickler M.S., Whitlow S.I. Complexity of Holocene climate as Reconstructed from a Greenland Ice Core. Science, 270, 1962-1964, 1995

Oerter H., Graf W., Wilhelms F., Minikin A., Miller H. Accumulation studies on Amundsenisen, Dronning Maud Land, Antarctica, by means of tritium, dielectric profiling and stable-isotope measurements: first results from the 1995-96 and 1996-97 field seasons. Annals of Glacilogy, 29, 1-9, 1999

Oerter H. and 6 others. Accumulation rates in Dronning Maud Land, Antarctica, as revealed by dielectricprofiling measurements of shallow firn cores. Annals of Glaciology, 30, 27-34, 2000

Ohno H. and Hondoh T. Micro-Raman study of air clathrate hydrates in polar ice from Dome Fuji Antractica, in Physics and Chemistry of Ice, Royal Society of Chemistry, pg.459, 2000

Ohno H., Igarashi M., Hondoh T. Salt inclusions in polar ice core: Location and chemical form of watersoluble impurities. Earth and Planetary Science Letters, 232, 171-178, 2005

Ohno H., Igarashi M., Hondoh T. Characteristics of salt inclusions in polar ice from Dome Fuji, East Antarctica. Geophysical Research Letters, 33, 8, L08501, 2006

Ohno H., Lipenkov V.Ya., Hondoh T. Formation of air clathrate hydrates in polar ice sheets: heterogeneous nucleation induced by micro-inclusions. Journal of Glaciology, 56(199), 917-921, 2010

Oldroyd D.R. Thinking about the earth: a history of ideas in geology, The Athlone Press, London, 1996

Owston P.G. The structure of ice I as determined by X-ray and neutron diffraction analysis. Advances in Physics, 7 (26), 171-188, 1958

Parish T.R. Surface air-flow over east Antarctica. Monthly Weather Review, 110, 2, 84-90, 1982

Parish T.R., Cassano J.J. The role of katabatic winds on the Antarctic surface wind regime. Monthly Weather Review, 131(2), 317-333, 2003

Parrenin F. and 26 others. The EDC3 chronology for the EPICA dome C ice core. Climate of the Past, 3(3), 485-497, 2007

Pasteris J.D., Wopenka B., Seitz J.C. Practical aspects of quantitative laser Raman microprobe spectroscopy for the study of fluid inclusions. Geochimica et Cosmochimica Acta, 52(5), 979-988, 1988

Pasteur E.C. and Mulvaney R. Migration of methane sulphonate in Antarctic firn and ice. Journal of Geophysical Research-Atmospheres, 105(D9), 11525-11534, 2000

Pauer F., Kipfstuhl S., Kuhs W.F., Shoji H. Classification of air clathrates found in polar ice sheets. Polarforschung 66(3), 31-38, 1996 (published 2000)

Pauer F., Kipfstuhl J., Kuhs W.F. Raman spectroscopic and statistical studies on natural clathrates from the Greenland ice core project ice core, and neutron diffraction studies on synthetic nitrogen clathrates. Journal of Geophysical Research, 102(C12), 26519-26526, 1997

Pauer F., Kipfstuhl S., Kuhs W.F., Shoji H. Air clathrate crystals from the GRIP deep ice core, Greenland: a number-, size- and shape-distribution study. Journal of Glaciology, 45(149), 22-30, 1999

Pearson P., Foster G.L., Wade B.S. Atmospheric carbon dioxide through the Eocene-Oligocene climate transition. Nature, 461(7267), 1110-1113, 2009 
Peixoto J.P. and Oort A.H. Physics of climate, American Inst. of Physics, New York, 1992

Peters S.E., Carlson A.E., Kelly D.C., Gingerich P.D. Large-scale glaciation and deglaciation of Antarctica during the Late Eocene, Geology, 38(8), 723-726, 2010

Peterson R.C., Nelson W., Madu B., Shurvell H.F. Meridianiite: A new mineral species observed on Earth and predicted to exist on Mars. American Mineralogist,92, 1756-1759, 2007

Petrenko V.F. and Whitworth R.W. Physics of ice. Oxford Univ. Press., Oxford, 1999

Petrenko W. and 11 others. (CH4)-C-14 Measurements in Greenland Ice: Investigating Last Glacial Termination CH4 Sources. Science, 324(5926), 506-508, 2009

Picciotto E., Demaere X., Friedman I. Isotopic composition and temperature of formation of Antarctic snows. Nature 187(4740), 857-859, 1960

Piel C., Weller R., Huke M., Wagenbach D. Atmospheric methane sulfonate and non-sea-salt sulfate records at the European Project for Ice Coring in Antarctica (EPICA) deep-drilling site in Dronning Maud Land, Antarctica. Journal of Geophysical Research-Atmosphere, 111(D3), D03304, 2006

Prodi F., Belosi F., Santachiara G., Contini D., Di Matteo L., Grasso F. Chemical composition and shape of snow crystals in Antarctica. Nuovo Cimento della Societa Italiana di Fisica C-Geophysics and Space Physics, 31(2), 157-173, 2008

Raisbeck G.M., Yiou F., Cattani O., Jouzel J. ${ }^{10} \mathrm{Be}$ evidence for the Matuyama-Brunhes geomagnetic reversal in the EPICA Dome C ice core. Nature 444(7115), 82-84, 2006

Ram M. and Illing M. Polar ice stratigraphy from laser-light scattering - scattering from melt water. Journal of Glaciology, 40(136), 504-508, 1994

Rankin A.M., Auld V., Wolff E.W. Frost flowers as a source of fractionated sea salt aerosol in the polar regions. Geophysical Research Letters, 27(21), 3469-3472, 2000

Rankin A.M., Wolff E.W., Martin S. Frost flowers: Implications for tropospheric chemistry and ice core interpretation. Journal of Geophysical Research-Atmospheres, 107(D23), 4683, 2002

Reijmer C.H. and van den Broeke M.R. Moisture source of precipitation in Western Dronning Maud Land, Antarctica. Antarctic Science, 13(2), 210-220, 2001

Rempel A.W., Waddington E.D., Wettlaufer J.S., Worster M.G. Possible displacement of the climate signal in ancient ice by premelting and anomalous diffusion. Nature, 411(6837), 568-571, 2001

Rempel A.W., Wettlaufer J.S., Waddington E.D. Anomalous diffusion of multiple impurity species: Predicted implications for the ice core climate records. Journal of Geophysical Research-Solid Earth, 107(B12), 2330, 2002

Ren J.W., Xiao C.D., Hou S.G., Li Y.S., Sun B. New focus of polar ice-core study: NEEM and Dome A. Chinese Science Bulletin, 54(6), 1009-1011, 2009

Richardson-Näslund C. Spatial characteristics of snow accumulation in Dronning Maud Land, Antarctica. Global and Planetary Change 42, 31-43, 2004

Röthlisberger R. and 10 others. Nitrate in Greenland and Antarctic ice cores: a detailed description of postdepositional processes. Annals of Glaciology, 35, 209-216, 2002

Röttger K., Endriss A., Ihringer J., Doyle S., Kuhs W.F. Lattice constants and thermal expansion of $\mathrm{H}_{2} \mathrm{O}$ and $\mathrm{D}_{2} \mathrm{O}$ ice $\mathrm{I}_{\mathrm{h}}$ between 10 and $265 \mathrm{~K}$. Acta Crystallographica, B50, 644-648, Part 6, 1994

Roots E.F. Preliminary note on the geology of western Dronning Maud Land, Brøgger i komm., Oslo, 1953

Rosasco G.J. and Roeder E. Application of a new Raman microprobe spectrometer to nondestructive analysis of sulfate and other ions in individual phases in fluid inclusions in minerals. Geochimica et Cosmochimica Acta, 43(12), 1907-1915, 1979

Rotschky G. and 6 others. A new surface accumulation map for western Dronning Maud Land, Antarctica, from interpolation of point measurements. Journal of Glaciology, 53(182), 2007

Ruddiman W.F. Ice-driven $\mathrm{CO}_{2}$ feedback on ice volume. Clim. Past, 2, 43-55, 2006

Rull F. and Sobrón F. Band profile analysis of the Raman-spectra of sulfate ions in aqueous slutions. Journal of Raman Spectroscopy, 25(7-8), 693-698, 1994

Rull F., Balarew C., Alvarez J.L., Sobrón F., Rodriguez A. Raman spectroscopic study of ion association in aqueous magnesium solutions. Journal of Raman Spectroscopy, 25(12), 933-941, 1994

Rull F. and Ohtaki H. Raman spectral studies on ionic interaction in aqueous alkali sulfate solutions. Spectrochimica Acta Part A-Molecular and biomolecular spectroscopy, 53(5), 643-653, 1997

Ruth U. and 19 others. EDML1: A chronology for the EPICA deep ice core from Dronning Maud Land, Antarctica, over the last 150000 years. Climate of the Past, 3(3), 475-484, 2007

Sakurai T. and 6 others. Direct observation of salts as micro-inclusions in the Greenland GRIP ice core. J. Glaciol., 55(193), 777-783, 2009

Sakurai T. Studies on phase equilibrium states and spatial distributions of water-soluble microparticles preserved in polar ice sheets. Ph.D. thesis, Graduate School of Environmental Science Hokkaido University, 2010 
Sakurai T., Ohno H., Horikawa S., Iizuka Y., Uchida T., Hondoh T. A Technique for Measuring Microparticles in Polar Ice Using Micro-Raman Spectroscopy, International Journal of Spectroscopy, vol. 2010, ID 384956, 2010a

Sakurai T. and 6 others. Magnesium methanesulfonate salt found in the Dome Fuji (Antarctica) ice core. Journal of Glaciology, 56(199), 837-842, 2010b

Sala M. and 10 others. Evidence of calcium carbonates in coastal (Talos Dome and Ross Sea area) East Antarctica snow and firn: Environmental and climatic implications. Earth and Planetary Science Letters, 271(1-4), 43-52, 2008

Salamatin A.N., Hondoh T., Uchida T., Lipenkov V.Y. Post-nucleation conversion of an air bubble to clathrate air-hydrate crystal in ice. Journal of Crystal Growth, 193(1-2), 197-218, 1998

Salamatin A.N., Lipenkov V.Y., Hondoh T. Air-hydrate crystal growth in polar ice. Journal of Crystal Growth, 257(3-4), 412-426, 2003

Samson I. Fluid inclusions: analysis and interpretation. Mineralogical Assoc. of Canada, Ottawa, 2003

Sarma L.P., Prasad P.S.R., Ravikumar N. Raman Spectroscopic Study of Phase Transitions in Natural Gypsum. Journal of Raman Spectroscopy 29, 851-856, 1998

Schlosser E., Manning K.W., Powers J.G., Duda M.G., Birnbaum G., Fujita K. Characteristics of highprecipitation events in Dronning Maud Land, Antarctica. Journal of Geophysical Research-Atmospheres, 115, D14107, 2010

Schulson E.M. The structure and mechanical behavior of ice. JOM-Journal of the Minerals Metals \& Materials Society, 51(2), 21-27, 1999

Schulson E.M. and Duval P. Creep and fracture of ice. Cambridge Univ. Press, Cambridge, 2009

Schwander J., Sowers T., Barnola J.M., Blunier T., Fuchs A., Malaize B. Age scale of the air in the summit ice: Implication for glacial-interglacial temperature change. Journal of Geophysical Research-Atmospheres, 102(D16), 19483-19493, 1997

Schwerdtfeger W. Weather and climate of the Antarctic, Elsevier, Amsterdam, 1984

Seddik H., Greve R., Placidi L., Hamann I., Gagliardini O. Application of a continuum-mechanical model for the flow of anisotropic polar ice to the EDML core, Antarctica. Journal of Glaciology, 54(187), 631-642, 2008

Severi M. and 13 others. Synchronisation of the EDML and EDC ice cores for the last 52 kyr by volcanic signature matching. Climate of the past, 3(3), 367-374, 2007

Shimada W. and Hondoh T. In situ observation of the transformation from air bubbles to air clathrate hydrate crystals using a Mizuho ice core. Journal of Crystal Growth, 265(1-2), 309-317, 2004

Shimohara K., Miyamoto A., Hyakutake K., Shoji H., Takata M., Kipfstuhl S. Cloudy band observations for annual layer counting on the GRIP and NGRIP, Greenland, deep ice core samples. Mem. Natl. Inst. Polar Res. Spec. Issue, 57, 161-167, 2003

Shoji H. and Langway C.C.Jr. Microscopic observations of the air hydrate-bubble transformation process in glacier ice, Journal de Physique (Paris), Colloq., 48(C1), 551-556, 1987

Sigl M. and 10 others. Towards radiocarbon dating of ice cores. Journal of Glaciology, 55(194), 2009

Sinisalo A. and Moore J. Antarctic blue ice areas - towards extracting palaeoclimate information. Antarctic Science, 22(2), 99-115, 2010

Smart C. The Poetical Works of Christopher Smart. Calderon Press, Oxford, 1987

Socrates G. Infrared and Raman characteristic group frequencies: tables and charts (3rd ed., reprinted as paperback), John Wiley \& Sons Ltd., Chichester, 2004

Sommer S., Wagenbach D., Mulvaney R., Fischer H. Glacio-chemical study spanning the past 2 kyr on three ice cores from Dronning Maud Land, Antarctica 2. Seasonally resolved chemical records. Journal of Geophysical Research-Atmospheres, 105(D24), 29423-29433, 2000

Spahi R. and 10 others. Atmospheric methane and nitrous oxide of the late Pleistocene from Antarctic ice cores. Science 310(5752), 1317-1321, 2005

Spassov S. Loess Magnetism, Environment and Climate Change on the Chinese Loess Plateau. PhD thesis, Swiss Federal Institute of Technology, (DISS. ETH NO.14976), Zürich, 2002

Stauffer B., Fluckiger J., Wolff E., Barnes P. The EPICA deep ice cores: first results and perspectives, Annals of Glaciology, 39, 93-100, 2004

London, 1971

Staveley L.A.K. The characterization of chemical purity: organic compounds (IUPAC), Butterworths,

Stenberg M., Isaksson E., Hansson M., Karlen W., Mayewski P.A., Twickler M.S., Whitlow S.I., Guadestrup N. Spatial variability of snow chemistry in western Dronning Maud Land, Antarctica. Annals of Glaciology, 27, 378-384, 1998

Stringer E.T. Foundations of climatology: an introduction to physical, dynamic, synoptic and geographical climatology, Freeman, San Francisco, 1972

Stocker T.F. and Johnsen S.J. A minimum thermodynamic model of the bipolar seesaw. Paleoceanography 18(4), 1087, 2003 
Sun J.M. and Ariya P.A. Atmospheric organic and bio-aerosols as cloud condensation nuclei (CCN): A review. Atmospheric Environment, 40(5), 795-820, 2006

Svensson A. and 7 others. Visual stratigraphy of the North Greenland Ice Core Project (NorthGRIP) ice core during the last glacial period. Journal of Geophysical Research-Atmospheres, 110(D2), D02108, 2005

Swamy V., Muddle B.C., Dai Q. Size-dependent modifications of the Raman spectrum of rutile $\mathrm{TiO}_{2}$. Applied Physics Letters, 89, 163118, 2006

Takata M., Iizuka Y., Hondoh T., Fujita S., Fujii Y., Shoji H. Stratigraphic analysis of Dome Fuji Antarctic ice core using an optical scanner. Annals of Glaciology, 39, 467-472, 2004

Taylor K. and 6 others. Ice core dating and Chemistry by direct-current electrolitical-conductivity, Journal of Glaciology, 38(130), 325-332, 1992

Taylor K.C. and 13 others. Dating the Siple Dome (Antarctica) ice core by manual and computer interpretation of annual layering. Journal of Glaciology, 50(170), 453-461, 2004

du Toit A.L. Our wandering continents: An hypothesis of continental drifting, Oliver \& Boyd, Edinburgh, 1957

Tomikawa K. and Kanno H. Raman study of sulfuric acid at low temperatures Journal of Physical Chemicatry A, 102(30), 6082-6088, 1998

Tompsett G.A., Bowmaker G.A., Cooney R.P., Metson J.B., Rodgers K.A., Seakins J.M. The Raman Spectrum of Brookite, $\mathrm{TiO}_{2}$ (Pbca, Z=8). Journal of Raman Spectroscopy, 26, 57-62, 1995

Thorsteinsson T. Textures and fabrics in the GRIP ice core, in relation to climate history and ice deformation. PhD Thesis, Alfred Wegener Inst. für Polar und Meeresforschung, Bremerhaven, 1996

Thorsteinsson T., Kipfstuhl J., Miller H. Textures and fabrics in the GRIP ice core. Journal of Geophysical Research-Oceans, 102(C12), 26583-26599, 1997

Traversi R. and 12 others. Sulfate Spikes in the Deep Layers of EPICA-Dome C Ice Core: Evidence of Glaciological Artifacts. Environmental Science and Technology, 43(23), 8737-8743, 2009

Uchida T., Hondoh T., Mae S., Lipenkov V.Ya., Duval P. Air-hydrate crystals in deep ice-core samples from Vostok Station, Antarctica. Journal of Glaciology, 40(134), 79-86, 1994

Ueltzhöffer K.J., Bendel V., Freitag J., Kipfstuhl S., Wagenbach D., Faria S.H., Garbe C.S. Distribution of air bubbles in the EDML and EDC (Antarctica) ice cores, using a new method of automatic image analysis. Journal of Glaciology, 56(196), 339-348, 2010

Ugolini F.C. and Jackson M.L. Weathering and mineral synthesis in Antarctic soils, in Craddock 1982, op.cit., pg. 1101-1108

Usoskin I.G., Mursula K., Solanki S., Schussler M., Alanko K. Reconstruction of solar activity for the last millennium using Be-10 data. Astronomy \& Astrophysics, 413(2), 745-751, 2004

Vallelonga P. and 12 others. Lead isotopic compositions in the EPICA Dome C ice core and Southern Hemisphere Potential Source Areas. Quaternary Science Reviews, 29(1-2), 247-255, 2010

Vandal G.M., Fitzgerald W.F., Boutron C.F., Candelone J.P. Variations in mercury deposition to Antarctica over the past 34,000 years. Nature 362(6421), 621-623, 1993

Velde B., Syono Y., Kikuchi M., Boyer H. Raman microprobe study of synthetic diapletic plagioclase feldspars. Physics and Chemistry of Minerals 16, 436-441, 1989

Van de Velde K., Barbante C., Cozzi G., Moret I., Bellomi T., Ferrari C., Boutron C. Changes in the occurence of silver, gold, platinum, palladium and rhodium in Mont Blanc ice and snow since the $18^{\text {th }}$ century. Atmospheric Environment, 34, 19, 3117-3127, 2000

Vonnegut K.Jr. Cat's cradle, Dell, New York, 1963

Wacker U., Ries H., Schaettler U. Precipitation simulation for Dronning Maud Land using the COSMO Model. Antarctic Science, 21(6), 643-662, 2009

Wahler W. Über die in Kristallen eingeschlossenen Flüssigkeiten und Gase, Geochimica et Cosmochimica Acta, 9(3), 105-114, 1956

Van de Wal R.S.W., Meijer H.A.J., De Rooij M., Van der Veen C. Radiocarbon analyses along the EDML ice core in Antarctica. Tellus series B-Chemical and Physical Meteorology, 59(1), 157-165, 2007

Wang F., Zhang Y.-H., Li S.-H., Wang L.-Y., Zhao L.-J. A Strategy for Single Supersaturated Droplet Analysis: Confocal Raman investigations on the Complicated Hygroscopic Properties of Individual $\mathrm{MgSO}_{4} \mathrm{Droplets}$ on the Quartz Substrate. Analitical Chemistry, 77, 7148-7155, 2005

Wang F., Shou J.J., Zhang Y.H. Micro-Raman investigations on the structures of the surface and the inner of $\mathrm{MgSO}_{4}$ droplets. Chinese Science Bulletin, 53(15), 2414-2416, 2008

Weikusat I., Kipfstuhl S., Faria S.H., Azuma N., Miyamoto A. Subgrain boundaries and related microstructural features in EDML (Antarctica) deep ice core. Journal of Glaciology, 55, 191, 461-472, 2009

Weller R. and Wagenbach D. Year-round chemical aerosol records in continental Antarctica obtained by automatic samplings. Tellus series B-Chemical and Physical Meteorology, 59(4), 755-765, 2007

Wesche C., Eisen O., Oerter H., Schulte D., Steinhage D. Surface topography and ice flow in the vicinity of the EDML deep-drilling site, Antarctica. Journal of Glaciology, 53(182), 442-448, 2007 
Wettlaufer J.S. Impurity effects in the premelting of ice. Physical Review Letters, 82(12), 2516-2519,

Wilhelms F., Sheldon S.G., Hamann I., Kipfstuhl S. Implications for and findings from deep ice core drillings - An example: The ultimate tensile strength of ice at high strain rates. In Physics and Chemistry of Ice, Royal Society of Chemistry, pg. 635-639, 2007

Williamson B.R. and 6 others. A coastal transect of McMurdo Dry Valleys (Antarctica) snow and firn: marine and terrestrial influences on glaciochemistry. Journal of Glaciology, 53(183), 681-693, 2007

Wilson A.T. Application of AMS C-14 dating to ice core research. Radiocarbon, 37(2), 637-641, 1995

Wilson E.G. The spiritual history of ice: romanticism science and the imagination. Palgrave Macmillan, New York, 2003

Wolff E.W. and 27 others. Southern Ocean sea-ice extent, productivity and iron flux over the past eight glacial cycles. Nature, 440, 491-496, 2006

Wolff E.W., Jones A.E., Bauguitte S.J.B., Salmon R.A. The interpretation of spikes and trends in concentration of nitrate in polar ice cores, based on evidence from snow and atmospheric measurements. Atmospheric Chemistry and Physics, 8(18), 5627-5634, 2008

Wopenka B. and Pasteris J.D. Limitations to quantitative-analysis of fluid inclusions in geological samples by laser Raman microprobe spectroscopy. 40(2), 144-151, 1986

Xiao H.-S., Dong J.-L., Wang L.-Y., Zhao L.-J., Wang F., Zhang Y.-H. Spatially Resolved Micro-Raman Observation on the Phase Separation of Effloresced Sea Salt Droplets. Environmental Science \& Technology, 42(23), 8698-8702, 2008a

Xiao C.D. and 5 others. Preliminary evidence indicating Dome A (Antarctica) satisfying preconditions for drilling the oldest ice core. Chinese Science Bulletin, 53(1), 102-106, 2008b

Zhang Y.-H. and Chan C.K. Study of Contact Ion Pairs of Supersaturated Magnesium Sulfate Solutions Using Raman Scattering of Levitated Single Droplets. Journal of Physical Chemistry A, 104, 9191-9196, 2000a

Zhang W.F., He Y.L., Zhang M.S., Yin Z., Chen Q. Raman scattering study on anatase $\mathrm{TiO}_{2}$ nanocrystals. Journal of Physics D: Applied Physics, 33, 912-916, 2000b

Zhou G.P. and Tazaki K. Seasonal variation of gypsum in aerosol and its effect on the acidity of wet precipitation on the Japan Sea side of Japan. Atmospheric Environment, 30(19), 3301-3308, 1996 


\section{Endnote}

Two scientific conclusions obtained after 03.2011/the thesis defence:

-) Raman spectra assignable to microinclusions in EDML ice containing $\mathrm{SO}_{4}{ }^{2-}$ and $\mathrm{CH}_{3} \mathrm{SO}_{3}{ }^{-}$

These spectra were recored for some microinclusions preserved in the investigated 1016.9 ice sample ( $23 \mathrm{kyr}$ old), and were insufficiently described in this thesis (Fig.2.2.2.12; Appendix 2.2.2.D). Based on further literature research peaks around $550 \mathrm{~cm}^{-1}$ can be assigned to the methanesulfonate anion ${ }^{46}$, and the peaks around $365 \mathrm{~cm}^{-1}$ to the $\mathrm{Mg}\left(\mathrm{OH}_{2}\right)_{6}$ moiety ${ }^{47}$. Thus, the formation of solid, liquid or metastable, inclusions with $\mathrm{Mg}^{2+}, \mathrm{SO}_{4}{ }^{2-}$ and $\mathrm{CH}_{3} \mathrm{SO}_{3}{ }^{-}$may be described by the following reaction chain:

$$
\begin{aligned}
\mathrm{Mg}\left(\mathrm{OH}_{2}\right)_{6} \mathrm{Cl}_{2} \cdot 6 \mathrm{H}_{2} \mathrm{O}+2 \mathrm{CH}_{3} \mathrm{SO}_{3}{ }^{-} & \leftrightarrow \mathrm{Mg}\left(\mathrm{OH}_{2}\right)_{6}\left(\mathrm{CH}_{3} \mathrm{SO}_{3}\right)_{2} \cdot 6 \mathrm{H}_{2} \mathrm{O}[1] \\
{[1]+\mathrm{SO}_{4}{ }^{2-} } & \leftrightarrow \mathrm{Mg}\left(\mathrm{OH}_{2}\right)_{6}\left(\mathrm{SO}_{4}\right) \cdot \mathrm{nH}_{2} \mathrm{O}+2 \mathrm{CH}_{3} \mathrm{SO}_{3}{ }^{-}
\end{aligned}
$$

that can develop in the polar atmosphere or in ice.

-) the graph that shows the (semi)quantitative results from the first Raman study of gaseous microinclusions preserved in EDML ice:

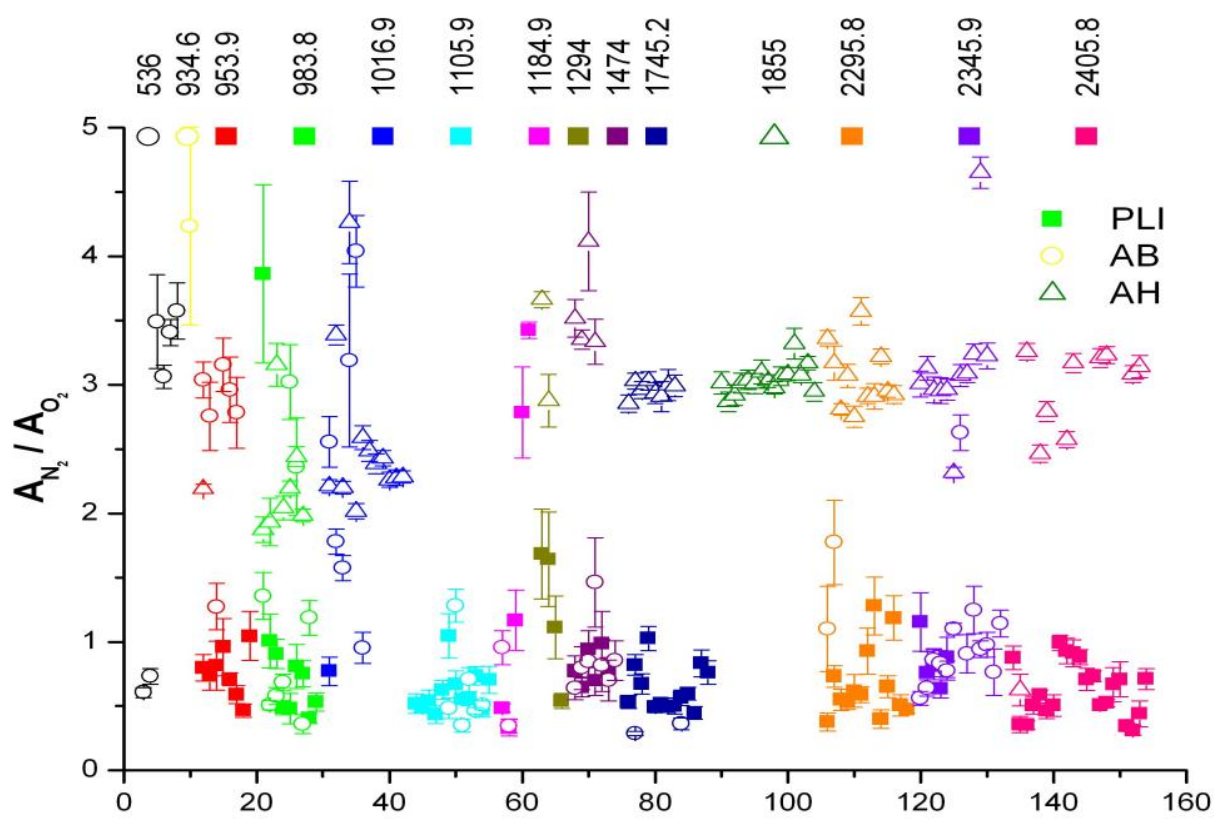

where $\mathrm{A}_{\mathrm{N} 2}$ and $\mathrm{A}_{\mathrm{O} 2}$ are the areas, calculated by Gaussian fitting, of the Raman peaks generated by the nitrogen, $\mathrm{N}_{2}$, and the oxygen, $\mathrm{O}_{2}$, molecules present in a microinclusion preserved in EDML ice; the $\mathrm{A}_{\mathrm{N} 2} / \mathrm{A}_{\mathrm{O} 2}$ ratio reflects the ratio between those molecules in a gaseous inclusion and is usually compared with the one for the atmospheric air. Each point in the graph is the mean (together with its standard deviation) of the four values for the $\mathrm{A}_{\mathrm{N} 2} / \mathrm{A}_{\mathrm{O} 2}$ ratio one can obtain when Gaussian fitting is used (notice that the indvidual $\mathrm{A}_{\mathrm{N} 2}$ and $\mathrm{A}_{\mathrm{O} 2}$ are calculated with a certain error). Explanations of numbers and acronyms in the graph are as in the thesis.

\footnotetext{
${ }^{46}$ Barletta R.E., Gros B.N. Herring M.P. Analysis of marine biogenic sulfur compounds using Raman spectroscopy: dimethyl sulfide and methane sulfonic acid. J. Raman Spectrosc., 40, 972-981, 2009. Lund Myhre C.E., D'Anna B., Nicolaisen F.M., Nielsen C.J. Properties of aqueous methanesulfonic acid: complex index of refraction and surface tension. Appl. Optics, 43(12), 2500-2509, 2004

${ }^{47}$ Rudolph W.W., Irmer G., Hefter G.T. Raman spectroscopic investigation of speciation in $\mathrm{MgSO}_{4}(\mathrm{aq})$. Phys. Chem. Chem. Phys., 5, 5253-5261, 2003. Wang A., Freeman J.J., Jolliff B.L., Chou I-M. Sulfates on Mars: A systematic Raman spectroscopic study of hydration states of magnesium sulfates. Geochim. Cosmochim. Acta, 70, 6118-6135, 2006
} 


\section{APPENDICES}

Appendix 1.2.A - frequently referred quotations

Appendix 2.2.1.A -Optical microscopy images for relaxed EDML ice Appendix 2.2.1.B -Microstructure mapping images for fresh EDML ice Appendix 2.2.1.C -Description of individual investigated PLIs in EDML ice Appendix 2.2.1.D -Representative Raman graphs of PLIs in EDML ice ( $2^{\text {nd }}$ set) Appendix 2.2.1.E -Representative Raman graphs of PLIs in EDML ice ( $1^{\text {st }}$ set)

Appendix 2.2.1.F -Values for the $\mathrm{N}_{2}$ and $\mathrm{O}_{2}$ peaks center in the Raman spectra of the analyzed microinclusions in EDML ice

Appendix 2.2.1.G - Values for the $\mathrm{N}_{2} / \mathrm{O}_{2}$ ratio of PLIs in EDML ice $\left(2^{\text {nd }}\right.$ set $)$

Appendix 2.2.2.A -Raman spectra attributed to mirabilite (meridianiite) containing microinclusions

Appendix 2.2.2.B -Raman spectra attributed to microinclusions with gypsum

Appendix 2.2.2.C -Raman spectra attributed to arcanite or $\mathrm{H}_{2} \mathrm{SO}_{4}$ containing microinclusions

Appendix 2.2.2.D -Raman spectra attributed to microinclusions containing a mixture of different compounds (sulfates or sulfates and silicates)

Appendix 2.2.2.E -Raman attributed to double sulfates of jarosite type

Appendix 2.2.2.F - Raman spectra attributed to $\mathrm{SiO}_{2}$ or (alumino)silicate containing microinclusions

Appendix 2.2.2.G -Raman spectra attributed to identified microinclusions that contain neither $\mathrm{SO}_{4}{ }^{2-}$ nor $\left(\mathrm{Si}_{\mathrm{x}} \mathrm{O}_{\mathrm{y}}\right)^{\mathrm{n}-}$

Appendix 2.2.2.H - Raman spectra attributed to unidentified microinclusions that contain neither $\mathrm{SO}_{4}{ }^{2-}$ nor $\left(\mathrm{Si}_{\mathrm{x}} \mathrm{O}_{\mathrm{y}}\right)^{\mathrm{n}-}$

Appendix 2.2.2.I - Relative distribution of the different types of microinclusions: percent of each class of microinclusion from the total number of assigned microinclusions

Appendix 2.2.2.J -Raman spectra of the EDML ice matrix 


\section{Appendix 1.2.A - frequently referred quotations:}

\section{From Robert Falcon Scott's journal of his last Antarctic expedition:}

"Thursday, January 16. [...] Noon sight showed us in Lat. 89०42'S., and we started off in high spirits in the afternoon, feeling that tomorrow would see us at our destination. About the second hour of the march Bower's sharp eyes detected what he thought was a cairn; he was uneasy about it, but argued that it must be a sastrugus. Half an hour later he detected a black speck ahead. Soon we knew that this could not be a natural snow feature. We marched on, found that it was a black flag tied to a sledge bearer; near by the remains of a camp; sledge tracks and ski tracks going and coming and the clear trace of dogs' paws-many dogs. This told us the whole story. The Norvegians have forestalled us and are first at the Pole. It is a terrible disappointment, and I am very sorry for my loyal companions. Many thoughts come and much discussion have we had. Tomorrow we must march on to the Pole and then hasten home with all the speed we can compass. All the daydreams must go; it will be a wearisome return. Certainly we are descending in altitude-certainly also the Norwegians found an easy way up." (in King, 1999, pg .152; Craddock, 1982, pg. xxiii)

\section{From Mawson's book "The home of the blizzard":}

"The equinox arrived and the only indication of settled weather was a more regularity in the winds. Nothing like it had been reported from any part of the world. Any trace of elation we may have felt at this meteorological discovery could not compensate for the ever-present discomfort of life. Day after day the cast skies of heavy nimbus cloud were the rule and the air was continually charged with drifting snow.

Lulls of a singular nature occasionally relieved the monotony. [...] Similar disturbances have been observed in every part of the world but seldom possessed of the same violence and regularity as is the case in Adelie Land. $[\ldots . .$.

The auditory sense was strangely affected by these lulls. The contrast was so severe when the racking gusts of an abating wind suddenly gave way to intense, eerie silence, that the habitual droning of many weeks would still reverberate in the ears. At night one would involuntarily wake up if the wind died away, and be loth of sleep "for the hunger of a sound." in the open air the stillness conveyed to the brain an impression of audibility, interpreted as a vibratory murmur." (Mawson, 1915)

\section{And a short description of the winds faced by Mawson's expedition:}

"by McLean, Editor of the Adelie Blizzard:

THE BLIZZARD

[......] Requiem peace from the hinter-snows / Soft as river music flows. / Dawn in a flushing glamour tints the sea; Serene her thrill of rhythmic ecstasy." (Mawson, 1915)

(last but not least) From R.L. Nichols paper "Captain Scott and His Last Expedition" (in Craddock, 1982)

"At the summit of Observation Hill near McMurdo Station, Antarctica, there is a nine-foot wooden cross erected by members of the expedition on January 20 and 21, 1913 in memory of Scott's Polar Party. It is the southernmost cross on the planet Earth. It faces the south and looks toward the Ross Ice Shelf and the Beardmore Glacier where Scott and his companions died [...]. It bears these words:

IN MEMORIAM

CAPT. R.F. SCOTT, R.N.

DR. E.A. WILSON

CAPT. L.E.G. OATES, INS. DRGS.

LT. H.R. BOWERS, R. I. M.

PETTY OFFICER E. EVANS, R. N.

WHO DIED ON THEIR

RETURN FROM THE

POLE MARCH

1912

TO STRIVE, TO SEEK,

TO FIND,

AND NOT TO

YIELD" 
Appendix 2.2.1.A

\section{Optical microscopy images for relaxed EDML ice}

When the ice grain in which the PLIs are embedded in has a suitable orientation (meaning that its $c$ is parallel with the transmitted light path), the shape of the PLIs can be described as hexagonal with regular edges or with smooth corners (or both). Sometimes shapes with lower symmetry (pentagonal, quadratic) were observed (and this can not be considered (totally) an artifact of the observing procedure).

Well defined polygonal shapes are a characteristic for PLIs in the EDML ice samples from the upper parts of the core (Fig. I, II, III). Less hexagonal and smaller relaxation features were observed for EDML ice samples from the deeper parts of the core (Fig. VI, VII).

For ice grains oriented with their $c$ axis perpendicular to the light path of the optical microscope, the PLIs appear as tubes (or better lenses). In most of these cases the PLIs are sandwiched between slip bands (Fig. Ie, IIIb, IVa, IVb; and not so obvious for Va, Vb, VIb).
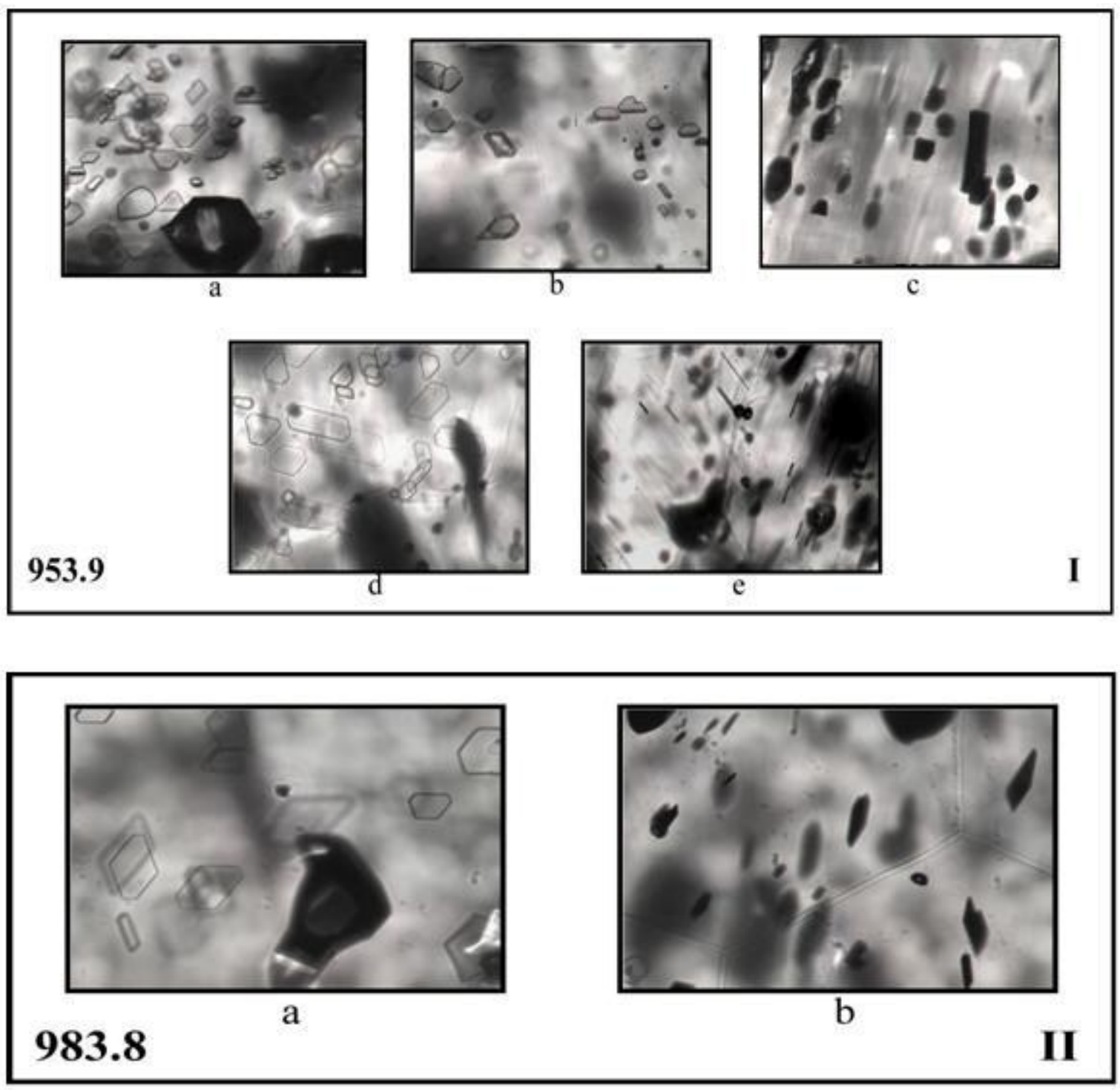

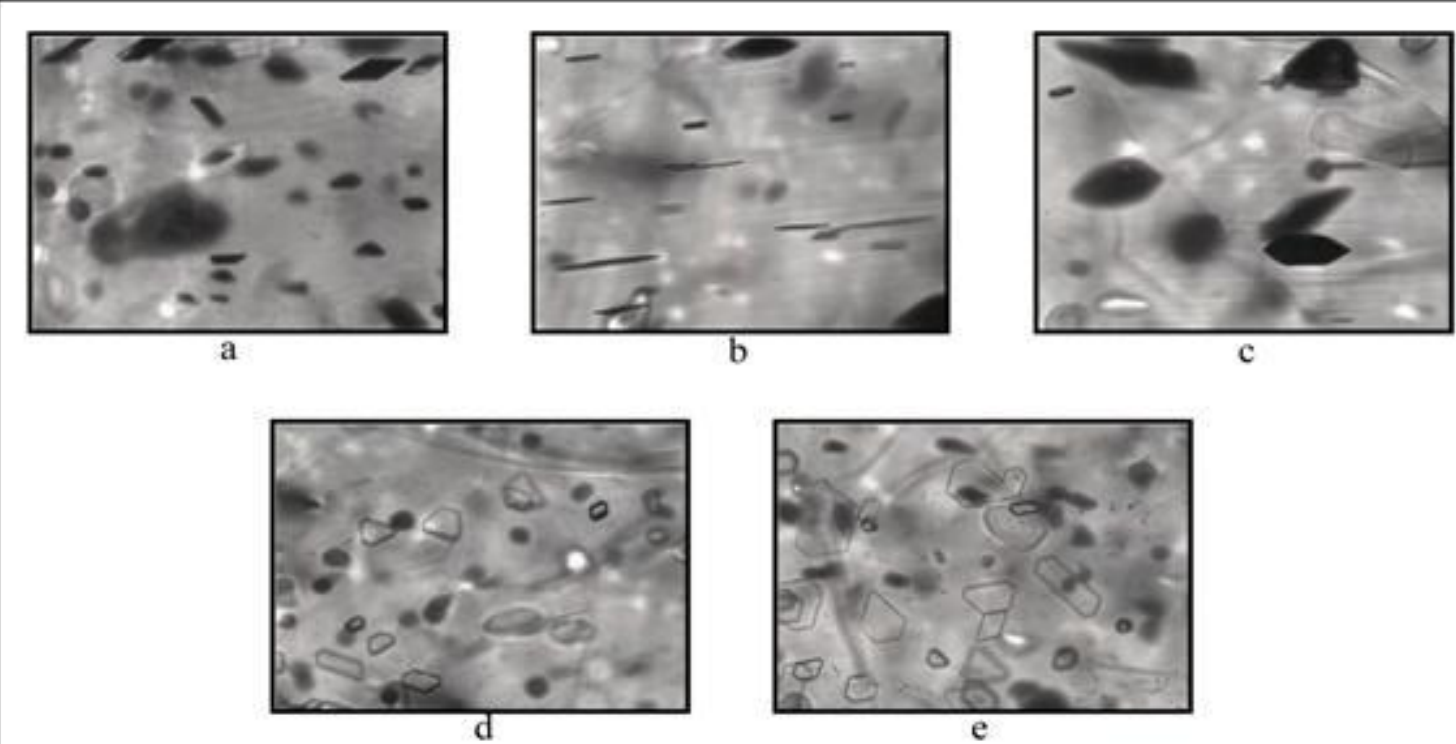

1105.9

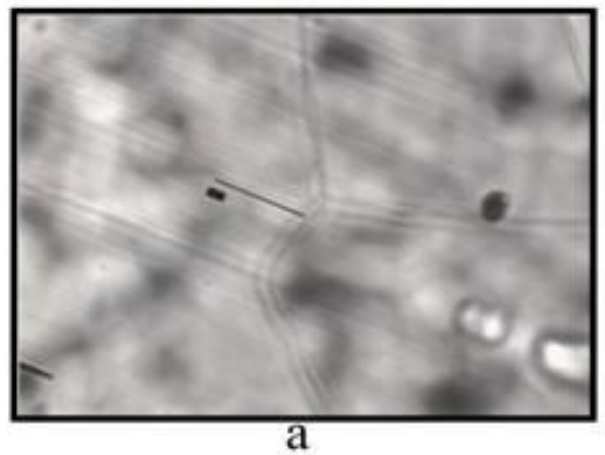

1745.2
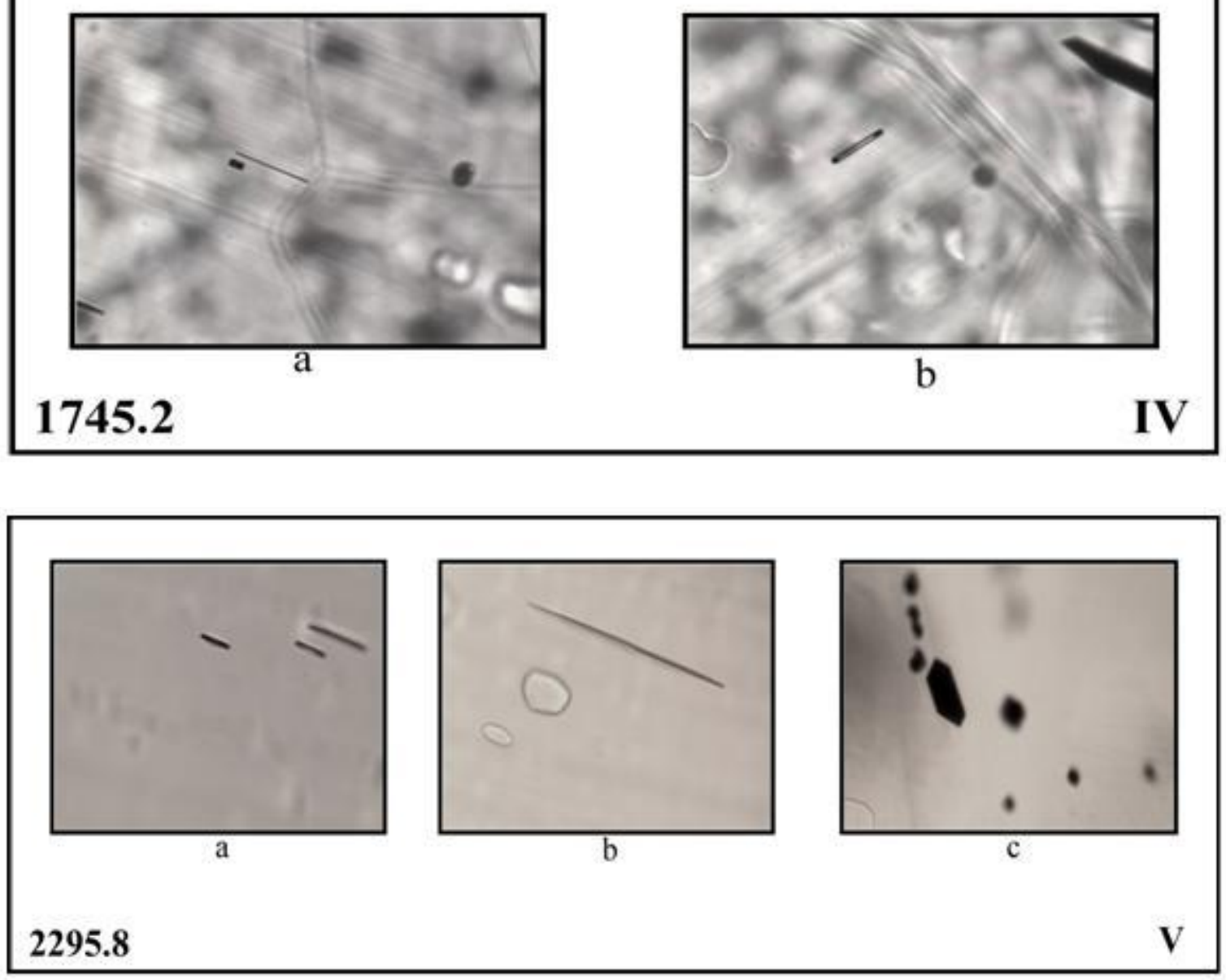


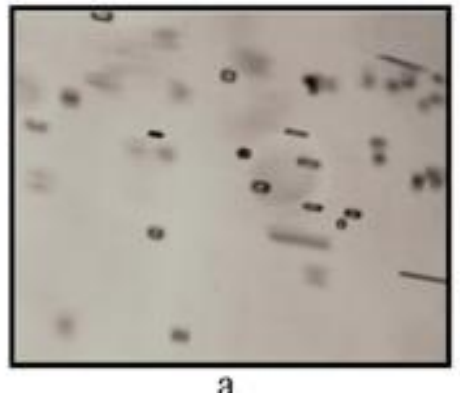

a

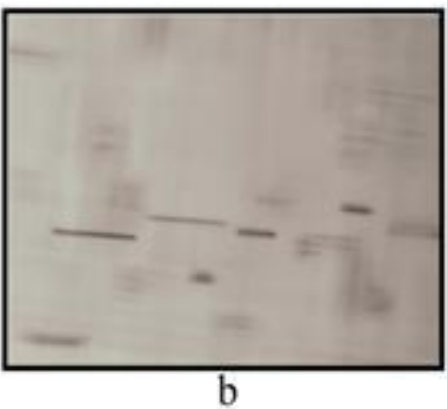

b

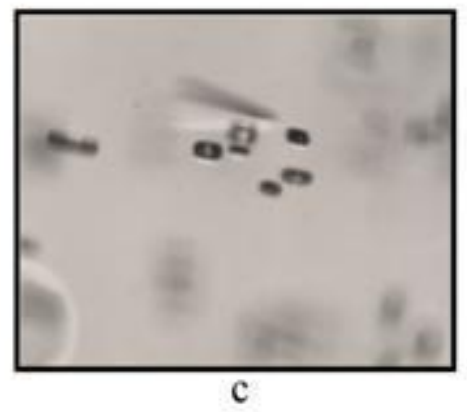

2345.9

VI
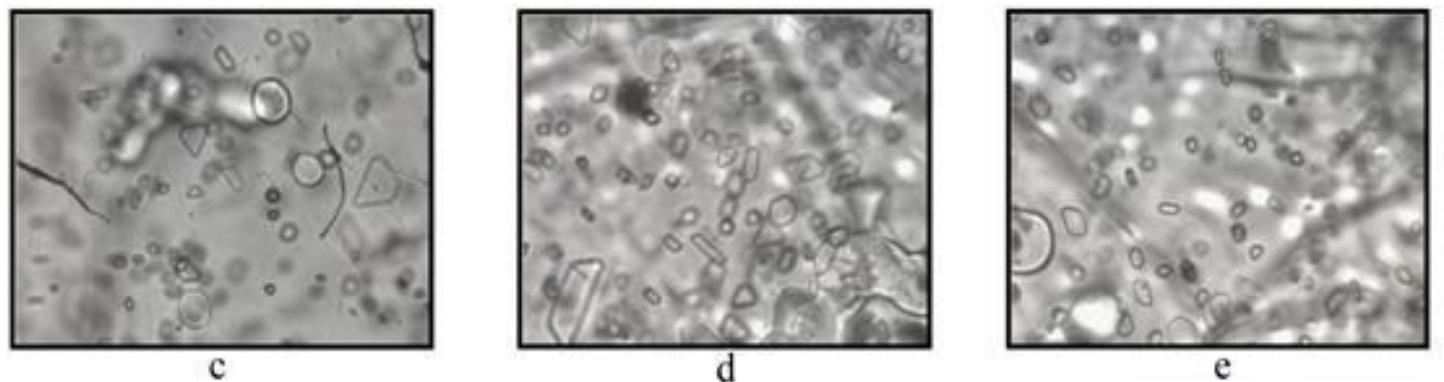

2405.8

VII

\section{Appendix 2.2.1.B}

Microstructure mapping images for EDML ice short after drilling

(Kipfstuhl, 2007)
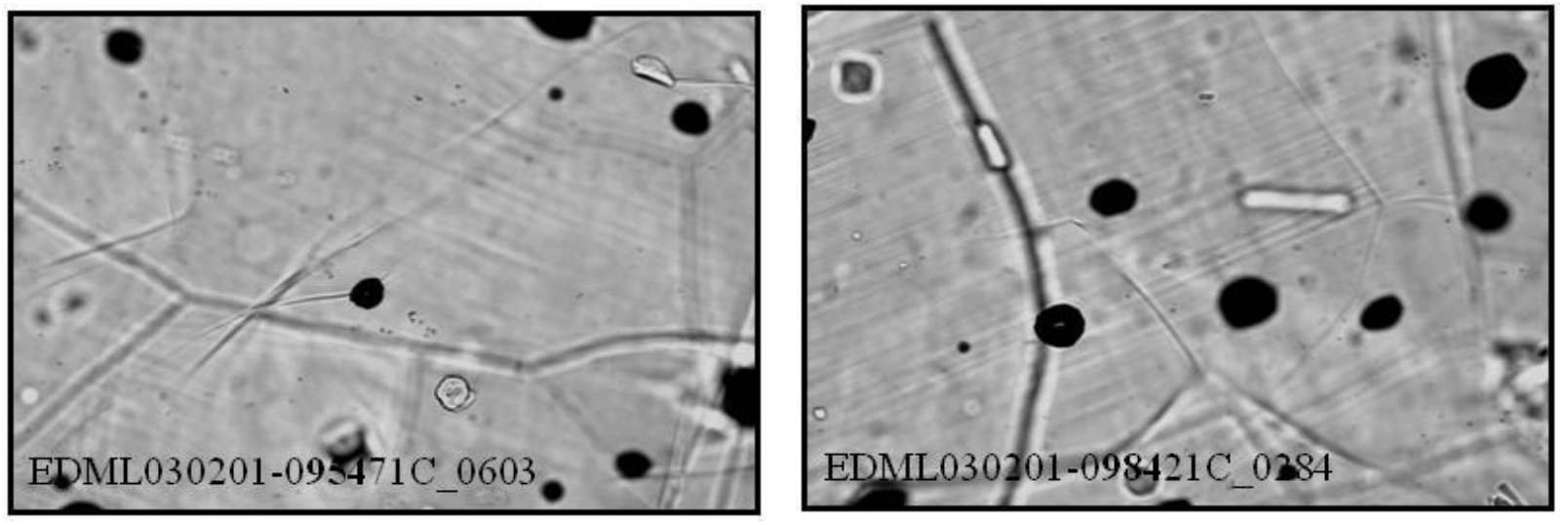

The black features are air bubbles embedded in the EDML ice matrix

The whiter inclusions that resemble the air bubbles are air hydrates

The smallest "black dots" can be gaseous, solid or liquid microinclusions

The thick, dark lines are grain boundaries between ice crystallites

The thin, straight packed lines are slip bands 

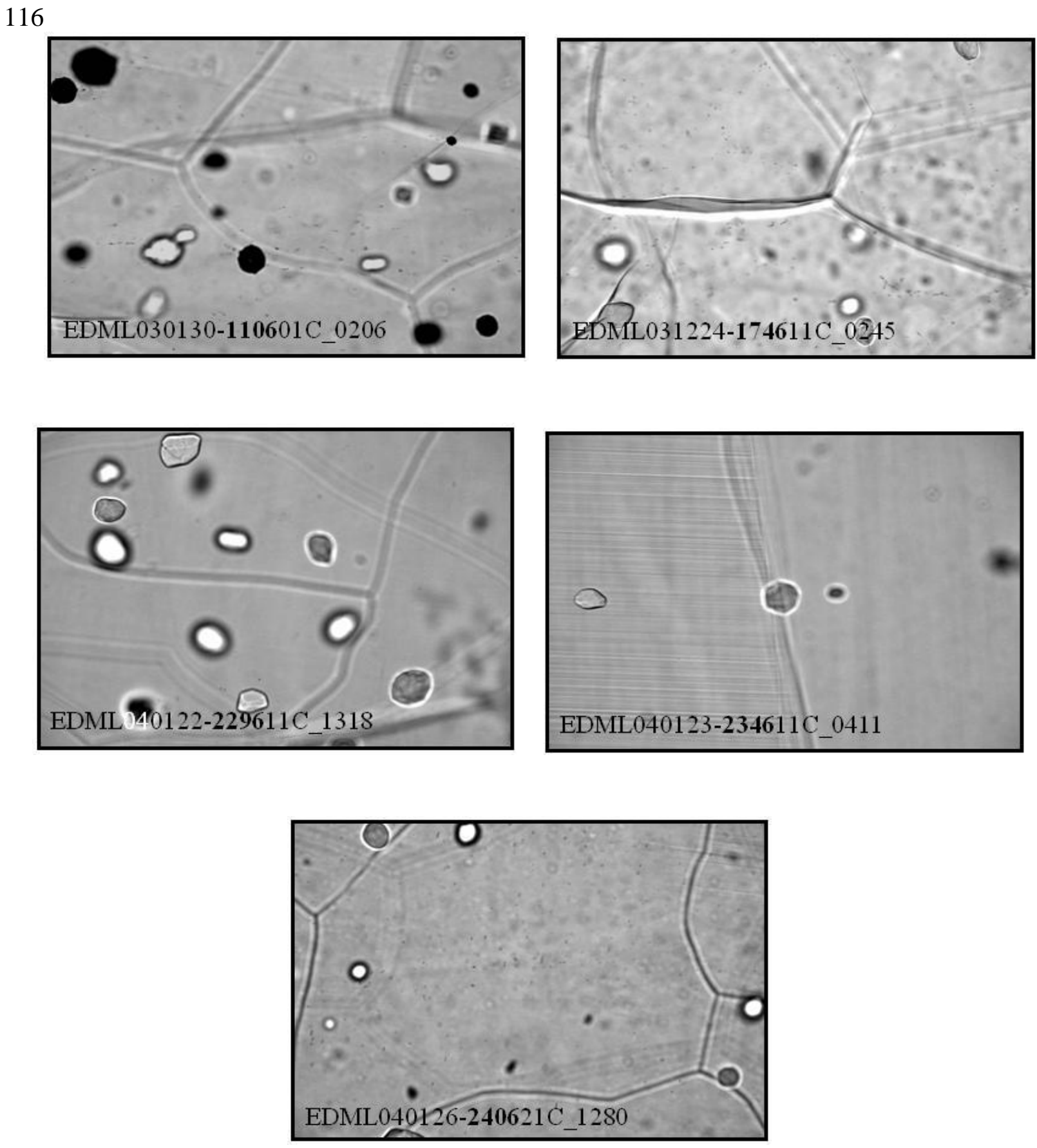
Appendix 2.2.1.C Description of individual investigated PLIs in EDML ice

\begin{tabular}{|c|c|c|c|c|c|c|c|}
\hline $\begin{array}{c}\text { EDML bag \# } \\
954.9\end{array}$ & Shape & Outline & $\begin{array}{c}\text { Dimensions } \\
(1(\mu \mathrm{m}) \times \mathrm{L}(\mu \mathrm{m}))\end{array}$ & $\begin{array}{c}\text { Aspect ratio } \\
\text { 1:n }(\mathrm{n}=\mathrm{L} / \mathrm{l})\end{array}$ & Colour & $\begin{array}{c}\text { Position } \\
\text { (orientation) }\end{array}$ & Vicinity \\
\hline PLI1 & hexagonal & regular & $4 \times 68$ & 1:17 & black & just tilted & BDs \\
\hline PLI2 & hexagonal & regular & $2 \times 52$ & $1: 26$ & transparent & well oriented & $\mathrm{CC}$ \\
\hline PLI4 & hexagonal & bit smooth & $10 \times 80$ & $1: 8$ & (not so) black & tilted & PLIs \\
\hline PLI5 & hexagonal & regular & $2 \times 90$ & $1: 45$ & black & tilted & alone \\
\hline PLI6 & hexagonal & regular & $3 \times 150$ & $1: 50$ & black & tilted & alone \\
\hline $\begin{array}{c}\text { EDML bag \# } \\
984.8\end{array}$ & Shape & Outline & $\begin{array}{c}\text { Dimensions } \\
(1(\mu \mathrm{m}) \times \mathrm{L}(\mu \mathrm{m}))\end{array}$ & $\begin{array}{c}\text { Aspect ratio } \\
\text { 1:n }(\mathrm{n}=\mathrm{L} / \mathrm{l})\end{array}$ & Colour & Position & Vicinity \\
\hline PLI1 & hexagonal & regular & $5 \times 100$ & $1: 20$ & black & tilted & PLIs \\
\hline PLI2 & hexagonal & regular & $4 \times 160$ & $1: 40$ & black & tilted & PLI \\
\hline PLI3 & oval & smooth & $15 \times 75$ & $1: 5$ & black & tilted & BDs \\
\hline PLI4 & oval & smooth & $6 \times 100$ & $1: 16$ & (half) black & (a bit) tilted & GB \\
\hline PLI5 & hexagonal & regular & $2 \times>100$ & $1:>50$ & ---- & well oriented & ?MBs, PLIs \\
\hline PLI6 & oval & (a bit) smooth & $8 \times 64$ & $1: 8$ & (half) black & well oriented & alone \\
\hline PLI7 & oval & smooth & $18 \times 58$ & $1: 3.2$ & (half) black & tilted & PLIs \\
\hline PLI8 & hexagonal & regular & $4 \times 64$ & $1: 16$ & black & tilted & PLI, GB \\
\hline PLI1 & hexagonal & regular & $8 \times 100$ & $1: 12.5$ & transparent & well oriented & GB \\
\hline PLI2 & hexagonal & regular & $5 \times 100$ & $1: 20$ & black & tilted & $\mathrm{MB}$ \\
\hline PLI3 & hexagonal & regular & $4 \times 80$ & $1: 20$ & black & tilted & PLI, BD \\
\hline PLI4 & hexagonal & regular & $3 \times 84$ & $1: 28$ & black & tilted & MB, PLI \\
\hline $\begin{array}{c}\text { EDML bag \# } \\
1106.9\end{array}$ & Shape & Outline & $\begin{array}{c}\text { Dimensions } \\
(\mathrm{l}(\mu \mathrm{m}) \times \mathrm{L}(\mu \mathrm{m}))\end{array}$ & $\begin{array}{c}\text { Aspect ratio } \\
1: n(n=L / l)\end{array}$ & Colour & Position & Vicinity \\
\hline PLI1 & hexagonal & smooth & $6 \times 100$ & $1: 16.6$ & black & (not so) tilted & decomp. AH \\
\hline PLI2 & hexagonal & smooth & $10 \times 60$ & $1: 6$ & (half) black & tilted & $\mathrm{AH}$ \\
\hline PLI3 & hexagonal & smooth & $5 \times 70$ & $1: 14$ & (half) black & tilted & alone \\
\hline PLI4 & ? rhomb & smooth & $8 \times 140$ & $1: 17.5$ & transparent & tilted & GB \\
\hline PLI5 & ? pentagonal & regular & $5 \times 85$ & $1: 17$ & black & tilted & ---- \\
\hline PLI6 & hexagonal & irregular & $3 \times>160$ & $1:>50$ & black & tilted & $\mathrm{MB}, \mathrm{GB}$ \\
\hline $\begin{array}{c}\text { EDML bag \# } \\
1106 . .9\end{array}$ & Shape & Outline & $\begin{array}{c}\text { Dimensions } \\
(1(\mu \mathrm{m}) \times \mathrm{L}(\mu \mathrm{m}))\end{array}$ & $\begin{array}{c}\text { Aspect ratio } \\
\text { 1:n }(n=L / l)\end{array}$ & Colour & Position & Vicinity \\
\hline PLI1 & hexagonal & regular & $5 \times 100$ & $1: 20$ & (half) black & tilted & alone \\
\hline PLI5 & hexagonal & regular & $10 \times 60$ & $1: 6$ & transparent & well oriented & alone \\
\hline PLI6 & hexagonal & regular & $1 \times>120$ & $1: 120$ & black & ---- & GB \\
\hline PLI7 & hexagonal & regular & $2 \times 100$ & $1: 50$ & black & ---- & PLI \\
\hline semiPLI & ?round & regular & $15 \times 40$ & $1: 2.67$ & (half) black & ---- & ---- \\
\hline
\end{tabular}




\begin{tabular}{|c|c|c|c|c|c|c|c|}
\hline $\begin{array}{l}\text { EDML bag \# } \\
1746.2\end{array}$ & Shape & Outline & $\begin{array}{c}\text { Dimensions } \\
(1(\mu \mathrm{m}) \times \mathrm{L}(\mu \mathrm{m}))\end{array}$ & $\begin{array}{l}\text { Aspect ratio } \\
\text { 1:n }(n=L / l)\end{array}$ & Colour & Position & Vicinity \\
\hline PLI2 & hexagonal & regular & $15 \times 50$ & $1: 3.33$ & (half) black & tilted & ---- \\
\hline $\begin{array}{c}\text { EDML bag \# } \\
1746.2\end{array}$ & Shape & Outline & $\begin{array}{c}\text { Dimensions } \\
(\mathrm{l}(\mu \mathrm{m}) \times \mathrm{L}(\mu \mathrm{m}))\end{array}$ & $\begin{array}{l}\text { Aspect ratio } \\
\text { 1:n }(n=L / l)\end{array}$ & Colour & Position & Vicinity \\
\hline PLI1 & hexagonal & regular & $2 \times 400$ & $1: 200$ & black & perpendicular & GB \\
\hline PLI2 & hexagonal & regular & $2 \times 400$ & $1: 200$ & black & perpendicular & GB \\
\hline PLI3 & ? tubular & regular & $5 \times 80$ & $1: 16$ & transparent & perpendicular & PLI \\
\hline PLI4 & ? tubular & regular & $10 \times 110$ & $1: 11$ & transparent & perpendicular & PLI \\
\hline PLI5 & ? rhomb & regular & $8 \times 110$ & $1: 14$ & black & tilted & alone \\
\hline PLI6 & hexagonal & regular & $20 \times 80$ & $1: 4$ & (half) black & well oriented & PLI \\
\hline PLI7 & ? hexagonal & ? regular & $6 \times 90$ & $1: 15$ & black & well oriented & PLI \\
\hline $\begin{array}{c}\text { EDML bag \# } \\
1746.2\end{array}$ & Shape & Outline & $\begin{array}{c}\text { Dimensions } \\
(1(\mu \mathrm{m}) \times \mathrm{L}(\mu \mathrm{m}))\end{array}$ & $\begin{array}{l}\text { Aspect ratio } \\
1: n(n=L / l)\end{array}$ & Colour & Position & Vicinity \\
\hline PLI1 & ? hexagonal & ? regular & $1.5 \times 55$ & $1: 36,67$ & ---- & well oriented & alone \\
\hline PLI2 & hexagonal & regular & $3 \times 120$ & $1: 40$ & black & tilted & PLI \\
\hline PLI3 & hexagonal & regular & $2 \times 50$ & $1: 25$ & black & (a bit) tilted & PLI \\
\hline PLI4 & ? hexagonal & regular & $10 \times 80$ & $1: 8$ & (half) black & tilted & alone \\
\hline PLI5 & ---- & ? regular & $4 \times>32$ & $1:>8$ & ---- & ---- & ---- \\
\hline $\begin{array}{c}\text { EDML bag \# } \\
2296.8\end{array}$ & Shape & Outline & $\begin{array}{c}\text { Dimensions } \\
(\mathrm{l}(\mu \mathrm{m}) \times \mathrm{L}(\mu \mathrm{m}))\end{array}$ & $\begin{array}{l}\text { Aspect ratio } \\
1: n(n=L / 1)\end{array}$ & Colour & Position & Vicinity \\
\hline PLI2 & ? rhomb & regular & $10 \times 70$ & $1: 7$ & (half) black & tilted & alone \\
\hline PLI3 & ? hexagonal & regular & $8 \times 64$ & $1: 8$ & (half) black & tilted & PLI \\
\hline PLI4 & ? hexagonal & smooth & $10 \times 50$ & $1: 5$ & (half) black & tilted & PLI \\
\hline PLI5 & hexagonal & (not so) regular & $10 \times 60$ & $1: 6$ & (half) black & tilted & ---- \\
\hline PLI6 & hexagonal & (quite) regular & $5 \times 100$ & $1: 20$ & transparent & tilted & $\mathrm{BD}$ \\
\hline PLI7 & hexagonal & regular & $2 \times 200$ & $1: 100$ & black & tilted & alone \\
\hline PLI8 & tubular & irregular & $10 \times 50$ & $1: 5$ & (half) black & tilted & PLI \\
\hline PLI9 & hexagonal & regular & $4 \times 84$ & $1: 21$ & (half) black & tilted & PLI \\
\hline PLI10 & hexagonal & ? regular & $3 \times 150$ & $1: 50$ & transparent & tilted & PLI \\
\hline PLI11 & hexagonal & regular & $2 \times 110$ & $1: 55$ & black & tilted & PLI \\
\hline PLI12 & hexagonal & regular & $8 \times 56$ & $1: 7$ & (half) black & tilted & alone \\
\hline PLI13 & hexagonal & regular & $8 \times 56$ & $1: 7$ & (half) black & tilted & alone \\
\hline PLI14 & ? hexagonal & regular & $4 \times 80$ & $1: 20$ & transparent & tilted & alone \\
\hline PLI15 & ? cillinder & irregular & $20 \times 40$ & $1: 2$ & transparent & tilted & alone \\
\hline PLI16 & --- & --- & $10 \times 60$ & $1: 6$ & - & ---- & ---- \\
\hline $\begin{array}{c}\text { EDML bag \# } \\
537\end{array}$ & Shape & Outline & $\begin{array}{c}\text { Dimensions } \\
\text { diameter }(\mu \mathrm{m})\end{array}$ & $\begin{array}{c}\text { Aspect ratio } \\
1: n(n=L / l)\end{array}$ & Colour & Position & Vicinity \\
\hline PLI1 & ? hexagonal & (a bit) smooth & $8 \times 30$ & $1: 4$ & (half) black & tilted & alone \\
\hline $\begin{array}{c}\text { EDML bag \# } \\
2346.9\end{array}$ & Shape & Outline & $\begin{array}{c}\text { Dimensions } \\
(1(\mu \mathrm{m}) \times \mathrm{L}(\mu \mathrm{m}))\end{array}$ & $\begin{array}{c}\text { Aspect ratio } \\
1: n(n=L / l)\end{array}$ & Colour & Position & Vicinity \\
\hline PLI1 & hexagonal & regular & $4 ? \times 30 \times 560$ & $1: 150$ & ---- & parallel & --- \\
\hline
\end{tabular}




\begin{tabular}{|c|c|c|c|c|c|c|c|}
\hline PLI2 & ? cillinder & irregular & $8 \times 60$ & $1: 7,5$ & ---- & $?$ tilted & ---- \\
\hline PLI3 & ? hexagonal & smooth & $6 \times 36 \times 56$ & $1: 11$ & ? (half) black & tilted & ---- \\
\hline PLI4 & ? hexagonal & smooth & $28 \times 48$ & $1: 7$ & (half) black & ---- & ---- \\
\hline PLI5 & hexagonal & regular & $4 \times 44 \times 64$ & $1: 1.45$ & ---- & parallel & ---- \\
\hline PLI6 & ? cillinder & irregular & $24 \times 44$ & $1: 8$ & (half) black & ---- & ---- \\
\hline PLI7 & hexagonal & (not so) regular & $28 \times 100$ & $1: 3.5$ & ---- & parallel & ---- \\
\hline PLI8 & ? tubular & ? regular & $2 \times 50$ & $1: 25$ & ---- & perpendicular & ---- \\
\hline PLI9 & ? hexagonal & ? regular & $90 \times 120$ & $1: 1.33$ & ---- & parallel & ---- \\
\hline $\begin{array}{c}\text { EDML bag \# } \\
2406.8\end{array}$ & Shape & Outline & $\begin{array}{c}\text { Dimensions } \\
(\mathrm{l}(\mathrm{um}) \times \mathrm{L}(\mathrm{um}))\end{array}$ & $\begin{array}{c}\text { Aspect ratio } \\
1: n(n=L / 1)\end{array}$ & Colour & Position & Vicinity \\
\hline PLI1 & hexagonal & (ir)regular & $6 ? \times 28 \times 56$ & $1: 2$ & ---- & parallel & ---- \\
\hline PLI2 & hexagonal & smooth & $26 \times 50$ & $1: 2$ & ---- & parallel & ---- \\
\hline PLI3 & hexagonal & smooth & $36 \times 45$ & $1: 1.25$ & ---- & parallel & ---- \\
\hline PLI4 & hexagonal & smooth & $10 \times 32$ & $1: 3$ & ---- & parallel & ---- \\
\hline PLI5 & hexagonal & smooth & $24 \times 36$ & $1: 1.5$ & ---- & parallel & ---- \\
\hline PLI6 & hexagonal & regular & $26 \times 50$ & $1: 2$ & ---- & parallel & ---- \\
\hline PLI7 & oval & rectangular & $40 \times 80$ & $1: 2$ & ---- & ---- & ---- \\
\hline PLI8 & round(er) & ---- & $30 \times 50$ & $1: 1.66$ & ---- & ---- & PLI \\
\hline PLI9 & ---- & rectangular & $32 \times 45$ & $1: 1.4$ & ---- & ---- & ---- \\
\hline PLI10 & ---- & smooth & $35 \times 40$ & $1: 1.14$ & ---- & ---- & ---- \\
\hline PLI11 & hexagonal & "fat" & $40 \times 50$ & $1: 1.25$ & ---- & paralel & \\
\hline PLI12 & round & smooth faces & 64 & ---- & ---- & ---- & ---- \\
\hline PLI13 & ? pentagonal & ---- & $50 \times 100$ & $1: 2$ & ---- & parallel & ---- \\
\hline PLI14 & deformed & ---- & 65 & ---- & ---- & (not so) parallel & ---- \\
\hline PLI15 & hexagonal & regular & $4 ? \times 85 \times 90$ & ---- & ---- & (a bit) tilted & ---- \\
\hline PLI16 & hexagonal & regular & $74 \times 108$ & $1: 1.46$ & ---- & parallel & ---- \\
\hline PLI17 & hexagonal & "fat" & $20 \times 36$ & $1: 1.8$ & ---- & parallel & --- \\
\hline PLI18 & hexagonal & "fat" & $32 \times 36$ & ---- & ---- & parallel & ---- \\
\hline PLI19 & rhomboedral & smooth & $24 \times 40$ & $1: 1.67$ & ---- & parallel & ---- \\
\hline PLI20 & rhomboedral & smooth & $20 \times 32$ & $1: 1.6$ & ---- & parallel & --- \\
\hline
\end{tabular}




\section{Appendix 2.2.1.D}

Representative graphs with Raman spectrochemical fingerprint of relaxation features in EDML ice, namely plate like inclusions, PLIs. Each graph represents the Raman intensity (in counts) versus the wavenumber in $\left(\mathrm{cm}^{-1}\right)$ The two observable peaks around $1560 \mathrm{~cm}^{-1}$ and $2335 \mathrm{~cm}^{-1}$ corresponding to the oxygen, $\mathrm{O}_{2}$, and nitrogen, $\mathrm{N}_{2}$, molecules respectively. (l=location, $\mathrm{f}=$ focus, $\mathrm{c}=$ center, $\mathrm{m}=$ marginal, $\mathrm{s}=$ seconds, $100 / 200 / 300=$ width confocal hole)
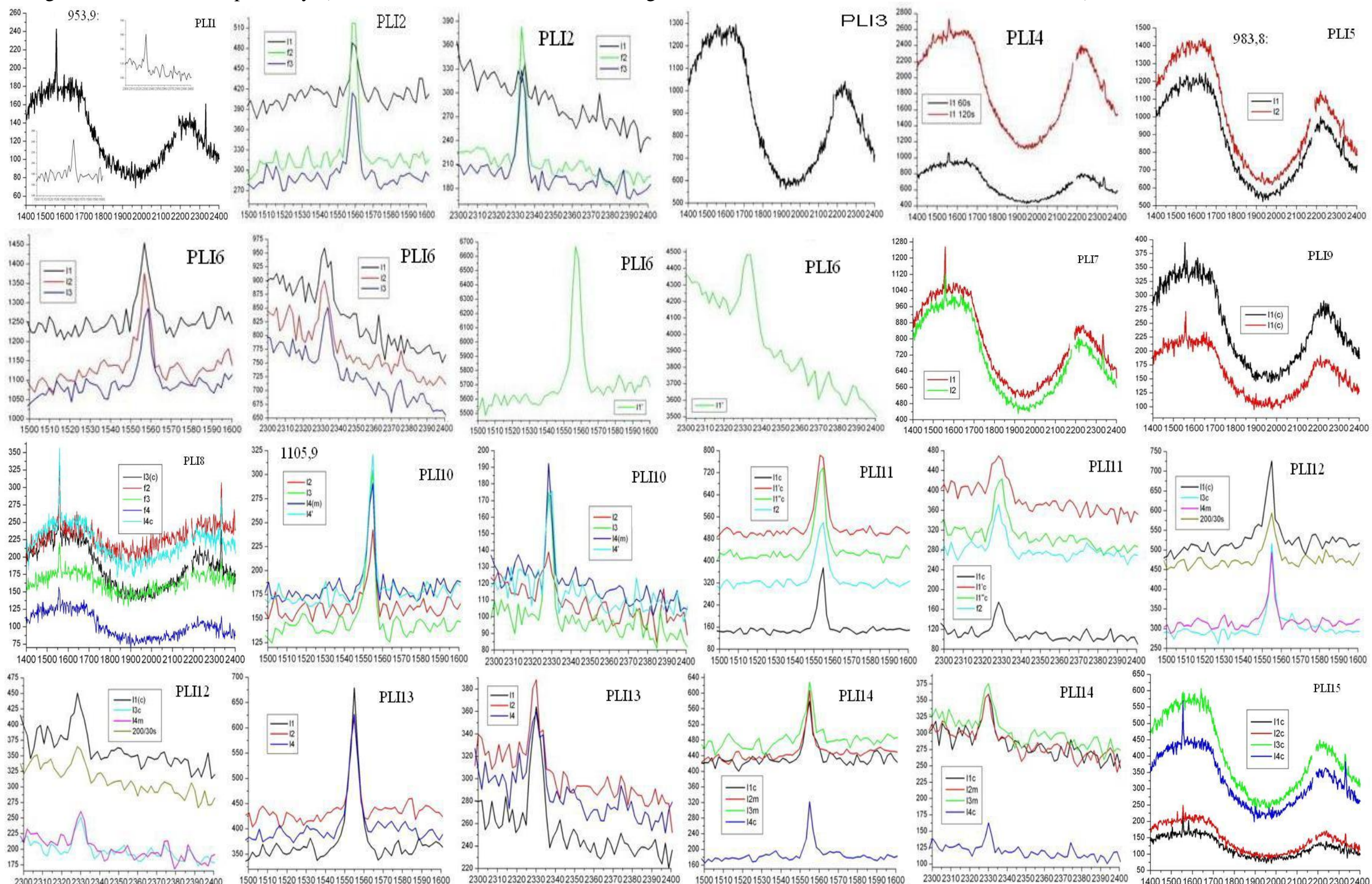

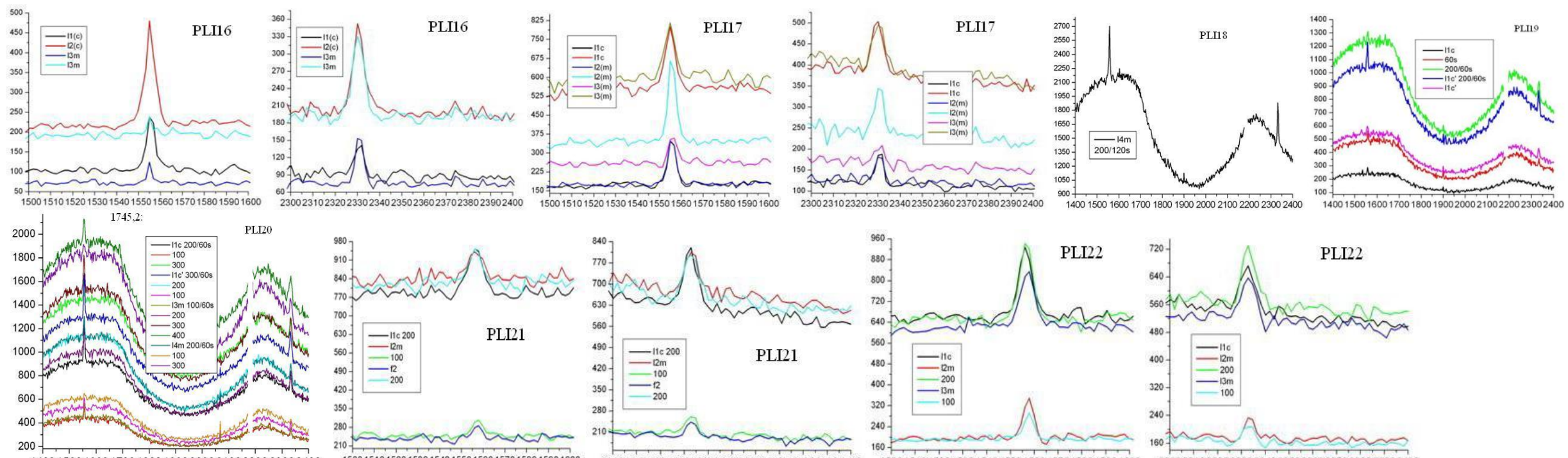

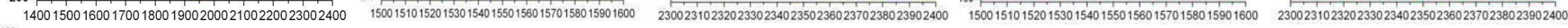
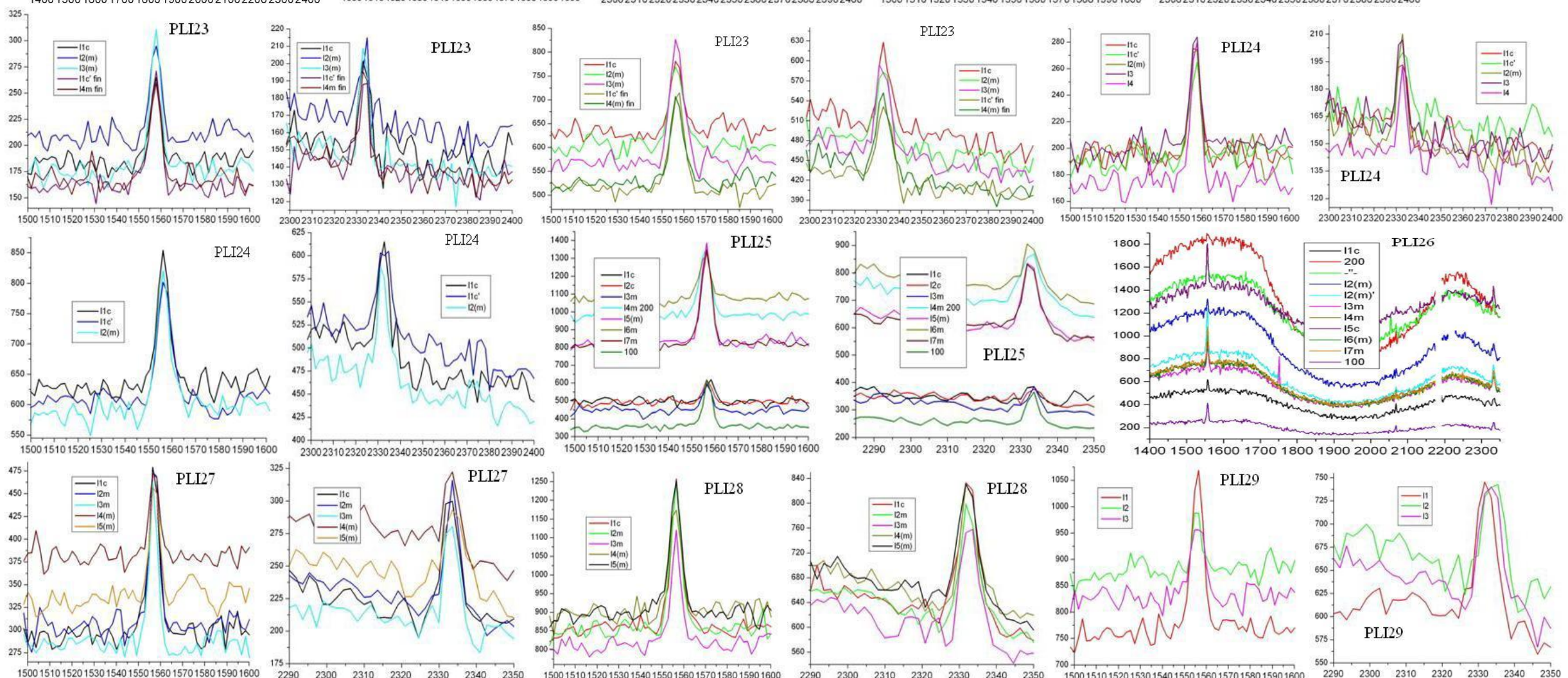

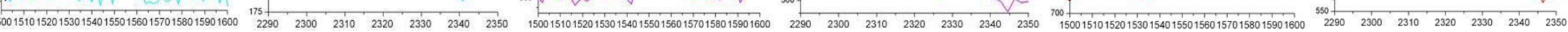



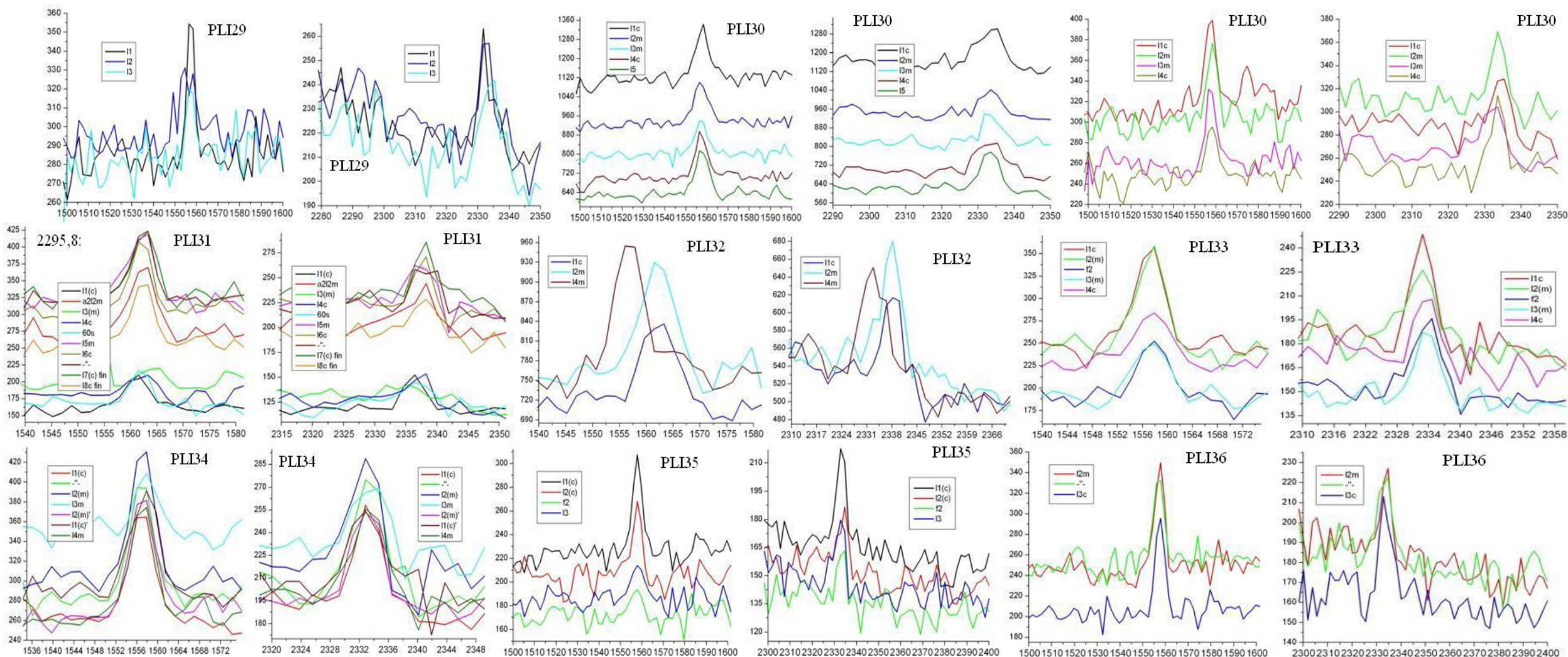

\begin{tabular}{lllllllllll}
2310 & 2316 & 2322 & 2328 & 2334 & 2340 & 2346 & 2352 & \multicolumn{1}{c}{$3^{\prime} 38$}
\end{tabular}

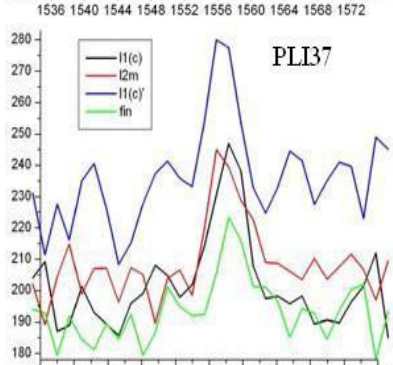

\begin{tabular}{lllllllll}
2320 & 2324 & 2328 & 2332 & 2336 & 2340 & 2344 & 23 & 1 \\
\hline
\end{tabular}
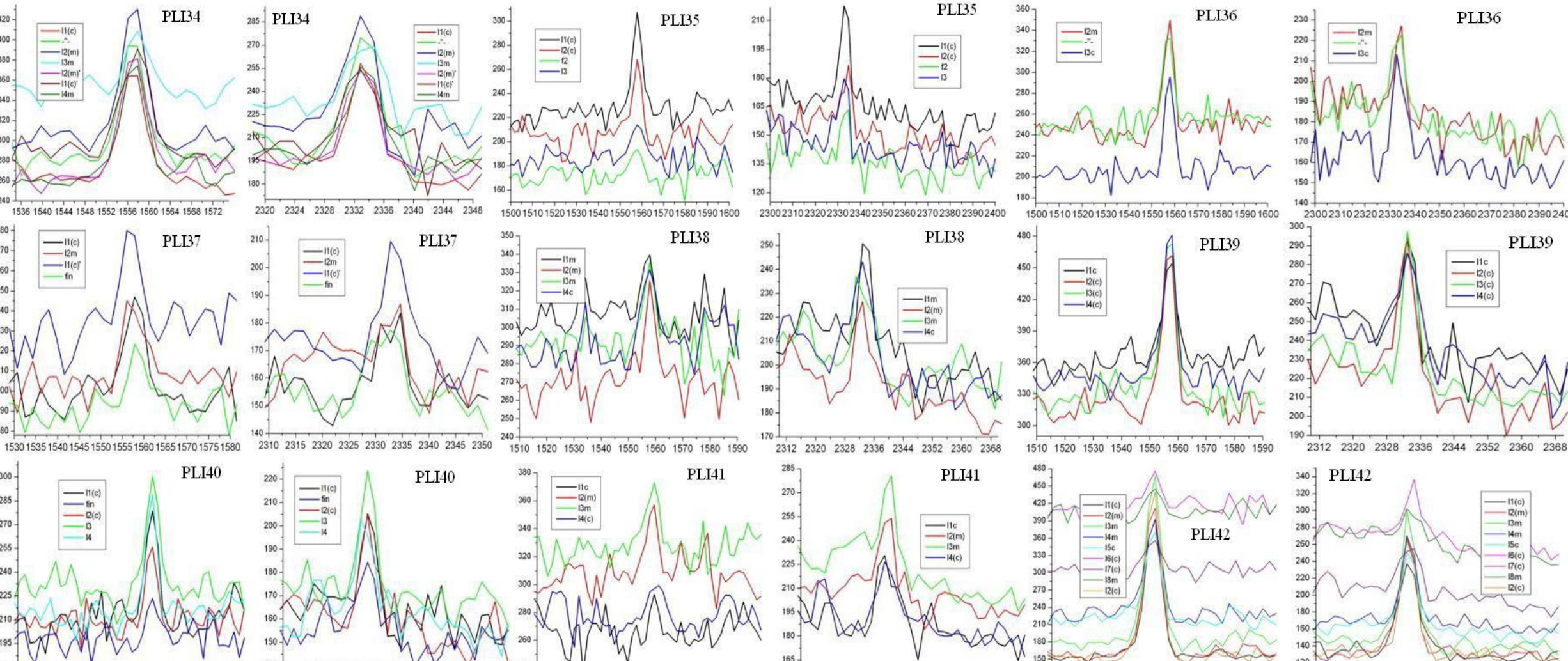

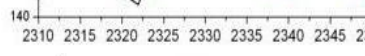
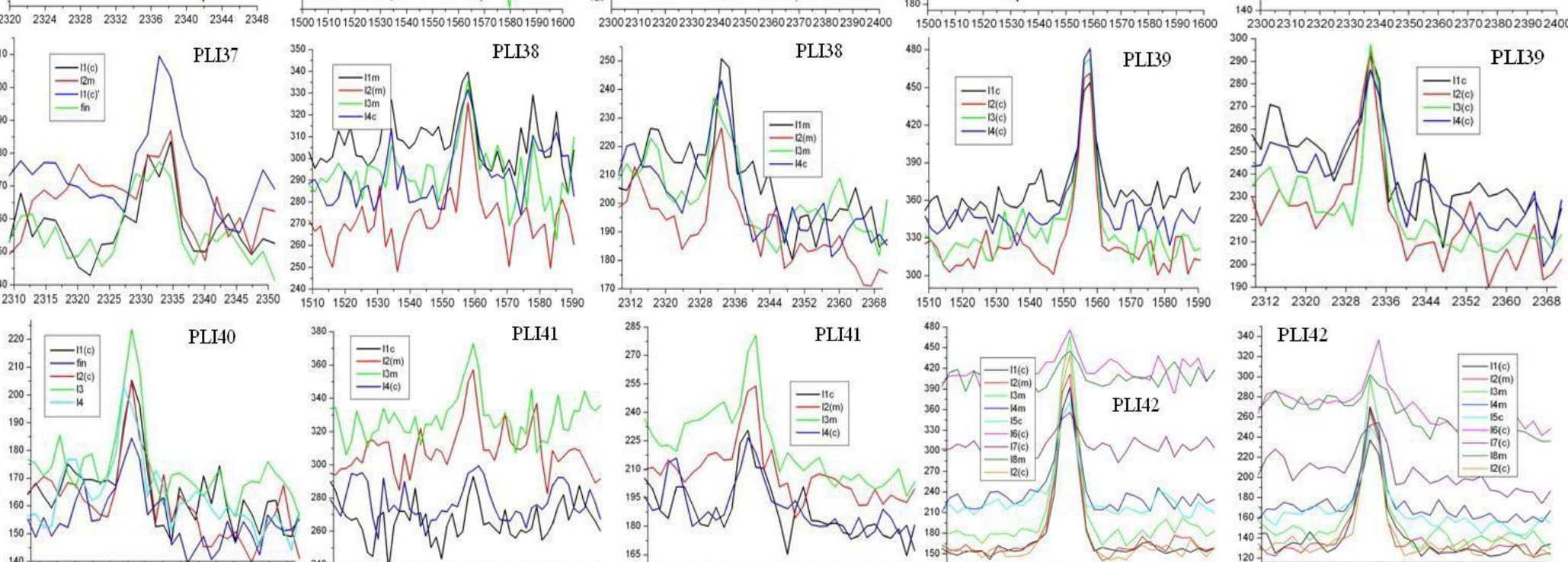

WANA
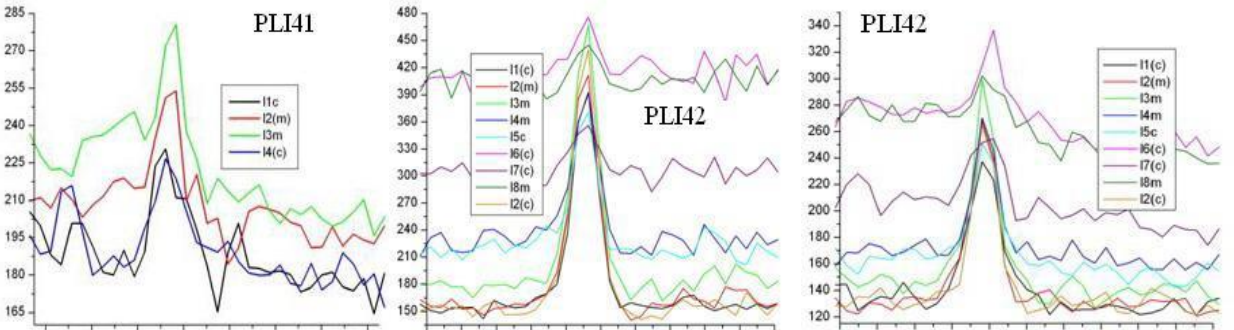

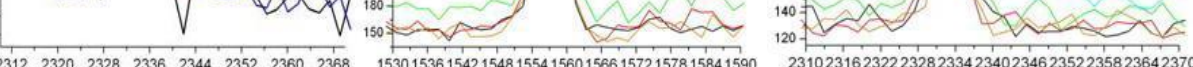



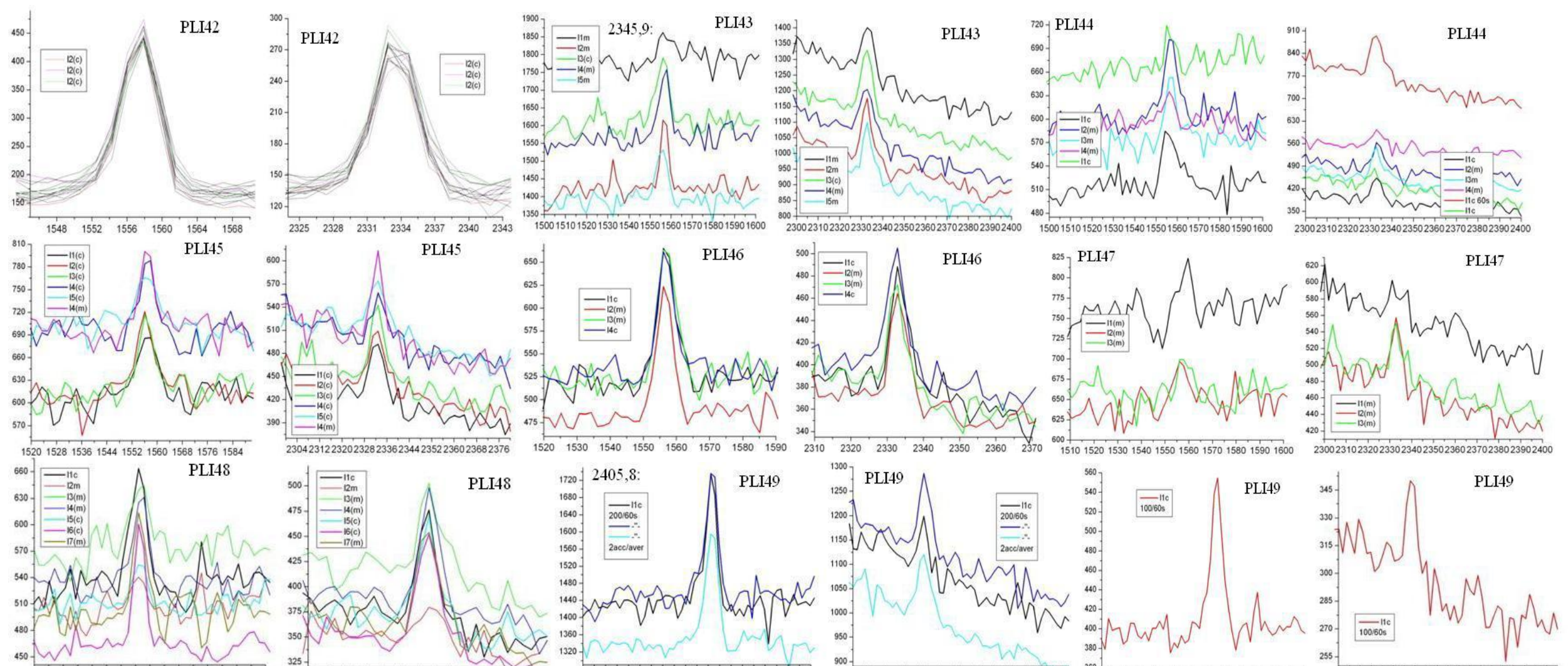

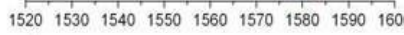

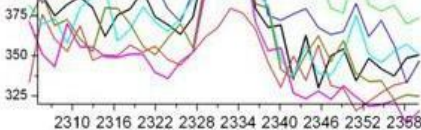

$\overbrace{136}^{1320} \int_{15001510152015301540155015601570158015901600}$
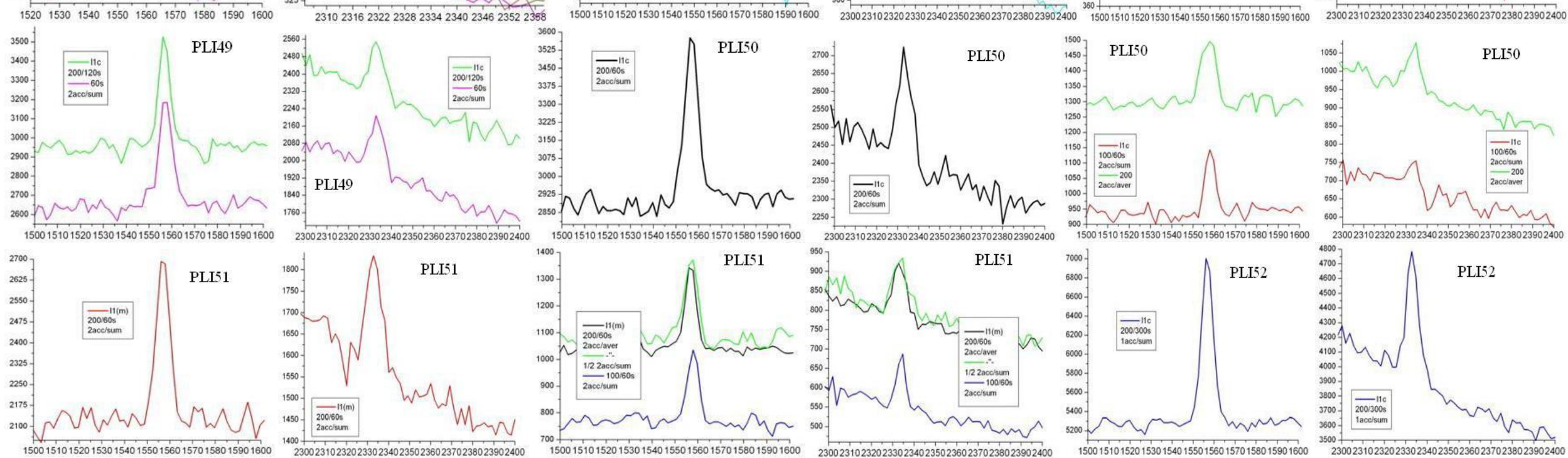

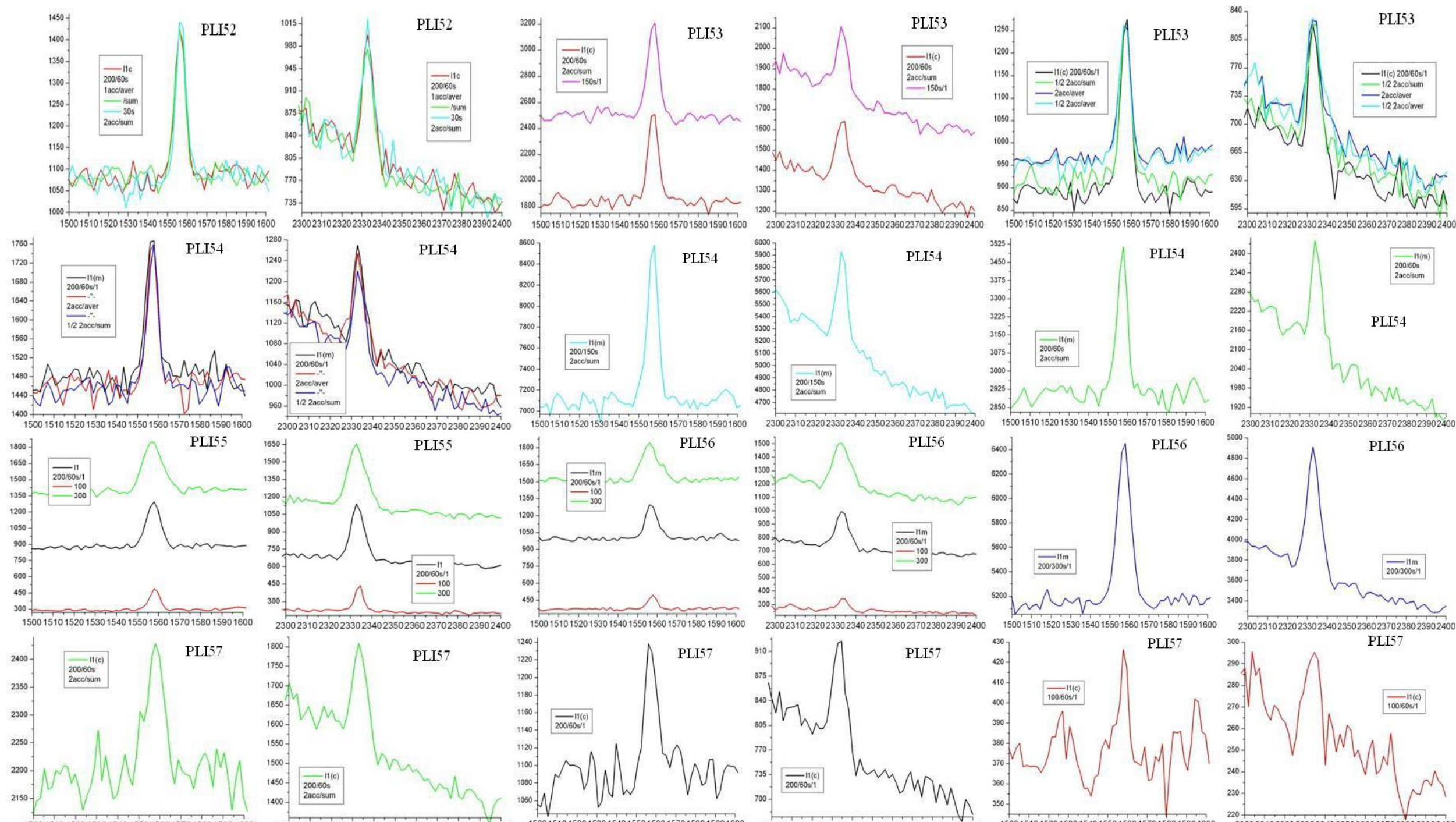

15001510152015301540155015601570158015901600
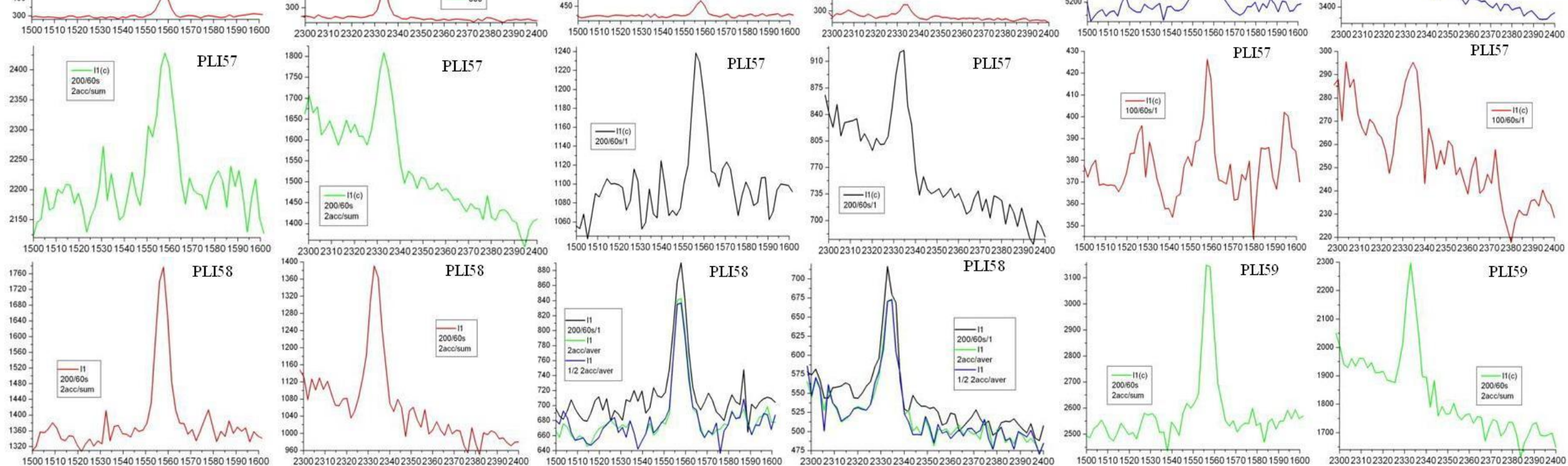

15001510152011501150015501501150158015001600
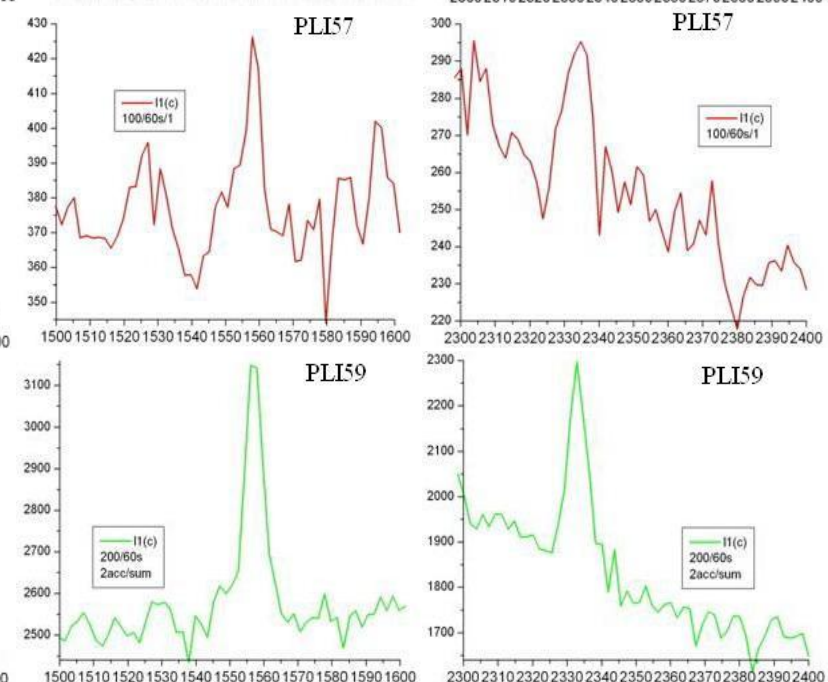

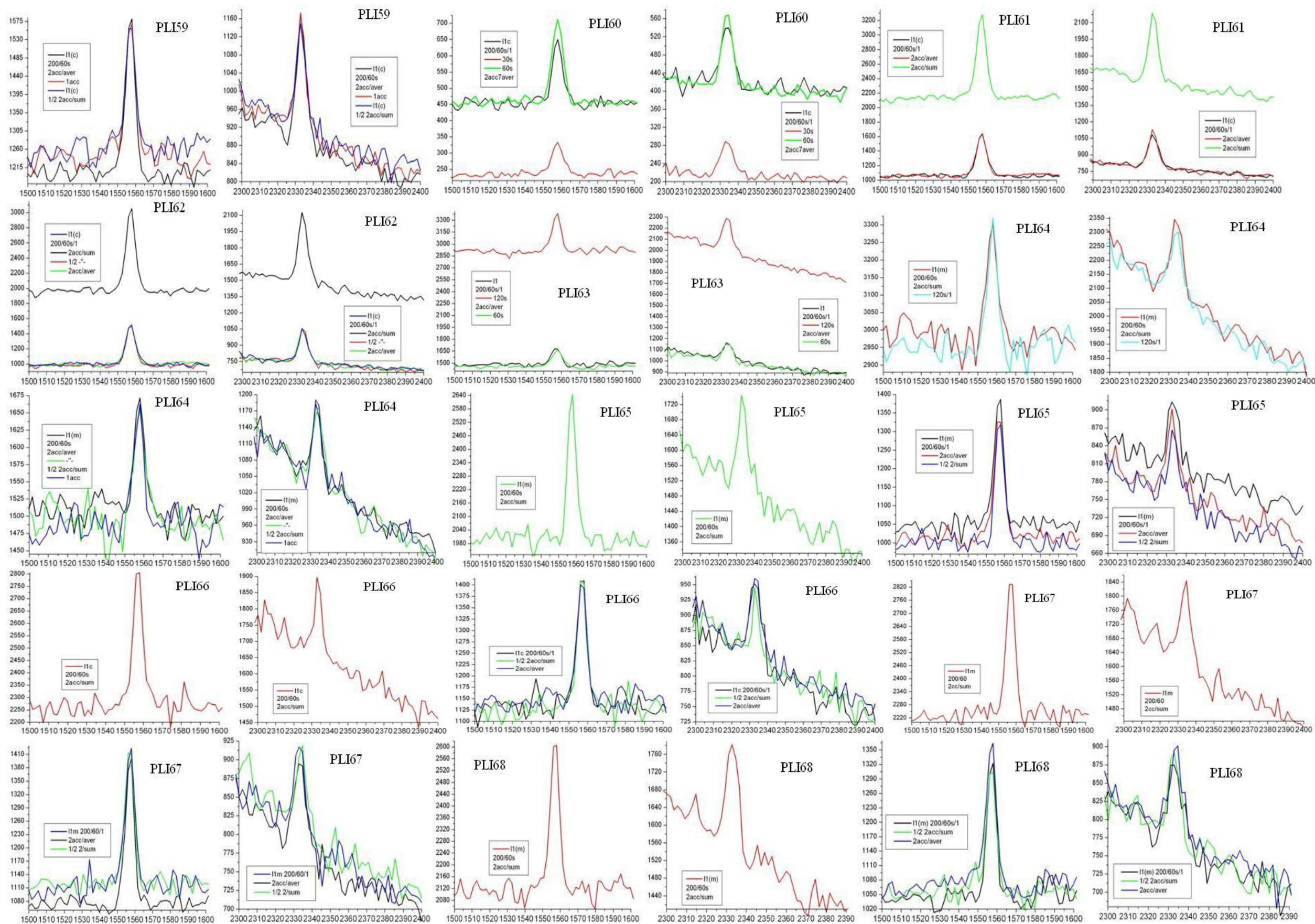


\section{Appendix 2.2.1.E}

Representative graphs with Raman spectrochemical fingerprint of relaxation features in EDML ice, namely plate like inclusions, PLIs.

Each graph represents the Raman intensity (in counts) versus the wavenumber in $\left(\mathrm{cm}^{-1}\right)$

The two observable peaks around $1560 \mathrm{~cm}^{-1}$ and $2335 \mathrm{~cm}^{-1}$ corresponding to the oxygen, $\mathrm{O}_{2}$, and nitrogen, $\mathrm{N}_{2}$, molecules respectively.

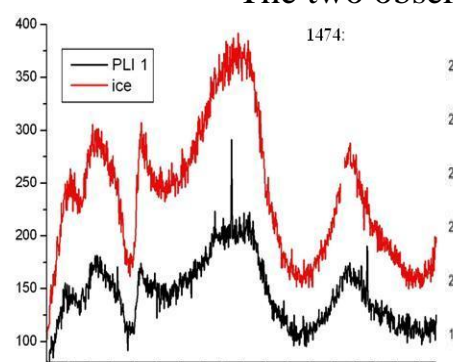

$500 \quad 7501000125015001750200022502500$

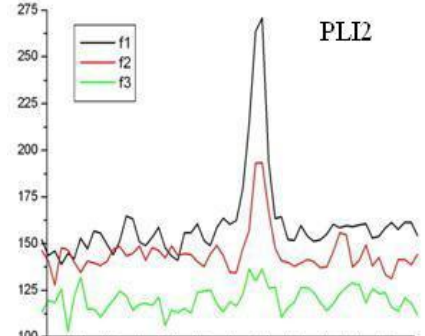

15001510152015301540155015601570158015901600

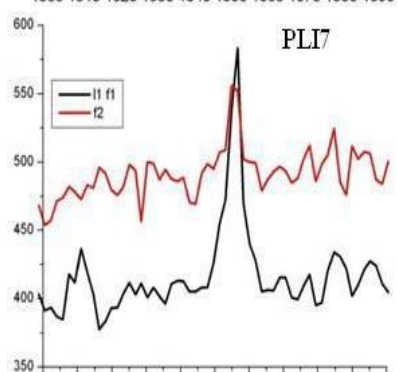

15001510152015301540155015601570158015901600

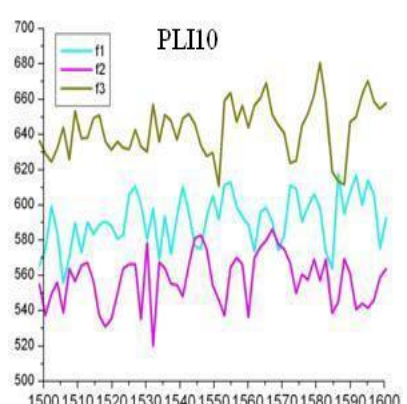

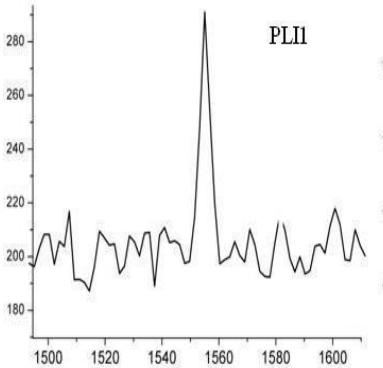
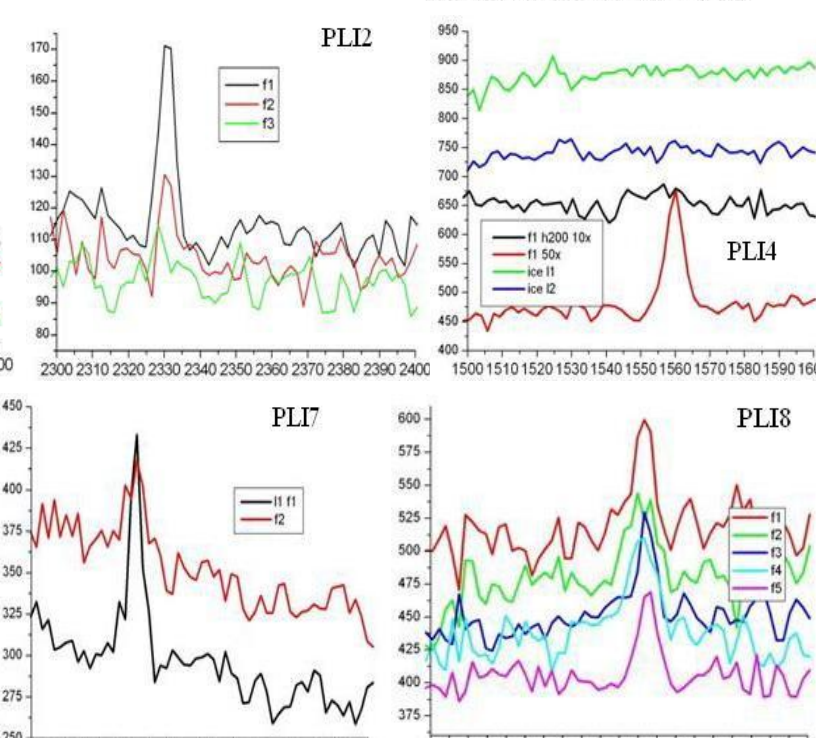

375.
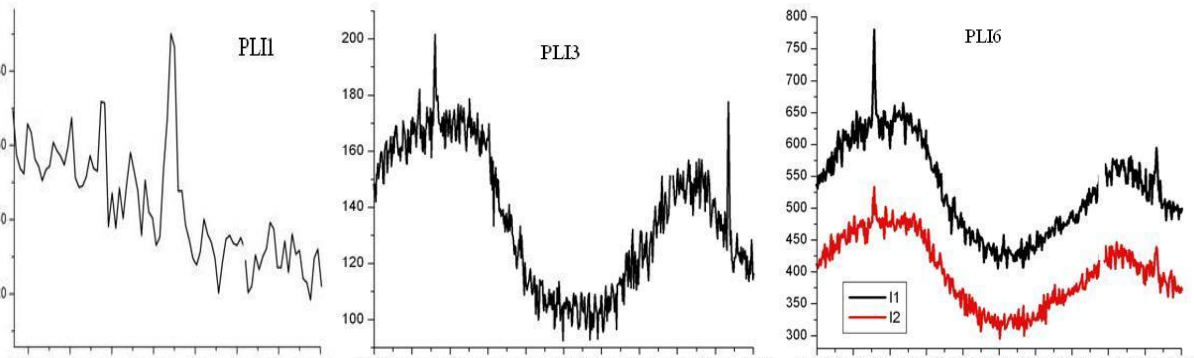

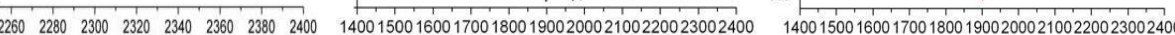
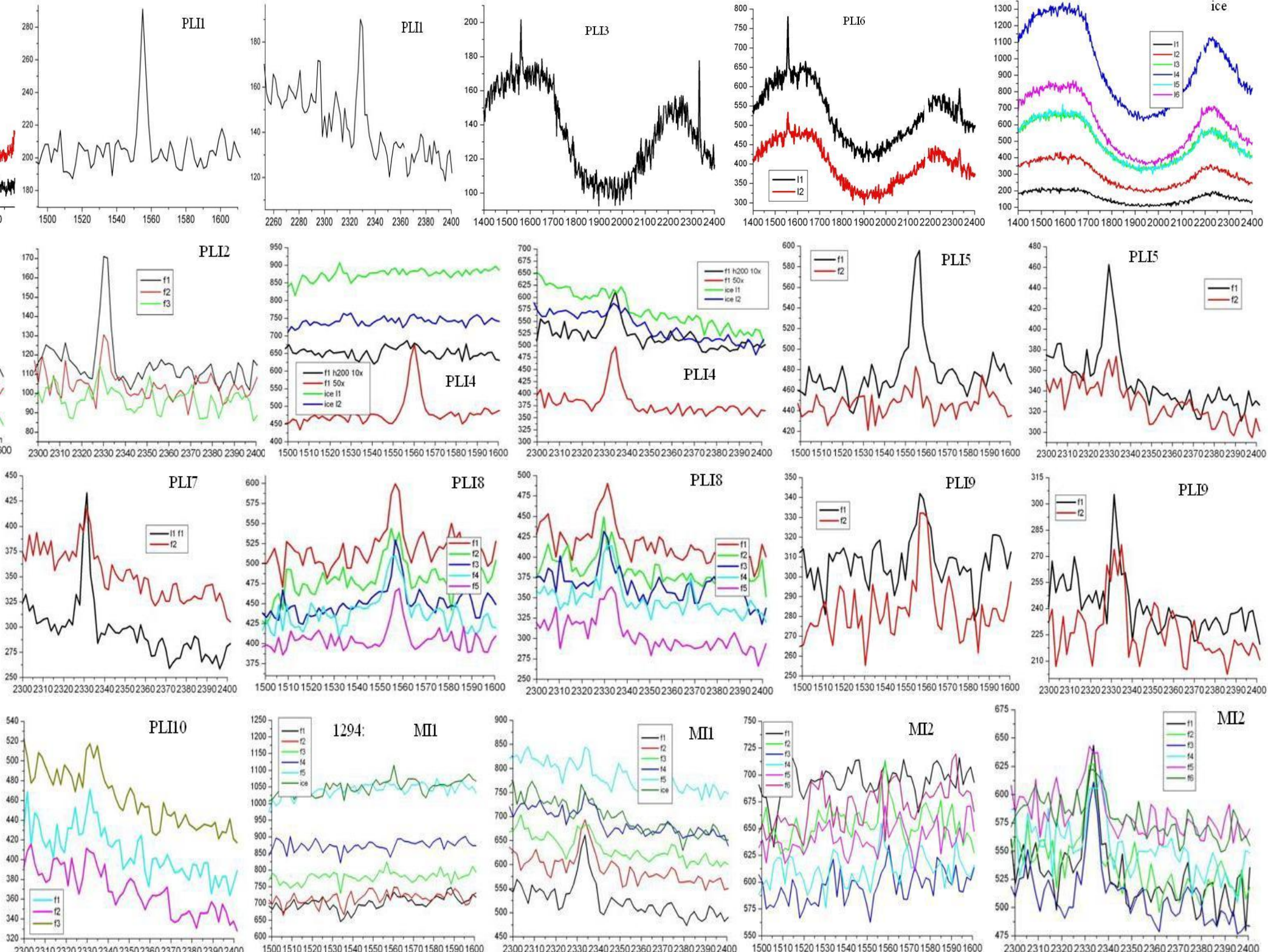
Appendix 2.2.1.F

Values for the $\mathrm{N}_{2}$ and $\mathrm{O}_{2}$ peaks center in the Raman spectra of the analyzed microinclusions in EDML ice.

Standard deviations, sd, and standard errors, se, of the mean are also included but they are roughly significant; for example the overall resolution was $2.2 \mathrm{~cm}^{-1}$ and the sd and se for individual microinclusions at a certain depth were neglected. Sd and se were computed automatically, with ORIGIN 6 software, by simply using its Statistics on Columns function over a number of individual values. Different ways for obtaining the peak center were used because of the overall poor quality of the peaks in the case of plate like inclusions, PLIs, and micro-bubbles, MBs, and only comparative for air hydrates, AHs.

\begin{tabular}{|c|c|c|c|c|c|c|c|}
\hline $\begin{array}{c}\text { PLIs } \\
\text { EDML ice } \\
\text { sample }\end{array}$ & $\begin{array}{c}\text { Area } \\
\text { calculation }\end{array}$ & $\begin{array}{l}\mathbf{N}_{2} \\
\text { Peak } \\
\text { center }\end{array}$ & sd & se & $\begin{array}{l}\mathrm{O}_{2} \\
\text { Peak } \\
\text { center }\end{array}$ & sd & se \\
\hline 953.9 & integration & 2332,771 & 0,89548 & 0,27 & 1558,236 & 1,24053 & 0,37404 \\
\hline 953.9 & $n$ fit & 2332,24 & 1,28569 & 0,57498 & 1557,2 & 84558 & 0,37815 \\
\hline 983.8 & integration & 2333,279 & 0,73098 & 0,13574 & 1558,044 & 4484 & 0,17856 \\
\hline 983.8 & Gau & 2332 & & & 1556,45 & 071 & 0,05 \\
\hline 1105.9 & intes & 2330,92 & 1,6406 & 0,25315 & 1556,121 & 1,57579 & 0,24315 \\
\hline 1745.2 & inte & 2332,534 & 1,08345 & 0,1365 & 1556,564 & 779 & 4965 \\
\hline 1745.2 & Gaus & 2333,026 & 0,62436 & 0,14324 & 1557,038 & 0,85354 & 0,17423 \\
\hline 2295.8 & ion & 2333,838 & 1,72488 & 0,26004 & 1558,221 & 1,84781 & 0,27857 \\
\hline & Gaus: & 2333,513 & & & 1557,447 & 372 & 0,03065 \\
\hline 234 & & 2332,493 & 0,23135 & 0,05973 & 1556,587 & 0,65013 & 0,16786 \\
\hline 2405.8 & integration & 2332,85 & ---- & ---- & 1556,08 & ---- & ---- \\
\hline 2405.8 & Gaussian fit & 2333,164 & 0,37672 & 0,03845 & 1557,141 & 0,41605 & 0,04711 \\
\hline & & & & 0,22 & 1556,286 & & 234 \\
\hline \multicolumn{2}{|c|}{ Average } & 2332,673 & 0,75803 & 0,21024 & 1557,032 & 0,77182 & 0,21406 \\
\hline $\begin{array}{l}\text { MBs } \\
\text { EDML ice } \\
\text { sample }\end{array}$ & $\begin{array}{c}\text { Area } \\
\text { calculation }\end{array}$ & $\begin{array}{l}\mathbf{N}_{2} \\
\text { Peak } \\
\text { center }\end{array}$ & & 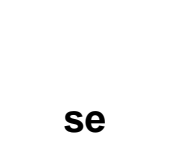 & $\begin{array}{l}\mathrm{O}_{2} \\
\text { Peak } \\
\text { center }\end{array}$ & sd & se \\
\hline 953.9 & integration & 2332,95 & 1,27279 & 0,9 & 1558,58 & 0 & 0 \\
\hline 983.8 & Integration & 2333,92 & 1,03984 & 0,2217 & 1559,07 & 0,98978 & 0,21102 \\
\hline 1105.9 & Integration & 2332,554 & 1,10307 & 0,25306 & 1557,831 & 1,26176 & 0,28947 \\
\hline 1745.2 & Integration & 2331,775 & 1,62522 & 0,40631 & 1556,557 & 1,25961 & 0,3149 \\
\hline 1745.2 & Gaussian fit & 2331,8 & ---- & ---- & 1558,6 & ---- & ---- \\
\hline 2295.8 & Integration & 2331,03 & 0 & 0 & 1554,27 & 0 & 0 \\
\hline 2295.8 & Gaussian fit & 2331,1 & 0,28284 & 0,2 & 1556 & 0 & 0 \\
\hline
\end{tabular}


128

\begin{tabular}{|c|c|c|c|c|c|c|c|}
\hline 2345. & Gaussian & fit 2332,438 & $8 \quad 0,8181$ & 90,1103 & $3 \quad 1556,635$ & $5 \quad 0,92883$ & $3 \quad 0,13269$ \\
\hline & Average & 2332,196 & $6 \quad 0,9726$ & $4 \quad 0,3438$ & $3 \quad 1557,193$ & 31,62643 & $3 \quad 0,57503$ \\
\hline At & Hs & & $\mathbf{N}_{2}$ & & & $\mathrm{O}_{2}$ & \\
\hline $\begin{array}{l}\text { EDML ice } \\
\text { sample }\end{array}$ & $\begin{array}{c}\text { Area } \\
\text { calculation }\end{array}$ & $\begin{array}{l}\text { Peak } \\
\text { center }\end{array}$ & sd & se & $\begin{array}{l}\text { Peak } \\
\text { center }\end{array}$ & sd & se \\
\hline 1745.2 & integration & 2327,209 & 1,4387 & 0,20346 & 1550,685 & 0,71343 & 0,10089 \\
\hline 2295.8 & Integration & 2327,703 & 0,74301 & 0,30333 & 1549,123 & 0,74301 & 0,30333 \\
\hline 2345.9 & Integration & 2328,159 & 0,75314 & 0,15063 & 1550,757 & 0,62329 & 0,12466 \\
\hline 2345.9 & Gaussian fit & 2327,772 & 1,32743 & 0,22124 & 1550,343 & 0,90448 & 0,1487 \\
\hline 2405.8 & Integration & 2328,471 & 0,92329 & 0,22393 & 1550,438 & 0,58855 & 0,13872 \\
\hline$A v$ & rage & 2327,863 & 0,47916 & 0,21429 & 1550,269 & 0,66298 & 0,2965 \\
\hline
\end{tabular}

\section{Appendix 2.2.1.G}

Values for the $\mathrm{N}_{2} / \mathrm{O}_{2}$ ratio for individual analyzed plate like inclusions, PLIs, together with some experimental details. The Standard deviations, sd, and standard errors, se, of the mean were computed automatically, with ORIGIN 6 software, by simply using its Statistics on Columns function over a number of individual values. 


\begin{tabular}{|c|c|c|c|c|c|}
\hline $\begin{array}{l}953.9 \text { ice } \\
\text { sample }\end{array}$ & $\mathbf{N}_{2} / \mathbf{O}_{2}$ & $\begin{array}{c}\text { Focus } \\
\text { position }\end{array}$ & Objective & $\begin{array}{l}\text { Confocal } \\
\text { hole }(\mu \mathrm{m})\end{array}$ & $\begin{array}{c}\text { Exposure } \\
\text { time (s) }\end{array}$ \\
\hline PLI1 & 0,49177 & & 50 & 100 & 30 \\
\hline \multirow[t]{4}{*}{ PLI2 } & 0,83694 & 11 & 50 & 200 & 30 \\
\hline & 0,63881 & 12 & 50 & 200 & 120 \\
\hline & mean & sd & se & & \\
\hline & 0,73788 & 0,1401 & 0,09906 & & \\
\hline \multirow[t]{4}{*}{ PLI2 / Gfit } & 0,96184 & 11 & 50 & 200 & 30 \\
\hline & 0,54027 & 12 & 50 & 200 & 120 \\
\hline & mean & sd & se & & \\
\hline & 0,75106 & 0,2981 & 0,21079 & & \\
\hline \multirow[t]{4}{*}{ PLI3 } & 0,59579 & fin & 50 & 100 & 60 \\
\hline & 0,75468 & fin> & 50 & 100 & 60 \\
\hline & mean & sd & se & & \\
\hline & 0,67524 & 0,11236 & 0,07945 & & \\
\hline \multirow[t]{6}{*}{ PLI4 } & 0,38402 & $11 \mathrm{f} 1$ & 50 & 100 & 60 \\
\hline & 0,4243 & $\mathrm{f} 1+5$ & 50 & 100 & 60 \\
\hline & 0,58159 & $\mathrm{f} 4+5$ & 50 & 100 & 60 \\
\hline & 0,40374 & $f 6+5$ & 50 & 100 & 60 \\
\hline & mean & sd & se & & \\
\hline & 0,44841 & 0,0903 & 0,04515 & & \\
\hline \multirow[t]{3}{*}{ PLI6 } & 0,73857 & 11 & 50 & 200 & 60 \\
\hline & 1,23872 & 11 & 50 & 200 & 120 \\
\hline & mean & sd & se & & \\
\hline $\begin{array}{l}983.8 \text { ice } \\
\text { sample }\end{array}$ & $\begin{array}{l}0,98865 \\
\mathbf{N}_{2} / \mathbf{O}_{2}\end{array}$ & $\begin{array}{c}0,35366 \\
\text { Focus } \\
\text { position }\end{array}$ & $\begin{array}{c}0,25007 \\
\text { Objective }\end{array}$ & $\begin{array}{l}\text { Confocal } \\
\text { hole }(\mu \mathrm{m})\end{array}$ & $\begin{array}{c}\text { Exposure } \\
\text { time (s) }\end{array}$ \\
\hline \multirow[t]{4}{*}{ PLI1 } & 0,78501 & 11 & 50 & 200 & 60 \\
\hline & 1,06765 & $12 \mathrm{f} 1$ & 50 & 200 & 60 \\
\hline & mean & sd & se & & \\
\hline & 0,92633 & 0,19986 & 0,14132 & & \\
\hline \multirow[t]{4}{*}{ PLI1 / Gfit } & 0,34861 & 11 & 50 & 200 & 60 \\
\hline & 1,29721 & $12 \mathrm{f} 1$ & 50 & 200 & 60 \\
\hline & mean & sd & se & & \\
\hline & 0,82291 & 0,67076 & 0,4743 & & \\
\hline \multirow[t]{5}{*}{ PLI3 } & 0,524 & 11 & 50 & 200 & 60 \\
\hline & 0,32817 & $11^{\prime}$ & 50 & 200 & 60 \\
\hline & 0,49407 & $12 \mathrm{f} 1$ & 50 & 200 & 60 \\
\hline & 0,50367 & $12 \mathrm{f} 2$ & 50 & 200 & 60 \\
\hline & mean & sd & se & & \\
\hline
\end{tabular}

\begin{tabular}{|c|c|c|c|c|c|}
\hline & 0,46248 & 0,0904 & 0,0452 & & \\
\hline \multirow[t]{5}{*}{ PLI4 } & 0,48712 & 12 & 50 & 200 & 60 \\
\hline & 0,46545 & $11^{\prime}$ & 50 & 200 & 300 \\
\hline & 0,41086 & 13 & 50 & 200 & 60 \\
\hline & mean & sd & se & & \\
\hline & 0,45448 & 0,0393 & 0,02269 & & \\
\hline \multirow[t]{4}{*}{ PLI6 } & 0,50651 & 11 & 50 & 200 & 60 \\
\hline & 0,66112 & 12 & 50 & 200 & 60 \\
\hline & mean & sd & se & & \\
\hline & 0,58381 & 0,10933 & 0,07731 & & \\
\hline \multirow[t]{4}{*}{ PLI7 } & 0,43232 & $\mathrm{f} 1$ & 50 & 200 & 60 \\
\hline & 0,57525 & $\mathrm{f} 2$ & 50 & 200 & 60 \\
\hline & mean & sd & se & & \\
\hline & 0,50379 & 0,10107 & 0,07147 & & \\
\hline \multirow[t]{11}{*}{ PLI1 } & 0,35656 & $12(\mathrm{~m})$ & 50 & 100 & 60 \\
\hline & 0,50866 & $13(\mathrm{c})$ & 50 & 100 & 30 \\
\hline & 0,36416 & $13^{\prime} / \mathrm{f} 2$ & 50 & 100 & 30 \\
\hline & 0,43574 & $14 \mathrm{c}$ & 50 & 100 & 30 \\
\hline & 0,43355 & $\mathrm{f} 2$ & 50 & 100 & 60 \\
\hline & 0,3672 & $14^{\prime}$ & 50 & 100 & 60 \\
\hline & 0,38295 & $14^{\prime}$ & 50 & 200 & 30 \\
\hline & 0,49263 & $14^{\prime}$ & 50 & 200 & 60 \\
\hline & 0,46763 & 14" & 50 & 100 & 60 \\
\hline & mean & sd & se & & \\
\hline & 0,42323 & 0,05814 & 0,01938 & & \\
\hline \multirow[t]{4}{*}{ PLI1 / Gfit } & 0,33696 & & 50 & 100 & 30 \\
\hline & 0,32719 & & 50 & 100 & 60 \\
\hline & mean & sd & se & & \\
\hline & 0,33208 & 0,00691 & 0,00489 & & \\
\hline \multirow[t]{6}{*}{ PLI2 } & 0,48421 & 11 & 50 & 100 & 30 \\
\hline & 0,50224 & $11^{\prime}$ & 50 & 200 & 30 \\
\hline & 0,52251 & $12 \mathrm{~m}$ & 50 & 100 & 30 \\
\hline & 0,41408 & $13 \mathrm{~m}$ & 50 & 100 & 30 \\
\hline & mean & sd & se & & \\
\hline & 0,48076 & 0,04713 & 0,02356 & & \\
\hline $\begin{array}{c}\text { PLI3 } \\
1105.9 \text { ice } \\
\text { sample }\end{array}$ & 0,23884 & $\begin{array}{c}11 \mathrm{~m} \\
\text { Focus } \\
\text { position }\end{array}$ & Objective & $\begin{array}{c}100 \\
\text { Confocal } \\
\text { hole }(\mu \mathrm{m})\end{array}$ & $\begin{array}{c}30 \\
\text { Exposure } \\
\text { time (s) }\end{array}$ \\
\hline PLI1 & 0,38385 & 13 & 50 & 100 & 30 \\
\hline
\end{tabular}




\begin{tabular}{|c|c|c|c|c|c|c|c|c|c|c|c|}
\hline & 0,33366 & 14(m) & 50 & 100 & 30 & & 0,43265 & $11 \mathrm{c}$ & 50 & 100 & 30 \\
\hline & 0,38283 & $14^{\prime}$ & 50 & 100 & 30 & & 0,24492 & $12(\mathrm{~m})$ & 50 & 100 & 30 \\
\hline & mean & sd & se & & & & 0,35577 & $12(\mathrm{~m})$ & 50 & 100 & 60 \\
\hline \multirow{3}{*}{ PLI2 } & 0,36678 & 0,02869 & 0,01656 & & & & mean & sd & se & & \\
\hline & 0,36685 & $11 \mathrm{c}$ & 50 & 200 & 30 & & 0,35047 & 0,07799 & 0,039 & & \\
\hline & 0,34334 & $12(\mathrm{~m})$ & 50 & 200 & 30 & PLI4 & 0,59183 & $11 \mathrm{c}$ & 50 & 100 & 30 \\
\hline \multirow{5}{*}{ PLI3 } & mean & sd & se & & & & 0,59785 & $13 \mathrm{~m}$ & 50 & 100 & 120 \\
\hline & 0,35509 & 0,01662 & 0,01176 & & & & 0,72897 & $14 \mathrm{~m}$ & 50 & 100 & 30 \\
\hline & 0,34056 & 11(c) & 50 & 200 & 30 & & 0,58295 & $14 \mathrm{~m}$ & 50 & 100 & 60 \\
\hline & 0,35634 & $13 c$ & 50 & 100 & 60 & & 0,594 & $14 \mathrm{~m}$ & 50 & 200 & 30 \\
\hline & 0,37686 & $14 \mathrm{~m}$ & 50 & 100 & 60 & & 0,70511 & $14 \mathrm{~m}$ & 50 & 200 & 60 \\
\hline \multirow{5}{*}{ PLI4 } & mean & sd & se & & & & 0,72894 & $14 \mathrm{~m}$ & 50 & 200 & 120 \\
\hline & 0,35792 & 0,0182 & 0,01051 & & & & mean & sd & se & & \\
\hline & 0,32125 & 11 & 50 & 200 & 30 & & 0,64709 & 0,06974 & 0,02636 & & \\
\hline & 0,36095 & 12 & 50 & 200 & 30 & PLI5 & 0,50663 & $11 \mathrm{c}$ & 50 & 100 & 60 \\
\hline & mean & sd & se & & & & 0,49786 & $11 \mathrm{c}$ & 50 & 100 & 30 \\
\hline \multirow{3}{*}{ PLI5 } & 0,3411 & 0,02807 & 0,01985 & & & & 0,52865 & $11 \mathrm{c}$ & 50 & 100 & 120 \\
\hline & 0,54212 & $11 \mathrm{c}$ & 50 & 200 & 30 & & 0,5995 & $11 \mathrm{c}$ & 50 & 200 & 60 \\
\hline & 0,55328 & $12 \mathrm{~m}$ & 50 & 200 & 30 & & 0,53541 & $12 \mathrm{~m}$ & 50 & 100 & 30 \\
\hline \multirow{7}{*}{ PLI6 } & 0,44232 & $13 \mathrm{~m}$ & 50 & 200 & 30 & & 0,59301 & $12 \mathrm{~m}$ & 50 & 200 & 60 \\
\hline & mean & sd & se & & & & mean & sd & se & & \\
\hline & 0,51257 & 0,0611 & 0,03527 & & & & 0,54351 & 0,04316 & 0,01762 & & \\
\hline & 0,68532 & $11 \mathrm{c}$ & 50 & 200 & 30 & PLI6 & 0,69458 & $11 \mathrm{c}$ & 50 & 100 & 30 \\
\hline & 0,66839 & $13 \mathrm{c}$ & 50 & 200 & 30 & & 0,85879 & $11 c^{\prime}$ & 50 & 200 & 60 \\
\hline & 0,87732 & $14 \mathrm{c}$ & 50 & 200 & 30 & & mean & sd & se & & \\
\hline & mean & sd & se & & & & 0,77669 & 0,11611 & 0,08211 & & \\
\hline \multirow{4}{*}{ PLI1 } & 0,74368 & 0,11605 & 0,067 & & & $\begin{array}{c}1745.2 \text { ice } \\
\text { sample }\end{array}$ & $\mathbf{N}_{2} / \mathbf{O}_{2}$ & $\begin{array}{l}\text { Focus } \\
\text { position }\end{array}$ & Objective & $\begin{array}{c}\text { Confocal } \\
\text { hole }(\mu \mathrm{m})\end{array}$ & $\begin{array}{l}\text { Exposure } \\
\text { time (s) }\end{array}$ \\
\hline & 0,63982 & $13 c$ & 50 & 100 & 30 & PLI1 / Gfit & 0,51988 & & 50 & 100 & 60 \\
\hline & 0,61354 & $13 \mathrm{c}$ & 50 & 100 & 60 & PLI2 & 0,65331 & 11 & 50 & 100 & 60 \\
\hline & 0,64084 & $13 \mathrm{c}^{\prime}$ & 50 & 100 & 60 & & 0,58814 & 11 & 50 & 100 & 30 \\
\hline \multirow{7}{*}{ PLI2 } & 0,62251 & $13 \mathrm{c}^{\prime}$ & 50 & 200 & 60 & & 0,6622 & 13 & 50 & 100 & 30 \\
\hline & mean & sd & se & & & & mean & sd & se & & \\
\hline & 0,62918 & 0,01339 & 0,0067 & & & & 0,63455 & 0,04044 & 0,02335 & & \\
\hline & 0,30458 & $11(\mathrm{c})$ & 50 & 100 & 30 & PLI2 / Gfit & 0,49764 & & 50 & 100 & 60 \\
\hline & 0,67164 & 12(c) & 50 & 200 & 30 & & 0,64814 & & 50 & 100 & 30 \\
\hline & mean & sd & se & & & & mean & sd & se & & \\
\hline & 0,48811 & 0,25955 & 0,18353 & & & & 0,57289 & 0,10642 & 0,07525 & & \\
\hline PLI3 & 0.36853 & $11 \mathrm{c}$ & 50 & 100 & 30 & PLI1 & 0,43392 & $12 \mathrm{c}$ & 50 & 100 & 60 \\
\hline
\end{tabular}




\begin{tabular}{|c|c|c|c|c|c|}
\hline & 0,61806 & $12 \mathrm{c}$ & 50 & 200 & 60 \\
\hline & 0,61148 & $15 \mathrm{c}$ & 50 & 100 & 60 \\
\hline & 0,74942 & $15 \mathrm{c}$ & 50 & 200 & 60 \\
\hline & 0,6939 & $16 \mathrm{~m}$ & 50 & 200 & 60 \\
\hline & mean & sd & se & & \\
\hline & 0,62136 & 0,11927 & 0,05334 & & \\
\hline & 1,30912 & $16 \mathrm{~m}$ & 50 & 200 & 90 \\
\hline & 1,54895 & $16 \mathrm{~m}$ & 50 & 200 & 120 \\
\hline & mean & sd & se & & \\
\hline & 0,85212 & 0,41182 & 0,15565 & & \\
\hline \multirow[t]{12}{*}{ PLI1 / bis } & 0,4694 & $12 \mathrm{c}$ & 50 & 100 & 60 \\
\hline & 0,672 & $12 \mathrm{c}$ & 50 & 200 & 60 \\
\hline & 0,66369 & $15 \mathrm{c}$ & 50 & 100 & 60 \\
\hline & 0,94403 & $15 \mathrm{c}$ & 50 & 200 & 60 \\
\hline & 1,07121 & $16 \mathrm{~m}$ & 50 & 200 & 60 \\
\hline & 0,60188 & $16 \mathrm{~m}$ & 50 & 100 & 60 \\
\hline & mean & sd & se & & \\
\hline & 0,73704 & 0,2254 & 0,09202 & & \\
\hline & 1,10292 & $16 \mathrm{~m}$ & 50 & 200 & 90 \\
\hline & 1,50052 & $16 \mathrm{~m}$ & 50 & 200 & 120 \\
\hline & mean & sd & se & & \\
\hline & 1,30172 & 0,28115 & 0,1988 & & \\
\hline \multirow[t]{16}{*}{ PLI2 } & 0,54518 & $11 \mathrm{c}$ & 50 & 200 & 60 \\
\hline & 1,00822 & $11 \mathrm{c}$ & 50 & 100 & 60 \\
\hline & 1,33778 & $11 c^{\prime}$ & 50 & 200 & 60 \\
\hline & 0,49512 & $11 c^{\prime}$ & 50 & 100 & 60 \\
\hline & 0,57317 & $13 \mathrm{~m}$ & 50 & 200 & 60 \\
\hline & 1,07721 & $14 \mathrm{~m}$ & 50 & 200 & 60 \\
\hline & 0,57007 & $14 \mathrm{~m}$ & 50 & 100 & 60 \\
\hline & mean & sd & se & & \\
\hline & 0,80096 & 0,33457 & 0,12645 & & \\
\hline & 0,97542 & $11 \mathrm{c}$ & 50 & 300 & 60 \\
\hline & 0,96327 & $11 c^{\prime}$ & 50 & 300 & 60 \\
\hline & 0,80266 & $13 \mathrm{~m}$ & 50 & 300 & 60 \\
\hline & 1,69519 & $13 \mathrm{~m}$ & 50 & 400 & 60 \\
\hline & 1,84885 & $14 \mathrm{~m}$ & 50 & 300 & 60 \\
\hline & mean & sd & se & & \\
\hline & 0,99101 & 0,44647 & 0,12888 & & \\
\hline
\end{tabular}

\begin{tabular}{|c|c|c|c|c|c|}
\hline \multirow[t]{5}{*}{ PLI3 } & 0,77932 & $11 \mathrm{c}$ & 50 & 200 & 60 \\
\hline & 0,69233 & $12 \mathrm{~m}$ & 50 & 100 & 60 \\
\hline & 0,71035 & $\mathrm{f} 2$ & 50 & 100 & 60 \\
\hline & mean & sd & se & & \\
\hline & 0,72733 & 0,04591 & 0,02651 & & \\
\hline \multirow[t]{6}{*}{ PLI4 } & 0,45622 & $11 \mathrm{c}$ & 50 & 200 & 60 \\
\hline & 0,52317 & $12 \mathrm{~m}$ & 50 & 200 & 60 \\
\hline & 0,60107 & $13 \mathrm{~m}$ & 50 & 200 & 60 \\
\hline & 0,59024 & $13 \mathrm{~m}$ & 50 & 100 & 60 \\
\hline & mean & sd & se & & \\
\hline & 0,54268 & 0,06715 & 0,03357 & & \\
\hline \multirow[t]{10}{*}{ PLI5 } & 0,58575 & $11 \mathrm{c}$ & 50 & 100 & 60 \\
\hline & 0,5398 & $12(\mathrm{~m})$ & 50 & 200 & 60 \\
\hline & 0,44677 & $12(\mathrm{~m})$ & 50 & 100 & 60 \\
\hline & 0,47678 & $13(\mathrm{~m})$ & 50 & 100 & 60 \\
\hline & 0,55859 & $13(\mathrm{~m})$ & 50 & 200 & 60 \\
\hline & 0,57518 & $11 c^{\prime}$ fin & 50 & 200 & 60 \\
\hline & 0,44038 & $11 c^{\prime}$ fin & 50 & 100 & 60 \\
\hline & 0,62399 & 14(m) fin & 50 & 200 & 60 \\
\hline & mean & sd & se & & \\
\hline & 0,53091 & 0,06833 & 0,02416 & & \\
\hline \multirow[t]{4}{*}{ PLI6 } & 0,58069 & $11 \mathrm{c}$ & 50 & 100 & 60 \\
\hline & 0,59378 & $14 \mathrm{~m}$ & 50 & 200 & 60 \\
\hline & mean & sd & se & & \\
\hline & 0,58723 & 0,00926 & 0,00654 & & \\
\hline \multirow[t]{7}{*}{ PLI7 } & 0,49454 & $11 \mathrm{c}$ & 50 & 200 & 60 \\
\hline & 0,50458 & $11 c^{\prime}$ & 50 & 200 & 60 \\
\hline & 0,49214 & $12(\mathrm{~m})$ & 50 & 200 & 60 \\
\hline & 0,75497 & $12(\mathrm{~m})$ & 50 & 100 & 60 \\
\hline & 0,59383 & 13 & 50 & 100 & 60 \\
\hline & mean & sd & se & & \\
\hline & 0,56801 & 0,11269 & 0,0504 & & \\
\hline \multirow[t]{7}{*}{ PLI1 / Gfit } & 0,55302 & I1c & 50 & 100 & 60 \\
\hline & 0,51395 & $12 \mathrm{c}$ & 50 & 100 & 60 \\
\hline & 0,46752 & I3m & 50 & 100 & 60 \\
\hline & 0,52062 & $14 \mathrm{~m}$ & 50 & 200 & 60 \\
\hline & 0,39784 & $15(\mathrm{~m})$ & 50 & 200 & 60 \\
\hline & 0,44143 & $16 \mathrm{~m}$ & 50 & 200 & 60 \\
\hline & 0,34009 & I7c & 50 & 200 & 60 \\
\hline
\end{tabular}




\begin{tabular}{|c|c|c|c|c|c|}
\hline & $\begin{array}{c}0,40037 \\
\text { mean } \\
0,45436\end{array}$ & $\begin{array}{c}17 \mathrm{c} \\
\text { sd } \\
0,07288\end{array}$ & $\begin{array}{c}50 \\
\text { se } \\
0.02577\end{array}$ & 100 & 60 \\
\hline \multirow[t]{6}{*}{ PLI2 } & 0,4593 & $12(\mathrm{~m})^{\prime}$ & 50 & 200 & 60 \\
\hline & 0,58395 & $14 \mathrm{~m}$ & 50 & 200 & 60 \\
\hline & 0,64547 & $16(\mathrm{~m})$ & 50 & 200 & 60 \\
\hline & 0,62757 & $17 \mathrm{~m}$ & 50 & 200 & 60 \\
\hline & mean & sd & se & & \\
\hline & 0,57907 & 0,08392 & 0,04196 & & \\
\hline \multirow[t]{9}{*}{ PLI3 } & 0,50484 & $11 \mathrm{c}$ & 50 & 100 & 60 \\
\hline & 0,51233 & $11 \mathrm{c}$ & 50 & 200 & 60 \\
\hline & 0,60338 & $12 \mathrm{~m}$ & 50 & 200 & 60 \\
\hline & 0,49596 & $12 \mathrm{~m}$ & 50 & 100 & 60 \\
\hline & 0,55319 & $13 \mathrm{~m}$ & 50 & 100 & 60 \\
\hline & 0,61085 & $14(\mathrm{~m})$ & 50 & 200 & 60 \\
\hline & 0,48479 & $15(\mathrm{~m})$ & 50 & 200 & 60 \\
\hline & mean & sd & se & & \\
\hline & 0,53791 & 0,05191 & 0,01962 & & \\
\hline \multirow[t]{5}{*}{ PLI4 } & 0,4835 & $11 \mathrm{c}$ & 50 & 100 & 60 \\
\hline & 0,59598 & $11 \mathrm{c}$ & 50 & 200 & 60 \\
\hline & 0,67434 & $13 \mathrm{~m}$ & 50 & 200 & 60 \\
\hline & mean & sd & se & & \\
\hline & 0,58461 & 0,09593 & 0,05538 & & \\
\hline PLI5 & 0,77143 & $11 \mathrm{c}$ & 50 & 200 & 60 \\
\hline \multirow[t]{8}{*}{ PLI5 / Gfit } & 0,7867 & $11 \mathrm{c}$ & 50 & 100 & 60 \\
\hline & 0,70206 & $12 \mathrm{~m}$ & 50 & 100 & 60 \\
\hline & 0,77369 & $12 \mathrm{~m}$ & 50 & 100 & 60 \\
\hline & 0,61829 & 15 & 50 & 200 & 60 \\
\hline & 0,65072 & 15 & 50 & 200 & 60 \\
\hline & 0,6293 & 15 & 50 & 200 & 60 \\
\hline & 0,66231 & 15 & 50 & 200 & 60 \\
\hline & mean & sd & se & & \\
\hline & 0,68901 & 0,06786 & 0,02565 & & \\
\hline $\begin{array}{l}2295.8 \text { ice } \\
\text { sample }\end{array}$ & $\mathbf{N}_{2} / \mathbf{O}_{2}$ & $\begin{array}{c}\text { Focus } \\
\text { position }\end{array}$ & Objective & $\begin{array}{l}\text { Confocal } \\
\text { hole }(\mu \mathrm{m})\end{array}$ & $\begin{array}{l}\text { Exposure } \\
\text { time (s) }\end{array}$ \\
\hline \multirow[t]{4}{*}{ PLI2 } & 0,47455 & $16 \mathrm{c}$ & 50 & 100 & 60 \\
\hline & 0,30019 & $17(\mathrm{c})$ fin & 50 & 100 & 60 \\
\hline & mean & sd & se & & \\
\hline & 0,38737 & 0,12329 & 0,08718 & & \\
\hline
\end{tabular}

\begin{tabular}{|c|c|c|c|c|c|}
\hline PLI3 & 0,81427 & $11 \mathrm{c}$ & 50 & 100 & 60 \\
\hline & 0,74202 & $14 \mathrm{~m}$ & 50 & 100 & 60 \\
\hline & mean & sd & se & & \\
\hline & 0,77815 & 0,05109 & 0,03613 & & \\
\hline PLI4 & 0,80577 & $11 \mathrm{c}$ & 50 & 100 & 60 \\
\hline & 0,83857 & $\mathrm{f} 2$ & 50 & 100 & 60 \\
\hline & 0,5462 & 13(m) & 50 & 100 & 60 \\
\hline & mean & sd & se & & \\
\hline & 0,73018 & 0,16017 & 0,09248 & & \\
\hline PLI5 & 0,37018 & 11(c) & 50 & 100 & 60 \\
\hline & 0,55038 & 11(c) & 50 & 100 & 60 \\
\hline & 0,35124 & $12(\mathrm{~m})^{\prime}$ & 50 & 100 & 60 \\
\hline & 0,36341 & 11(c)' & 50 & 100 & 60 \\
\hline & mean & sd & se & & \\
\hline & 0,4088 & 0,09471 & 0,04735 & & \\
\hline PLI6 & 0,9423 & $11(\mathrm{c})$ & 50 & 100 & 60 \\
\hline & 0,79443 & $12(\mathrm{c})$ fin & 50 & 100 & 60 \\
\hline & mean & sd & se & & \\
\hline & 0,86837 & 0,10456 & 0,07394 & & \\
\hline PLI7 & 0,9816 & $11 \mathrm{c}$ & 50 & 200 & 60 \\
\hline PLI8 & 0,3499 & $12 \mathrm{~m}$ & 50 & 100 & 60 \\
\hline & 0,36685 & 13c fin & 50 & 100 & 60 \\
\hline & 0,40084 & $12 \mathrm{~m}$ & 50 & 100 & 60 \\
\hline & mean & sd & se & & \\
\hline & 0,37253 & 0,02594 & 0,01498 & & \\
\hline PLI9 & 0,51245 & 11(c)' & 50 & 100 & 60 \\
\hline & 0,42068 & 11(c) & 50 & 100 & 60 \\
\hline & mean & sd & se & & \\
\hline & 0,46657 & 0,06489 & 0,04588 & & \\
\hline PLI10 & 0,88771 & $11(\mathrm{c})$ & 50 & 100 & 60 \\
\hline & 0,83449 & 12 & 50 & 100 & 60 \\
\hline & mean & sd & se & & \\
\hline & 0,8611 & 0,03763 & 0,02661 & & \\
\hline PLI11 & 0,81499 & $11 \mathrm{~m}$ & 50 & 100 & 60 \\
\hline & 0,63957 & 12(m) & 50 & 100 & 60 \\
\hline & mean & sd & se & & \\
\hline & 0,72728 & 0,12404 & 0,08771 & & \\
\hline PLI12 & 0,44203 & 13(c) & 50 & 100 & 60 \\
\hline & 0,4977 & 14(c) & 50 & 100 & 60 \\
\hline
\end{tabular}




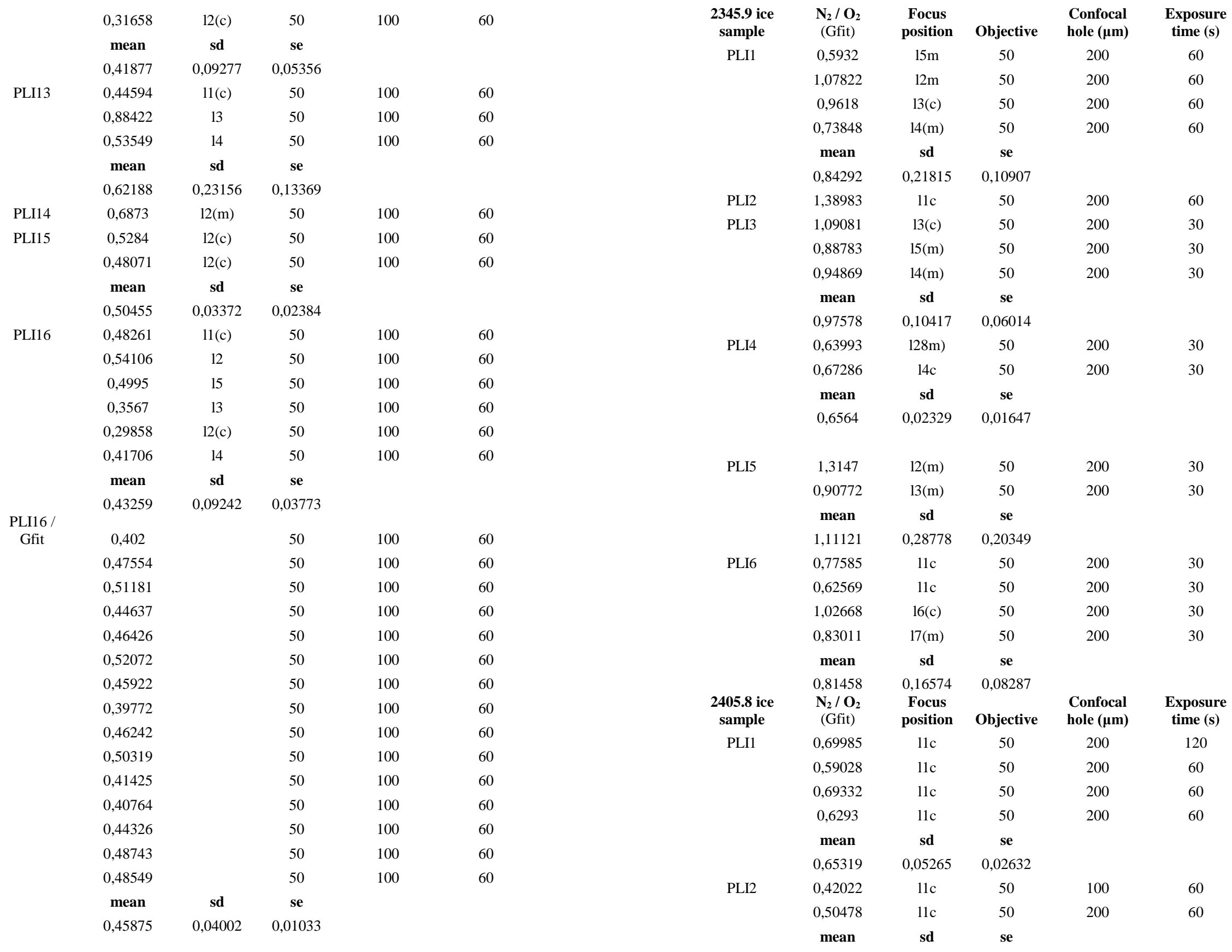




\begin{tabular}{|c|c|c|c|c|c|}
\hline & 0,4625 & 0,05979 & 0,04228 & & \\
\hline \multirow[t]{10}{*}{ PLI3 } & 0,58696 & $11(\mathrm{~m})$ & 50 & 200 & 60 \\
\hline & 0,53991 & $11(\mathrm{~m})$ & 50 & 200 & 60 \\
\hline & 0,58014 & $11(\mathrm{~m})$ & 50 & 200 & 60 \\
\hline & 0,53166 & $11(\mathrm{~m})$ & 50 & 200 & 60 \\
\hline & 0,5181 & $11(\mathrm{~m})$ & 50 & 200 & 60 \\
\hline & 0,50565 & $11(\mathrm{~m})$ & 50 & 200 & 60 \\
\hline & 0,39698 & $11(\mathrm{~m})$ & 50 & 100 & 60 \\
\hline & 0,41766 & $11(\mathrm{~m})$ & 50 & 100 & 60 \\
\hline & mean & sd & se & & \\
\hline & 0,50963 & 0,06927 & 0,02449 & & \\
\hline \multirow[t]{7}{*}{ PLI4 } & 0,51863 & $11 \mathrm{c}$ & 50 & 200 & 60 \\
\hline & 0,61905 & $11 \mathrm{c}$ & 50 & 200 & 60 \\
\hline & 0,50044 & $11 \mathrm{c}$ & 50 & 200 & 300 \\
\hline & 0,35414 & $11 \mathrm{c}$ & 50 & 200 & 300 \\
\hline & 0,66867 & $11 \mathrm{c}$ & 50 & 200 & 30 \\
\hline & mean & sd & se & & \\
\hline & 0,53219 & 0,12152 & 0,05434 & & \\
\hline \multirow[t]{6}{*}{ PLI5 } & 0,53916 & $11(\mathrm{c})$ & 50 & 200 & 60 \\
\hline & 0,48578 & $11(\mathrm{c})$ & 50 & 200 & 60 \\
\hline & 0,52632 & $11(\mathrm{c})$ & 50 & 200 & 60 \\
\hline & 0,53916 & 11(c) & 50 & 200 & 60 \\
\hline & mean & sd & se & & \\
\hline & 0,5226 & 0,02529 & 0,01264 & & \\
\hline \multirow[t]{8}{*}{ PLI6 } & 0,61648 & $11(\mathrm{~m})$ & 50 & 200 & 60 \\
\hline & 0,59443 & $11(\mathrm{~m})$ & 50 & 200 & 60 \\
\hline & 0,56284 & $11(\mathrm{~m})$ & 50 & 200 & 60 \\
\hline & 0,55806 & $11(\mathrm{~m})$ & 50 & 200 & 60 \\
\hline & 0,5978 & $11(\mathrm{~m})$ & 50 & 200 & 60 \\
\hline & 0,67978 & $11(\mathrm{~m})$ & 50 & 200 & 60 \\
\hline & mean & sd & se & & \\
\hline & 0,60157 & 0,04427 & 0,01807 & & \\
\hline \multirow[t]{5}{*}{ PLI7 } & 1,03278 & 11 & 50 & 200 & 60 \\
\hline & 0,89145 & 11 & 50 & 100 & 60 \\
\hline & 1,06581 & 11 & 50 & 300 & 60 \\
\hline & mean & sd & se & & \\
\hline & 0,99668 & 0,09262 & 0,05347 & & \\
\hline \multirow[t]{2}{*}{ PLI8 } & 0,96769 & $11 \mathrm{~m}$ & 50 & 200 & 60 \\
\hline & 0,70034 & $11 \mathrm{~m}$ & 50 & 200 & 60 \\
\hline
\end{tabular}

\begin{tabular}{|c|c|c|c|c|}
\hline 0,8211 & $11 \mathrm{~m}$ & 50 & 100 & 60 \\
\hline 0,65299 & $11 \mathrm{~m}$ & 50 & 100 & 60 \\
\hline 0,99053 & $11 \mathrm{~m}$ & 50 & 200 & 300 \\
\hline mean & sd & se & & \\
\hline 0,82653 & 0,15239 & 0,06815 & & \\
\hline 1,20737 & $11 \mathrm{~m}$ & 50 & 300 & 60 \\
\hline 1,44281 & $11 \mathrm{~m}$ & 50 & 300 & 60 \\
\hline mean & sd & se & & \\
\hline 1,32509 & 0,16648 & 0,11772 & & \\
\hline 0,81628 & $11(\mathrm{c})$ & 50 & 200 & 60 \\
\hline 0,87484 & 11(c) & 50 & 200 & 60 \\
\hline mean & sd & se & & \\
\hline 0,84556 & 0,04141 & 0,02928 & & \\
\hline 0,91587 & 11 & 50 & 200 & 60 \\
\hline 0,90016 & 11 & 50 & 200 & 60 \\
\hline 1,12189 & 11 & 50 & 200 & 60 \\
\hline mean & sd & se & & \\
\hline 0,97931 & 0,12373 & 0,07144 & & \\
\hline 0,72985 & $11(\mathrm{c})$ & 50 & 200 & 60 \\
\hline 0,6827 & 11(c) & 50 & 200 & 60 \\
\hline 0,74361 & 11(c) & 50 & 200 & 60 \\
\hline 0,76446 & 11(c) & 50 & 200 & 60 \\
\hline mean & sd & se & & \\
\hline 0,73016 & 0,03469 & 0,01734 & & \\
\hline 0,92947 & $11 \mathrm{c}$ & 50 & 200 & 60 \\
\hline 0,85825 & $11 \mathrm{c}$ & 50 & 200 & 30 \\
\hline 0,58569 & $11 \mathrm{c}$ & 50 & 200 & 60 \\
\hline mean & sd & se & & \\
\hline 0,79114 & 0,18145 & 0,10476 & & \\
\hline 0,53323 & 11(c) & 50 & 200 & 60 \\
\hline 0,52276 & $11(\mathrm{c})$ & 50 & 200 & 60 \\
\hline 0,51597 & 11(c) & 50 & 200 & 60 \\
\hline 0,57181 & 11(c) & 50 & 200 & 60 \\
\hline mean & sd & se & & \\
\hline 0,53594 & 0,02494 & 0,01247 & & \\
\hline 0,5504 & $11(\mathrm{c})$ & 50 & 200 & 60 \\
\hline 0,58479 & 11(c) & 50 & 200 & 60 \\
\hline 0,52881 & $11(\mathrm{c})$ & 50 & 200 & 60 \\
\hline 0,48192 & 11 (c) & 50 & 200 & 60 \\
\hline
\end{tabular}




\begin{tabular}{|c|c|c|c|c|c|}
\hline & mean & sd & se & & \\
\hline & 0,53648 & 0,04306 & 0,02153 & & \\
\hline \multirow[t]{6}{*}{ PLI15 } & 0,64645 & 11 & 50 & 200 & 60 \\
\hline & 0,62988 & 11 & 50 & 200 & 60 \\
\hline & 0,71494 & 11 & 50 & 200 & 60 \\
\hline & 0,60359 & 11 & 50 & 200 & 60 \\
\hline & mean & sd & se & & \\
\hline & 0,64872 & 0,04755 & 0,02377 & & \\
\hline \multirow[t]{10}{*}{ PLI16 } & 0,83607 & $11(\mathrm{~m})$ & 50 & 200 & 60 \\
\hline & 1,32141 & $11(\mathrm{~m})$ & 50 & 200 & 60 \\
\hline & 0,83247 & $11(\mathrm{~m})$ & 50 & 200 & 60 \\
\hline & 1,14049 & $11(\mathrm{~m})$ & 50 & 200 & 60 \\
\hline & 0,66283 & $11(\mathrm{~m})$ & 50 & 200 & 60 \\
\hline & 1,35777 & $11(\mathrm{~m})$ & 50 & 200 & 60 \\
\hline & 0,63214 & $11(\mathrm{~m})$ & 50 & 200 & 60 \\
\hline & 0,67501 & $11(\mathrm{~m})$ & 50 & 200 & 60 \\
\hline & mean & sd & se & & \\
\hline & 0,93227 & 0,29855 & 0,10555 & & \\
\hline \multirow[t]{9}{*}{ PLI17 } & 0,40202 & $11(\mathrm{~m})$ & 50 & 200 & 60 \\
\hline & 0,40679 & $11(\mathrm{~m})$ & 50 & 200 & 60 \\
\hline & 0,23633 & $11(\mathrm{~m})$ & 50 & 200 & 60 \\
\hline & 0,33881 & $11(\mathrm{~m})$ & 50 & 200 & 60 \\
\hline & 0,24529 & $11(\mathrm{~m})$ & 50 & 200 & 60 \\
\hline & 0,27205 & $11(\mathrm{~m})$ & 50 & 200 & 60 \\
\hline & 0,18162 & $11(\mathrm{~m})$ & 50 & 200 & 60 \\
\hline & mean & sd & se & & \\
\hline & 0,29756 & 0,08672 & 0,03278 & & \\
\hline \multirow[t]{7}{*}{ PLI18 } & 0,56579 & $11 \mathrm{c}$ & 50 & 200 & 60 \\
\hline & 0,37572 & $11 \mathrm{c}$ & 50 & 200 & 60 \\
\hline & 0,33126 & $11 \mathrm{c}$ & 50 & 200 & 60 \\
\hline & 0,28745 & $11 \mathrm{c}$ & 50 & 200 & 60 \\
\hline & 0,50384 & $11 \mathrm{c}$ & 50 & 200 & 60 \\
\hline & mean & sd & se & & \\
\hline & 0,41281 & 0,11772 & 0,05265 & & \\
\hline \multirow[t]{5}{*}{ PLI19 } & 0,54547 & $11 \mathrm{~m}$ & 50 & 200 & 60 \\
\hline & 0,24977 & $11 \mathrm{~m}$ & 50 & 200 & 60 \\
\hline & 0,363 & $11 \mathrm{~m}$ & 50 & 200 & 60 \\
\hline & 0,27192 & $11 \mathrm{~m}$ & 50 & 200 & 60 \\
\hline & 0,42465 & $11 \mathrm{~m}$ & 50 & 200 & 60 \\
\hline
\end{tabular}




\section{EXPLANATIONS}

\section{Appendix 2.2.2.A}

Raman spectra (Raman intensity (in counts) versus the wavenumber in $\left(\mathrm{cm}^{-1}\right)$ ) attributed to mirabilite (meridianiite) containing microinclusions

\section{Appendix 2.2.2.B}

Raman spectra (Raman intensity (in counts) versus the wavenumber in $\left(\mathrm{cm}^{-1}\right)$ ) attributed to gypsum containing microinclusions

\section{Appendix 2.2.2.C}

Raman spectra (Raman intensity (in counts) versus the wavenumber in $\left(\mathrm{cm}^{-1}\right)$ ) attributed to arcanite (or $\left.\mathrm{H}_{2} \mathrm{SO}_{4}\right)$ containing microinclusions

\section{Appendix 2.2.2.D}

Raman spectra (Raman intensity (in counts) versus the wavenumber in $\left(\mathrm{cm}^{-1}\right)$ ) attributed to microinclusions containing a mixture of different compounds (sulfates or sulfates and silicates)

\section{Appendix 2.2.2.E}

Raman spectra(Raman intensity (in counts) versus the wavenumber in $\left.\left(\mathrm{cm}^{-1}\right)\right)$ attributed to double sulfates of jarosite type $\left((\mathrm{Na} / \mathrm{K}) \mathrm{Fe}{ }_{3}(\mathrm{SO})_{2}(\mathrm{OH})_{6}\right)$

\section{Appendix 2.2.2.F}

Raman spectra (Raman intensity (in counts) versus the wavenumber in $\left(\mathrm{cm}^{-1}\right)$ ) attributed to $\mathrm{SiO}_{2}$ containing microinclusions

Appendix 2.2.2.F

Raman spectra (Raman intensity (in counts) versus the wavenumber in $\left(\mathrm{cm}^{-1}\right)$ ) attributed to (alumino)silicate containing microinclusions

\section{Appendix 2.2.2.G}

Raman spectra (Raman intensity (in counts) versus the wavenumber in

$\left.\left(\mathrm{cm}^{-1}\right)\right)$ attributed to identified microinclusions that contain neither $\mathrm{SO}_{4}{ }^{2-}$ nor $\left(\mathrm{Si}_{\mathrm{x}} \mathrm{O}_{\mathrm{y}}\right)^{\mathrm{n}-}$

\section{Appendix 2.2.2.H}

Raman spectra (Raman intensity (in counts) versus the wavenumber in $\left(\mathrm{cm}^{-1}\right)$ ) attributed to unidentified microinclusions that contain neither $\mathrm{SO}_{4}{ }^{2-}$ nor $\left(\mathrm{Si}_{\mathrm{x}} \mathrm{O}_{\mathrm{y}}\right)^{\mathrm{n}-}$

\section{Appendix 2.2.2.J}

Raman spectra (Raman intensity (in counts) versus the wavenumber in $\left(\mathrm{cm}^{-1}\right)$ ) of the EDML ice matrix 
Appendix 2.2.2.A
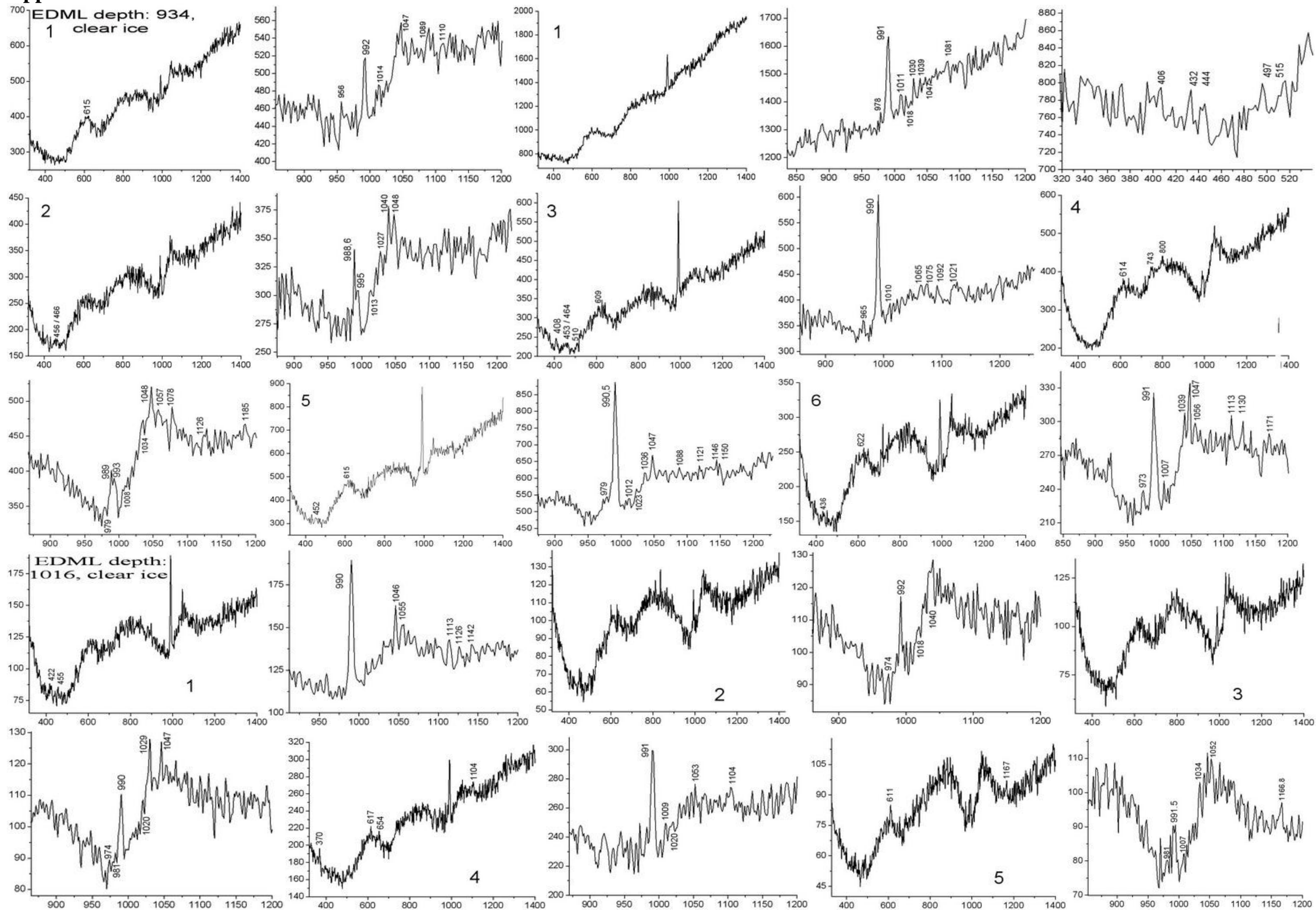

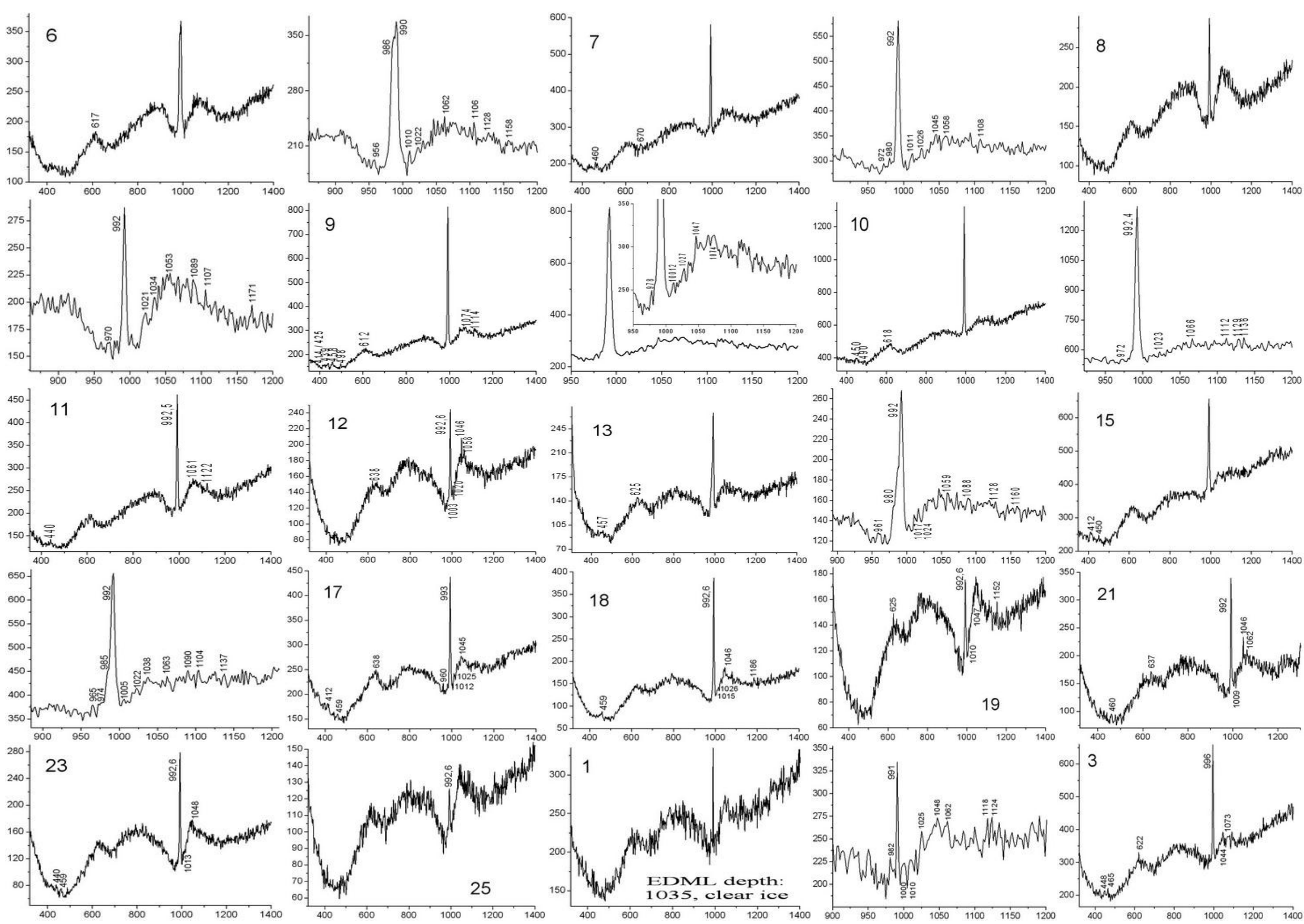

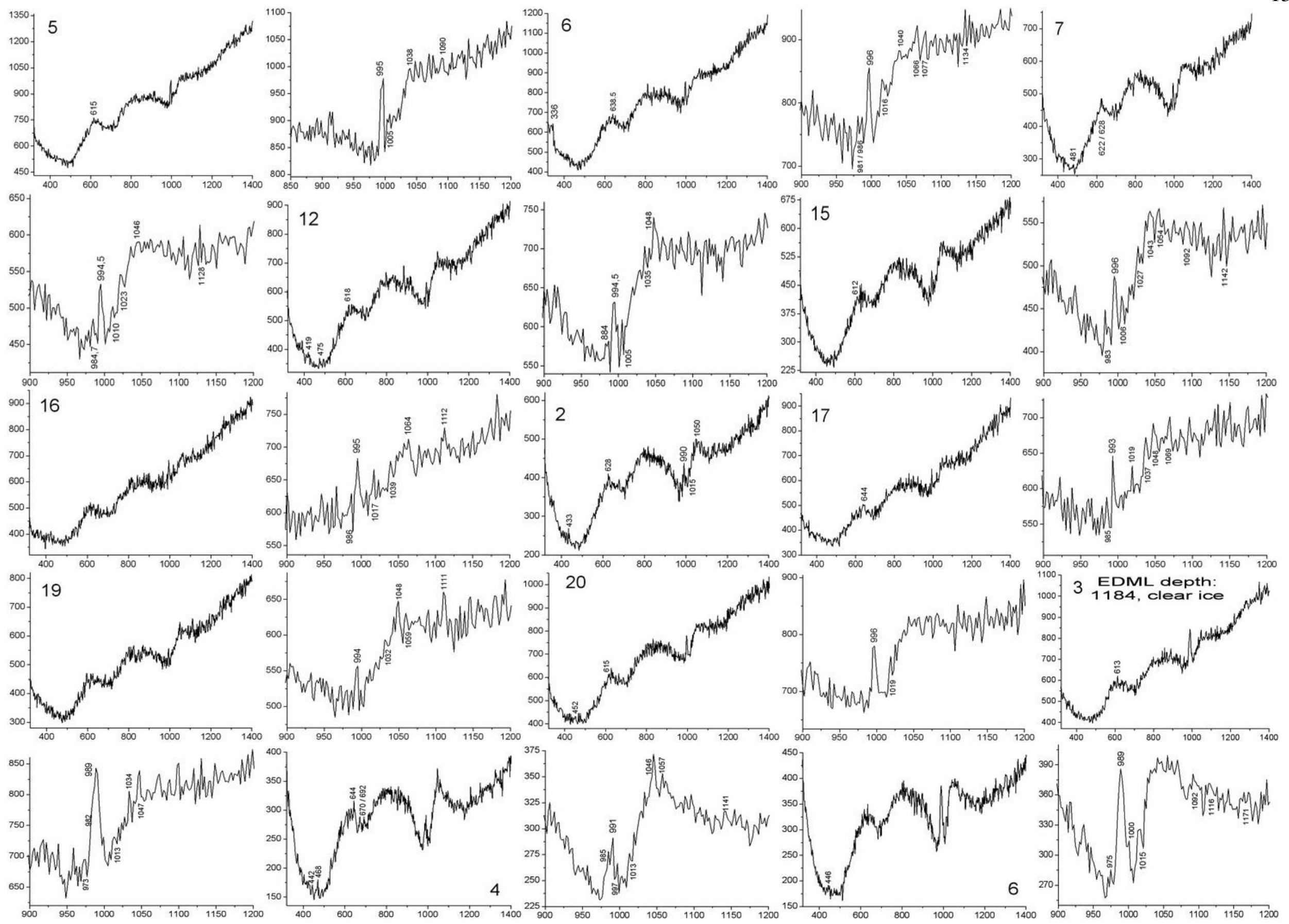

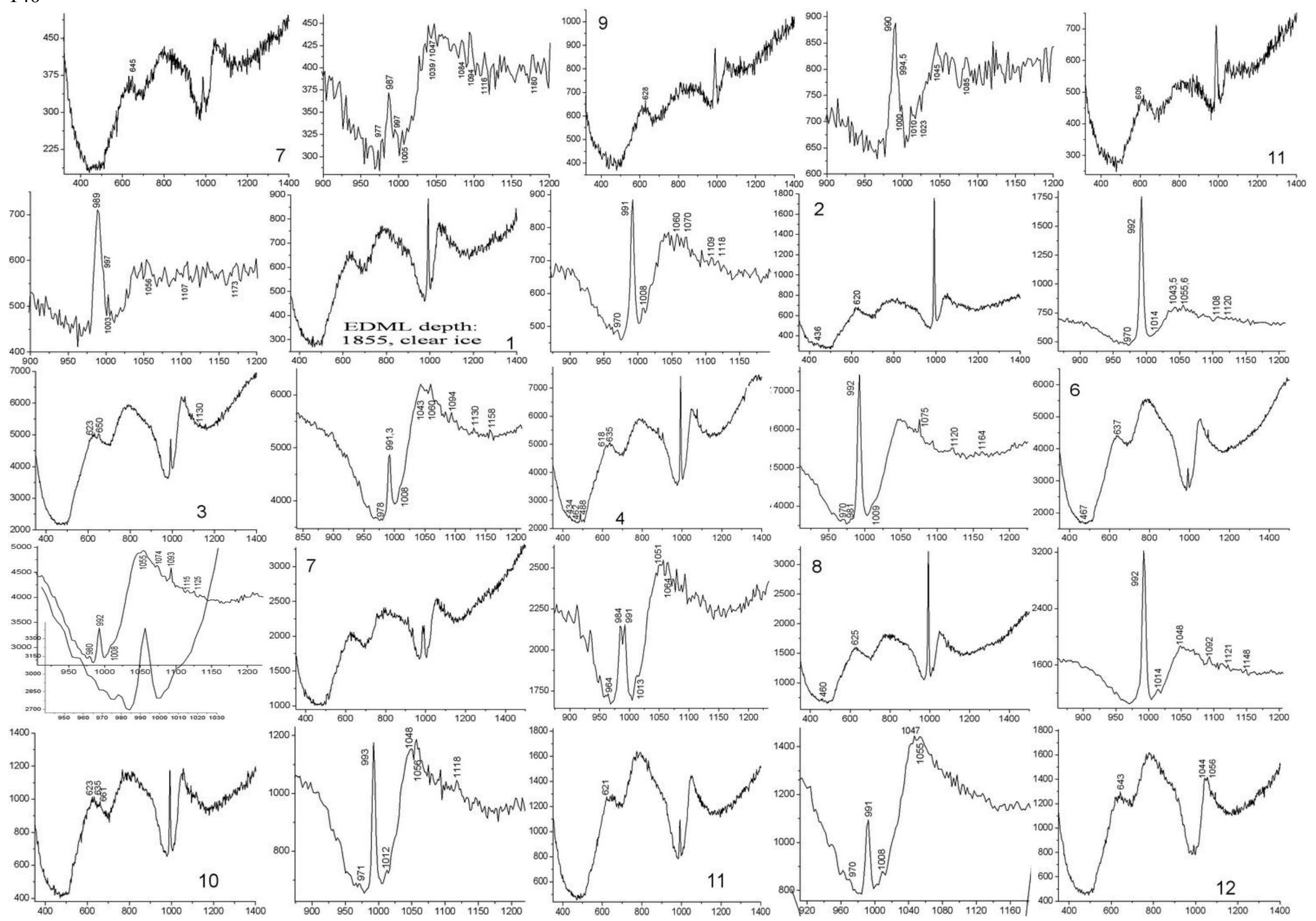

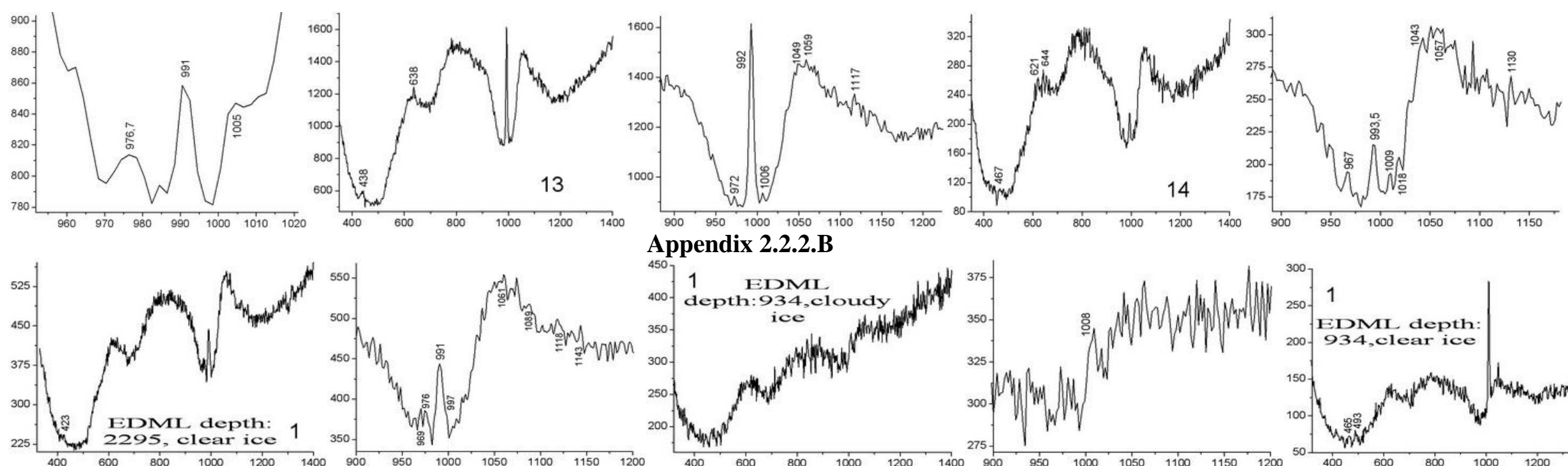

Appendix 2.2.2.B
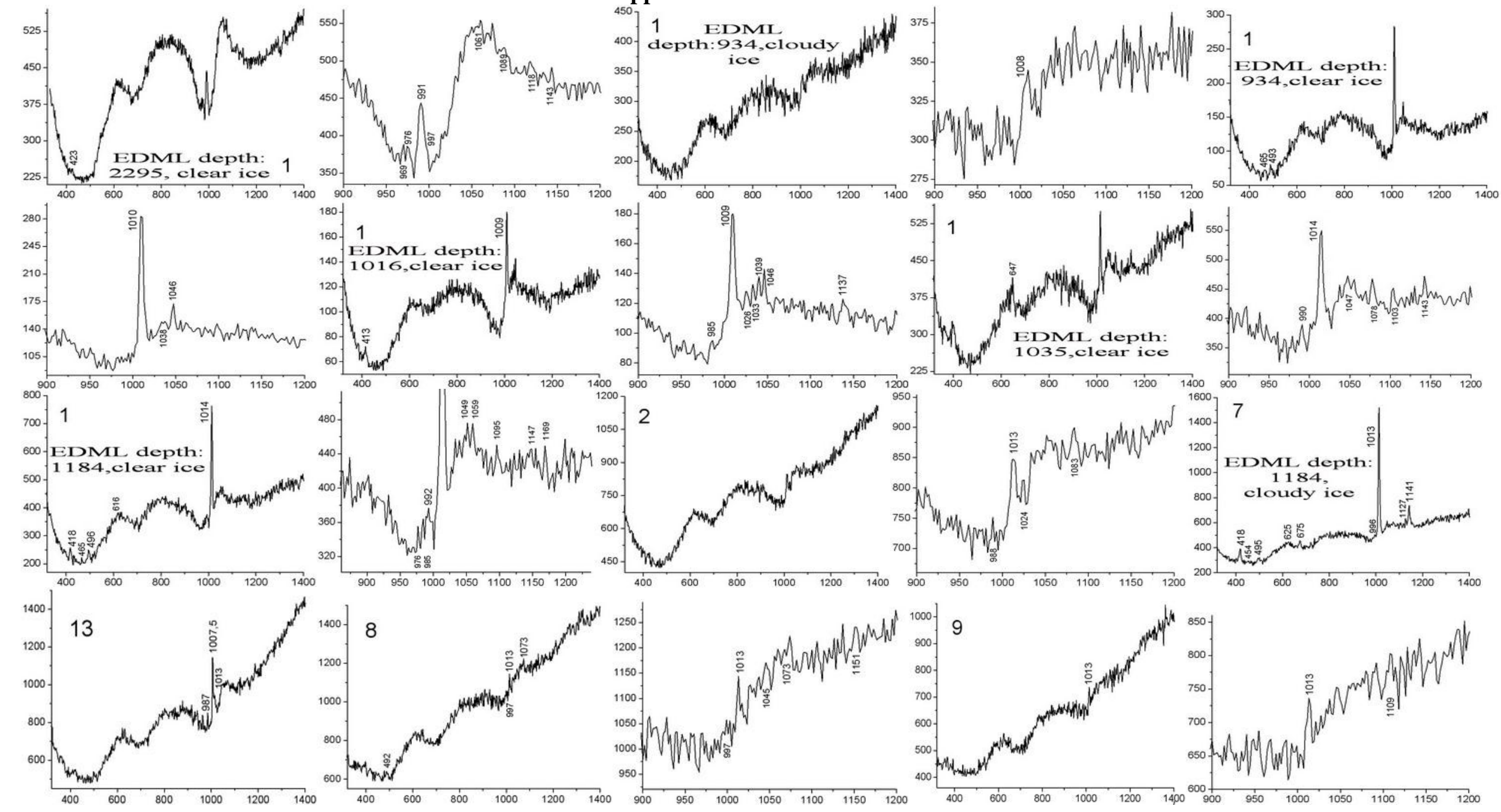
142
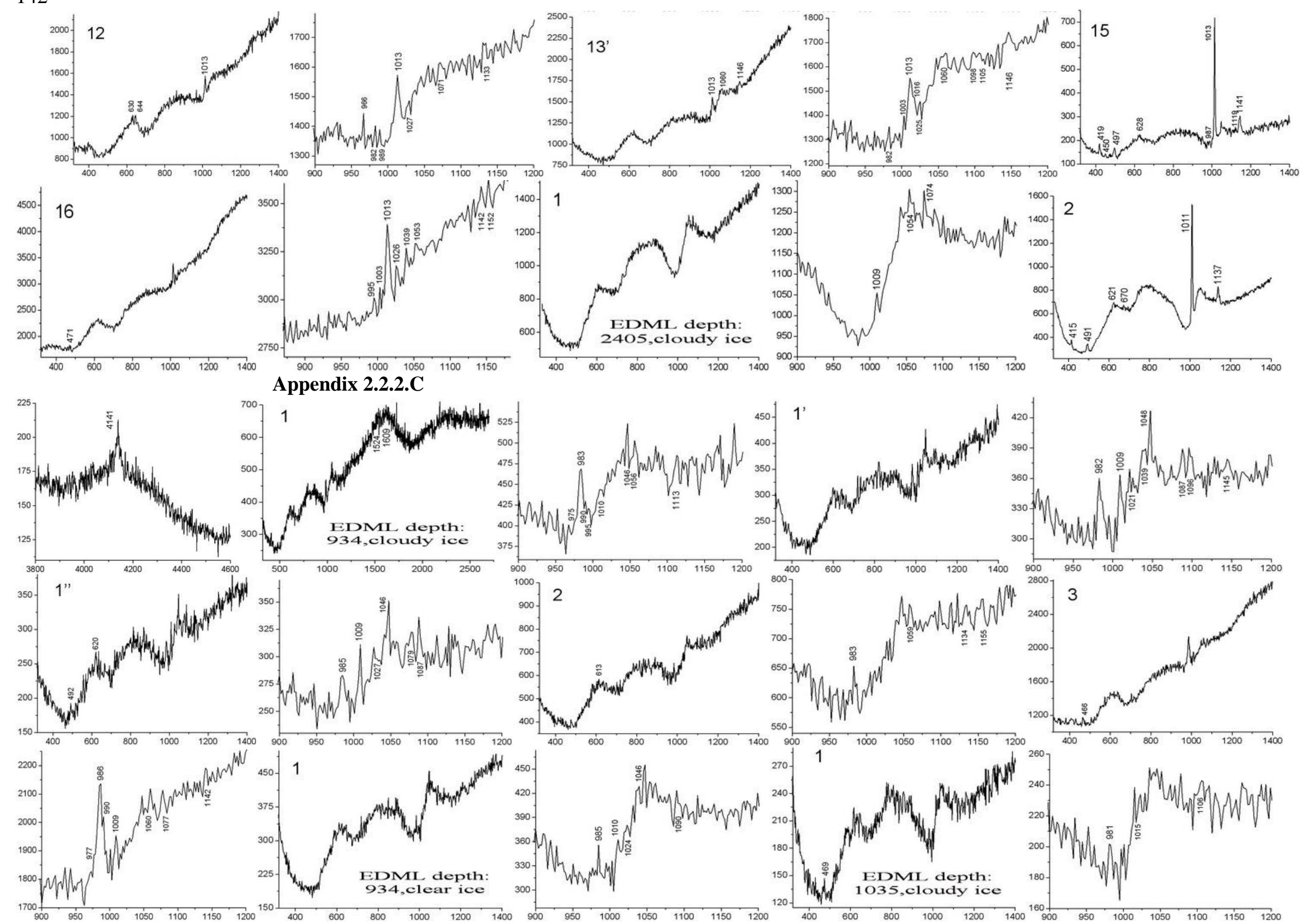

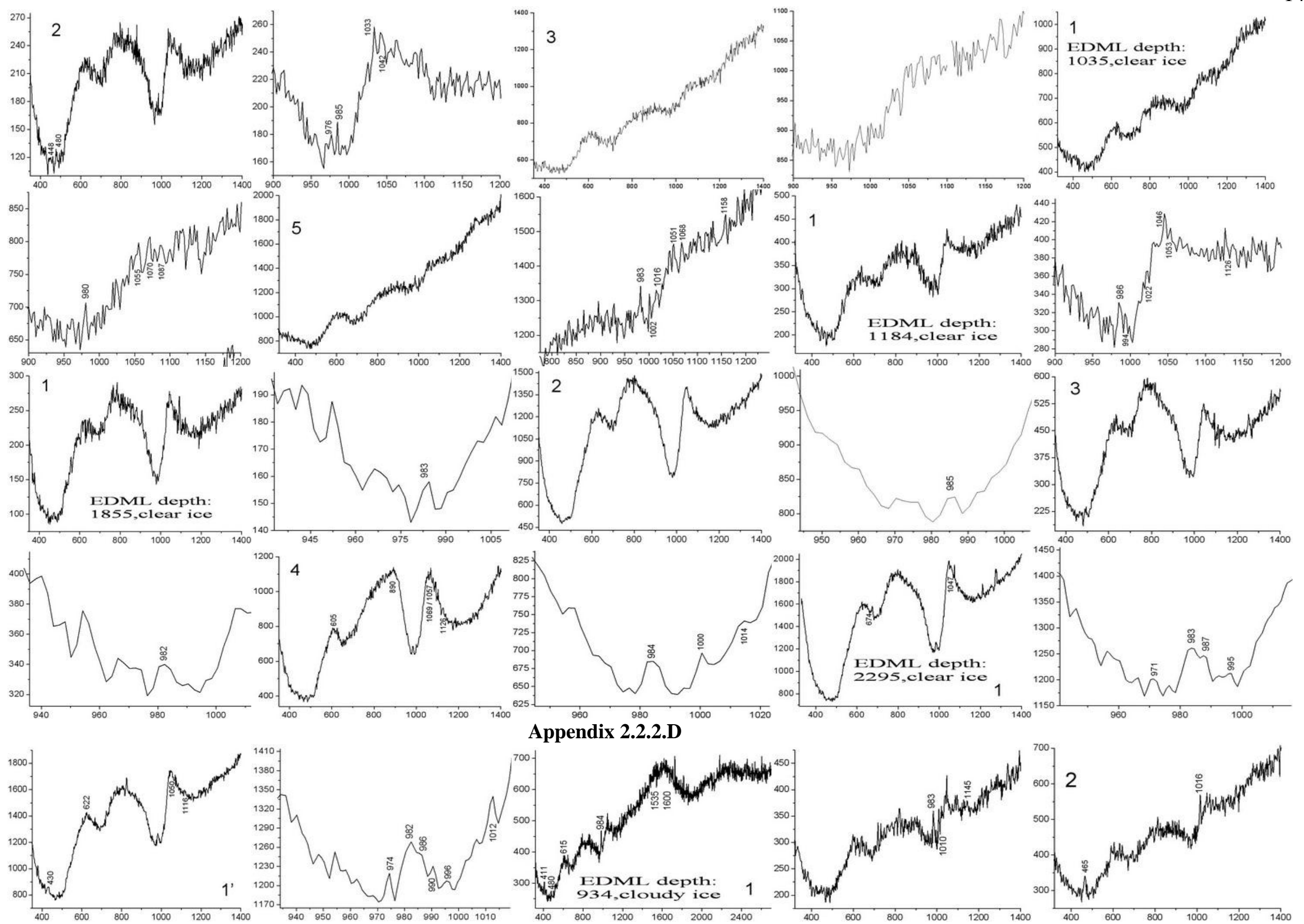


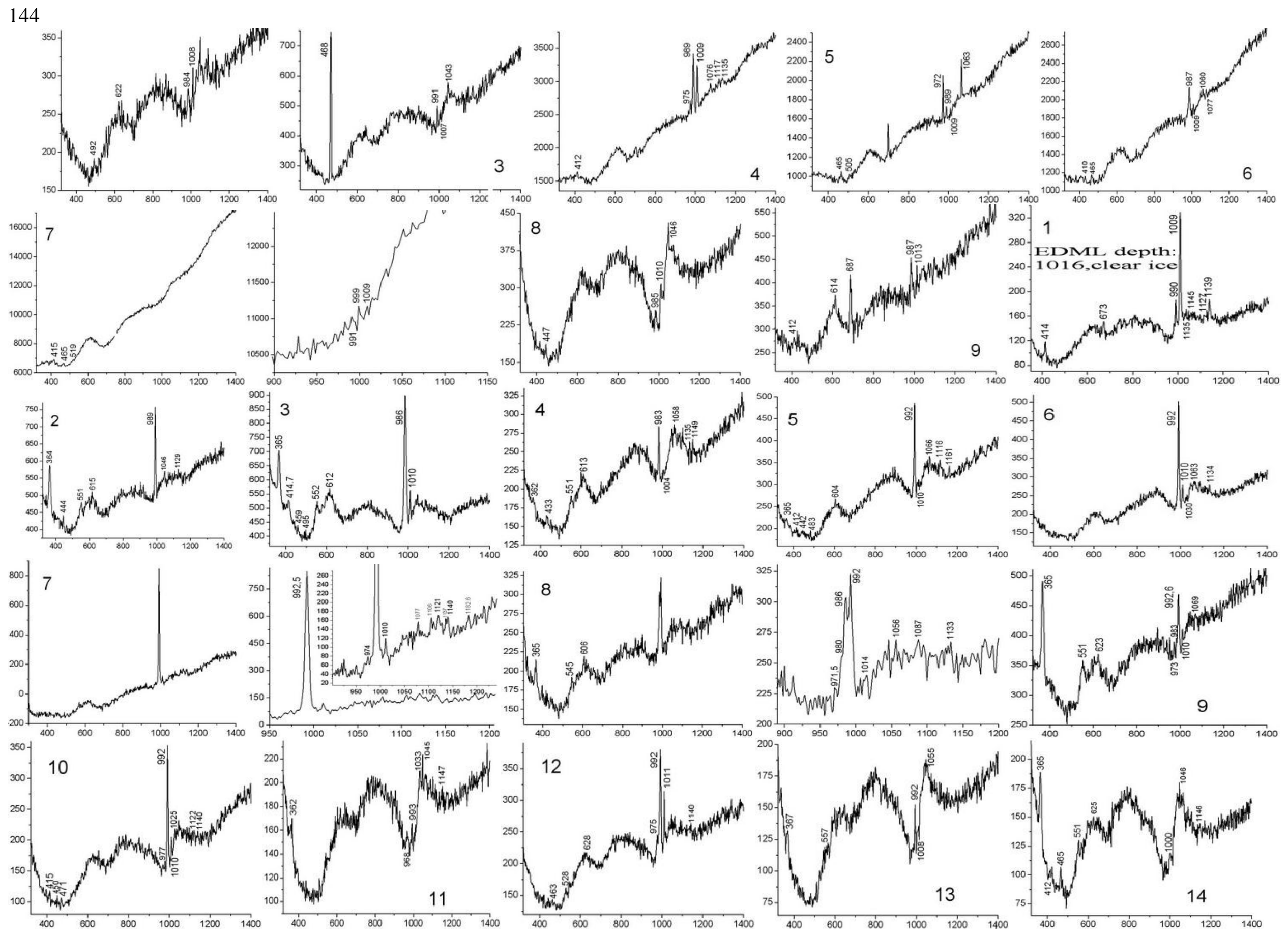



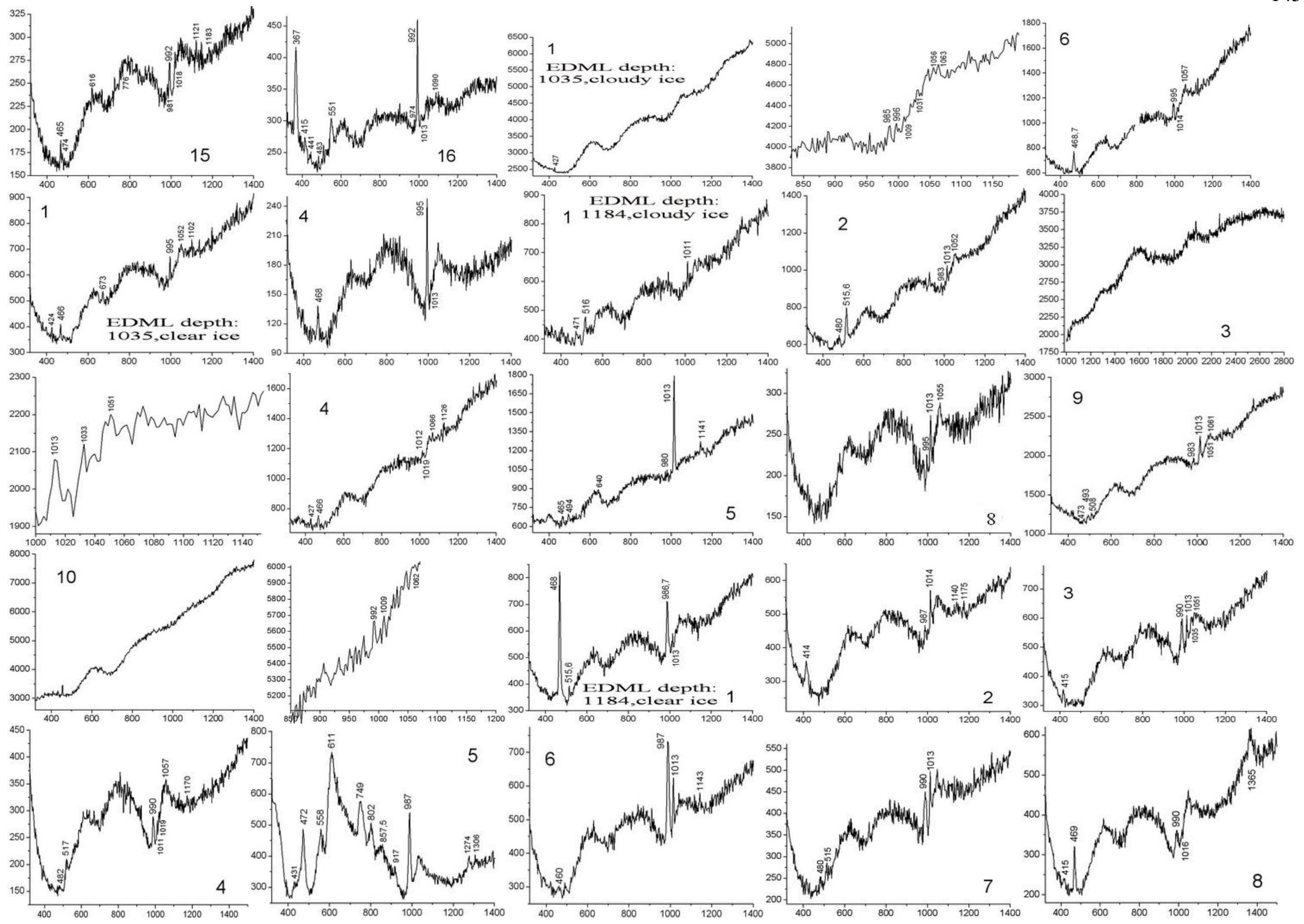
146
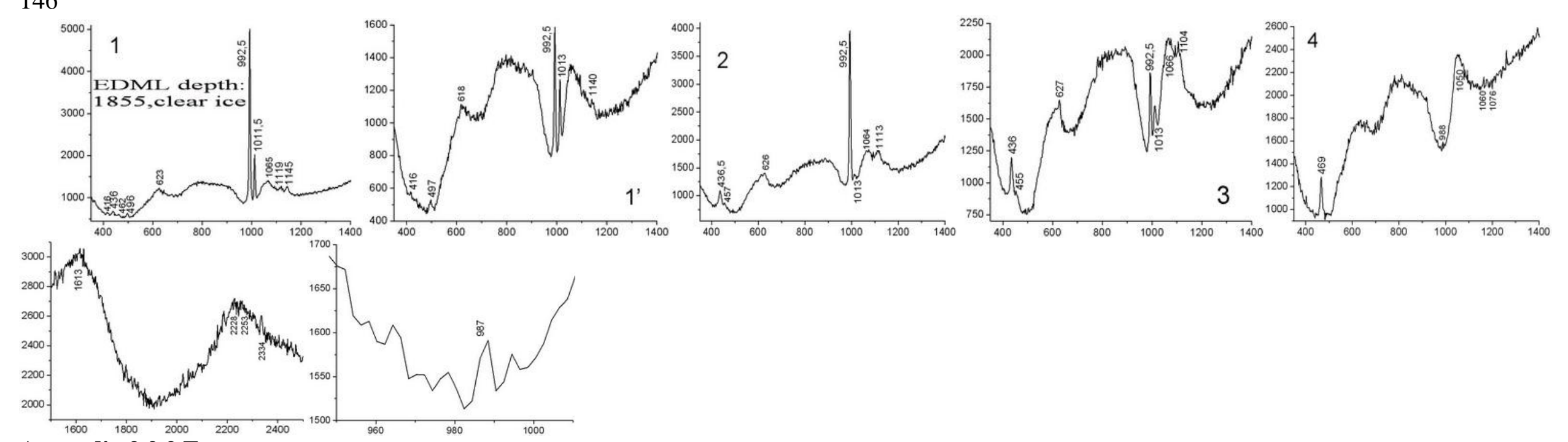

Appendix 2.2.2.E
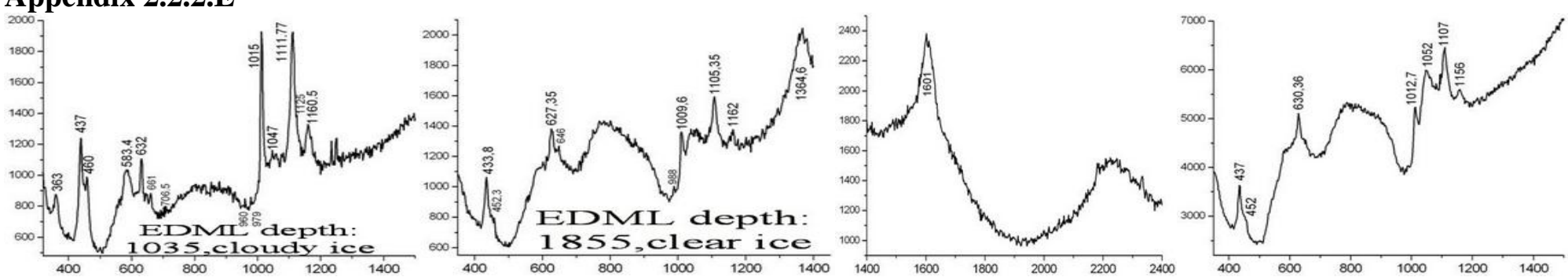

Appendix 2.2.2.F
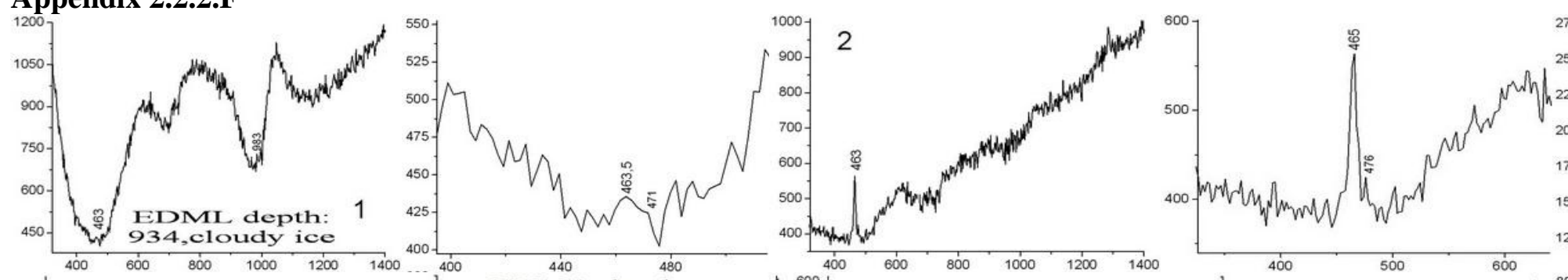

$\left.{ }^{275}\right] 1$ EDMI depth:
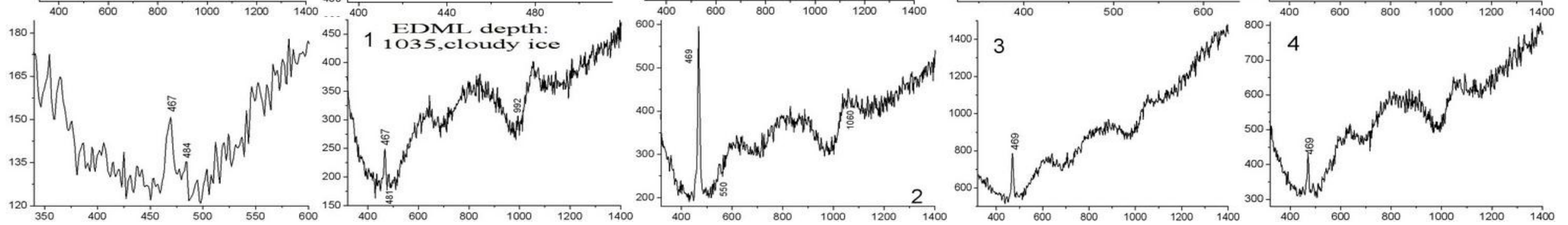

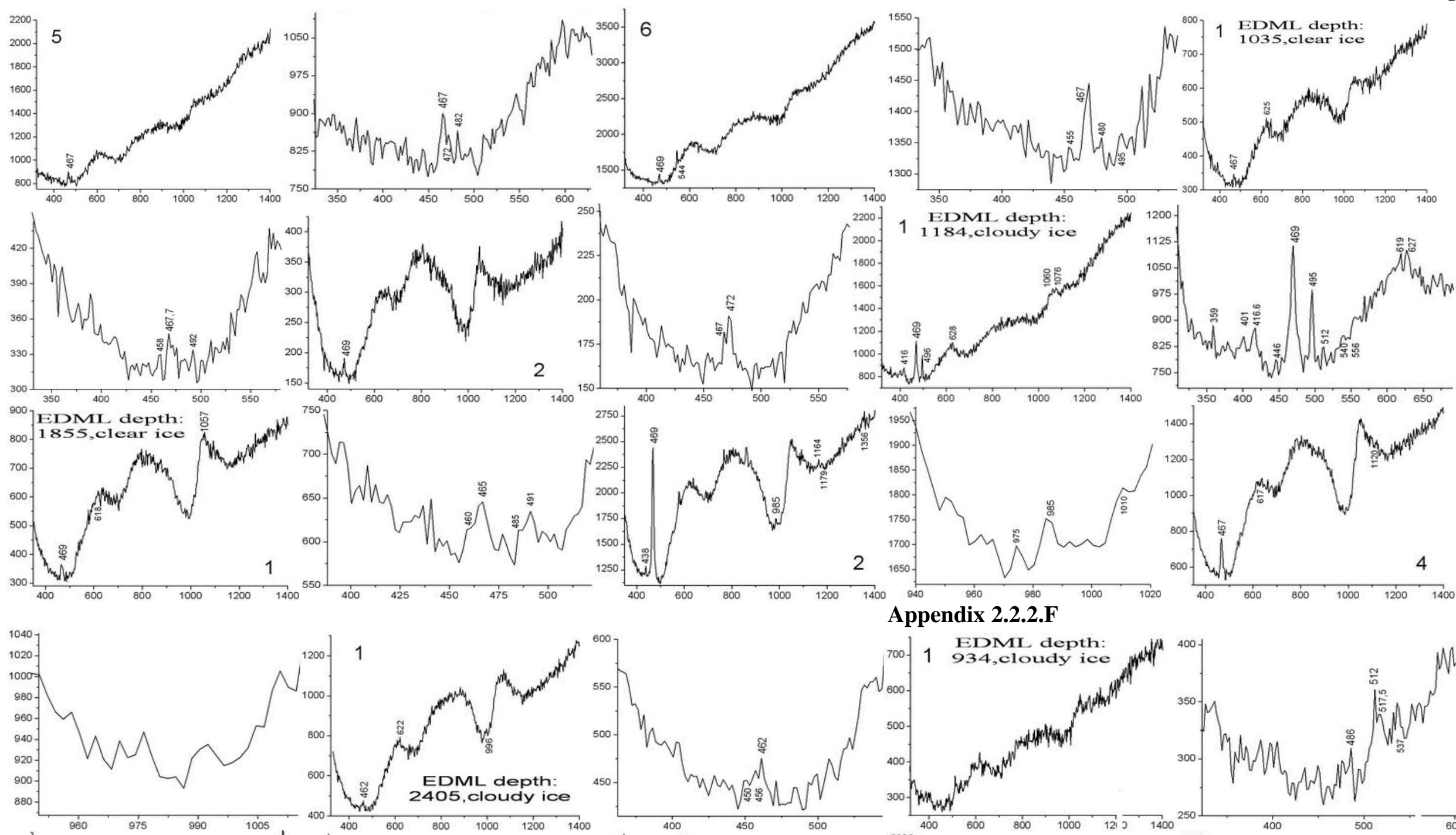

\section{Appendix 2.2.2.F}
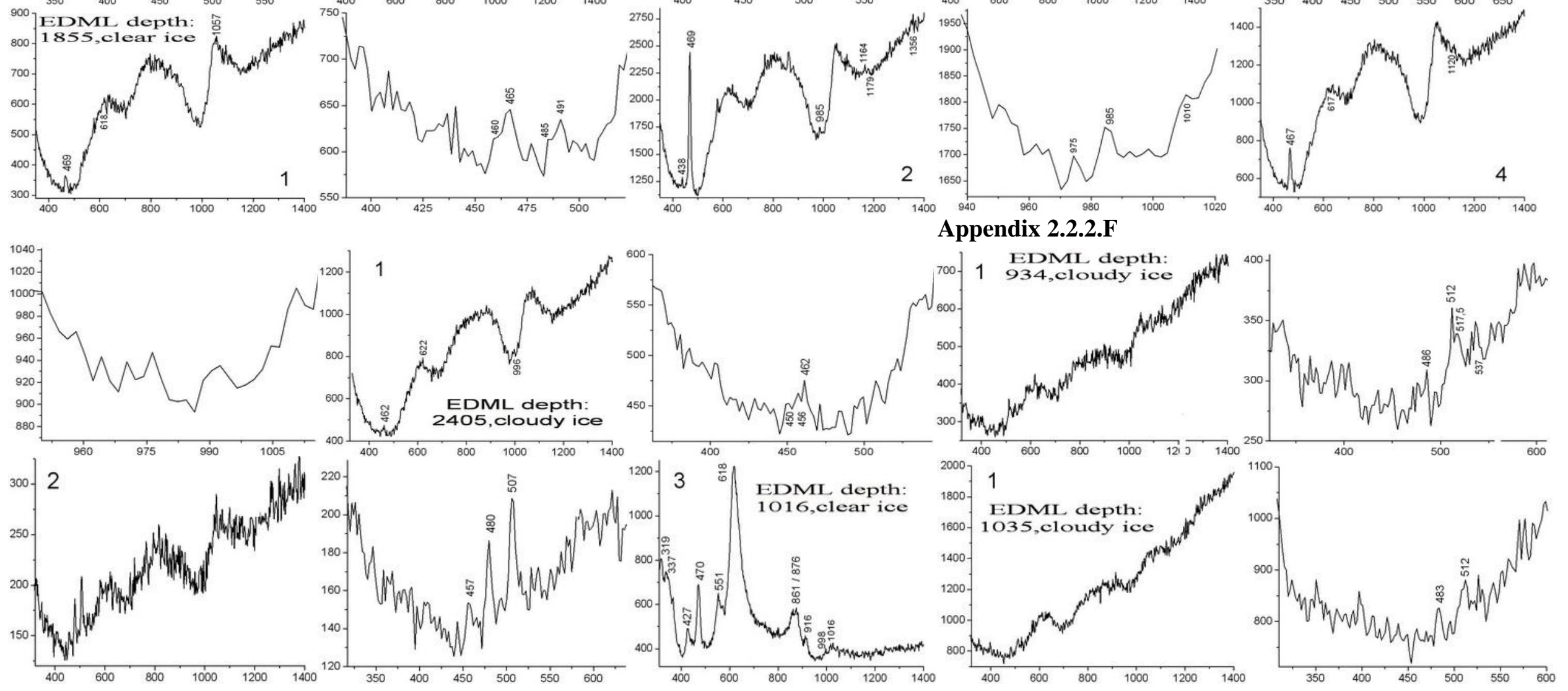
148
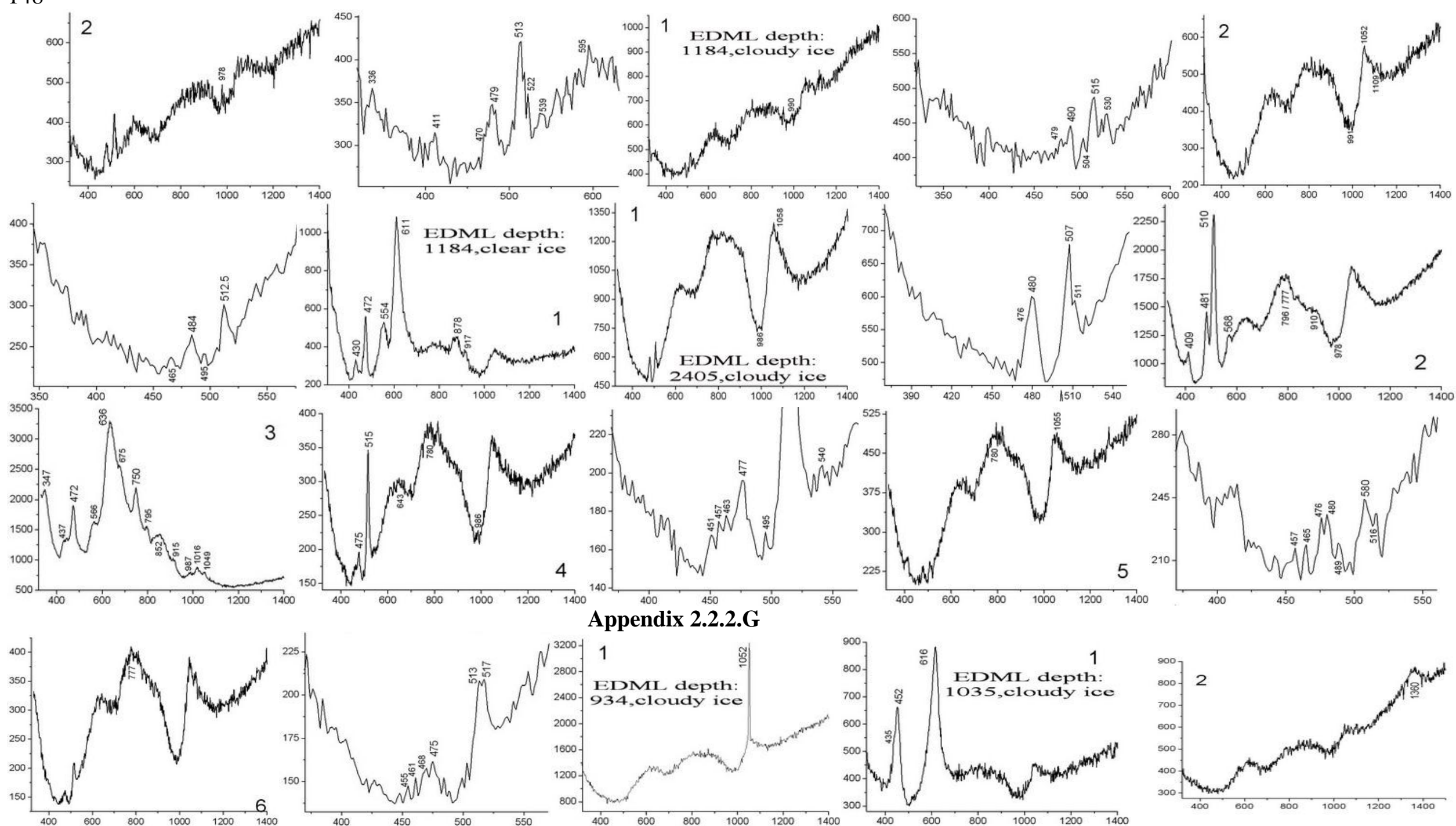

Appendix 2.2.2.G
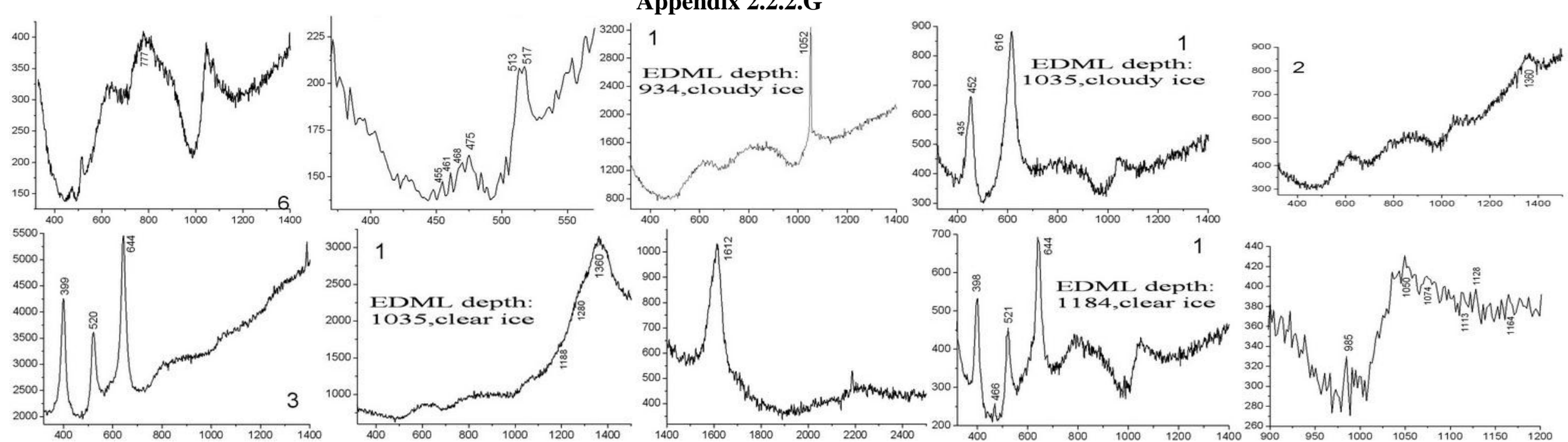

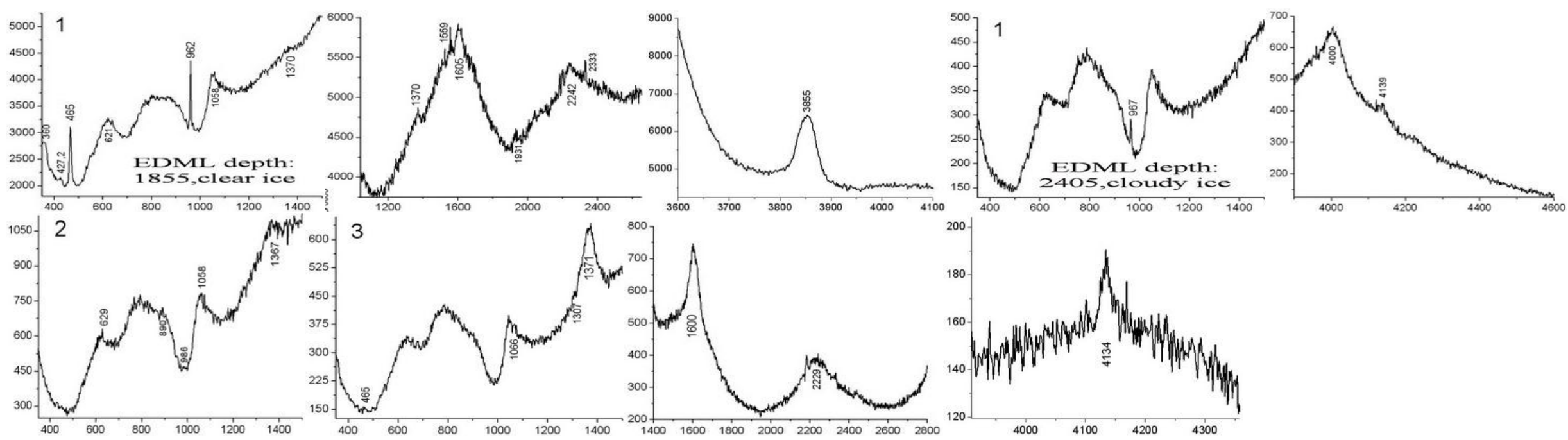

\section{Appendix 2.2.2.H}
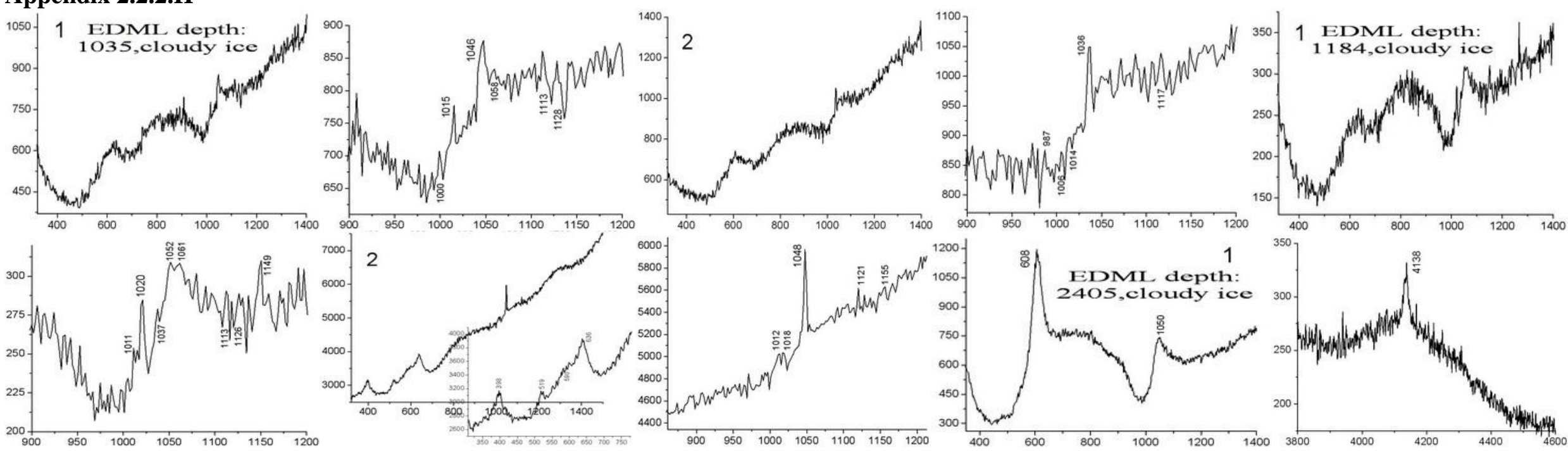


\section{Appendix 2.2.2.I}

Relative distribution of the different types of microinclusions identified in the analyzed EDML ice samples, cut from cloudy band (CB) or clear ice (CI) regions. The relative frequency is represented as percent of each class of microinclusion from the total number of assigned microinclusions (written in the right end of each raw). "Na" stands for mirabilite (or meridianiite), "Ca" for gypsum, "mx" includes microinclusions containing more than one substance, either different sulfates or silicate and sulfate, "Si" for silicon containing compounds (silica, silicates, aluminosilicates), "dif" represents the microinclusions that were assigned but are not included in the other classes. The numbers for the microinclusions that could not be assigned are not considered. Also, the results for the 2295 ice sample were excluded.

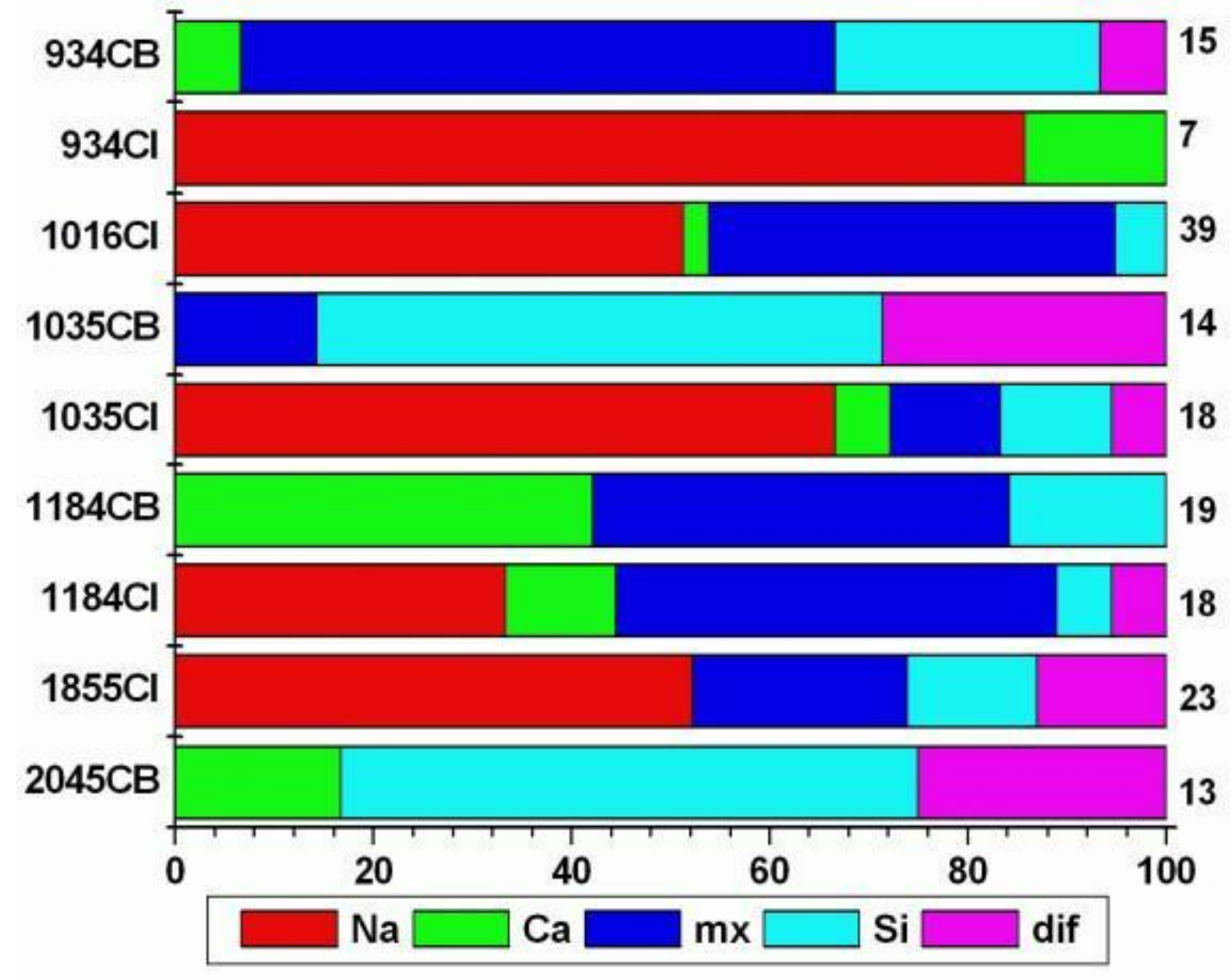




\section{Appendix 2.2.2.J}
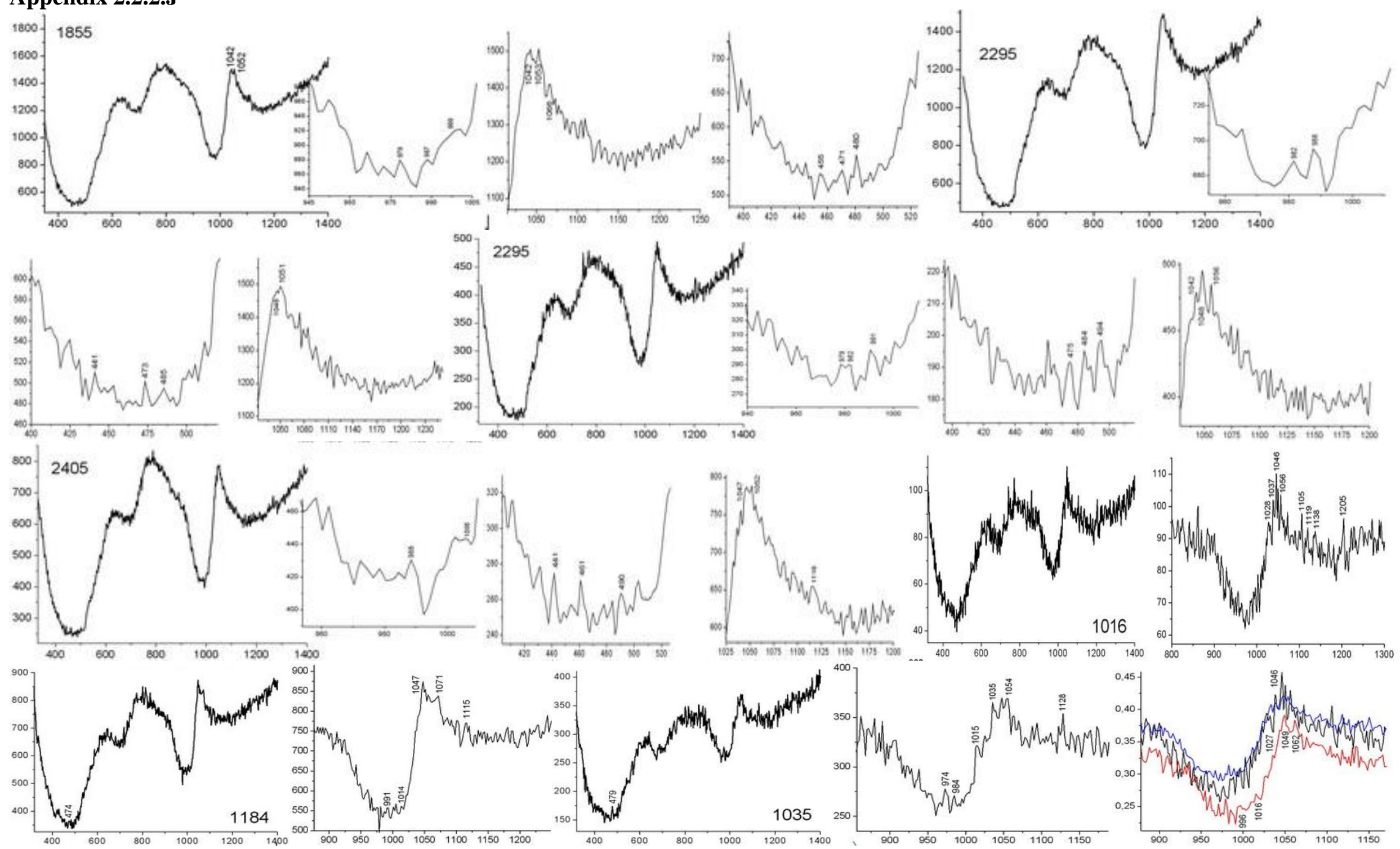
152
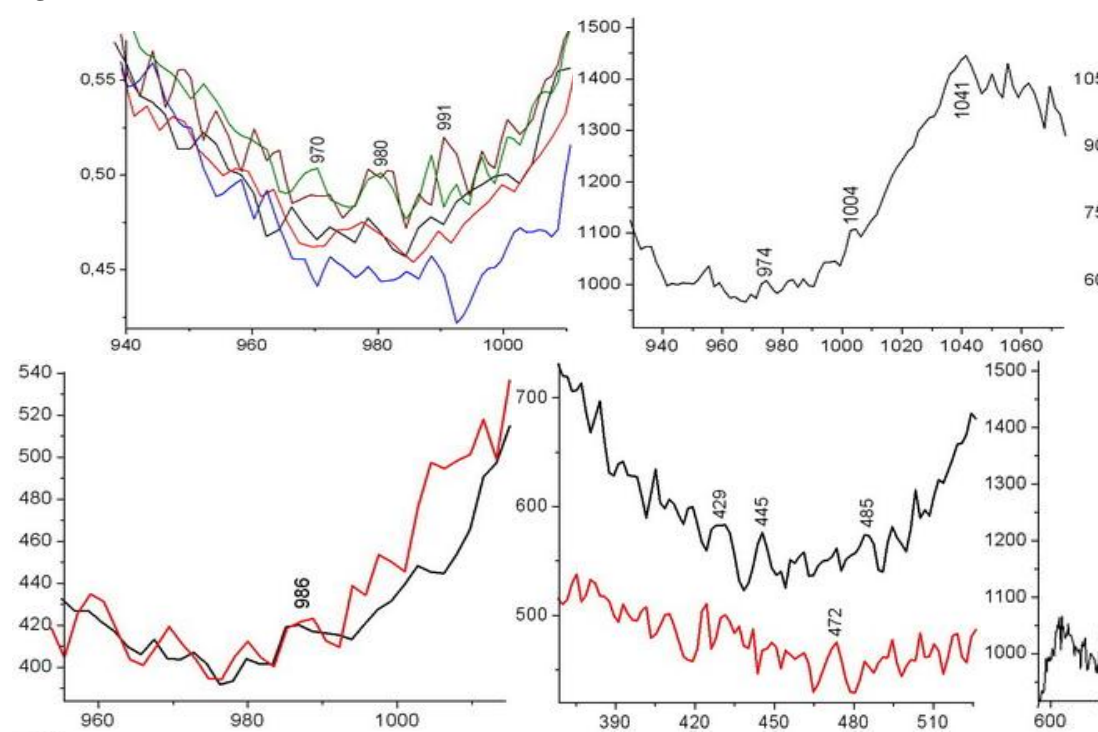

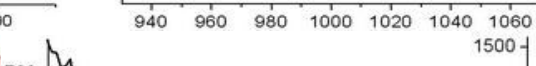
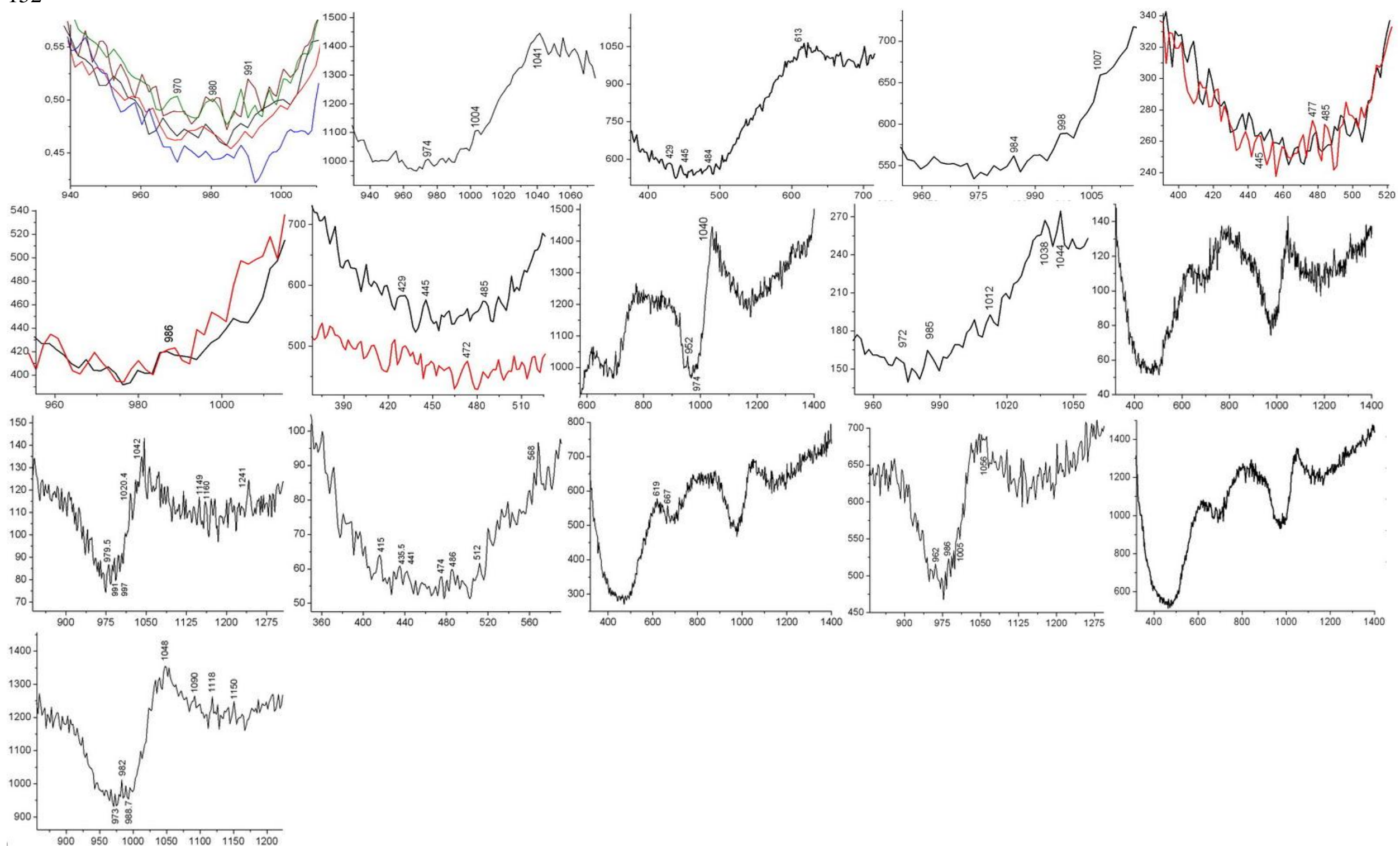